\title{
FINAL CLOSE-OUT REPORT
}

Prepared by Mark A. Carl

Report Submitted August 3, 2004

For

Department Of Energy Award No.: DE-FG26-01BC15336

Report Submitted

By The

Interstate Oil and Gas Compact Commission

P.O. Box 53127

Oklahoma City, OK 53127-3127 


\section{DISCLAIMER}

This report was prepared as an account of work sponsored by an agency of the United States Government. Neither the United States Government nor any agency thereof, nor any of their employees, makes any warranty, express or implied, or assumes any legal liability or responsibility for the accuracy, completeness, or usefulness of any information, apparatus, product, or process disclosed, or represents that its use would not infringe privately owned rights,. Reference herein to any specific commercial product, process, or service by trade name, trademark, manufacturer, or otherwise does not necessarily constitute or imply its endorsement, recommendation, or favoring by the United States Government or any agency thereof. The views and opinions of authors expressed herein do no necessarily state or reflect those of the United States Government or any agency thereof. 


\section{ABSTRACT}

The Interstate Oil and Gas Compact Commission (IOGCC) engaged in numerous projects outlined under the scope of work discussed in the United States Department of Energy (DOE) grant number \#DE-FG26-01BC15336 awarded to the IOGCC. Numerous projects were completed that were extremely valuable to state oil and gas agencies as a result of work performed utilizing resources provided by the grant. There are numerous areas in which state agencies still need assistance. This additional assistance will need to be addressed under another grant because funding resources have been exhausted under this grant.

The scope of work objectives for the eight projects covered under this grant is as follows:

- Improve uniformity within state oil and gas data management efforts.

- Conduct environmental compliance workshops and related educational projects on natural gas and oil exploration and production.

- Improve regulatory efficiency through partnering opportunities provided by the Appalachian Illinois Basin Directors.

- Promote the development and implementation of risk-based environmental regulation at the state level through an expertise-sharing program that brings stakeholders together to develop guidelines and models to meet regulatory challenges.

- Support the IOGCC's regulatory streamlining efforts, including the identification and elimination of unnecessary duplications of effort between state and federal programs dealing with exploration and production on public lands, and identify the need to enhance and regionalize regulatory coordination and cooperation among the states.

- Involve states and provinces of Canada that have offshore petroleum exploration and production in a regulatory sharing alliance to identify areas of concern that may be incorporated into standard practices for offshore environmental and regulatory compliance.

- Coordinate efforts with the U.S. Environmental Protection Agency (EPA) to ensure that adequate information is available to the public regarding oil and gas exploration and production operations consistent with the intent of "community right-to know" programs.

- Demonstrate leadership in educating the public about the exploration, extraction and refining of petroleum; the economic value of domestic petroleum and its byproducts; conservation measures and their benefits; and other topics designed to assist the American public in gaining understanding of the importance of domestic resources and defining a true picture of those resources. 
III. TABLE OF CONTENTS

\begin{tabular}{|c|c|c|c|c|}
\hline I. & \multicolumn{2}{|c|}{ Disclaimer } & 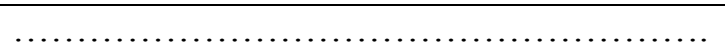 & Page 2 \\
\hline II. & \multicolumn{2}{|c|}{ Abstract } & ..... & Page 3 \\
\hline III. & \multicolumn{2}{|c|}{ Table of Contents } & $\ldots .$. & Page 4 \\
\hline IV. & \multicolumn{2}{|c|}{ Introduction } & & Page 6 \\
\hline V. & \multicolumn{2}{|c|}{ Executive Summary } & & Page 8 \\
\hline VI. & \multicolumn{2}{|c|}{ Regulatory Streamlining } & & Page 9 \\
\hline & A. & \multicolumn{2}{|c|}{\begin{tabular}{l|l} 
Appalachian-Illinois Basin Directors Workgroup &
\end{tabular}} & Page 9 \\
\hline & B. & \multicolumn{2}{|c|}{ North American Coastal Alliance } & Page 9 \\
\hline & C. & \multicolumn{2}{|c|}{ IOGCC-EPA Regional Meetings } & Page 10 \\
\hline & D. & \multicolumn{2}{|c|}{ National Association of Regulatory Utility Commissioners } & Page 10 \\
\hline & E. & \multicolumn{2}{|c|}{ Royalty-In-Kind } & Page 11 \\
\hline & F. & \multicolumn{2}{|c|}{ Oil Pollution Act of 1990 (OPA-90) } & Page 11 \\
\hline & G. & \multicolumn{2}{|c|}{ IOGCC Model Oil and Gas Conservation Act } & Page 11 \\
\hline & H. & \multicolumn{2}{|c|}{ The National Inspector Certification Program } & Page 12 \\
\hline & I. & \multicolumn{2}{|c|}{ Performance Measurement and Strategic Planning } & Page 13 \\
\hline & $\mathrm{J}$. & \multicolumn{2}{|c|}{ Well Spacing } & Page 13 \\
\hline & $\mathrm{K}$. & \multicolumn{2}{|c|}{ EPA's Cross-Media Electronic Reporting and Recordkeeping Rule } & Page 13 \\
\hline VII. & \multicolumn{2}{|c|}{ Environmental and Technical } & & Page 14 \\
\hline & A. & \multicolumn{2}{|c|}{ Toxic Release Inventory } & Page 14 \\
\hline & B. & \multicolumn{2}{|c|}{ Environmental Outreach } & Page 15 \\
\hline & $\mathrm{C}$. & \multicolumn{2}{|c|}{$\begin{array}{l}\text { National Pollution Discharge Elimination System (NPDES) } \\
\text { Stormwater Discharge, Phase II }\end{array}$} & Page 16 \\
\hline & D. & \multicolumn{2}{|c|}{ IOGCC NPDES Storm Water Discharge Workgroup } & Page 16 \\
\hline & E. & \multicolumn{2}{|c|}{ Spill Prevention Control and Countermeasure (SPCC) } & Page 16 \\
\hline & F. & \multicolumn{2}{|c|}{ Bentonite Plugging Study and Report } & Page 17 \\
\hline & G. & \multicolumn{2}{|c|}{$\mathrm{CO}_{2}$ Sequestration } & Page 17 \\
\hline & H. & \multicolumn{2}{|l|}{ Stewardship Awards } & Page 17 \\
\hline VIII. & \multicolumn{2}{|c|}{ Training } & 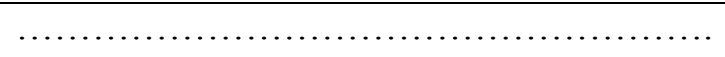 & Page 19 \\
\hline & A. & \multicolumn{2}{|c|}{ IOGCC Blue Ribbon Task Force } & Page 19 \\
\hline & B. & IOGCC Training Cour & & Page 22 \\
\hline & & 1. Amplified Expl & and Production & Page 22 \\
\hline & & 2. Geographic Inf & on Systems (GIS) & Page 22 \\
\hline & & 3. Global Position & stems (GPS) & Page 22 \\
\hline & & 4. Hydrogen Sulfi & S) Awareness & Page 22 \\
\hline & & Naturally Occu & Radioactive Materials (NORM) & Page 23 \\
\hline & & Risk-Based De & Making of Oil-Impacted Soil at E \& P Sites & Page 23 \\
\hline & & 7. Waste Minimiz & & Page 23 \\
\hline & & 8. Well Control - & ut Prevention - Revised & Page 24 \\
\hline
\end{tabular}




\begin{tabular}{|l|l|l|r|}
\hline IX. & Information Technology & $\ldots \ldots \ldots \ldots \ldots \ldots \ldots \ldots \ldots \ldots \ldots \ldots \ldots \ldots \ldots \ldots \ldots \ldots \ldots \ldots \ldots \ldots \ldots \ldots \ldots \ldots \ldots \ldots \ldots \ldots \ldots \ldots \ldots \ldots \ldots \ldots \ldots \ldots \ldots$ & Page 25 \\
\hline X. & Acronyms and Abbreviations & $\ldots \ldots \ldots \ldots \ldots \ldots \ldots \ldots$ & Page 29 \\
\hline XI. & Appendices & & $\ldots \ldots \ldots \ldots$ \\
\hline
\end{tabular}




\section{INTRODUCTION}

The Interstate Oil and Gas Compact Commission (IOGCC) is a 69-year-old state government organization representing the governors of 30 oil and gas producing states and seven associate states. In addition, Venezuela, Egypt, Republic of Georgia, Nova Scotia, Alberta, British Columbia, Newfoundland and Labrador are international affiliates of the IOGCC.

The IOGCC's mission is to promote the conservation and efficient recovery of oil and natural gas while protecting health, safety, and the environment. The organization, a congressionally approved compact of states ratified in 1935, maintains a staff at its national headquarters in Oklahoma City, Oklahoma. The IOGCC is classified as a state government recipient and has received federal funding through the U.S. Environmental Protection Agency, the U.S. State Department, and the U.S. Department of Energy.

Since its inception in 1935, the IOGCC has assisted states in the orderly development of oil and natural gas resources in fulfillment of the organization's congressional charter. This mission is accomplished in part through encouraging states to share regulatory expertise and by serving as a unique forum for state and federal regulators, industry, environmentalists and citizens to share viewpoints and concerns.

The Multi-State projects of the IOGCC focus on issues including technical and training assistance, public advocacy, environmental issues, regulatory streamlining, and information technology related to regulatory and data management standardization.

The Information Technology project included updating of the IOGCC Web page, coordinating state employees in meetings to improve uniformity, and educating state employees in the latest available technology so they can perform their duties more efficiently.

The Training program coordinated and conducted workshops, seminars and training programs to educate and inform state and federal regulators, as well as industry and the public on gas and oil related exploration and production issues.

The Toxic Release Inventory coordinated efforts with the U.S. Environmental Protection Agency and the states to ensure that adequate information is available to the public regarding oil and gas exploration and production operations, consistent with the intent of the "community right-to-know" programs.

Regulatory Streamlining efforts included identifying unnecessary duplication of efforts between state and federal programs related to oil and gas exploration and production on public lands and eliminating these unnecessary duplications. The IOGCC also realized and worked toward enhancing regional regulatory coordination and cooperation among the states. 
The Environmental and Technical Assistance project addressed the importance of promoting the development and implementation of risk-based environmental regulations at the state level through an expertise-sharing program that will bring stakeholders together to develop guidelines and models to meet regulatory challenges.

The Appalachian-Illinois Basin project provided partnering opportunities for oil and gas directors working within the Appalachian-Illinois Basin to improve regulatory efficiency in each director's state program through meetings and training programs.

The North American Coastal Alliance involved bringing together states and Canadian provinces that have offshore petroleum exploration and production. This alliance enabled regulators with unique regulatory needs to come together to share and identify areas of concern that may be studied and incorporated into standard practices for offshore environmental and regulatory compliance.

The Public Advocacy project educated the public and private sectors about exploration, extraction and refining of petroleum; the economic value of domestic petroleum and its byproducts; and conservation measures and their benefits. This program was funded in full by the IOGCC.

The following pages contain an evaluation of efforts involving the Multi-State projects in support of state regulation of domestic petroleum and production. 


\section{EXECUTIVE SUMMARY}

The Interstate Oil and Gas Compact Commission (IOGCC) identified several areas of concern as designated in the abstract portion of this evaluation report. The continuation of this extensive project will better prepare the oil and gas industry, state and federal regulators, and the environmental community in this $21^{\text {st }}$ Century and the energy problems associated with the changing needs of the world.

The principal issue areas that the project funded were:

- Regulatory Streamlining

- Environmental Technology

- Training

- Information Technology

The IOGCC will meet these issues through a cooperative effort of IOGCC committees, their subcommittees, and the numerous volunteers provided by the states and industry. The IOGCC operates through standing committees, each consisting of members appointed by IOGCC governors or their official representatives. Standing committees involved in providing invaluable assistance in the various areas of this grant are:

- Energy Resources, Research and Technology Committee

- Environmental and Safety Committee

- Legal and Regulatory Affairs Committee

- Public Lands Committee

- Public Outreach Committee

The commission establishes the goals and activities of the IOGCC through development of a Strategic Plan and periodic resolutions, which address various targeted, emerging issues. 


\section{REGULATORY STREAMLINING}

\section{Appalachian-Illinois Basin Directors Workgroup:}

The Appalachian-Illinois Basin Directors held roundtable discussions at each mid-year and annual IOGCC meeting during the duration of the multi-project grant period. Topics discussed included idle and orphan well location and plugging, new technology, production and permitting activity, and deep gas plays within the basin. The group also is investigating study projects on the coexistence of oil and coal development, and their regulatory implications.

During the summer of 2003, the Appalachian-Illinois Basin Directors held a group workshop that allowed the directors to bring a number of their staff to the meeting so they could coordinate with their colleagues in other states on issues and problem solving. This workshop was issue specific and will result in a written product that can be utilized by all of the states. The goal of the workshop was to work on an in-depth project to solve a problem the states are experiencing.

The project developed during the workshop was to assess coal-seam natural gas potential in the Appalachian Basin. Work on this project is ongoing and is not anticipated to be complete until the fourth quarter of calendar year 2004.

Member states of the Appalachian-Illinois Basin Directors are New York, Pennsylvania, West Virginia, Virginia, Ohio, Illinois, Kentucky, Indiana, Maryland, North Carolina, Tennessee and Missouri.

MISSION STATEMENT: The Appalachian-Illinois Directors focus on improving regulatory efficiency through partnering opportunities. The Appalachian-Illinois Basin Directors' emphases are both existing and emerging issues facing regulators and the petroleum industry in the participating states, and coordinating state efforts and responses to these issues. The continued dialogue provided through the Appalachian-Illinois Basin Directors has made and will continue to make significant contributions in furthering the long-range goals of both state and federal entities and the general public.

\section{North American Coastal Alliance:}

Members of the North American Coastal Alliance (NACA) met at each mid-year and annual IOGCC meeting during the duration of this multi-project grant period. They also met in Long Beach, California in September 2002 to discuss offshore issues such as mercury contamination and why oil and gas production is not a contributor to this problem. They also discussed the Coastal Zone Management Act and how states can work more effectively with the federal government. The group toured Thums Island, an offshore facility that is camouflaged to look like high-rise buildings surrounded by lush landscaping. The participants also toured an urban oil field in Beverly Hills.

The NACA worked toward developing a dialogue between the group and National Oceanic and Atmospheric Administration (NOAA). NACA member states hope to develop a cooperative scenario as well as a potential Memorandum of Understanding 
(MOU) between the states and NOAA. The states also hope to develop a model MOU for use between bordering states.

The latest project NACA is working on is a study of North American offshore moratoria. A final report is anticipated to be completed by the end of calendar year 2004.

Member states and Canadian provinces include Alaska, California, Texas, Louisiana, Mississippi, Alabama, Florida, Virginia, British Columbia, Newfoundland, and Nova Scotia.

MISSION STATEMENT: The North American Coastal Alliance focuses on examining, publishing, providing oversight and identifying areas of concern to the coastal states and provinces through a forum of open dialogue and sharing of compliance information and environmental research results.

\section{IOGCC-EPA Regional Meetings:}

At the recommendation of the 2002 IOGCC Chairman, Arkansas Governor Mike Huckabee, the IOGCC attempted to sponsor meetings between state oil and gas directors and the regional administrator of their respective EPA regions. Meetings were held in Oklahoma City to organize the effort. Meetings with regional directors were held in Dallas for EPA Region 6 (Arkansas, Louisiana, Texas, Oklahoma and New Mexico) and two meetings were held in Denver with the EPA Region 8 administrator. States in EPA Region 8 are Colorado, Utah, Wyoming, Montana, North Dakota and South Dakota. Subsequently, meetings were held in Kansas City with the EPA Region 7 administrator and in Chicago with the EPA Region 5 administrator. IOGCC member states in EPA Region 7 include Kansas, Nebraska and Missouri, and member states in EPA Region 5 include Illinois, Indiana, Ohio, and Michigan.

The purpose of these meetings was to build a stronger working relationship between the EPA regional offices and state oil and gas agency offices. A better understanding by EPA of what the states do in their oil and gas regulatory enforcement work will ease the duplication of effort that now occurs. In addition, the states believe they waste a good deal of time responding to EPA initiatives begun because EPA does not understand that the task is already being handled within the state.

The grant supported some travel money for these meetings, the organization of the meetings, and a small amount of related expenses. The states contributed in-kind many hundreds of hours of manpower. Not all the states required assistance with expenses. The grant paid for less than one-third of the trips, allowing the IOGCC to stretch the dollars involved.

\section{National Association of Regulatory Utility Commissioners:}

The IOGCC coordinated with the International Association of Regulatory Utility Commissioners (NARUC) on pipeline siting and streamlining projects. The pipeline site streamlining report developed jointly by the IOGCC and NARUC was posted at the IOGCC Web page in 2001 and was posted on the NARUC Web page during 2002. A 
copy of the Final Report of the Pipeline Siting Workgroup is on the Project Report CD, included with this report, as Appendix 1.

\section{Royalty-In-Kind:}

The IOGCC monitored royalty-in-kind issues, which are very important to the large public land states.

\section{Oil Pollution Act of 1990 (OPA-90):}

The IOGCC worked with U.S. Coast Guard officials and the Environmental Protection Agency (EPA) in an attempt to streamline the process of site cleanup at abandoned, orphaned well sites that qualify for funding under the Oil Pollution Act of 1990 (OPA90) through the Coast Guard. This has continued to be a sticking point for some of the states, but not for others, because of uneven enforcement and requirements of stated policies from the Coast Guard National Headquarters.

The IOGCC coordinated the flow of information from the states through interested parties in Washington, DC, and continued a dialogue with Coast Guard officials in charge of the oil pollution fund. Former Louisiana Governor Foster took the lead in the IOGCC efforts for this project, and a good deal of coordination was between the IOGCC and his oilfield coordinator. Based on the progress of this project and the level of cooperation from the Coast Guard it is anticipated that this project will continue to be a long-term, multi-year project and will have to be continued under a different funding mechanism.

\section{IOGCC Model Oil and Gas Conservation Act:}

When this project began the latest model act was 20 years old. In 2001, William Wynne of Arkansas, chairman of the IOGCC Legal and Regulatory Affairs Committee (LRA), asked Owen Anderson, with the College of Law at the University of Oklahoma, to chair a subcommittee that would be charged with revising the 1981IOGCC Model Oil and Gas Conservation Act.

In 2002, Chairman Wynn formed a subcommittee of the LRA. Members of the group working on the revised model act were: Professor Anderson, subcommittee chair; Michael Decker, Oklahoma; Diana Edmiston, Kansas; Carol Harmon, Colorado; Marvin Rogers, Alabama; Stephen Ross, New Mexico; Bob Travis, Mississippi; David Brooks, New Mexico; and Christine Hansen and Keith Thomas of the IOGCC.

Rather than following the form of the 1981 document, the subcommittee decided to use the form of those statutes created by the uniform statutes drafting officials so that state legislators would feel more comfortable with the new act.

During a period from 2002 until 2004, subcommittee members were asked to review assigned sections and make suggestions regarding revisions. The subcommittee convened meetings as needed to discuss changes. During the drafting of the new model it was decided that the IOGCC also should provide model underground gas storage provisions for the states to use in conjunction with the revised Model Oil and Gas Conservation Act. The result was the Model Underground Gas Storage Provisions. 
A final meeting was held in January 2004. Final revisions were made and a draft of the document was submitted to the representatives of the IOGCC member states for review and comment. Comments were received and changes were made. A final draft of the model act and its underground gas storage provisions were posted on the IOGCC Web site in the spring of 2004.

Various guidance documents and regulatory models will grow out of the 2004 Model Oil and Gas Conservation Act and the 2004 Model Underground Gas Storage Provisions. Both the Act and the Provisions are on the Project Report CD, included with this report, as Appendix 2 and Appendix 3, respectively. These documents are expected to be a welcome update of a model that has been used by state legislatures for six decades.

\section{The National Inspector Certification Program:}

The National Inspector Certification Program was instituted in 2000 by the IOGCC to ensure that all state oil and gas officials have the necessary knowledge to conduct efficient and effective inspections of production operations.

The program establishes national standards for state regulatory agencies to certify personnel responsible for inspecting oil and natural gas wells. The program includes mandatory criteria applicable to all states and options that are specific to individual states.

At the time of this report 123 oil and gas field inspectors and supervisors from 12 IOGCC member states had passed the National Inspector Certification Program examination. The states are Alabama, Arkansas, California, Colorado, Maryland, Montana, Nebraska, North Dakota, Oklahoma, Utah, West Virginia, and Wyoming. A list of the individuals who have passed the examination may be found on the IOGCC Web site at http://www.iogcc.state.ok.us.

As participants in the National Inspector Certification Program, states provide guidelines and structure to an important part of the oil and gas regulatory process. Inspections of oil and gas operations are one of the most important elements of regulation. Prior to the IOGCC's institution of this program, no official national program had been established to standardize this procedure.

Member states offering the IOGCC certification program ensure that their state oil and gas field inspectors and technicians have the skills and knowledge necessary to conduct inspections in a safe and competent manner. In addition, the National Inspector Certification Program helps define a consistent nationwide level of expertise among state oil and gas field inspectors and technicians. States are encouraged to build upon the IOGCC certification program by instituting sub-certifications for advancement in grade and initiating training programs. 


\section{Performance Measurement and Strategic Planning:}

The IOGCC began working of a project to provide performance measurement and strategic planning services to its member states. There has been substantial interest in the IOGCC providing expert assistance and guidance to state oil and gas programs in this area. During December 2003, the IOGCC hosted a one-day workshop for state oil and gas directors on this initiative in Dallas, Texas. The workshop was presented by Weidner Consulting, Inc., based in Austin, Texas. The IOGCC received positive response from this workshop and plans to begin providing this service subsequent to obtaining additional funding in the future.

\section{Well Spacing:}

Marvin Rogers, of Alabama, chaired a Well Spacing workgroup whose members included John Baza, from Utah; Bruce Hicks, from North Dakota; Todd Keating, from Louisiana; John Land McDavid, from Mississippi; and Patrick Martin, from Louisiana.

The workgroup compiled spacing regulations through a questionnaire sent to IOGCC member states and published a Model Statute addressing well spacing based on information submitted by member states. The process for developing the Model Statute involved the workgroup meeting for two days to gather the information from the member states, create the statute, and prepare the publication. Different states' ideas and issues were discussed and an agreement was reached by the states represented as to what was to be included in the Model Statute. Definitions were agreed upon that are included in the document. A copy of this document is on the Project Report CD, included with this report, as Appendix 4.

EPA's Cross-Media Electronic Reporting and Recordkeeping Rule (CROMERRR): Members of the IOGCC provided the EPA with comments and attended a meeting between the states and EPA Headquarters hosted by the Environmental Council of States in Washington, DC, during 2002. The IOGCC also passed a resolution on CROMERRR in 2002. A copy of that resolution is on the Project Report CD, included with this report, as Appendix 5. 


\section{ENVIRONMENTAL AND TECHNICAL}

\section{Toxic Release Inventory:}

In May 2001, the TRI Subcommittee met for the last time at the IOGCC annual meeting in Anchorage, Alaska. A summary of its projects and completion of its mission is as follows:

\section{Summary}

The Interstate Oil and Gas Compact Commission (IOGCC), through more than five years of advocacy work with the Environmental Protection Agency (EPA), has been successful in persuading EPA to end consideration of extending the toxic release inventory (TRI) reporting requirements of oil and gas wells.

In 1992, EPA began investigating the possibility of including the oil and gas exploration and production (E\&P) industry in the TRI regulatory list. On May 25, 1995, EPA established a list in the Federal Register of possible industries to include under federal TRI regulations. The oil and gas exploration and production (E\&P) industry was noted in the section of a paper titled Industries Under Current Consideration. At that time, EPA encouraged comments from the public.

A resolution titled, In Opposition to Expansion of EPA's Toxic Release Inventory Program to the Oil and Gas Exploration and Production Industry, was adopted unanimously at the IOGCC annual meeting in December 1995. The resolution was sent to EPA and other interested parties. In early 1996, IOGCC encouraged many governors and state regulators to write EPA to explain why inclusion of the oil and gas E\&P industry under the TRI regulatory program would not be necessary.

IOGCC's Environmental and Safety Committee tracked the TRI issue, and in May 1996, a subcommittee was created to educate EPA on the excellent state regulatory programs. Members of the subcommittee and the IOGCC's executive director met with EPA in July 1996 to open discussions on EPA's plans for the oil and gas E\&P industry in relationship to the TRI regulatory program. One of the complaints received by EPA was that the information was not readily available on oil and gas operations, thus hindering the community in their right to know. EPA received suggestions from state regulators on the best methods to obtain this information in an efficient manner.

In late 1996, the TRI Subcommittee prepared a three-volume publication to educate EPA on regulatory programs in the states. The book was titled Review of Existing Reporting Requirements for Oil and Gas Exploration and Production Operators in Five Key States. The states included California, Louisiana, New Mexico, Oklahoma, and Texas - most of the major oil and gas producing states. EPA's director of the Environmental Assistance Division in the Office of Prevention, Pesticides, and Toxic Substances received a complete set.

In October 1998, the TRI Subcommittee conducted a field trip to oil and gas facilities in Oklahoma. The two EPA employees were impressed with the operations managed by the 
state. Another field trip by the TRI Subcommittee was undertaken in October 1999 in Ohio. An EPA employee involved in preparing federal TRI regulations and a regional EPA staff person participated in the one-day trip. It was the first visit by these Washington-based EPA staff to an oil or gas facility. TRI Subcommittee members and IOGCC staff arranged three such trips.

In March 2000, the TRI subcommittee met in Washington, DC, with David Hindin, associate division director of EPA's TRI Program Division in the Office of Information Analysis and Access, and Tim Crawford, environmental program specialist in the Office of Information Collection. Mr. Hindin reported that the TRI issue for the oil and gas E\&P industry was a low priority item that "was not on their radar screen" and was on the "back burner". At that time, however, he could not rule out any possible future action because the oil and gas E\&P industry was still on their list for future possible inclusion in the TRI regulatory program. The group requested a list of those who submitted public comments in response to the notice in the Federal Register. EPA informed IOGCC's subcommittee that two letters, written in 1996, were submitted in response to EPA's request for comments in the May 25, 1995, issue of the Federal Register.

The TRI Subcommittee met in May 2001, at the IOGCC midyear meeting in Anchorage. The group agreed that if the oil and gas E\&P industry was included on the latest list of possible industries under the TRI regulatory program (due out immediately), then a meeting would be planned with EPA in Washington, DC. In the May 14, 2001, Federal Register (Volume 66, Number 92) there is no mention of the oil and gas E\&P industry as an area of expansion for TRI.

After diligent work by IOGCC's TRI Subcommittee during the past five years, the oil and gas E\&P industry has been removed from the list of inclusion in EPA's TRI Regulatory Agenda.

\section{Environmental Outreach:}

The IOGCC executive director has explored a number of potential environmental outreach efforts. She contacted other state associations with a focus on environmental protection and has participated in extensive outreach with the Environmental Protection Agency to develop cooperative projects.

The IOGCC initiated a monthly program of sharing "Best Practices" among the states. Many of these are environmental practices. The executive director, along with IOGCC's Washington representative, also worked with a variety of other organizations to develop data and correct information concerning the environmental impact of fracturing wells to produce natural gas from coal. This issue has been one of interest to the EPA, which was conducting a study. This EPA study was released in June 2004

The IOGCC repeatedly reached out to the EPA, and will continue to do so, to provide member states information on this study, as well as for the states to provide comments and information to assist the EPA in understanding an issue with which the states have had decades of experience. 
National Pollution Discharge Elimination System (NPDES) Stormwater Discharge, Phase II:

The IOGCC worked with member states to provide the EPA factual and accurate information on how the states were already enforcing erosion control requirements at oil and gas sites. Additionally, the EPA was provided information on the number of well sites that would potentially be impacted by implementation of their NPDES Stormwater Discharge Phase II Rule. The EPA had not considered the tremendous impact and therefore was required to further evaluate incorporating oil and gas activities under the rules umbrella.

\section{IOGCC NPDES Storm Water Discharge Workgroup:}

This working group was tasked with determining how to best meet the Environmental Protection Agency's needs and develop appropriate documents. After thorough review of stormwater issues and concerns, the members of this multi-state group found that existing state programs currently have statutory and regulatory authority that will sufficiently address any concerns regarding the impact of clearing, grading and excavating (CGE) activities that take place at exploration and production sites. Therefore, there was no need for EPA to attempt to solve a problem that does not exist.

The workgroup further found that Congress specifically exempted those who explore for domestic energy resources from obtaining stormwater discharge permits under the Clean Water Act. There is no definition in the Act that states that CGE activities should be considered separate and apart from other exploration and production activities. It would be an expansion of EPA's jurisdiction to include CGE activities where there is no need shown for such expansion.

The review indicated a "stormwater incidence" of less than two per state per year over the last three years. The additional costs on the industry are estimated to be in the hundreds of millions of dollars. There is no need to place an additional burden on exploration and production companies in an arena that has not shown any historical need for increased regulation. Such exorbitant costs would negatively impact oil and gas exploration activities that are critically needed for increased domestic energy production.

In summary, all evidence reviewed by the workgroup indicates that the environmental impact of stormwater discharges from CGE activities is minimal, and currently is being well managed by one or more regulatory agencies within a state. Any expansion of jurisdiction by the EPA would impose a huge regulatory burden on this nation's oil and gas producers without benefit to the environment.

\section{Spill Prevention Control and Countermeasures (SPCC):}

The IOGCC and its member states provided comments to the EPA on the impact of implementing the 2002 modifications to their SPCC rules. Additionally, the IOGCC developed a protocol for implementation of the revised SPCC rules and presented them to the EPA at an EPA-IOGCC MOU Task Force meeting on January 18, 2004, in Denver, Colorado. This information assisted the EPA in modifying its proposed revisions to the 
rule and the protocol was provided to the other EPA regions as a model for implementation as it relates to oil and gas exploration and production sites.

\section{Bentonite Plugging Study and Report:}

In May 2001, the IOGCC Environmental and Safety Committee created the Bentonite Subcommittee to investigate the viability of using highly compressed sodium bentonite nodules to plug and abandon oil and gas wells.

The subcommittee's task was to determine if compressed sodium bentonite was a viable alternative to cement in well plugging operations and, if so, what technical issues or regulatory barriers exist that would prevent the use of compressed sodium bentonite as a plugging agent and, if so, how those barriers could be eliminated. This report addresses these issues and concerns presented to the Environmental and Safety Committee. A draft of this report was presented to the Environmental and Safety Committee at the December 2001 IOGCC annual meeting in Santa Fe, NM.

The report described several types of well completions and the generic well plugging processes using compressed sodium bentonite as the plugging agent. It outlines standards and guidelines for use and design specifications. Plug characteristics, plug hydration, and pilot studies are discussed in the report. The subcommittee also surveyed its member states as to any existing regulatory barriers to the use of sodium bentonite as a plugging agent in those states.

The subcommittee found that compressed sodium bentonite is a viable alternative for use in most typical oil and gas well plugging and abandonment procedures. The process provides a nearly impermeable, permanent plug that can be easily drilled out should the need arise for future use of the well bore and, depending on well bore conditions, reduces the cost involved by eliminating the need for servicing rigs, trucks, and equipment normally used in plugging operations. However, certain well bore conditions will prohibit the use of compressed sodium bentonite. These conditions include, but are not limited to, the presence of high saline fluids, down-hole obstacles, high well bore pressures, and highly deviated well bores. A copy of this report is included on the Project Report CD, included with this report, as Appendix VI.

\section{$\mathrm{CO}_{2}$ Sequestration:}

Funding through this grant also assisted the IGOCC in a project requested by the U.S. Department of Energy to bring together state regulators and state geologists to discuss the regulatory approach to $\mathrm{CO}_{2}$ sequestration. This effort culminated in a well-attended twoday meeting in Alta, Utah, in July 2002. A report of the meeting outcomes is on the Project Report CD, included with this report, as Appendix VII.

\section{Stewardship Awards:}

In an effort to focus on positive accomplishments, the Interstate Oil and Gas Compact Commission (IOGCC), through its annual Stewardship Awards, honors producers for their diligent efforts to protect the environment. The IOGCC honors significant achievements in the following four categories: 
- Major oil and natural gas company

- Independent oil and natural gas company

- Environmental partnership

- Energy education

The 2001 winners were:

- Phillips Alaska Inc. - Major or large oil or natural gas company

- Evergreen Resources Inc. - Independent or small oil or natural gas company

- Southwest Indiana Brine Coalition (SWIBC) - Environmental partnership

- National Energy Foundation (NEF) and Oklahoma Energy Resources Board (OERB) - Co-winners - Energy education

The 2002 winners were:

- Marathon Oil Co. - Major category

- Dominion Exploration and Production - Independent category

- Wasatch-Cache Petroleum Showcase - Energy Education

- Michigan Natural Resources Trust Fund - Environmental Partnership

The 2003 winners were:

- Illinois Petroleum Resources Board - Energy Education

- Ohio Oil \& Gas Energy Education Program - Energy Education

- Oklahoma Energy Resources Board - Environmental Partnership

Overviews of the 2001, 2002 and 2003 awards are on the Project Report CD, included with this report, as Appendix VIII, Appendix IX and Appendix X, respectively. 


\section{TRAINING}

\section{IOGCC Blue Ribbon Task Force:}

A tight labor market for U.S. petroleum professionals (geologists, engineers and geophysicists) is looming. This task force developed recommendations, or tasks to be worked toward, in an attempt to solve that quandary before it damages the vital domestic petroleum industry. Before addressing the issue of how to assure the future supply of petroleum professions, it was important to put the dilemma into context.

The oil shocks of the 1970's and 1980's and the subsequent collapse in world energy prices from 1984 to 1986 resulted in a major retrenchment of the energy industry. The domestic industry alone lost more than a half million jobs in the mid-1980's. Subsequent to the price collapse that culminated in 1986, the industry has experienced substantial volatility in energy prices that has posed special challenges to maintaining a stable workforce.

First, investment in new infrastructure, refineries and other critical facilities for delivery of energy to the global economy has dropped significantly. This dramatic slowdown in investment has caused a large reduction in the excess delivery capacity that the industry traditionally had maintained. This loss of excess capacity is to blame, in part, for the recent spikes in prices that have occurred as the industry struggles to meet market demand in the growing global economy.

Second, proprietary research and development $(\mathrm{R} \& \mathrm{D})$ by the major operating companies were reduced dramatically as part of the austerity mindset that major operators were forced to adopt. Operators shifted from programs of highly competitive, proprietary $\mathrm{R} \& \mathrm{D}$ to a reliance on outside technology developed by service companies and universities. However, the funding cuts imposed by the industry during this period also affected the programs at universities and service companies and caused many of these programs to fall into ill health as well. In the same period, government-funded energy R\&D also came under pressure, and dramatic reductions in federal spending made an already serious problem even worse.

Third, dramatic changes in employment demographics of the energy industry emerged. The industry hired aggressively from 1974 to 1983, and built up large staffs. Many of these people lost their jobs in the mid 1980's. In the following years, those who stayed in the industry have witnessed a seemingly unending process of layoffs, reorganizations, mergers and consolidation. The "survivors," who are a large part of the current employment base of the industry, are now approaching retirement age, as evidenced by current industry demographics (Figure 1). At present, the average age of employees with the major operators and service companies is 46-49 years old. With the average retirement age for the industry being 55 years, it is obvious that the industry faces a crisis in the next 7 to 10 years as more than half of the employee base leaves the business. 
At the same time, the reduction in global spending by the industry, coupled with mergers, resulted in significant reductions in hiring of geoscientists, engineers, field personnel and other skilled workers.

The impact of this change in hiring practices is two-fold. First, the decline in hiring prevented the industry from addressing the demographic problem by filling in the tail of the age curve in Figure 1. Second, the operators and service companies diminished their recruiting efforts at universities and reduced funding for R\&D activities, which resulted in dramatic declines in the number of domestic students preparing to enter the oil and gas industry.

These declines in undergraduate and graduate enrollments, as evidenced by data from the geosciences and petroleum engineering disciplines (Figure 2), have created a progressive weakening in the health and viability of major educational programs that are critical to the future of the industry, and, therefore, to the energy stability and security of the United States and global economies. The decline in enrollment levels also has been exacerbated by the fact that experts working in the industry frequently advise their children not to follow in their footsteps because they perceive that the downward spiral will continue.

Coinciding with these difficult times in the energy industry were sweeping changes in the global economy. The information age and the Internet revolution, which began in the mid to late 1980's, were fueled, ironically, by the same low energy prices that created the crisis in the petroleum industry. Fortunately, the energy industry benefited from the effects of the information age. Major improvements in computer hardware, software, and operating environments, coupled with technological advances, including high-quality 3D seismic data and horizontal drilling, allowed the industry to consolidate its manpower requirements while significantly increasing efficiency.

It is estimated that this set of unique factors has allowed the energy industry to reduce technical manpower requirements at a rate that has more than offset the lack of recruiting and hiring over the last 15 years. However, the efficiency improvements in the energy sector created by the growth of the information age are not sustainable. Over time, the rate of change has begun to slow, and current data indicate that future improvements in efficiency from this technical revolution will not be sufficient to offset the impending loss of senior expertise that will occur over the next 7 to 10 years.

At the same time these major changes were occurring in the energy industry, dramatic changes were taking place in domestic and global environmental policy and in the public perception of the energy industry. Major accidents such as the Amoco Cadiz and the Exxon Valdez and the subsequent environmental and legal fallout, caused a severe deterioration in the public view of the petroleum industry.

A coordinated industry effort involving industry, government agencies and educational institutions is needed to reach out and educate the public about the importance of oil and gas to the national and global economy. Unfortunately, the lack of such a cooperative 
effort in recent years has allowed negative perceptions of the U.S. oil and gas industry to dominate public opinion.

The shifts in domestic environmental policy coupled with the domestic access challenges faced by industry also have resulted in a major change in the investment profile for the domestic industry. The major and super-major operating companies that once dominated the domestic industry have shifted their investment emphasis to other regions that hold large reserves and present less environmental and legal risk.

Mid-size majors and independent operators have rapidly filled the void left by the majors and super-majors, and these smaller companies now represent the majority of the investment made in the domestic petroleum business. This should not be dismissed or taken lightly, because these smaller companies do not have the same level of recruiting, hiring and R\&D resources that the major and super-major operators historically have provided.

Another factor that affects the quality of energy solutions provided to the U.S. economy is the relationship between the key players in our energy future. The United States has so far lacked a cooperative, directed effort involving government, industry and academia to address key energy issues confronting the nation.

The task force recommended doing the following:

1. Education/outreach:

a. Promote a conference, hosted by Gov. John Hoeven of North Dakota, to discuss the problem and solutions from the perspective of key exploration, production and service companies and leaders from the trade organizations. Send letters from Gov. Hoeven to state and federal officials (secretaries of Labor/Energy, President, congressional committees)

i. To support adequate R\&D funding

ii. To insert manpower issues into President Bush's energy plan

iii. To encourage state employment agencies to develop outreach efforts

b. Ask national and state associations to advance outreach efforts

c. Survey current oil/gas students on why they were drawn to the industry (communicate the results to the states and industry to build on the identified strengths).

2. The IOGCC will establish an electronic career resource center, creating a new Webbased information site); include postings of mentoring opportunities, internship programs, academic scholarships, fellowships and other support available for those interested in a career as a petroleum professional.

a. Link the career resource center electronically to professional and industry associations (including state associations), university systems with related resources and programs, and appropriate industry references.

b. Make the page known to high school counselors, undergraduate advisors at the top tier petroleum education universities, and others that would find the career resources to be useful. 
3. Commit the IOGCC to identify federal grant opportunities to develop a broader communications/education program and submit grant applications to secure funds.

4. Survey IOGCC member states' oil and gas agencies for an assessment of state or regional R\&D needs that need to be championed.

5. Reconvene the task force to submit its final report, and assess progress no later than May 2003.

A full report is on the Project Report CD, included with this report, as Appendix XI.

\section{IOGCC Training Courses:}

The following classes were made available through IOGCC under this grant:

\section{Amplified Exploration and Production}

This one- or two-day presentation begins with researching and developing a prospect, acquiring mineral leases, economic analysis, drilling logging and completing the well, plugging, and site restoration. This is a basic discourse on the exploration and production operations of an individual well, and is tailored to students with little or no background in actual field operations. The program was created to combine requests for all phases of oil and gas exploration and designed to clarify the concerns of normal E\&P operations most important to your state.

\section{Geographic Information Systems (GIS)}

The newly revised GIS instruction is specifically designed for your staff. The IOGCC has an excellent cooperation of industry trainers that know about the specific system that you use, or are interested in using. The impact of GIS and the comprehension of its future applications are beginning to afford us real problem-solving tools instead of futuristic predictability models. This course is designed to be as flexible as necessary to assure that all interested associates learn about these powerful tools.

\section{Global Positioning Systems (GPS)}

The class is specifically designed for your needs (from one to three days), and is geared to the novice or the person already familiar with the basics of Global Positioning Systems and the required equipment. The participants learn the advantages and disadvantages of certain types and brands of equipment. They are taught how to navigate from point-to-point, plot points, close the area, and differentiate between latitude and longitude and elevation points. Field operations may be included to allow participants hands on experience.

\section{Hydrogen Sulfide $\left(\mathrm{H}_{2} \mathrm{~S}\right)$ Awareness}

The half day to full day program is designed to offer state E\&P regulatory staff, industry personnel, and the public, a basic understanding of the dangers associated with $\mathrm{H}_{2} \mathrm{~S}$. This naturally occurring gas is one of the most dangerous gases and is perennially a leading cause of injuries and deaths within the oil and gas industry. A certification of $\mathrm{H}_{2} \mathrm{~S}$ training is now available and requires passing an examination of the materials covered in the program. 


\section{Naturally Occurring Radioactive Materials (NORM)}

This class can be designed as a half day introductory seminar, or an intensely handson combination of classroom and field presentation of specific applications that are of interest to your constituents.

\section{Risk-Based Decision Making of Oil-Impacted Soil at E\&P Sites}

Risk-based decision-making (RBDM) is a process that integrates traditional corrective action steps with exposure and risk assessment activities (e.g., site assessment, risk assessment, risk management and remediation). Regulators and operators are beginning to apply RBDM concepts to cleanup and closure of E\&P sites. Important policy issues for implementing RBDM programs will be discussed along with the status of E\&P RBDM programs in several states.

\section{Waste Minimization}

This presentation on the various aspects of a logical and workable waste minimization program supports the producers and the stare regulators by explaining how to reduce, eliminate, recycle, or properly handle the problems associated with waste streams generated in E\&P operations. Several cost-saving programs are offered that demonstrate their advantage and success. This training was presented to the states shown in Table 1.

Table 1. IOGCC Waste Minimization Workshops

\begin{tabular}{|l|l|c|}
\hline \multicolumn{1}{|c|}{ Location } & \multicolumn{1}{|c|}{ Date } & \multicolumn{1}{c|}{$\begin{array}{c}\text { Number of } \\
\text { Participants }\end{array}$} \\
\hline Pittsburgh, PA & January 13, 1999 & 52 \\
\hline Gaylord, MI & April 15, 1999 & 30 \\
\hline Denver, CO & April 30, 1999 & 21 \\
\hline Anchorage, AK & May 4, 1999 & 12 \\
\hline Wichita, KS & May 19, 1999 & 32 \\
\hline Mt. Vernon, IL & July 14, 1999 & 25 \\
\hline Oklahoma City, OK & September 17, 1999 & 10 \\
\hline Bakersfield, CA & October 14, 1999 & 23 \\
\hline Lafayette, LA & February 1, 2000 & 27 \\
\hline Shreveport, LA & March 13, 2000 & 25 \\
\hline Tuscaloosa, AL & November 19, 2002 & 17 \\
\hline Salt Lake City, UT & July 29, 2003 & 20 \\
\hline & Total Number of Participants & $\mathbf{2 9 4}$ \\
\hline
\end{tabular}


IOGCC Waste Minimization Video

A training video was filmed on May 20, 1999, at the offices of Murfin Drilling in Wichita, Kansas, and is available through IOGCC headquarters.

\section{IOGCC Waste Minimization Manual}

Work on the IOGCC manual began about October 1997. The first edition has a publication date of March 1998. A subsequent revision to the manual was published in April 1999, which is the most current edition available.

\section{Well Control - Blowout Prevention - REVISED}

The non-technical one-day presentation is for the person that is not in direct control of a blowout prevention situation, but has an official interest in the proper way to address the problem. The subject matter presented is intended to offer the participant basic knowledge of the equipment and process used in correcting the adverse conditions that may result in the loss of control of a well. The presentation is an overview to assist regulators in better understanding the mechanics of well control. This course has been revised and has excellent technical materials for reference in the event it becomes necessary for a thorough understanding of the subject. 


\section{INFORMATION TECHNOLOGY}

Many state oil and gas agencies are taking increasing advantage of electronic commerce. States are beginning to offer the electronic filing of various kinds of regular reports by their oil and gas industries, and many states are developing electronic permitting for various oil and gas operations. Nowhere has the scope of this state effort been assembled.

The IOGCC has contracted with a consultant who is surveying all of the states to get details of their current electronic commerce offerings.

In addition, the contractor will identify the source of software used for each of the applications. For instance, some states may be utilizing off-the-shelf software and some may have developed an in-house system that would be made available to other states free of charge. The person responsible in each state for maintaining the electronic commerce function also will be identified, along with the contact information.

The research phase of this project will last through the summer of 2001, with publication of the information to come in the fall or winter of the same year. A presentation at the IOGCC annual meeting in December 2001 is planned to round out the communication of this project.

The end result will be a document that provides states with a wealth of reference material concerning electronic commerce for state regulatory programs. In addition, we will identify software that is available free from the states that developed the software. This will assist states in keeping the cost of electronic commerce to a minimum.

In addition, the states will be able to build upon existing electronic commerce to add additional features by sharing from other states.

Mike Nickolaus, who is the consultant, is also on the staff of the Indiana Commission. Mr. Nickolaus will prepare an individual analysis of state electronic commerce. Information obtained from this research will not be published, but will be shared privately with each state as a way to assist states in upgrading their programs.

In 1995, the IOGCC, through the Ad Hoc Drilling and Production Database Standardization Committee, took on the task of documenting the data management technologies (hardware and software) being utilized by IOGCC member states for E\&P data management.

The Ad Hoc Drilling and Production Database Standardization Committee was reorganized in 1998 and is now known as the Information Technology Subcommittee. The new subcommittee, a group of the Energy Resources, Research and Technology Committee, is composed of an informal, small work-group. Since the reorganization of the group, the IOGCC staff has coordinated some major projects. 1) State Technology Exchange groups, composed of oil and gas statisticians; and 2) a pilot project using handheld personal computers introduced in two states. 
The following projects have been created, or are in the process of completion under this portion of the grant.

- A survey of the IOGCC member states obtained general information on the oil and gas regulatory agencies' Web sites. This information was compiled; comments were made regarding different parts of projects; and the book is in the process of being printed.

The survey included the following information and questions:

$\checkmark$ Name and title.

$\checkmark$ Name and e-mail address of Webmaster

$\checkmark$ Name and e-mail address of persons responsible for maintaining Web site, other than Webmaster.

$\checkmark$ Name and URL of the agency or agencies that regulate oil and gas.

$\checkmark$ Name of the person, company, or state agency that designed the Web site.

$\checkmark$ Name and version of software used to maintain the Web site.

$\checkmark$ Name and version of software used to provide security for the Web site.

$\checkmark$ Name and version of software used to prepare graphics for use on the Web site.

$\checkmark$ If your state authorizes the use of electronic signatures for Web site submissions, how is this accomplished?

$\checkmark$ If your site serves database information, what is the name and version of the software used to export or link your data to the Internet?

$\checkmark$ Does your Web site reside behind a firewall? (If no, please describe the method(s) you use to restrict access to the server on which your site resides).

$\checkmark$ Was the development of your site funded through a grant from an entity such as the IOGCC, DOE, or EPA? If no, would you be willing to share site documents, graphics, etc. with other states?

$\checkmark$ When did your Web site first go online?

$\checkmark$ What is the total number of hits your home page has received since going online?

$\checkmark$ Describe the biggest obstacle to maintaining your Web site?

$\checkmark$ Please list upcoming additions to or plans for your Web site and their estimated implementation dates.

$\checkmark$ Please add any comments, observations, or suggestions for Web site development that you believe would be helpful to other member states.

- Palm pilot projects creating new reporting forms in several states have been created, or are in the process of completion. Theyt will assist the inspectors in performing their jobs in a more efficient manner. The states are:

$\checkmark$ California - converting the Palmtop field inspection application to the Windows CE platform to run on the Pocket PC. Will include new forms and reporting features. 
$\checkmark$ Illinois - developing a field data capture software system for oil and gas inspectors. The Pocket CE hand-held computers will be used as the hardware, purchased by the state.

$\checkmark$ Indiana - developing a data collection and transfer application for the Palm Computing Operating System ${ }^{\circledR}$. The system will increase the portability of database information, eliminate iterate data entry tasks and minimize the use of paper records.

$\checkmark$ Currently three other states have indicated an interest in participating in a Palm Computer system for state regulators.

State statisticians will meet prior to the IOGCC annual meeting in December to discuss reports on projects within their states. This meeting will be designed to assist the state statisticians as well as the oil and gas directors in learning of the latest projects in the states that assist the regulators in addressing regulatory/statistical issues in a more efficient manner. Presentations will be made, as well as a round-table discussion. 


\section{ACRONYMS AND ABBREVIATIONS}

$\mathrm{A} / \mathrm{I}$

DOE

EPA

E\&P

GIS

GPS

IOGCC

LRA

NARUC

NACA

NETL

NOAA

NORM

OPA'90

RBDM

TRI
Appalachian-Illinois Basin Directors

Department of Energy

Environmental Protection Agency

Exploration and Production

Geographical Information System

Global Positioning Satellite

Interstate Oil and Gas Compact Commission

Legal and Regulatory Affairs

National Association of Regulatory Utilities Commissioners

North American Coastal Alliance

National Energy Technology Laboratory

National Oceanic and Atmospheric Administration

Naturally Occurring Radioactive Material

Oil Pollution Act of 1990

Risk Based Decision Making

Toxic Release Inventory 


\section{APPENDICES}

See individual file appendices. 
Appendix 1 
Final Report

of the

\section{IOGCC / NARUC \\ Pipeline Siting Work Group}

July 2001 


\section{RECOMMENDATIONS OF THE NARUC/IOGCC PIPELINE WORK GROUP}

\section{Sustaining Economic Expansion}

States striving to sustain and encourage economic development will find the challenge increasingly dependent upon energy availability. As a result of recent events, new and expanding businesses often no longer assume needed energy supplies will be available. In order to expand, or develop new businesses, as well as meet basic human needs of the population, states must ensure that an adequate energy infrastructure is available. The recent California experience with energy shortages has prompted businesses, generally, to ask state development offices about the availability of electricity and natural gas within a state. Governors will increasingly be called upon, as they promote economic development in their states, to respond to the energy availability question.

The current natural gas infrastructure was not planned to meet the expected rate of natural gas consumption growth which the nation will see in the next decade, particularly demand driven by needs in electric power generation. More than 90 percent of all planned new power generation in the United States will be fueled by natural gas. Almost all small, supplemental back-up generating units (such as those used by hospitals and schools) are powered by natural gas. Natural gas demand has been well documented by the National Petroleum Council (NPC) report which spurred creation of this work group.

One of the key challenges to energy availability is an adequate natural gas pipeline and distribution system to provide an ever increasing gas demand across the country. The NPC report estimates over 38,000 miles of new transmission lines will be needed, as well as 263,000 miles of new distribution lines. That much pipeline will require the attention of every state, and many regulatory bodies within the states. It will require the attention of the Federal Energy Regulatory Commission (FERC), the Bureau of Land Management (BLM), the U.S. Forest Service and many other federal entities.

The work group has found pipeline siting controlled by a variety of state and local government offices, as well as by the federal government. In terms of permit volume, the bulk of individual permits, required for infrastructure expansion, are state and local. State and local regulations are not only necessary, but add an element of local oversight which is critical to a project being reviewed with the unique interests of the state or locality at the forefront. However, only a few states have effective coordination of the natural gas pipeline permitting process while state and local regulatory steps can add many months - and sometimes years - to building a pipeline.

State and local regulation is perhaps the most effective level of regulation because it rests closest to the public being served. However, state and local regulation is sometimes duplicative both between levels of government and between different state agencies, and for interstate pipelines must take federal requirements into consideration. 


\section{$\underline{\text { Recommendations }}$}

1. Every governor should establish within the office of governor a coordinating effort to organize and expedite the activities of all state and local natural gas permitting entities. The purpose of the coordination would be to monitor the process and encourage prompt consideration, while eliminating duplication of effort. This coordinating effort will not be a new level of regulation, but will draw upon the expertise of the appropriate state agencies. The coordinating effort will insure all data needed are provided by the applicant in a timely fashion and will facilitate sharing of information and experts among state and federal agencies, and with local government.

2. States should decide, prior to beginning a natural gas pipeline siting process, what information they need to collect and communicate that information to the general public and to the pipeline. States should identify all of the participants in the permitting process and coordinate regulatory roles, to the goal of processing information only once. States should consider naming a lead agency which would have the authority to monitor processing schedules within existing regulatory requirements.

3. Every state economic development office (Commerce Department) should be involved with the coordination effort and recommend actions to streamline the process.

4. States should work with the federal government to conduct regional needs and pipeline/utility corridor identification. This federal-state coordination is endorsed in Executive Order 13212, issued May 18, in which President Bush created a federal interagency task force charged with “... setting up appropriate mechanisms to coordinate federal, state, tribal and local permitting in geographic areas where increased permitting activity is expected."

5. States should consider a special task force of state environmental experts to focus and coordinate all environmental issues stemming from the proposed pipeline. When time-sensitive issues arise, the governors need a plan for reaction, which would be coordinated with federal entities where appropriate. This is recognized in the National Energy Policy released in May by the Bush Administration which recommends that "... the President direct agencies to continue their interagency efforts to improve pipeline safety and expedite pipeline permitting in an environmentally sound manner and encourage the Federal Energy Regulatory Commission to consider improvements in the regulatory process governing approval of interstate natural gas pipeline projects."

6. States should encourage research spending, including government, university and pipeline spending, to continue the development of pipeline installation techniques to disturb less surface, complete the installation more quickly and enhance safety. 
7. States should undertake a comprehensive review of policies, procedures and regulations for the siting and installation of natural gas pipelines to determine how to eliminate duplication, reduce the cost and time of review, without any compromise to state regulatory oversight.

8. States should be a partner in FERC pipeline pre-filing citizen meetings, and consider developing similar citizen meetings for intrastate projects. Stakeholder notification and involvement in the process must be adequate to evaluate their interests.

9. States should encourage public education and outreach on the part of the pipeline. Pipelines, and states, should exchange innovative and high quality effective public outreach techniques, including informing the public about economic development and human needs issues as they link to new natural gas infrastructure requirements. Such public education should include adequate information about steps taken to ensure public safety, details of construction and contingency plans (i.e. what happens when it rains for a week in the middle of construction?), and information about the direct benefits of the project.

10. States should consider developing a model for clear and accessible state and local regulations governing the siting of natural gas pipelines. 


\section{IOGCC/NARUCPIPELINE SITING WORKGROUP}

\section{Working Group Coordinators}

Christine Hansen

Executive Director

Interstate Oil and Gas Compact Commission

Commissioner Edward J. Holmes

Chairman

NARUC Committee on Gas

\section{IOGCC Participants}

Commissioner Philip Asprodites

Commissioner of Conservation

Division Natural Resources

Office of Conservation

\section{Staff:}

Mariano G. Hinojosa

Director of Pipelines

Louisiana Division Natural Resources

Office of Conservation

Commissioner Don Mason

Utility Commissioner

Public Utilities Commission of Ohio

John T. King

Supervisor, Gas Division

Petroleum Engineering Section

Michigan Public Service Commission

Staff:

Bill Bokram

Gas Division

Michigan Public Service Commission

\section{Department of the Interior (BLM) Participant}

Bob Anderson

Deputy Assistant Director

Minerals, Realty and Resources Protection

Bureau of Land Management

U. S. Department of the Interior

\section{FERC Participant}

Randolph E. Mathura

Director

Division of Pipeline Certificates

FERC - Office of Energy Projects

\section{INGAA Participants}

Cuba Wadlington, Jr.

President and Chief Executive Officer

Williams Gas Pipeline

Geoffrey A. Emerson

Regulatory State Government Affairs Director

CMS Energy

\section{NARUC Participants}

Commissioner Frederick Butler

New Jersey Board of Public Utilities

Staff:

John Caleca

Assistant to Commissioner Butler

New Jersey Board of Public Utilities

Commissioner Clark Jones (retired)

Utah Public Service Commission

Commissioner R. Marshall Johnson

Minnesota Public Utilities Commission

\section{AGA Participant}

Jeff Petrash

American Gas Association

US DOE Participant

Yvonne Caudillo

Natural Gas Analyst

United States Department of Energy

Office of Fossil Energy 
Appendix 2 


\title{
2004 MODEL OIL AND GAS CONSERVATION ACT
}

\author{
Interstate Oil and Gas Compact Commission
}

\section{Preface}

The Interstate Oil and Gas Compact Commission (IOGCC) has promulgated this Model Oil and Gas Conservation Act as a guide for use by states in enacting comprehensive oil and gas conservation statutes. This Model Act also centralizes oil and gas conservation regulatory (regulation) in one state agency, with the exception of certain clean air, water permitting and land use authority. The IOGCC recognizes that some states may not choose to provide for market demand prorationing, compulsory unitization, exploratory unitization, forced pooling, royalty valuation regulation, underground gas storage, enforcement, or other provisions of this Model Act. Depending on the context, bracketed material indicates language that may have to be changed to fit within a particular state's statutory or organizational framework or contains provisions that are optional. To facilitate the ability to "pick and choose" particular segments, the Model Act has been subdivided into the following ten Parts:

PART I: Definitions

PART II: $\quad$ Scope of the Act and Authority of Conservation Agency Provisions

PART III: Market Demand Prorationing Provisions

PART IV: Well Spacing and Density Provisions

PART V: Compulsory Pooling and Voluntary Unitization Provisions

PART VI: Compulsory Unitization Provisions

PART VII: Compulsory Exploratory Unitization Provisions

PART VIII: Underground Gas Storage Provisions

PART IX: Enforcement Provisions

PART X: $\quad$ Title, Severability, and Repealer Provisions

Note that Part I, "Definitions," is relevant to all other parts, but particular defined terms within Part I are not relevant to all other parts. The IOGCC further recognizes that, in some states, some of the subjects covered by this Model Act may be regulated by other agencies. Nevertheless, suitable provisions covering these and related subjects are included for information and use as a guide to a state desiring to consider the adoption of comprehensive oil and gas conservation legislation or desiring to update existing oil and gas conservation laws. In some states, potash, brine, or both, should also be included within the resources subject to this Act and legislative language in Part I would have to be added to accomplish these ends.

\section{Declaration of Purpose}

Because of the economic and strategic importance of oil and gas, the prevention of waste of oil and gas, the promotion of oil and gas conservation, and the protection of correlative rights, public health, public safety, and the environment are declared to be in the public interest. Accordingly, the purpose of this Act is the prevention of waste, the promotion of conservation, and the protection of correlative rights, public health, public safety, and the environment. 


\section{PART I.}

SECTION 1. DEFINITIONS. In this [슬 $]$

(1) "By-product" means a commodity made from oil or gas.

(2) "[Commission]" means the [

(3) "Developed area" means the spacing unit on which a well has been completed that is capable of producing oil or gas or the acreage that is otherwise attributed to a well by the [commission] for production purposes.

(4) "Field" means a general area underlain by a reservoir or reservoirs.

(5) "Gas" means a gaseous substance, including natural gas, carbon dioxide, helium, nitrogen, fluid hydrocarbons and by-products of gas production not defined as oil, which is produced by drilling or injected for storage or pressure maintenance.

(6) "Geophysical data" means (definition to be determined).

(7) "Just and equitable share of the production" means, as to a separately owned tract or combination of tracts, that fraction of the authorized production from a reservoir that corresponds reasonably to the proportion that the amount of recoverable oil or gas under the developed area of that separately owned tract or combination of tracts bears to the recoverable oil or gas in the total of the developed areas in the reservoir.

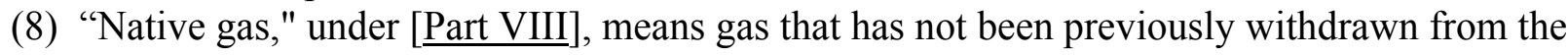
earth.

(9) "Natural gas" means gaseous hydrocarbons, including casinghead gas, and gas found in coal beds, and all other hydrocarbons not defined as oil in this [슬 except and not including liquid petroleum gas, and includes gas either while in its original state or after the same has been processed by removal of component parts not essential to its use for light and fuel.

(10) "Oil" means crude petroleum, oil, and all hydrocarbons, regardless of gravity, that are in the liquid phase in the reservoir and that are produced and recovered at the wellhead in liquid form and oil extracted from shale or tar sands and a by-product of oil production not defined as gas. (11) "Oil and gas operation" means exploration for oil and gas, including the conduct of geophysical operations and the drilling of test bores; the siting, drilling, deepening, recompletion, reworking, plugging, replugging, abandoning or re-entering an oil and gas well, underground injection well, or gas storage well; production, processing, flow lines, gathering lines, transportation and transporter operations as they pertain to safety, environmental protection, the prevention of waste, the protection of correlative rights, and illegal oil and gas; the generation, transportation, storage, treatment, or disposal of oil, gas, by-product, or refuse used or produced during exploration and production operations; and a related construction, site preparation, recycling, remediation, reclamation operation, or facility.

(12) "Operator" means a person who is designated by an operating agreement or by the [commission] as being responsible for an oil and gas operation.

(13) "Owner" means a person having the right to drill into and to produce from a reservoir and to appropriate the oil or gas produced therein, either for that person or for that person and others.

(14) "Person" means an individual, corporation, business trust, estate, trust, partnership, limited liability company, association, joint venture, government; governmental subdivision, agency, or instrumentality; public corporation, or other legal or commercial entity.

(15) "Processing," "processes" or "processed" means an operation which separates oil and gas, treats oil or gas, dehydrates oil or gas, or extracts gas liquids or by-products from oil or gas, including associated compression. 
(16) "Protection of correlative rights" or "protect correlative rights" means to afford a reasonable opportunity to each owner to recover, or to receive without causing waste, a just and equitable share of the production.

(17) "Reasonable market demand" means:

(A) the amount of oil reasonably needed for current consumption, use, storage, and working stocks, within and without this state; or

(B) the amount of gas reasonably needed for current consumption, use, and storage, within and without this state.

(18) "Reservoir" means an underground accumulation of oil or gas or both which is a common source of supply, or one or more underground accumulations of oil or gas or both which by order, permit, rule, or regulation of the [commission] are allowed to be produced on a commingled basis and which are treated by the [commission] as a common source of supply. Unless otherwise determined by an order, permit, rule or regulation of the [commission], each zone of a general structure that is completely separated from another zone in the structure is a separate common source of supply.

(19) "Responsible party" means the operator, as well as a person who conducts or controls an oil and gas operation in a manner, whether by act or omission, that contravenes this [Act] or an order, permit, rule, or regulation of the [commission] which threatens to harm or harms air, water, soil, or biological resource and a person who disposes of refuse by mixing it with exploration and production refuse that threatens to harm or harms a resource. "Responsible party" does not mean innocent landowners or royalty owners who do not tamper with an oil and gas operation, interfere with access by the responsible party or the [commission] to remediate the threat of harm or harm to air, water, soil, or biological resource, or assume by written contract express and specific responsibility for an oil and gas operation.

(20) "Royalty interest owner" means a person who has a right to a share of production or a payment relating to a share of production, whether in the form of a nonparticipating royalty, lease royalty, overriding royalty, or production payment, but who does not have a present right to drill into and to produce from a reservoir.

(21) "Take" or "taken" means to transport, purchase, or remove oil or gas.

(22) "Transportation," "transport," "transported," or "transporting" means to gather oil or gas within a field or area and to move it to locations within or outside that field or area, including associated compression, but not including market pipeline transmission.

(23) "Underground storage," under [Part VIII], means storage in a subsurface sand, stratum, formation, aquifer, or cavity, cavern or void (whether natural or artificially created). (24) "Waste" means:

(A) the inefficient, excessive, or improper use of reservoir energy or unnecessary dissipation of reservoir energy;

(B) the inefficient storing of oil or gas;

(C) the locating, drilling, equipping, operating, or producing of an oil or gas well in a manner that causes or tends to cause a reduction in the quantity of oil or gas ultimately recoverable from a reservoir under prudent and proper operations, the drilling of unnecessary wells, or the loss or destruction of oil or gas either at the surface or below the surface;

(D) the production of oil or gas in excess of pipeline, marketing, or storage capacities, in excess of reasonable market demand, in excess of the amount reasonably required for properly drilling, completing, testing, or operating a well or other facilities for 
recovering, processing, or transporting oil, gas, or by-products, or in excess of the amount otherwise utilized on the acreage from which the oil or gas is produced; or (E) other dissipation, production, or use of oil or gas underground or above ground, or in storage, that is careless, needless, or without valuable result.

\section{PART II.}

SECTION 2. WASTE PROHIBITED. The waste of oil or gas is prohibited. In the event of a conflict between the duty to prevent waste and the duty to protect correlative rights, the primary duty of the [commission] is to prevent waste in a manner that will protect correlative rights to the extent reasonably possible given the [commission]'s primary duty while also assuring the adequate protection of public health, public safety, and the environment.

SECTION 3. SCOPE OF ACT. This [Act] applies to all lands, operations or activities in this state and to all persons over which this state has regulatory authority. A person conducting an oil and gas operation in this state submits to the jurisdiction of this state and the [commission].

[Alternative language for possible use in states with large tracts of federal or Indian land:

[[ALTERNATIVE] SECTION 3. SCOPE OF ACT. This [Act] shall apply to all lands within this state, except as follows:

(a) As to lands of the United States or lands which are subject to its supervision, this [Act] shall apply only to the extent necessary to permit the [commission] to protect the correlative rights, health, safety, and the environment. The other provisions of this [Act] shall also apply if the officer of the United States having jurisdiction over the lands approves an order, permit, rule, or regulation of the [commission] purporting to affect the lands.

(b) This article shall not apply to lands committed to federal exploratory unit or federal communized unit except to the extent approved by the Department of Interior and except as to affected privately owned or state lands.]

\section{SECTION 4. GENERAL AUTHORITY OF THE [COMMISSION].}

The [commission] shall have exclusive authority [,subject only to any applicable local zoning and land-use regulations]:

(a) to regulate an oil and gas operation;

(b) to prevent the waste of oil, gas, or by-products;

(c) to protect correlative rights;

(d) to identify reservoirs to be classified or reclassified as oil or gas reservoirs and to classify or reclassify oil or gas wells;

(e) to protect public health, public safety, and the environment in relation to other operations or activities regulated by this [Act], including the authority to enter into or approve environmental covenants;

(f) to exercise continuing authority over all persons and property necessary to carry out the missions and duties of the [commission];

(g) to exercise the right of ingress and egress without warrant to all lands and facilities within the jurisdiction of the [commission];

(h) to regulate all lands, operations, and persons within the jurisdiction of the [commission] to assure adequate protection of public health, public safety, and the environment and to investigate, test, analyze, and model as may be necessary to achieve appropriate protection of public health, public safety, and the environment; and 
(i) to make and enforce orders, permits, rules, and regulations reasonably necessary to promote conservation, to prevent waste, to protect correlative rights, to protect public health, public safety, and the environment, to govern the practice and procedure before the [commission], and to administer and enforce this [Act], including rules as the [commission] may consider reasonably necessary and appropriate to implement the responsibility of this state under federal laws or rules governing activities within the jurisdiction of the [commission].

\section{SECTION 5. SPECIFIC AUTHORITY OF THE COMMISSION.}

Without limiting the general authority of the [commission], the [commission] has the exclusive authority to require the following:

(a) the permitting of an oil and gas operation;

(b) the identification and, absent identification, the designation of the operator responsible for wells, producing areas, tanks, plants, and other facilities for the production, storage, treatment, transportation, or refining of oil and gas and to identify, and as necessary to enforce this [Act] and orders, permits, rules, or regulations of the [commission] to identify other responsible parties;

(c) the making and filing with the [commission] of [geophysical data,] well logs, directional surveys, and reports on the location, drilling, and production of wells, but [geophysical data] marked "confidential" must be kept confidential for the period prescribed by the [commission], not exceeding [five (5)] years and] well logs marked "confidential" must be kept confidential for the period prescribed by the [commission], not exceeding [six (6)] months;

(d) the sampling and coring of wells and the filing of samples and cores and reports derived from those samples and cores;

(e) the drilling, casing, completing, operating, and plugging of wells to prevent:

(1) the escape of oil or gas out of the reservoir into another formation;

(2) the detrimental intrusion of water or other substance into an oil or gas reservoir that is avoidable by efficient operation;

(3) harm or pollution; and

(4) blowouts, cave-ins, seepages, and fires;

(f) the testing of wells used in oil and gas production, including production, injection, and disposal wells;

(g) the separating of the production from wells into gaseous and liquid hydrocarbons, by means and upon standards prescribed by the [commission].

(h) the operation of wells at efficient gas-oil or water-oil ratios and the limiting of production from wells with inefficient gas-oil or water-oil ratios;

(i) the certification of clearance in connection with transporting or delivering oil, gas, or byproduct;

(j) the metering or other measuring of oil, gas, or by-product, by means and upon standards prescribed by the [commission];

(k) the maintenance of complete and accurate records, available for examination by the [commission] or its agents at all reasonable times, of quantities produced, sold, purchased, acquired, stored, transported, refined, or processed by each person who produces, sells, purchases, acquires, stores, transports, refines, or processes oil, gas, or by-product in this state; (1) the filing of reports, plats, and existing data related to matters within the jurisdiction of the [commission];

(m) [the payment of nonparticipating royalties, lease royalties, and overriding royalties in accordance with valuation and accounting standards established by the [commission], including 
the authority to impair contracts as may be reasonably necessary to achieve a uniform and orderly system of royalty valuation and accounting; ] and (n) the construction, operation, suspension, or abandonment by a responsible party of an oil and gas operation within the jurisdiction of the [commission] to protect public health, public safety, or the environment, including the abatement of dust and noise and the establishment of aesthetic, lighting, visual, and location requirements suited to the surrounding area; [and]

(o) to solicit bids and enter into contracts to provide for the plugging of wells and for other remedial work to protect public health, safety, and welfare[; and

(p) to establish and collect fees].

SECTION 6. FINANCIAL ASSURANCE. The [commission] shall require an operator to furnish a reasonable performance bond or other good and sufficient surety, including cash deposits, but excluding mere financial statements, conditioned on the performance of the duty to plug each dry or abandoned well, to plug, repair, remediate, or replug each well causing waste or pollution, reclaim impoundments, restore well sites, or properly operate and close a commercial oil and gas waste disposal facility. The [commission] may require a responsible party to furnish a reasonable performance bond or other good and sufficient surety conditioned on compliance with a provision of this [Act] or underlying regulation.

SECTION 7. ADDITIONAL AUTHORITY OF THE COMMISSION. Without limiting the general authority of the [commission], the [commission] has the additional exclusive authority to regulate the following [, subject only to the authority of [another state agency] to regulate air pollution, water pollution, and water-use permits]:

(a) the drilling, testing, equipping, completing, operating, producing, and plugging of wells and other operations for and related to the production of oil or gas, including transporting, processing, loading, and tracing oil and gas;

(b) the stimulation and treatment of wells;

(c) the spacing and location of wells, including the authority to establish spacing units;

(d) the disposal of salt water and field wastes and underground storage of oil, gas, or by-product;

(e) the amount of oil or gas that may be produced without waste from a field, reservoir, or developed area and the allocation of the allowed production to and among the wells in fields, reservoirs, or areas in this state;

(f) the venting and flaring of gas; and

(g) a unit operation of any kind.

\section{PART III.}

\section{SECTION 8. ALLOCATION OF PRODUCTION.}

(a) If the [commission] limits the amount of oil, gas, or by-product produced in this state, the [commission] may allocate the allowable production among fields or reservoirs on a reasonable basis, including the setting of allocation priorities as may be necessary to prevent waste or to protect correlative rights. The [commission] may allocate the allowable production of oil, gas, or by-product to prevent undue discrimination among fields and reservoirs as a result of selective buying or nomination by purchasers.

(b) When the [commission] has permitted production by commingling oil or gas, or oil and gas from multiple stratigraphic or lenticular accumulations of oil or gas, the [commission] may allocate, distribute, or apportion the production of commingled separate multiple stratigraphic or lenticular accumulations of oil or gas, or oil and gas as if they were a single common source of 


\section{supply.}

SECTION 9. RATABLE PRODUCTION OF OIL AND GAS.

(a) To prevent unreasonable discrimination in favor of one pool against another, and on written complaint and proof of discrimination, the [commission] may allocate or apportion the allowable production of oil on a fair and reasonable basis among the various pools in this state. In fixing the allowable production of oil based on reasonable market demand, the [commission] is not required to determine the reasonable market demand applicable to a single field or reservoir, except in relation to other fields and reservoirs and in relation to the reasonable market demand applicable to this state. In allocating the allowable production of oil to fields and reservoirs, the [commission] may consider, but is not bound by, nominations of purchasers to purchase from particular fields or reservoirs. In allocating or ascertaining the reasonable market demand for the entire state, the reasonable market demand of one pool shall not be discriminated against in favor of another pool. The [commission] shall determine the reasonable market demand of the respective pool as the basis for determining the allotments to be assigned to the respective pool so that discrimination may be prevented.

(b) If full production from wells producing gas, including a gas by-product, from a common source of supply of gas in this state is in excess of the reasonable market demand, the [commission] shall inquire into the production and reasonable market demand for the gas and shall determine the allowable production from the common source of supply. The allowable production from a common source of supply is that portion of the reasonable market demand that can be produced without waste. The [commission] shall allocate, distribute, or apportion the allowable production from the common source of supply among the various owners on a reasonable basis and shall limit the production of each owner to the amount allocated or apportioned to the owner. The [commission] may give priority to the production of gas from oil wells when allocating the allowable production of gas under this section.

\section{PART IV.}

\section{SECTION 10. WELL SPACING.}

(a) [Except for exploratory units established under [Part VII], after] [After] discovery of oil or gas, the [commission], to prevent waste and to protect correlative rights, shall issue an order establishing a field and reservoir, providing for allowable production, and providing for uniform well spacing units, which may be established in accordance with applicable statewide spacing rules. Except as otherwise provided in subsection (b), and in light of the information available to the [commission] at the time of an order establishing spacing units for a reservoir, a spacing unit must consist of the maximum area of a reservoir that may be efficiently and economically drained by one well, and an order establishing spacing units for a reservoir must cover lands determined or reasonably believed to be underlain by that reservoir.

(b) If reasonably necessary to prevent waste or to protect correlative rights, the [commission] may establish a spacing unit that is larger or smaller than the uniform spacing units for a reservoir, but that larger or smaller spacing unit must produce in proportion to the size of the uniform units established for that reservoir.

(c) The [commission] may grant exceptions to applicable spacing rules when the [commission] determines that one or more of the following conditions exist:

(1) A topographic condition makes drilling in compliance with spacing rules unduly burdensome. 
(2) An environmental consideration makes drilling in compliance with spacing rules unduly harmful or potentially harmful to the environment.

(3) A spacing unit is partly outside the reservoir.

(4) A well drilled in compliance with spacing rules is or will be noncommercial.

(5) Oil and gas confiscation will be prevented.

(6) The exception will otherwise prevent waste or protect correlative rights.

(7) The owners adversely affected by an exception to applicable spacing rules consent to that exception.

(d) If an exception to applicable spacing rules is granted, the [commission] shall take whatever action may be reasonably necessary to protect correlative rights, including adjustment of the well's rate of production.

(e) An order establishing spacing rules may be modified by the [commission] from time to time to prevent waste or to protect correlative rights, including the addition of lands determined to be underlain by the reservoir or to the exclusion of lands determined not to be underlain by the reservoir. The [commission], if reasonably necessary to prevent waste or to protect correlative rights, may change the size or shape of one or more spacing units or permit the drilling of additional wells on a reasonably uniform spacing pattern.

(f) Unless specifically authorized by the [commission], upon completion of a producing well not subject to applicable spacing rules, additional wells may not be commenced for production from that reservoir until an order establishing spacing rules is adopted. The [commission] shall provide for the retroactivity of an initial order establishing spacing rules for a reservoir to the date that notice of a hearing to establish spacing units for the reservoir was issued, but may provide for retroactivity to the date of first production for the discovery well for that reservoir. (g) The [commission] may establish horizontal well spacing units for horizontal drilling and development of a common source of supply. A horizontal well is an oil or gas well drilled, completed or recompleted in a manner in which the horizontal component of the completion interval in the geological formation exceeds the vertical component in the geological formation and which horizontal component extends a minimum of [one hundred fifty (150) feet] into the formation. A horizontal well spacing unit may be established for a common source of supply for which there are already established non-horizontal well spacing units. A horizontal well spacing unit may include within the boundaries thereof more than one existing non-horizontal well spacing unit for the common source of supply. A horizontal well spacing unit may exist concurrently with producing non-horizontal well spacing units; however, where there are no producing non-horizontal well spacing units, a horizontal well spacing unit shall supersede existing non-developed non-horizontal well spacing units for the duration of the horizontal well spacing unit.

[(h) In case of a spacing unit of [one hundred sixty (160) acres] or more, no oil and gas leasehold interest outside the spacing unit involved may be held by production from the spacing unit more than [ninety (90) days] beyond the expiration of the primary term of the lease.]

\section{PART V.}

\section{SECTION 11. POOLING.}

(a) When two or more separately owned tracts or interests are within an existing or proposed spacing unit, the persons owning the tracts or interests may voluntarily pool their tracts or 
interests.

(b) In absence of voluntary pooling and upon application by an owner within a unit, the [commission] may, either before or after drilling, enter an order pooling all tracts and interests within the spacing unit. All operations, including the commencement, drilling, operation, or production of a well, upon a portion of a pooled spacing unit shall be deemed the commencement, drilling, operation, or production of a well upon each separately owned tract or interest in the unit. That portion of the production allocated to a separately owned tract or interest included in a unit shall be deemed produced from that tract or interest. To protect correlative rights, the [commission] may provide for the retroactivity of a pooling order to the date that notice of a hearing to establish spacing units for the reservoir was issued and may provide for retroactivity to the date of first production for the discovery well for that reservoir.

(c) In a pooling order, the [commission] shall designate an owner to serve as operator of the unit to manage and supervise the drilling, completion, operation, and plugging and abandonment of the well or wells on a pooled unit. All owners shall share in reasonable costs of drilling, completing, operating, and plugging and abandonment of the well or wells on a pooled unit. Production and costs associated with a pooled unit must be allocated among the owners in that unit in the same proportion each owner's acreage in the unit bears to the total acreage in the unit or must be allocated according to a method approved by the [commission]. The [commission] may reallocate production and costs to prevent waste or to protect correlative rights and may equitably reallocate costs.

(d) An owner whose tract or interest has been involuntarily pooled may elect not to participate in a proposed operation in which case the operator may recover on behalf of all participating owners that owner's share of the costs of the operation out of any resulting production, plus a risk and interest penalty not to exceed [three hundred (300)] percent of the owner's share of these costs.

\section{SECTION 11. POOLING (OKLAHOMA STYLE ALTERNATIVE)}

(a) When there are separately owned tracts, or when there are separately owned undivided interests, or when there are both separately owned tracts and separately owned undivided interests embraced within a well spacing unit, the owners thereof may validly pool their interests and develop their lands as a unit. Where, however, the owners within a well spacing unit have not agreed to pool their tracts and interests for joint operations and development and where one or more owners have drilled or propose to drill a well on a well spacing unit to the common source of supply, the [commission], to prevent waste or to protect correlative rights, shall require all owners to pool and develop their interests and lands in the well spacing unit.

(b) The pooling applicant shall give all owners whose addresses are known or could be known through the exercise of due diligence proper notice of the application and hearing as required by law.

[(b) [Alternative] The pooling applicant shall give all owners whose addresses are known or could be known through the exercise of due diligence at least [thirty (30)] days' notice by mail, return receipt requested. The applicant shall also give notice by one publication, at least [thirty (30)] days before the hearing, in [the official newspaper] [newspaper of general circulation published] in the county or counties where the affected tracts or interests are located. The applicant shall file proof of publication and an affidavit of mailing with the [commission].] (c) An order requiring pooling shall be made after notice and hearing, and upon terms and conditions that are just and reasonable and will afford to the owner of a tract or interest in the 
unit the opportunity to recover or receive without unnecessary expense his just and fair share of the oil and gas.

(d) The portion of the production allocated to the owner of each tract or interest included in a well spacing unit formed by a pooling order shall, when produced, be considered as if produced by the owner from the separately owned tract or interest by a well drilled thereon.

(e) The pooling order of the [commission] shall designate an operator and make definite provisions for the payment of costs of the development and operation, which shall be limited to the actual expenditures required for that purpose not in excess of what are reasonable, including a reasonable charge for supervision. In the event of a disputed cost, the [commission] shall determine proper costs after due notice to interested parties and a hearing.

(f) The operator of a pooled unit, in addition to other rights provided by the pooling order of the [commission], shall have liens on the oil or gas estates or rights of the other owners therein and upon their shares of the production from the unit to the extent that costs incurred in the development and operation upon the unit are a charge against the estates or interests by order of the [commission] or by operation of law. These liens shall be separable as to each separate owner within the unit, and shall remain liens until the operator has been paid the amount due under the terms of the pooling order.

(g) The [commission] is authorized to provide that the owner or owners paying for the drilling or operation of a well shall be entitled, subject to the payment of royalty, if any, to that production from the well that would be received by the nonpaying owner or owners for whose benefit the well was drilled or operated until the paying owners have been paid the amount due under the terms of the pooling order or order settling the dispute. No part of the production or proceeds accruing to an owner of a separate tract or interest in a well spacing unit shall be applied toward payment of costs properly chargeable to another tract or interest in the well spacing unit.

(h) For the purpose of this section, the owner or owners of oil or gas estates or rights in an unleased tract of land shall be regarded as a lessee to the extent of not more than a [seven-eighths (7/8)] interest in and to the rights and a lessor to the remaining interest therein.

(i) In the event a producing well or wells are completed upon a well spacing unit where there are, or may thereafter be, two or more separately owned tracts or interests, each royalty interest owner shall share in all production from the well or wells drilled within the unit, or in a shut-in royalty as to which the royalty interest owner may be entitled under a lease or other instrument and covering a separately owned tract or interest in the unit, to the extent of the royalty interest owner's interest in the unit. Each royalty interest owner's share in the unit shall be the percentage of royalty owned in each separate tract or interest by the royalty interest owner, multiplied by the proportion that the acreage in each separately owned tract or interest bears to the entire acreage of the unit.

\section{SECTION 12. ANTITRUST IMMUNITY FOR VOLUNTARY UNITS.}

(a) An agreement to develop a well spacing unit jointly or an agreement for the joint development or operation of a field, reservoir, or part thereof, may be submitted to the [commission] for approval as being in the public interest or reasonably necessary to prevent waste or to protect correlative rights. Approval by the [commission] is a full defense to a civil action charging violation of a statute of this state relating to trusts and monopolies because of the agreement or because of operations conducted under the agreement.

(b) Failure to submit an agreement to the [commission] for approval does not imply or constitute evidence that the agreement or operations conducted pursuant thereto are in violation of laws relating to trusts and monopolies. 


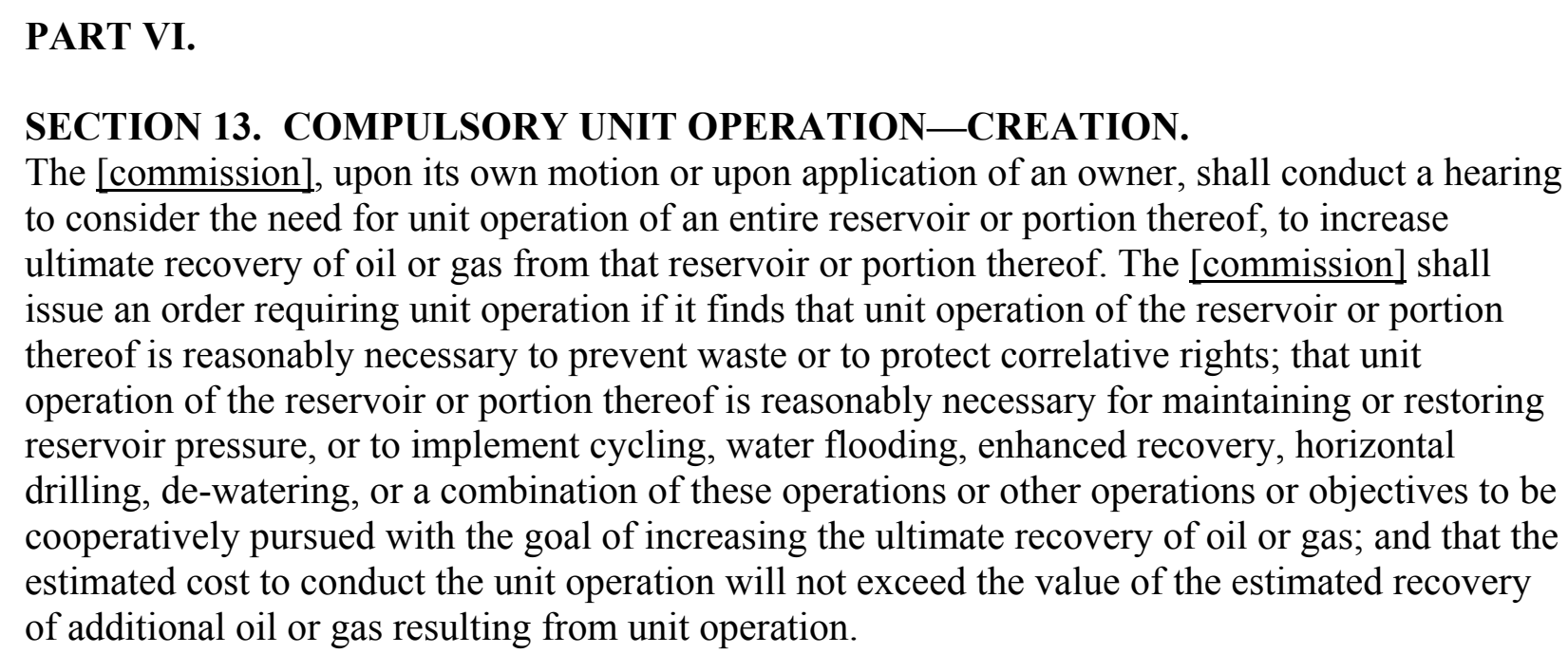

\section{PART VI.}

SECTION 13. COMPULSORY UNIT OPERATION-CREATION.

The [commission], upon its own motion or upon application of an owner, shall conduct a hearing to consider the need for unit operation of an entire reservoir or portion thereof, to increase ultimate recovery of oil or gas from that reservoir or portion thereof. The [commission] shall issue an order requiring unit operation if it finds that unit operation of the reservoir or portion thereof is reasonably necessary to prevent waste or to protect correlative rights; that unit operation of the reservoir or portion thereof is reasonably necessary for maintaining or restoring reservoir pressure, or to implement cycling, water flooding, enhanced recovery, horizontal drilling, de-watering, or a combination of these operations or other operations or objectives to be cooperatively pursued with the goal of increasing the ultimate recovery of oil or gas; and that the estimated cost to conduct the unit operation will not exceed the value of the estimated recovery of additional oil or gas resulting from unit operation.

\section{SECTION 14. COMPULSORY UNIT OPERATION-APPLICATION.}

(a) An application for compulsory unitization shall contain, at a minimum, a description of the proposed unit and the vertical limits to be included therein with a map or plat thereof attached; a statement that the reservoir or portion thereof involved in the application area has been reasonably defined by development; a statement of the type of operations contemplated for the unit area; the proposed plan of unitization; a proposed operating plan that addresses the manner in which the unit will be supervised and managed and costs allocated and paid.

(b) The [commission] may, by regulation, impose additional requirements for an application for compulsory pooling.

\section{SECTION 15. COMPULSORY UNIT OPERATION—ORDER FOR UNIT OPERATION.}

(a) An order for a unit operation must be upon just and reasonable terms and conditions and shall include all of the following:

(1) a precise definition of the vertical and horizontal limits of the unit area;

(2) a statement of the nature of the operation contemplated;

(3) a provision designating one of the owners as operator of the unit and providing a means to remove the operator and designating a successor operator;

(4) a provision for recording in the [county] land records documents sufficient to give constructive notice of the establishment of the unit operation respecting all lands included in the unit area;

(5) a provision to protect correlative rights, allocating to each separately owned tract in the unit area a just and equitable share of the production that is produced and saved from the unit area, other than production used or unavoidably lost in the conduct of the unit operation;

(6) a provision for credits and charges to adjust among owners in the unit area for their interest in wells, tanks, pumps, machinery, materials, and equipment that contribute to the unit operation;

(7) a provision that describes:

(A) how the costs of unit operation, including capital investments and costs of terminating the unit operation, are to be determined and charged to each owner or the interest of each owner;

(B) how, when, and by whom the share of unit production allocated to an owner who 
does not pay the share of those costs charged to that owner or to the interest of that owner may be sold and the proceeds applied to the payment of that owner's share of those costs; and

(C) how accounts will be settled upon termination of the unit. (8) a provision, if reasonable, for carrying or otherwise financing an owner who elects to be carried or otherwise financed, which allows a reasonable charge for the cost and risk of that service payable out of that owner's share of the production;

(9) a provision for the supervision and conduct of the unit operation, in respect to which each owner is entitled to a vote whose value corresponds to the percentage of the costs of the unit operation chargeable to that owner or to the interest of that owner;

(10) a time when the unit operation is to commence and the manner in which, and the circumstances under which, the unit operation is to terminate and the unit is to be dissolved; and

(11) additional provisions found to be appropriate to carry on the unit operation, to prevent waste, and to protect correlative rights.

(b) An order for a unit operation may provide for a unit operation of less than the whole of a reservoir so long as the unit area is of size and shape reasonably required for that purpose and the conduct thereof will have no significant adverse effect upon other portions of the reservoir.

\section{SECTION 16. COMPULSORY UNIT OPERATION-TERMINATION.}

The [commission], upon its own motion or upon the application of an owner, may for good cause terminate a unit operation and dissolve the unit on just and equitable terms. If not terminated earlier, the unit operation shall terminate upon final cessation of production from the reservoir or unitized portion thereof and the plugging and abandonment of unit wells and facilities. At the time of dissolution of the unit operation, the operator shall file with the [commission] and record in the [county] land records of the [county] or [counties] documents sufficient to give constructive notice of the dissolution of the unit operation respecting the lands that were included in the unit area.

SECTION 17. UNIT AGREEMENT-EFFECTIVE DATE OF COMPULSORY UNIT. An order requiring a unit operation shall not become effective until a unit agreement, approved by the [commission], has been signed and approved in writing by the owners of at least [sixty (60)] percent as costs are shared under terms of the allocation of costs under [Section 15(a)] and the royalty interest owners of at least [sixty (60)] percent, excluding owners of overriding royalties, production payments, and other interests carved from a working interest, in the unit area as revenues are distributed under the terms of the allocation under [Section 15(a)]. The unit agreement is subordinate to the terms of an order requiring a unit operation and to an order amending an order requiring a unit operation.

SECTION 18. CHANGES IN A COMPULSORY UNIT-UNITIZATION OF LESS THAN ALL OF A RESERVOIR-AMENDMENTS TO UNIT ORDER.

(a) The [commission] may approve additions to the unit of portions of a reservoir not previously included within the unit and may extend the unit area as reasonably necessary to prevent waste or to protect correlative rights. The [commission] may approve exclusions from the unit area as reasonably necessary to prevent waste or to protect correlative rights. An order adding to or excluding from a unit area must be upon just and reasonable terms. An order to provide for an addition to a unit area may not become effective until approved by the owners of at least [sixty (60)] percent as costs are shared in the area to be added to unit operation under the terms of the order and [sixty (60)] percent of the royalty interest owners in the area to be added as revenues 
are distributed under the terms of the order. An order providing for an exclusion from a unit area

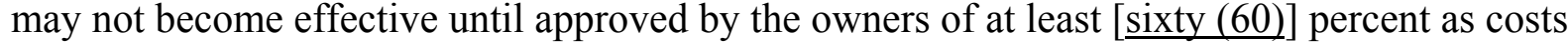
are shared under terms of the allocation of costs under [Section 15(a)] in the original unit area and the royalty interest owners of at least [sixty (60)] percent, excluding owners of overriding royalties, production payments, and other interests carved from a working interest, as revenues are distributed under the terms of the allocation under [Section 15(a)] in the original unit area, but if the [commission] determines that the area to be excluded does not overlie the reservoir, then the order excluding the area shall become effective without approval of owners or royalty interest owners.

(b) An order providing for unit operation may be amended by an order of the [commission] in the same manner and subject to the same conditions as an original order providing for the unit operation, except that the approval of the amendment by royalty interest owners whose interests are free of cost is not required if the amendment affects only the rights and interests of the owners who are subject to costs.

\section{SECTION 19. EFFECT OF COMPULSORY UNITIZATION.}

(a) Operations, including the commencement, drilling, or operation of a well upon a portion of a unit area, are deemed conducted on each separately owned tract in the unit area by the owner or owners thereof. That portion of a unit's production allocated to a separately owned tract in a unit area, when produced, is deemed produced from a well drilled on that tract. Operations conducted under an order of the [commission] providing for a unit operation shall constitute fulfillment of expressed or implied obligations of a lease or contract covering lands within the unit area to the extent that compliance with those obligations is not possible without a further order of the [commission].

(b) That portion of unit production allocated to a tract and the proceeds of sale for that portion are deemed the property and income of the several persons to whom or to whose credit that portion is allocated or payable under the order providing for unit operation.

(c) A division order or other contract relating to a sale or purchase of production from a separately owned tract or combination of tracts remains in force and applies to oil and gas allocated to the tract until terminated in accordance with provisions of the order providing for unit operation.

(d) Except to the extent that all affected parties agree, an order providing for unit operation does not result in a transfer of all or part of a person's title to the oil and gas rights in a tract in the unit area.

(e) All property, whether real or personal, that may be acquired in the conduct of a unit operation hereunder is deemed acquired for the account of the owners within the unit area and is deemed the property of the owners in the proportion that the expenses of the unit operation are charged. (f) The creation of a unit operation shall not constitute approval or permitting of underground injection operations for a well or wells. Injection operations, whether for storage, disposal, or enhanced recovery, must be separately approved and permitted.

(g) The creation of a unit operation shall not constitute approval or permitting of the use of fresh water. Use of fresh water must be separately approved and permitted.

SECTION 20. OVERLAPPING UNITS. The [commission] may issue an order for the unit operation of a reservoir or reservoirs or parts thereof that include a unit created by a prior order of the [commission] or by voluntary agreement. This subsequent order, in providing for the allocation of the unit's production, must treat first the unit area previously created as a single tract and then allocate, in the same proportions as those specified in the prior order, the portion 
of the new unit's production allocated to the previous unit among the separately owned tracts included in the previously created unit area.

SECTION 21. ANTITRUST IMMUNITY FOR COMPULSORY UNIT OPERATION. An order or permit and related agreements in the interest of conservation of oil or gas and for the prevention of waste to explore, to develop, to produce, to maintain or restore reservoir pressure, to cycle, to water flood, to de-water, to engage in an operation to enhance recovery, or to engage in a combination of those operations, or in another method of unit or cooperative development and operation of a reservoir or portion thereof is authorized and does not violate statutes relating to trusts, monopolies, or contracts and combinations in the restraint of trade.

\section{PART VII.}

SECTION 22. COMPULSORY EXPLORATORY UNITS-CREATION. The [commission], upon application of an owner, shall conduct a hearing to consider the need for an exploratory unit operation in a specified area [not exceeding [ ] acres]. The [commission] shall issue an order requiring an exploratory unit operation, if it finds that all of the following conditions exist:

(1) Exploratory unit operation for that area or portion thereof is reasonably necessary to prevent waste, to encourage reasonable, orderly, effective, and efficient exploration and potential development, to avoid the drilling of potentially unnecessary wells, and to protect correlative rights.

(2) The estimated costs of conducting the exploratory unit operation are reasonable in light of the risk that exploration may prove to be unsuccessful and in light of the potential rewards of successful exploration and discovery of oil or gas.

\section{SECTION 23. COMPULSORY EXPLORATORY UNITS-ORDER FOR EXPLORATORY UNIT OPERATION.}

An order for an exploratory unit operation must be upon just and reasonable terms and conditions and must include all of the following:

(1) a description of the area, a description of the geologic formations, and minimum [,which may not be less than [ ] feet below sea level], and maximum depths for the exploratory unit operation;

(2) a provision for the recordation in the [county] land records of documents sufficient to give constructive notice of the unit operation regarding all lands included in the unit area;

(3) a statement of the nature of and the plan for exploration, appraisal, development, production, and abandonment contemplated;

(4) a provision to protect correlative rights allocating to each separately owned tract in the exploratory unit area a just and equitable share of production that may be produced and saved from that unit area, other than production used or unavoidably lost in the conduct of the exploratory unit operation;

(5) a provision for credits and charges as an adjustment among owners in the unit area for their interest in geological studies, geophysical data, or other information that contributes to the exploratory unit operation;

(6) provisions for:

(A) how the costs of the exploratory unit operation, including capital investments and costs of terminating exploratory unit operation, are to be determined and charged to each owner or the interest of each owner; 
(B) how those costs are to be paid; and

(C) how, when, and by whom the unit interest of, or production from, the exploratory unit operation allocated to an owner who does not pay the share of those costs charged to that owner or to the interest of that owner may be sold and the proceeds applied to the payment of that owner's share of those costs;

(7) a provision for acquiring and allocating the interest of an owner and for compensating that owner for that interest where that owner elects not to participate in the exploratory unit operation;

(8) a provision for compensating an owner whose interest is excluded from the unit if that interest is determined to be non-productive;

(9) a provision for the creation of subunits if more than one reservoir is discovered and developed;

(10) a provision, if reasonable, for carrying or otherwise financing an owner who elects to be carried or otherwise financed during the development phase of the exploratory unit operation, allowing for a reasonable charge for cost and risk of that service payable out of that owner's share of the production;

(11) a provision for the supervision and conduct of the exploratory unit operation, with respect to which each owner is entitled to a vote whose value corresponds to the percentage of the costs of the exploratory unit operation chargeable to that owner or to the interest of that owner, which may be subject to change as the unit is modified;

(12) a time when the exploratory phase is to commence and the duration of that phase, a time when the appraisal phase is to commence (or the unit is to be dissolved) and the duration of that phase, a time when the development phase is to commence (or the unit is to be dissolved) and the duration of that phase, the time when the productive phase is to commence (or the unit is to be dissolved) and the duration of that phase, which must be for so long as oil or gas is produced in paying quantities with sufficient time thereafter for the proper abandonment of the exploratory unit operation;

(13) the various circumstances for each phase of the exploratory unit operation under which the unit is to be reduced in size or the exploratory unit operation is to terminate and unit is to be dissolved; and

(14) additional provisions found to be appropriate for carrying on the exploratory unit operation, to prevent waste, and to protect correlative rights.

\section{SECTION 24. EXPLORATORY UNIT AGREEMENT-EFFECTIVE DATE OF} COMPULSORY EXPLORATORY UNIT. An order requiring an exploratory unit operation may not become effective until a unit agreement, approved by the [commission], has been signed and approved or ratified in writing by the owners of at least [sixty (60)] percent as costs are shared under terms of the allocation of costs under [Section 23] and the royalty interest owners of at least [sixty (60)] percent, excluding owners of overriding royalties, production payments, and other interests carved from a working interest, in the unit area as revenues are distributed under the terms of the allocation under [Section 23]. An order providing for unit operation may be amended by an order made by the [commission] in the same manner and subject to the same conditions as an original order providing for the unit operation, except that the approval of the amendment by royalty interest owners whose interests are free of cost is not required if the amendment affects only the rights and interests of the owners who are subject to costs, and if the amendment is necessary to protect correlative rights, no approval of the amendment by owners and royalty interest owners is required. The unit agreement is subordinate to the terms of an 
order requiring a unit operation and to an order amending an order requiring a unit operation. SECTION 25. CHANGES IN A COMPULSORY EXPLORATORY UNITAMENDMENT OF EXPLORATORY UNIT ORDER.

(a) The [commission] may approve additions to the unit of portions of a reservoir not previously included within the unit, may extend the unit area as reasonably necessary, and may combine two or more exploratory units in whole or in part to prevent waste, to protect correlative rights, and to achieve effective and efficient exploratory unit operation. The [commission] may approve reductions to a unit area as reasonably necessary to prevent waste, to protect correlative rights, and to achieve effective and efficient exploratory unit operation. An order adding to or excluding from a unit area must be upon just and reasonable terms. An order to provide for an addition to or extension of the unit area may not become effective until approved by the owners of at least [sixty (60)] percent as costs are shared in the area to be added to the exploratory unit operation under the terms of the order and [sixty (60)] percent of the royalty interest owners in the area to be added as revenues are distributed under the terms of the order. An order to combine two or more exploratory units in whole or in part may not become effective until approved by the owners of at least [sixty (60)] percent as costs are shared in each of the unit areas or parts thereof to be combined under the terms of each order requiring exploratory unit operation and [sixty (60)] percent of the royalty interest owners in each of the unit areas or parts thereof to be combined as revenues are distributed under the terms of each order requiring exploratory unit operation. Nevertheless, if the [commission] determines by clear and convincing evidence that the area to be excluded does not overlie the reservoir, then the order excluding the area becomes effective without approval of owners or royalty interest owners.

(b) The [commission] may modify from time to time the nature and the plan for exploration, appraisal, development, and production as reasonably necessary to prevent waste, to protect correlative rights, and to achieve effective and efficient exploratory unit operation.

\section{SECTION 26. COMPULSORY EXPLORATORY UNITS-TERMINATION.}

The [commission], upon its own motion or upon the application by an owner, may for good cause terminate an exploratory unit operation and dissolve the unit. Good cause includes the failure of owners to prosecute a phase of the exploratory unit operation or plan with due diligence. At the time of dissolution of the exploratory unit operation, the operator shall file with the [commission] and record in the [county] land records of the [county] or [counties] documents sufficient to give constructive notice of the dissolution of the exploratory unit operation respecting all lands that were included in the unit area. SECTION 27. EFFECT OF COMPULSORY EXPLORATORY UNITIZATION. (a) Operations, including the commencement, geophysical surveying, drilling, or operation of a well upon a portion of the unit area, are deemed the conduct of the operations on each separately owned tract in the exploratory unit area by the owners, but only to the extent of the geologic formations and depths included in the exploratory unit. A portion of exploratory unit production allocated to a separately owned tract in an exploratory unit area, when produced, is deemed produced from a well drilled on that tract, but only to the extent of the geologic formations and depths included in the exploratory unit. Operations conducted under an order of the [commission] providing for an exploratory unit operation constitute a fulfillment of expressed or implied obligations of a lease or contract covering lands in an exploratory unit area to the extent that compliance with those obligations cannot be had without the order of the [commission], but only to the extent of the geologic formations and depths included in the exploratory unit. (b) That portion of exploratory unit production allocated to a tract and the proceeds of sale for 
that portion are deemed the property and income of the several persons to whom or to whose credit that portion is allocated to or payable to under the order providing for exploratory unit operation.

(c) Except to the extent that all affected parties agree, an order providing for exploratory unit operation does not result in a transfer of all or part of a person's title to the oil and gas rights in a tract in the unit area.

(d) All property, whether real or personal, that may be acquired in the conduct of an exploratory unit operation hereunder is deemed acquired for the account of the owners within the exploratory unit area and is deemed the property of the owners in the proportion that the expenses of the exploratory unit operation are charged.

(e) An order providing for an exploratory unit operation may not be construed to result in a transfer of the part of a title of a person to the oil and gas rights in a tract in the unit area unless the affected person agrees to that transfer.

\section{SECTION 28. ANTITRUST IMMUNITY FOR EXPLORATORY UNIT OPERATION.}

An agreement in the interest of conservation of oil or gas for an exploratory unit operation is authorized and can not be held or construed to violate statutes relating to trusts, monopolies, or contracts and combinations in the restraint of trade.

\section{PART VIII.}

SECTION 29. JURISDICTION TO REGULATE UNDERGROUND GAS STORAGE. The [commission] shall have the exclusive jurisdiction and authority to regulate the underground storage of gas within the boundaries of the state. In exercising jurisdiction, the [commission] shall have and may exercise all powers and authorities granted to it in the [Model Oil and Gas Conservation Act] with respect to holding hearings and enforcing orders, permits, rules, or regulations.

SECTION 30. ADOPTION OF RULES AND REGULATIONS. The [commission] shall promulgate rules and regulations establishing requirements, procedures and standards for the underground storage of gas for the purpose of protecting the safety and property of the people of the state, preventing surface and subsurface water pollution and soil pollution, preventing waste, and protecting correlative rights. These rules and regulations shall include provisions for the permitting, monitoring and inspecting of underground storage of gas, for the closure and abandonment of underground storage of gas, the designation of an underground gas storage facility operator, the transfer of an underground gas storage permit to a successor operator, and the establishment of fees and financial assurance requirements for permitting, monitoring, inspecting, closing and abandoning underground gas storage facilities. The provisions of [the Civil Penalty provisions of the Model Oil and Gas Conservation Act] shall apply to violations of this Act and of orders, permits, rules, or regulations issued under this [Act].

\section{SECTION 31. PLAT MAP OF LOCATION OF UNDERGROUND GAS FACILITY} REQUIRED. In addition to any other information the [commission] may require, the owner of an underground gas storage facility shall file with the [commission] a plat map identifying the location of the facility and a description of the geological formation or formations to be used for storage. 


\section{PART IX.}

SECTION 32. ENFORCEMENT AUTHORITY; JURISDICTION. The [commission] shall have and exercise exclusive power and authority to enforce the provisions of this [Act] and its orders, permits, rules, and regulations. In all matters pertaining to the making, issuing and enforcement of its orders, permits, rules and regulations made under the provisions of this [Act], the [commission] shall have and exercise all of the following exclusive powers and authority: (1) to investigate and adjudicate complaints alleging violations of statutes, orders, permits, rules and regulations;

(2) to administer oaths;

(3) to compel attendance of witnesses;

(4) to compel the production of books and records;

(5) to impose sanctions, including civil penalties against a person guilty of disorderly conduct in the presence of the [commission] while in session; and

(6) to impose sanctions, including civil penalties for a violation of this [Act] and of an order, permit, rule, regulation, or judgment made or rendered under the provisions of this [Act].

SECTION 33. AGENTS OF THE COMMISSION; AUTHORITY; INGRESS AND

EGRESS. The [commission] may empower its agents and employees to make investigations, to serve process, and to otherwise act on behalf of the [commission], including the power to enter upon an oil or gas lease or property without warrant to enforce the provisions of this [Act] and the [commission]'s orders, permits, rules, and regulations.

SECTION 34. COMMENCEMENT OF ENFORCEMENT PROCEEDINGS; STANDING; VERIFICATION OF PLEADINGS. A proceeding to adjudicate an alleged violation of this [Act] or of a [commission] order, permit, rule, or regulation may be commenced on the [commission]'s own motion, or upon the filing of a [verified] complaint with the [commission] by the Attorney General, designated agents or employees of the [commission], or by a person who has been directly and substantially affected by the alleged violation.

\section{SECTION 35. CONTENTS OF ENFORCEMENT COMPLAINT; SERVICE.}

(a) The complaint shall:

(1) state the name of the complainant;

(2) cite the statute, order, permit, rule, or regulation that allegedly has been violated;

(3) briefly describe the alleged violation; and

(4) name the respondent.

(b) A copy of the complaint shall be served on the respondent as provided by [the administrative procedures act] [the rules of the [commission]].

SECTION 36. VIOLATION OF A STATUTE, RULE OR ORDER. A complaint alleging that a person or persons have violated this [Act] or a [commission] order, permit, rule or regulation shall be adjudicated by the [commission] in accordance with [the administrative procedures act] of this state.

SECTION 37. CIVIL PENALTIES; INCREASE IN SURETY. In addition to other sanctions or remedies ordered by the [commission] pursuant to this [Act], punishment by the [commission] for a violation of this [Act], or a [commission] order, permit, rule, or regulation may be by civil penalty as determined by the [commission], not exceeding [five thousand dollars $(\$ 5,000)]$, or by other manner of penalty as determined by the [commission]. Each day the violation continues shall constitute a separate and additional violation, punishable by separate and additional civil penalties in like amount or other manner of penalty as determined by the 
[commission], including the authority to order an increase in the penalty or a change in the form or amount of operator surety.

\section{SECTION 38. SHUT IN, CURTAILMENT, SHUT DOWN ORDERS; SUSPENSION OF OPERATING AUTHORITY OR PERMITS.}

(a) The [commission] shall have the authority, without prior notice, to order a party or the [commission]'s agent or employee to shut in a well, to curtail the production of a well, or shut down an oil and gas operation; or to deny approval of or revoke a permit for an oil and gas operation; or suspend the authority of a person to conduct an oil and gas operation, if the [commission] finds that:

(1) the respondent has no operator surety in force and effect;

(2) there is a condition of pollution or other condition that constitutes an imminent threat of serious and irreparable damage or injury to persons, property or the environment as a consequence of an existing and continuing violation of the [commission]'s orders, permits, rules, or regulations affecting an oil and gas operation;

(3) the respondent has failed or refused to pay a previously imposed fine or civil penalty for a violation of this [Act] or a [commission] order, permit, rule, or regulation issued pursuant to this [Act]; or

(4) the respondent has failed or refused to comply with an enforcement or compliance order issued pursuant to this [Act].

(b) The party against whom an order under this subsection (a) has been issued shall have the right to appear before the [commission] within [five (5)] days after the order has been issued, to move that the order be dissolved or modified.

(c) In addition to other sanctions or remedies ordered by the [commission] pursuant to this [Act] for a violation of this [Act] or a [commission] order, permit, rule, or regulation, the [commission] shall have the power, after notice and opportunity for hearing, to order a party or the [commission]'s agent or employee to shut in a well, curtail the production from a well, or shut down or curtail an oil and gas operation, or to deny approval of or revoke a permit for an oil and gas operation, or suspend the authority of a person to conduct an oil and gas operation.

(d) During the pendency of a proceeding and before the issuance of a final order, the [commission], on its own motion or upon the motion by an interested party, may issue an interim order directing a party or the [commission]'s agent or employee immediately to shut in a well, to curtail the production from a well, or to shut down an oil and gas operation. The party against whom the interim order has been issued shall have the right to appear before the [commission] within [five (5)] days after the interim order has been issued, to move that the interim order be dissolved or modified.

SECTION 39. DISORDERLY CONDUCT BEFORE THE COMMISSION. Punishment by the [commission] of a person guilty of disorderly conduct in the presence of the [commission] while in session, or for disobedience of its subpoena, summons or other process, may be by civil penalty, not exceeding [one thousand dollars $(\$ 1,000)]$.

SECTION 40. FOREIGN JUDGMENT. A civil penalty assessed under this [Act] may be enforced in the same manner as a foreign judgment pursuant to [the Uniform Enforcement of Foreign Judgments Act], but this procedure shall be followed regardless of whether the offender is a resident or nonresident of this state. Until paid or satisfied, a civil penalty shall constitute a lien upon all the non-exempt property of the offender within this state, if a copy of the order imposing the civil penalty, certified by the [commission], is filed as provided by law. 
SECTION 41. INJUNCTIONS. Where the [commission] shall make and issue an order, permit, rule, or regulation and the same has been or is being violated by a person, the Attorney General of this state, or the [commission], may in the name of this state, bring an action in the appropriate district court where the violation has been or is being committed, for a prohibitory or a mandatory injunction, enjoining and prohibiting the offender from further violations or commanding and compelling the offender to obey the order, permit, rule, or regulation. The court is hereby given jurisdiction to grant an injunction or other relief as may be proper, and shall have power to grant temporary restraining orders or injunctions without bond. Neither a temporary nor permanent injunction granted under the provisions of this section shall be stayed or superseded on appeal, except upon order of a state appellate court, and then only upon application and hearing after reasonable notice to the [commission]. Insofar as not prohibited by other law, all suits brought under the provisions of this section shall be given precedence over other actions pending in that court.

[SECTION 42. FALSE STATEMENTS; CRIMINAL PENALTIES. A person or persons who shall knowingly or willfully file or make a false statement to the [commission] with respect to a provision of this [Act] or a [commission] order, permit, rule, or regulation shall be guilty of a [class B] felony [[and shall be fined not more than [five thousand dollars $(\$ 5,000)]$, and shall be imprisoned for a period not to exceed [five (5) years], or both].].]

\section{[SECTION 43. OBSTRUCTION OF ENFORCEMENT ACTIVITIES; CRIMINAL} PENALTIES. A person who knowingly or willfully delays or obstructs an agent of the [commission], in the performance of a duty assigned to the agent in accordance with this [Act] or by an order, permit, rule or regulation of the [commission]; or who knowingly and willfully delays or obstructs a public officer of this state or municipal subdivision thereof in the discharge or attempted discharge of a duty arising by virtue of or growing out of this [Act] or an order, permit, rule, or regulation of the [commission]; or who attempts by means of a threat or violence to deter or prevent an agent of the [commission] from performing a duty that arises by virtue of this [Act] or of an order, permit, rule, or regulation of the [commission], shall be guilty of a [class B] felony [[and conviction thereof may be punished by a fine not exceeding [five thousand dollars $(\$ 5,000)$ ] and by imprisonment not exceeding [five (5) years], or both.]] If the violence or threat of violence or if the interference, obstruction, or attempted interference or obstruction is accompanied by the use or attempted use of firearms by the person so offending, then the person shall be guilty of a [ class A] felony [ [ and may be imprisoned for a period of not more than [ten (10) years ].].]

[SECTION 44. CONSPIRACY; CRIMINAL PENALTIES. Two or more persons who conspire to violate a provision of this [Act], or an order, permit, rule, or regulation of the [commission], and a person, who shall do an act to effect the object of the conspiracy, shall be guilty of a [class B] felony [ [and be fined not more than [ five thousand dollars $(\$ 5,000)]$ and imprisoned for a period of not exceeding [five (5) years], or both].].] 


\section{PART X.}

2

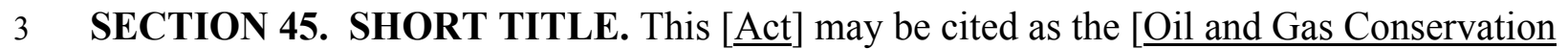

4 Act].

5 SECTION 46. SEVERABILITY CLAUSE. If a provision of this [Act] or its application to a

6 person or circumstances is held invalid, the invalidity does not affect other provisions or

7 applications of this [슬 which can be given effect without the invalid provision or application,

8 and to this end the provisions of this [Act $]$ are severable.

9 SECTION 47. REPEAL OF LAWS IN CONFLICT. All other laws or parts of laws in 10 conflict with this $[\underline{\text { Act }}]$ are repealed. 
Appendix 3 


\title{
2004 MODEL UNDERGROUND GAS STORAGE PROVISIONS
}

\author{
Interstate Oil and Gas Compact Commission
}

\section{Preface}

The underground storage of gas promotes conservation and permits the accumulation of reserves for orderly withdrawal in periods of peak demand, and serves to make gas resources to the domestic, commercial and industrial consumers more readily, reliably, and efficiently available to meet year-round market demand. The Interstate Oil and Gas Compact Commission (IOGCC) has prepared the following provisions to supplement Part VIII of the Model Oil and Gas Conservation Act, which deals with the regulation of Underground Gas Storage. These provisions address the acquisition of properties suitable for underground gas storage through eminent domain and recognize certain property rights in stored gas. These Model Provisions do not address the initial ownership of storage rights vis-à-vis the surface and mineral interest owner. These supplementary provisions should not be codified under a state's conservation act, but Part I should be included in a state's eminent domain or public utilities code and Part II should be included in a state's property code.

\section{Declaration of Purpose}

Because of the economic and strategic importance of gas, the conservation of property suitable for underground gas storage, the prevention of waste, and the protection of correlative rights, public health, public safety, and the environment are declared to be in the public interest. Accordingly, the purpose of these provisions is to conserve property suitable for underground gas storage, to prevent waste, and to protect correlative rights, public health, public safety, and the environment.

\section{PART I.}

\section{[Procedures for Gas Public Utilities]}

SECTION 1. DEFINITION. "Natural gas public utility" means any person, firm or corporation authorized to do business in this state and that holds a certificate of convenience from the [commission] or the Federal Energy Regulatory Commission to engage in the business of transporting storing or distributing gas by means of pipelines into, within or through this state for ultimate public use.

SECTION 2. PUBLIC INTEREST. The underground storage of gas promotes conservation and permits the building up of reserves for orderly withdrawal in periods of peak demand, and serves to make gas resources to the domestic, commercial and industrial consumers more readily, reliably, and efficiently available to meet year-round market demand, thereby promoting the public interest and the general welfare. Therefore the [legislature of this state] finds that the orderly and efficient underground storage of gas is in the public interest. SECTION 3. APPROPRIATION OF CERTAIN PROPERTY. Any natural gas public utility may appropriate for its use for the underground storage of gas any subsurface stratum or formation in any land which the [oil and gas conservation commission] shall have found to be suitable and in the public interest for the underground storage of gas, and 
in connection therewith may appropriate other interests in property as may be required adequately to examine, prepare, maintain and operate underground gas storage facilities. The right of appropriation shall be without prejudice to the rights of the owner of the land, minerals, or other rights or interests therein, as to all other uses of property, including the right to drill or bore through the appropriated underground stratum or formation, if done in accordance with any order, permit, rule, or regulation that the [oil and gas conservation commission] may issue for the purpose of protecting the underground storage strata or formation against pollution and against the escape of gas.

\section{SECTION 4. APPLICATION FOR GAS STORAGE CERTIFICATE; NOTICE AND HEARING; ASSESSMENT OF COSTS.}

(a) Any natural gas public utility desiring to exercise the right of eminent domain as to any property for use for underground storage of gas shall, as a condition precedent to the filing of its petition in the district court, obtain from the [oil and gas conservation commission] a certificate setting out findings of the [oil and gas conservation commission] that:

(1) the underground stratum or formation sought to be acquired is suitable for the underground storage of gas and that its use for this purpose is in the public interest; and

(2) the amount of proven commercially producible accumulations of oil or native gas, or both, if any, remaining in the proposed storage stratum or formation.

(c) The [commission's] finding under subparagraph (2) above that the underground stratum or formation is suitable for the underground storage of gas shall include specific findings, including:

(1) that the use of the storage facility for the underground storage of gas will not contaminate other formations containing fresh water or containing oil, gas or other commercial mineral deposits; and

(2) that the proposed storage will not unduly endanger lives or property. (d) the [oil and gas conservation commission] shall not issue a certificate without reasonable notice to interested parties and an opportunity for a hearing. [The applicant shall be responsible for all costs of this proceeding.]

SECTION 5. EMINENT DOMAIN PROCEDURE. Any natural gas public utility, having first obtained the certificate specified in [Section 4] from the [oil and gas conservation commission] and desiring to exercise the right of eminent domain for the purpose of acquiring property for the underground storage of gas, shall proceed in accordance with [eminent domain procedure of this state]. The petitioner shall file the certificate as a part of its petition and no order by the court granting said petition shall be entered unless accompanied by the certificate. The appraisers in awarding damages shall also take into consideration the amounts of proven commercially producible accumulations of oil or native gas or both, if any, remaining in the property sought to be appropriated and, for this purpose, shall receive the findings of the [oil and gas conservation commission] as prima facie evidence of these amounts.

\section{SECTION 6. NOTICE OF ABANDONMENT OF UNDERGROUND GAS} STORAGE FACILITY; REVERSION OF PROPERTY RIGHTS. When the owner of an underground gas storage facility has permanently abandoned the storage facility and that facility was certificated by the [oil and gas conservation commission], the owner shall file with the [oil and gas conservation commission] a notice of abandonment. If any storage facility was certificated pursuant to federal authority, the owner shall file a copy of any federal abandonment authority with the [oil and gas conservation commission]. Unless notice of abandonment authority has been filed with the [oil and gas conservation commission], there shall be a presumption that the storage facility and all rights associated 
with it remain as certificated. In either case the owner shall file an instrument with the [recorder] in the appropriate county or counties, stating that storage has ceased and, except in cases in which the owner of the storage facility has purchased the fee, that the ownership of all property acquired by the owner, both mineral and surface, has reverted to those who owned the property at the time of the acquisition or their heirs, successors or assigns.

\section{PART II.}

\section{Determining Property Rights to Injected Gas}

SECTION 1. OWNERSHIP OF INJECTED GAS. All gas that has previously been reduced to possession, and which is subsequently injected into underground storage fields, sands, reservoirs and facilities, whether storage rights were acquired by eminent domain or otherwise, shall at all times be the property of the injector, or the injector's heirs, successors or assigns, whether owned by the injector or stored under contract. Absent a final judgment of willful abandonment rendered by a court of competent jurisdiction, in no event shall this gas be deemed the property of a surface owner or mineral owner, or the property of persons claiming by or under these owners, under whose lands the gas is stored. Only the injector, or the injector's heirs, successors and assigns, may produce, take, reduce to possession this stored gas.

21 SECTION 2. EFFECT ON SURFACE AND MINERAL RIGHTS. Nothing in this subsection shall be deemed to affect the otherwise lawful right of a surface or mineral owner to drill or bore through the underground storage fields, sands, reservoirs and facilities, if done in accordance with [commission] rules for protecting the underground storage strata or formation against pollution and against the escape of gas. SECTION 3. IDENTIFICATION OF MIGRATING GAS-COSTS-INJUNCTION. (a) If gas that has been injected into property or has migrated to adjoining property or to a stratum, or portion thereof, which has not been acquired by eminent domain or otherwise acquired, the injector shall not lose title to or possession of injected gas if the injector can prove by a preponderance of the evidence that the gas was originally injected into the underground storage. The court, on its own motion or upon motion of a party, may appoint the [oil and gas conservation commission] as a special master to provide assistance regarding this issue.

(b) If gas that has been injected into property or has migrated to adjoining property or to a stratum, or portion thereof, which has not been acquired by eminent domain or otherwise acquired, the injector, at the injector's sole risk and expense, shall have the right to conduct reasonable testing on any existing wells on adjoining property including tests to determine ownership of the gas, and to determine the value of any lost production of other than the injector's gas.

(c) If gas that has been injected into property or has migrated to adjoining property or to a stratum, or portion thereof, which has not been acquired by eminent domain or otherwise acquired, the owner of the stratum and the owner of the surface shall be entitled to compensation for use of or damage to the surface or substratum, the value of the storage right, and shall be entitled to recover all costs and expenses, including reasonable attorney fees.

(d) The injector shall have the right to interim relief through injunctive or other appropriate relief. 
Appendix 4 


\section{Interstate Oil and Gas Compact Commission}

\section{Report of the Technology and Well Spacing Subcommittee}

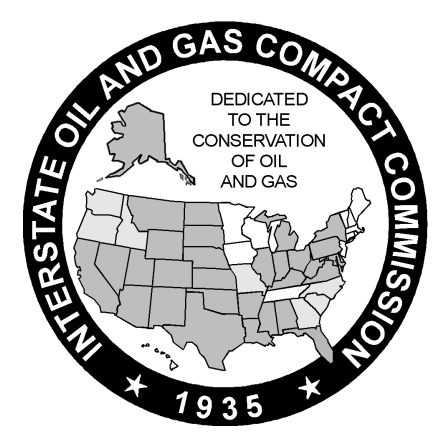

Marvin Rogers, Chairman - Alabama

John Baza - Utah

Bruce Hicks - North Dakota

Todd Keating - Louisiana

John Land McDavid - Mississippi

Patrick Martin - Louisiana 



\section{TABLE of CONTENTS \\ Report of the Technology and Well Spacing Subcommittee}

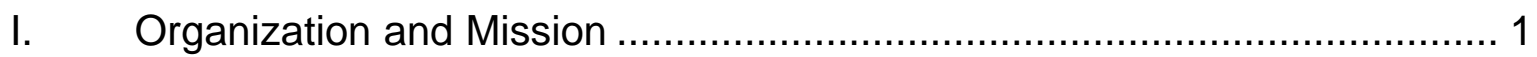

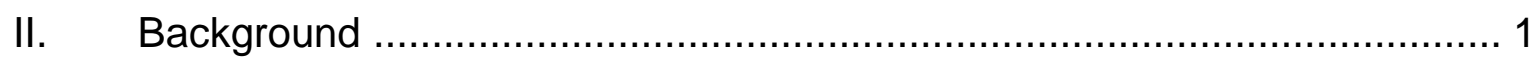

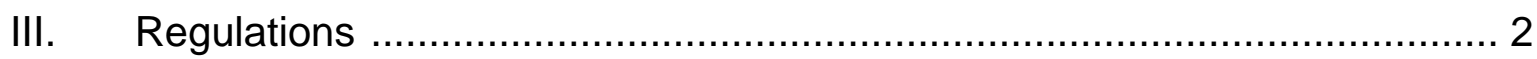

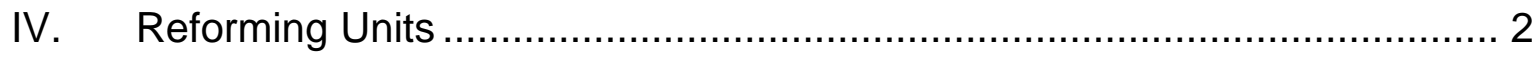

A. Geographical or Governmental Spacing Units .................................. 3

B. Spacing Regulations by Property Lines or Lease Lines ........................ 3

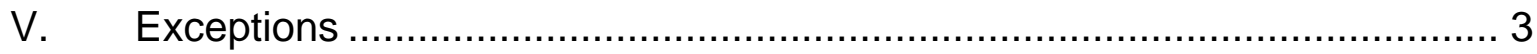

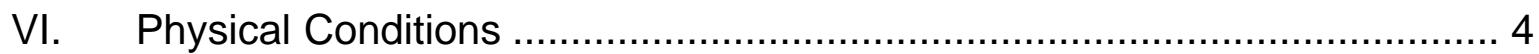

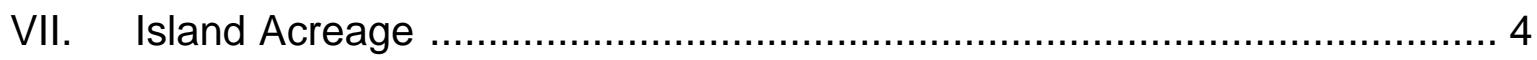

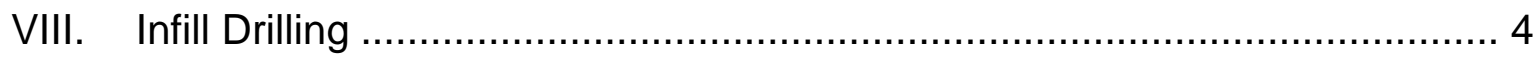

IX. Limitations on Spacing Units ........................................................... 5

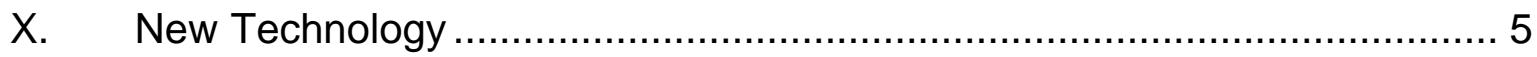

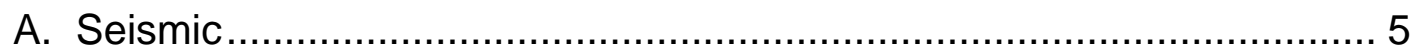

B. Horizontal and Multilateral Drilling ................................................... 6

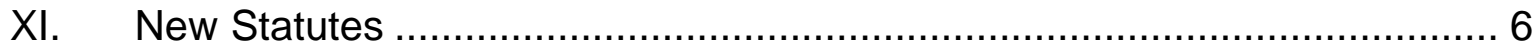

A. Louisiana's Deep Drilling Statute ................................................... 6

B. Michigan's Multi-well Units ............................................................. 7

C. Environmental Concerns .................................................................. 7

D. Nongovernmental or Irregular .......................................................... 7

E. Exploratory Units in Arkansas ........................................................... 7

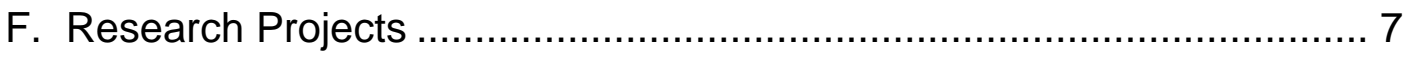

XII. Model Statute Addressing Well Spacing …….................................... 7

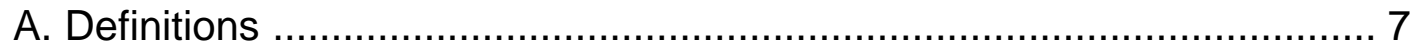

B. . .

C.

D.

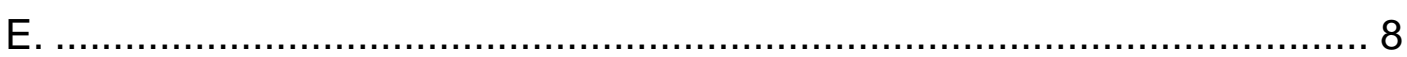

F. . 


\section{State Compilations}

$\begin{array}{lr}\text { Alabama } & 9\end{array}$

Alaska 11

Arizona 13

Arkansas $r$

California $\quad 15$

Colorado $r$

Florida $\quad 21$

Georgia $\quad 21$

Idaho $\quad 22$

Illinois 22

Indiana 23

Kansas $\quad 25$

Kentucky $\quad 27$

Louisiana $\quad 28$

Maryland $\quad 31$

Michigan $\quad 31$

Mississippi

$\begin{array}{ll}\text { Missouri } & 37\end{array}$

Montana $\quad 39$

Nebraska $\quad 40$

Nevada $\quad 41$

New Mexico $\quad 43$

New York $\quad 45$

North Carolina $\quad 47$

North Dakota $\quad 48$

Ohio

Oklahoma $\quad 54$

Oregon $\quad 56$

Pennsylvania $\quad 56$

South Carolina $\quad 58$

South Dakota $\quad 58$

$\begin{array}{ll}\text { Tennessee } & 60\end{array}$

$\begin{array}{ll}\text { Texas } & 61\end{array}$

$\begin{array}{ll}\text { Utah } & 62 \\ \text { Virginia } & 65\end{array}$

$\begin{array}{ll}\text { Virginia } & 65\end{array}$

Washington $\quad 66$

West Virginia $\quad 66$

$\begin{array}{ll}\text { Wyoming } & 67\end{array}$

$\begin{array}{ll}\text { Alberta Canada } & 68\end{array}$ 



\section{REPORT OF THE TECHNOLOGY AND WELL SPACING SUBCOMMITTEE}

\section{ORGANIZATION AND MISSION}

The Energy Resources, Research and Technology (ERRT) Committee established the Technology and Well Spacing Subcommittee. The mission of the subcommittee was "to review oil and gas spacing statutes in light of modern exploration techniques."

To accomplish its mission, the subcommittee requested each member state of the IOGCC to prepare a brief narrative discussion of the state's spacing laws and regulations, emphasizing the following:

1. Whether the spacing laws promote use of seismic to establish units;

2. Whether the spacing laws provide adequately for horizontal drilling;

3. Whether certain aspects of the spacing laws are particularly useful, and if they are a good example for other states.

\section{BACKGROUND}

Every state with oil and gas development has established an oil and gas conservation commission to regulate oil and gas operations and has adopted statutes and regulations addressing the spacing of wells. The purpose of spacing statutes and regulations is the same as the purpose of the conservation commission itself - to promote conservation of oil and gas, to prevent waste and to protect correlative rights.

Spacing regulations, however, perform a more specific purpose. They prevent physical waste caused by drilling too close to another well, prevent economic waste caused by the drilling of unnecessary wells, and protect the rights of mineral owners by preventing drainage.

Well spacing regulations address the location of the wells and the density of drilling within a field. An integral part of well spacing regulations is the commission's establishment of spacing units. Spacing units are also called "drainage units," "drilling units" or "production units" in the various states. The principle behind the establishment of spacing units is that one well drilled within a defined geographic area will produce all the recoverable oil or gas in the unit without waste and without uncompensated drainage from other units in the field.

Following this principle, all states have adopted statutes or regulations providing for spacing units. Similar to laws of other states, the Louisiana oil and gas conservation laws provide that a unit "means the maximum area which may be efficiently and economically drained by one well." La. R.S. § 30:9(2)B. The establishment of the spacing units allows for only one well to be drilled and produced within the spacing unit.

Well spacing is governed by statewide or general regulations, which address "wildcat wells" (wells outside an established field) or by field or reservoir rules that are adopted by the conservation commission for a particular field.

Early on, the spacing statutes and regulations were challenged as being an unconstitutional taking of private property without due process under the Fifth Amendment to the U.S. 
Constitution. However, courts upheld the spacing regulations as a valid exercise of the states' power because the states had valid purposes in preventing waste of oil and gas resources and protecting correlative rights of mineral owners. Oxford Oil Co. v. Atlantic Oil and Producing Co., 22 F.2d 597 (5 $5^{\text {th }}$ Cir. 1927).

\section{REGULATIONS}

Spacing regulations vary from state to state. The subcommittee has compiled a summary of the spacing regulations of each member state of the IOGCC as a part of this study.

Although the statutes and regulations vary from state to state, all the states include some common provisions.

Virtually all states define a spacing unit to be the maximum area that is produced by one well. The precise language varies. For example, Alabama's statute states "the maximum area which may be efficiently and economically drained by one well." Alabama Code 1975 § 9-17-12 (b). The spacing statutes of Arkansas and Louisiana are virtually identical. South Dakota provides that "The size of the spacing unit shall not be smaller than the maximum area that can be efficiently and economically drained by one well." South Dakota Codified Laws § 45-9-22. Utah's statute states that "a drilling unit may not be smaller than the maximum area that can be efficiently and economically drained by one well." Utah Code $\S 40-6-6(-3)$.

Some states do not precisely define a spacing unit. North Dakota states that "Spacing units when established must be of uniform size and shape for the entire pool . . . The size and shape of spacing units are to be such as will result in the efficient and economical development of the pool as a whole." North Dakota Century Code § 38-08-07.

Oklahoma's statute states that "The Corporation Commission ... shall have the power to establish well spacing and drilling units of specified and approximately uniform size and shape covering any common source of supply, or prospective source of supply, of oil or gas within the State of Oklahoma." 52 Oklahoma St. $\S 87.1$. Kentucky requires wells to be at least 330 feet or 220 feet from a lease line depending on the area drilled. If a well is drilled and completed as a productive well the Commission (Department of Mines and Minerals) establishes a unit.

\section{REFORMING UNITS}

The oil and gas conservation commission may reform spacing units. The North Dakota statute expressly grants that power to its commission. "[A]n order establishing spacing units in a pool may be modified by the commission to increase or decrease the size of spacing units in the pool." North Dakota Century Code $\S 38-08-07$. Oklahoma's statute states that the "Commission . .. may establish, reestablish, or reform well spacing and drilling unit." 52 Oklahoma St. § 87.1.

The "statewide" or "wildcat" regulations for several states are particularly interesting. Mississippi requires that "spacing units" (called "drilling units" in the Mississippi regulations) for oil wells "be encompassed by the perimeter of a rectangle 1,600 feet by 2,725 feet." Rule 7 of the Mississippi Oil and Gas Regulations. Gas wells must "be encompassed by the perimeter of a rectangle 5,580 feet by 6,245 feet." Rule 8 of the Mississippi Oil and Gas Regulations. North Dakota rules provide for temporary spacing units to be set by the commission for a period of 18 
months. A hearing is held at that time to determine the proper spacing for the pool. North Dakota Administrative Code $\S 43-02-03-18$.

\section{A. Geographical or Governmental Spacing Units}

Most oil and gas producing states were originally surveyed based on townships containing thirty-six sections or square miles. By either regulation or practice, most states establish spacing units based on these governmental divisions (640-acre sections, 160-acre quarter sections or 40 -acre quarter-quarter sections). Some examples are Alabama, Alaska, Nebraska and New Mexico.

Establishing spacing units or governmental divisions inevitably results in units containing land over which an operator is unable to obtain the consent of a mineral owner. Virtually all states have enacting compulsory forced pooling or integrate statutes, by which an operator can force nonconsenting owners into a spacing unit. Michael Stogner, who drafted the New Mexico text, correctly states that, "forced or compulsory pooling provisions assist in keeping governmental well spacing patterns consistent and orderly. Otherwise spacing units would have to be formed by mineral leases and ownership alone which can quickly become hard to manage and result in a haphazard pattern of development within a pool."

\section{B. Spacing Regulations by Property Lines or Lease Lines}

Some states provide for spacing of wells based on oil and gas leases. Louisiana allows wells to be drilled on leases without creating a unit. These wells are governed by Statewide Order No. 29-E. That order provides, with certain exceptions, that oil and gas wells be no closer than 330 feet from the property line, and no closer than 900 feet between oil wells and 2,000 feet between gas wells. Oklahoma's well spacing regulations in Statewide Rule 1-501 provide:

1. Depth less than 2,500 feet:

(a) 165 feet from property line or lease line;

(b) 300 feet from any other producible or drilling oil or gas well when drilling to the same common source of supply.

2. Depth greater than 2,500 feet:

(a) 330 feet from property line or lease line;

(b) 600 feet from any other producible or drilling oil or gas well when drilling to the same common source of supply.

Further, Texas Statewide Rule 37 provides for minimum distances for the location of wells as follows:

1. 467 feet to property line.

2. 1,200 feet to any well completed in, or drilling to the same horizon on the same tract or farm.

\section{EXCEPTIONS}

All states grant the oil and gas conservation commission the authority to approve exceptions to the general spacing statutes or regulations. Grounds for granting the exception well location include (1) topographic; (2) a well located at the exception location would be at the optimum location for efficient and economic drainage; and (3) a well at a regular location would not be commercial. 
A number of states allow exceptions to the spacing rules without a hearing where adjoining mineral owners consent to the exception well location. Idaho requires a showing of a reason for the exception location and consent of adjoining mineral owners. Similarly, Nebraska allows "off-pattern wells with the consent of adjoining mineral owners." South Dakota approves exception locations without a hearing in cases where there is no objection to the proposal.

\section{PHYSICAL CONDITIONS}

Statutory and regulatory requirements generally address the conservation issues of waste and correlative rights. Some spacing regulations, however, address actual surface physical conditions. Alabama's regulations require a minimum distance of 200 feet from a permanent residence. State Oil and Gas Board of Alabama Administrative Code, Rule 400-1-2-.02. Maryland allows no well closer than 1,000 feet to a church or occupied dwelling without permission of the owner. Under North Dakota law, no wells may be drilled closer than 330 feet from any building. North Dakota Adm. Code § 43-02-03-28.

\section{ISLAND ACREAGE}

The oil and gas conservation commission attempts to avoid "island acreage." The Mississippi oil and gas regulations expressly provide that "no unit shall be permitted which will create island acreage." Mississippi Oil and Gas Board Statewide Rules and Regulations 7 and 8. The Mississippi Supreme Court has defined "island acreage" to be acreage so surrounded by drilling units that it cannot be produced. Biglane v. Brown, 347 So.2d 1310 (Mississippi 1977).

Similarly, Indiana's regulations allow irregular units as long as the exception does not create "isolated tracts of land." Under North Dakota law, no wells shall be drilled closer than 330 feet from any building.

\section{INFILL DRILLING}

Infill drilling is the drilling of an additional well or wells in excess of those provided for by a spacing order to more adequately drain a reservoir. Anderson, New Directions in Oil and Gas Conservation Law, Institute on Oil and Gas Conservation Law and Practice 14-1, 14-13 (Rocky Mountain Minerals Law Foundation, 1985). An infill well is one drilled on an irregular pattern disregarding normal target and spacing requirements.

In order to accommodate infill drilling, many states will allow multiple wells within a single spacing unit. In Louisiana, the commission allows alternate wells which are multiple wells within a unit.

IOGCC International Affiliate Alberta, Canada, reports that its commission, called the Energy Resources Conservation Board will not usually give the necessary permission for an infill well unless there is substantial agreement among operators that infill drilling is required. Crommelin, Government Management of Oil and Gas in Alberta, 13 Alberta L. Rev. 146, 174 (1975).

In Utah, the board is allowed to modify drilling units for additional wells. In the Utah Code $\S 40-6-6(6)$, the board may modify an order that establishes drilling units for a 
pool to provide for: (a) an exception to the authorized location of a well; (b) the inclusion of additional areas which the board determines overlays the pool; (c) the increase or decrease of the size of drilling units; or (d) the drilling of additional wells within drilling units.

\section{LIMITATIONS ON SPACING UNITS}

Early on, many states required wells to be drilled in the center of a geographic area. The Law of Oil and Gas by Summers, page 285. According to the subcommittee survey, most states have enacted statutes restricting the size of spacing units. Alabama, for example, limits spacing units to 160 acres for oil wells and 640 acres for gas wells, plus a "tolerance" of fifty percent. Alabama Code 1975 § 9-17-12. Arizona law establishes a minimum size for units - a minimum of 80 acres for oil wells.

Undoubtedly these limitations were based in part on some geologic and engineering evidence concerning the accepted characteristics of oil and gas reservoirs. These limitations were also based in part on concerns of mineral owners that absent strict limitations, aggressive lessees would establish units far larger than necessary merely to hold leases and reduce the number of wells they were obligated to drill.

The better practice is to place no statutory limitation on the size of units granting the oil and gas conservation commission the authority to determine the size of units.

North Dakota does not restrict the size of spacing units, allowing the Industrial Commission the discretion to determine the size. North Dakota Century Code $\S 38-08-07$. The North Dakota statute however does provide that the spacing units must be of uniform size and shape.

\section{$X$. NEW TECHNOLOGY}

\section{A. Seismic}

Modern seismic technology came into use for oil and gas exploration during the 1960's. Seismic technology reduces drilling risks by allowing accurate determination of potential reservoirs. During the 1990's, 3-D seismic technology has been developed and utilized to explore for oil and gas. Currently, almost all seismic oil and gas exploration is conducted with 3-D techniques. It is generally accepted that 3-D seismic allows for accurate determination of geologic strata and reservoirs. The subcommittee arranged for Brian Sims to address the Energy Resources, Research and Technology Committee and members of the Technology and Well Spacing Subcommittee during the subcommittee's first session. Sims, an exploration geologist in Jackson, Mississippi, practicing in the Southeastern United States, discussed the need for oil and gas conservation agencies to allow flexibility in applying oil and gas spacing laws so operators could drill at optimum geologic locations. He presented a detailed set of geologic maps supplied at oil and gas conservation commission hearings to show how seismic and other geologic tools could be utilized to identify precise well locations. Sims suggested to the subcommittee that flexibility in applying spacing laws and regulations would cause more wells and more productive wells to be drilled. 


\section{B. Horizontal and Multilateral Drilling}

According to the subcommittee's survey in the attached compilation of Spacing Regulations, most states have no special statutes or regulations addressing horizontal drilling, and horizontal drilling is conducted in accordance with general spacing statutes and regulations.

Most spacing statutes and regulations are perhaps too restrictive with setback requirements limiting the length of horizontal wells. Modern horizontal wells can be drilled laterally over a mile in length.

As discussed above, every state allows exception locations under certain conditions, and as John Land McDavid of Mississippi notes in his textual comments, an operator may obtain exception locations for horizontal wells. Some states have defined "horizontal wells," for example, Louisiana Administrative Code 43:XIX.4301-4305.

North Dakota has adopted specific regulations addressing horizontal drilling, in the absence of spacing. Horizontal wells drilled shallower than 9,000 feet drilled at an angle of at least $80^{\circ}$ within the same productive formation for 300 feet, must be drilled on a drilling unit of two adjacent 40 -acre quarter-quarter sections and must be at least 500 feet from the boundary of the drilling unit. Horizontal wells drilled deeper than 9,000 feet and drilled at an angle of at least $80^{\circ}$ within the same productive formation for 500 feet, must be drilled on a drilling unit of two adjacent 160 -acre quarter sections and must be at least 660 feet from the boundary of the drilling unit. Furthermore, the horizontal well is the only well allowed in the drilling unit. North Dakota Administrative Code § 43-02-03-18.

More horizontal wells have been drilled in Texas than in any other state. These wells are drilled under Texas' general spacing regulations, and no special regulations have been adopted.

To accommodate these special circumstances of horizontal drilling, Alabama recently amended its statutes relating to fieldwide units to allow a field to be unitized in order to conduct horizontal drilling operations.

Since the late 1980s, there has been a major increase in the use of horizontal drilling technology in the United States. This technique involves substantial deviation of a wellbore from the vertical and well completion in a longer extent of drainhole than is found with traditional drilling and completion. Horizontal drilling leads to significantly improved recovery from a reservoir because a greater area of the reservoir is penetrated. Several states have responded to the new drilling and production techniques by amending their regulatory programs to accommodate the developments.

\section{NEW STATUTES}

\section{A. Louisiana's Deep Drilling Statute}

In 1999, Louisiana adopted a statute to promote deep exploration. La. R.S., § 30:9(2)B. The statute was adopted at a time when oil and gas prices were depressed. Under the statute, the commissioner may establish a unit for multiple wells based on a development plan submitted by the operator. The unit established under the statute gives the operator the flexibility to drill wells at optimum locations without setback limitations. 


\section{B. Michigan's Multi-well Units}

In 1996, Michigan revised its state law on oil and gas in the Natural Resources and Environmental Protection Act. Under the Act and regulations, Michigan allows more than one well in a unit with a plan of exploration or development being submitted to the oil and gas conservation commission.

\section{Environmental Concerns (No Limit on Offshore)}

In recent years, environmental matters have become considerations in establishing units. Alabama amended its oil and gas laws deleting limitations on the size of offshore units. Alabama Code § 9-17-12. Utilizing the statute, the Commission has spaced wells on units of over 1,000 acres thereby reducing the number of wells, drilling platforms, and associated equipment in an environmentally sensitive area.

\section{Nongovernmental or Irregular}

States that customarily follow a spacing pattern based on governmental subdivisions may allow units to vary where the technical data supports a different nongovernmental configuration. The presentation of Brian Sims to the subcommittee about the use of seismic exploration in connection with well spacing was an excellent example of how the establishment of nongovernmental spacing units can promote drilling at optimum locations.

\section{E. Exploratory Units in Arkansas}

Arkansas adopted exploratory units in the 1980 s in order to accommodate pre-drilling forced integration of 640-acre gas units in North Arkansas. The Arkansas practice prior to this addition and presently, except where advantage is taken of the exploratory unit provision is that a well may be drilled without a spacing/drilling/ production unit being assigned. Spacing does not come into play until a field has been designated and spacing for the field determined. After a discovery well, the field must be established and spacing units assigned when not more than three wells have been drilled or six months have elapsed. Rule B-38. After spacing has been established, then interests may be force pooled but not until the spacing pattern has been established. Wells in South Arkansas are generally more productive of oil and drilled on smaller spacing. This presented a problem when putting together a 640-acre gas unit in North Arkansas in advance of drilling. The exploratory unit provision allows a 640 -acre unit to be established for drilling upon notice and hearing, and thereafter, force integrated. This was not possible under the prior practice and is not possible under the present practice unless the exploratory unit provision is invoked.

\section{F. Research Projects}

Missouri allows its oil and gas conservation commission to waive spacing requirements for wells drilled in research or development projects leading to initiation or improvement of methods for the economic recovery of oil or gas.

\section{MODEL STATUTE ADDRESSING WELL SPACING}

\section{A. Definitions}

Field - the general area underlaid by one or more reservoirs or pools.

Horizontal well - a well bore drilled laterally at an angle of at least eighty (80) degrees to 
the vertical or with a horizontal projection exceeding one hundred (100) feet measured from the initial point of penetration into the productive formation through the terminus of the lateral in the same common source of supply.

Pool - an underground reservoir containing a common accumulation of oil or gas or both. Each zone of a general structure that is completely separated from any other zone in the structure is a separate pool. "Common source of supply" and "reservoir" is synonymous with "pool."

Reservoir - a common accumulation of oil and/or natural gas or both.

B.

The oil and gas conservation commission is authorized to establish spacing units of such size and shape that will provide for the efficient and economic development of the oil and gas reservoir (pool). A spacing unit shall consist of the maximum area that can efficiently and economically be drained by one well.

C.

The oil and gas conservation commission shall establish spacing units that will provide that each owner in the reservoir will have the opportunity to receive his just and equitable share of production of the oil and gas in the reservoir.

\section{D.}

After discovery of oil or gas, the oil and gas conservation commission shall establish a field providing for production allowables and uniform well spacing.

E.

If a spacing unit is smaller than units established for the reservoir, such unit shall be allowed to produce only in the proportion the size of the unit bears to the size of the uniform units established for the reservoir.

\section{F.}

The oil and gas conservation commission may grant exceptions to the well spacing provisions when the oil and gas conservation commission determines, after notice and hearing, that:

1. topographic conditions make drilling in compliance with spacing regulations unduly burdensome;

2. environmental considerations;

3. the spacing unit is partly outside the pool;

4. a well drilled in compliance with spacing regulations would be noncommercial;

5. to prevent the confiscation of oil or gas;

6. owners will not otherwise receive their fair and equitable share of production; or

7. owners of oil and gas affected by the exception have consented to the exception.

When an exception is granted, the oil and gas conservation commission shall take such action to protect the correlative rights of other owners in the reservoir to offset any advantage granted by reason of the drilling of the well at the exception location. 


\section{STATE COMPILATIONS}

\section{ALABAMA}

1. Spacing requirements: Rule 400-1-2-. 02 (onshore), 400-2-2-. 02 (offshore), 400-3-2-. 02 (coalbed methane)

(a) Density: Onshore

(1) Oil wells - 40-acre units.

160-acre units (supervisor may require written justification).

(2) Gas wells - 40-acre units.

160-acre units (supervisor may require written justification).

320-acre units (Fayette, Lamar, Pickens and Tuscaloosa Counties only).

640-acre units (Baldwin, Mobile, Escambia and Washington Counties only) (supervisor may require written justification).

All well units shall consist of governmental sections or divisions. However, upon receipt of written justification, units consisting of $40,160,320$ and 640 contiguous acres other than a governmental section or division may be approved by the supervisor or may be referred to the board for notice and hearing.

Offshore (for offshore wells in offshore tracts).

(1) Deeper than 6,000 feet - Entire offshore tract, 3/4 tract or $1 / 2$ tract (where operator owns or controls $100 \%$ of working interest in entire offshore tract).

(2) Deeper than 6,000 feet - up to 1,400 acres (irregular offshore tracts).

(3) 6,000 feet or shallower $-1 / 2$ offshore tract or $1 / 4$ tract (where operator owns or controls $100 \%$ of working interest in entire offshore tract).

(4) 6,000 feet or shallower - quarter-quarter tract for regular tract and up to 360 acres for irregular tracts.

(5) For offshore wells not a 40-acre unit.

(6) In an offshore tract - 160-acre units (supervisor may require written justification).

(7) 640-acre units (Baldwin and Mobile Counties, only) (supervisor may require written justification).

All well units shall consist of governmental sections or divisions. However, upon receipt of written justification, units consisting of 40,160 and 640 contiguous acres other than a governmental section or division may be approved by the supervisor or may be referred to the board for notice and hearing.

(b) Lineal:

(1) Coalbed gas -40 acres -330 feet from every exterior boundary.

(2) Onshore

(a) 40 -acre units -330 feet from every exterior boundary.

(b) 160 and 320 -acre units -660 feet from every exterior boundary.

(c) 640-acre units - 1,320 feet from every exterior boundary.

(3) Offshore - Wells deeper than 6,000 feet $-1,320$ feet from every exterior boundary and 500 feet from the state/federal boundary.

Wells shallower than 6,000 feet -660 feet from every exterior boundary and 500 feet from state/federal boundary.

2. Exceptions: Rule 400-1-2-. 02(2)(g) (onshore), 400-2-2-. 02(4) (offshore), 400-3-2-. 02(2)(d) 
coalbed.

(a) Basis: If the well would be non-productive or if topographical or other conditions make the drilling in compliance with the spacing requirements unduly burdensome. See $\S$ 9-17-12(c) of the Code of Alabama (1975).

(b) Approval: After notice and hearing.

\section{Summary (Marvin Rogers)}

The Alabama oil and gas conservation statute addressing well spacing is $\S 9-17-12$ of the Code of Alabama (1975). It provides that, except in extraordinary circumstances, the largest spacing unit for an oil well is 160 acres and the largest spacing unit for a gas well is 640 acres. In oil and gas statutes, the terms spacing units, production units and drainage units are used interchangeably.

The statute does not expressly require spacing units to be on governmental sections or divisions of governmental sections (i.e. sections, quarter sections or quarter-quarter sections). However, the regulation of the State Oil and Gas Board (OGB) provides that wells must be on governmental divisions, unless the operator provides written justification otherwise.

\section{Exception Locations}

The regulations of the OGB establish minimum setback requirements - minimum distances from the boundaries of the unit. That is, on a 40-acre unit, the well must be 330 feet from the unit boundary; and on a 160-acre unit, the well must be 660 feet from the unit boundary. The oil and gas conservation statutes and the regulations provide that the OGB may grant exceptions to the setback requirements on exception locations under these circumstances:

1. The unit is partly outside the pool;

2. A well located in accordance with applicable rules would be nonproductive;

3. A well located in accordance with applicable rule would not be at the optimum position, for the most efficient and economic drainage; and

4. Topographical conditions.

The OGB may grant exceptions to the setback requirements allowing wells to be closer to the boundaries of the unit after a public hearing during which evidence is presented in support of the exception locations.

\section{Non-Governmental Units or Irregular Units}

Although they are rare, the OGB may establish non-governmental spacing units. Since the regulations provide for units consisting of governmental sections or smaller divisions of a section, the OGB must approve most non-governmental or irregular units after notice and hearing.

\section{Seismic}

Seismic evidence is accepted and frequently submitted at hearings in support of petitions for exception locations and petitions to establish a non-governmental unit. 


\section{Horizontal Drilling}

An operator may permit a horizontal well, like any other well or a spacing unit. The setback requirements (330 feet for 40 -acre units, 660 feet for 160 -acre units) can be limiting for drilling a horizontal well. Therefore, operators often prefer to unitize a field before drilling horizontal wells. Under Alabama's liberal unitization statute, fields may be unitized for horizontal drilling.

\section{ALASKA}

1. Spacing requirements: Yes, in the absence of an order by the commission establishing drilling units or prescribing a spacing pattern for a pool, the following statewide spacing requirements apply:

(a) Density: Governmental quarter section for an oil well; governmental section for a gas well.

(b) Lineal: An oil well may be open to test or regular production within 500 feet of a property line only if the owner is the same and the landowner is the same on both sides of the line. 1,000 feet minimum separation from any well drilling to, or capable of producing from, the same pool.

A gas well may be open to test or regular production within 1,500 feet of a property line only if the owner is the same and the landowner is the same on both sides of the line 3,000 feet minimum separation from any well drilling to, or capable of producing from, the same pool.

2. Exceptions: Yes.

(a) Basis: Prevention of waste and protection of the correlative rights of lessees in a pool based on operating and technical data.

(b) Approval: Applicant must file for exception. The Alaska Oil and Gas Conservation Commission (AOGCC) must publish notice and hold a hearing, if protest is received.

\section{Summary (Robert Crandall)}

\section{Seismic}

Statewide spacing rules establish the spacing units for an oil well as a governmental quarter section (160 ac) and a gas well as a governmental section (640 ac). These determinations do not require the use of seismic data. Spacing pool rules written in conservation orders are part of an overall development plan for a pool or portion of a pool and therefore require a more comprehensive level of information, which in almost all cases relies in part on seismic data.

\section{Horizontal Drilling}

Horizontal wells including multilateral are treated in AOGCC regulations as a single wellbore. No distinction between vertical or horizontal wellbores is required by AOGCC statewide spacing rules. Horizontal and multilateral wells are encouraged where appropriate in a development plan of a pool. 


\section{Spacing Rules}

Recent revisions of the statewide spacing regulations limit the requirements for spacing exceptions because of proximity to a spacing unit boundary to those cases where the spacing unit boundary coincides with a change of ownership or a property boundary. This is useful to us because most leases in Alaska cover at least several square miles. Our notice requirements for spacing exceptions can be modified to accommodate areas with complex ownership such as sub-divisions.

\section{Drilling Units and Well Spacing}

1. The commission will in its discretion, establish drilling units to govern well spacing and prescribe a spacing pattern by pool rules adopted in accordance with 20 AAC 25.520 . In the absence of an order by the commission establishing drilling units or prescribing a spacing pattern for a pool, the following statewide spacing requirements apply:

(a) For a well drilling for oil, a wellbore may be open to production within 500 feet of a property line only if the owner is the same and the landowner is the same on both sides of the line;

(b) For a well drilling for gas, a wellbore may be open to production within 1,500 feet of a property line only if the owner is the same and the landowner is the same on both sides of the line;

(c) If oil has been discovered, the drilling unit for the pool is a governmental quarter section; not more than one well may be drilled to and completed in that pool on any governmental quarter section; a well may not be drilled or completed, closer than 1,000 feet to any well drilling to or capable of producing from the same pool;

(d) If gas has been discovered, the drilling unit for the pool is a governmental section; not more than one well may be drilled to and completed in that pool on any governmental section; a well may not be drilled or completed closer than 3,000 feet to any well drilling to or capable of producing from the same pool.

2. A well may not begin regular production of oil from a property that is smaller than the governmental quarter section upon which the well is located or begin regular production of gas from a property that is smaller than the governmental section upon which the well is located, unless the interests of the persons owning the drilling rights in and the right to share in the production from the quarter section or section, respectively, have been pooled under AS 31.05.100.

3. A pooling agreement under AS 31.05.100 must be filed with the commission before regular production from the affected property begins.

4. The commission will review an application for an exception to the provisions of this section in accordance with 20 AAC 25.540. The applicant for an exception shall send notice of the application by certified mail to the owners, landowners and operators described in (1) of this subsection. They shall furnish the commission with a copy of the notice, the date of mailing and the addresses to which the notice was sent. The application must include:

(a) The names of all owners, landowners and operators of all properties within 1,000 feet of a well drilling for oil or within 3,000 feet of a well drilling for gas for which an exception is 
sought;

(b) A plat drawn to a scale of one inch equaling 2,640 feet or larger, showing the location of the well for which the exception is sought, all other completed and drilling wells on the property and all adjoining properties and wells; and

(c) An affidavit by a person acquainted with the facts, verifying that all facts are true and that the plat correctly portrays pertinent and required data.

5. Upon application by the operator, the commission will establish notice requirements different from those of $(d)$ of this section if the operator demonstrates to the commission's satisfaction that compliance with the notice requirements in (d) of this section is not feasible because of the complexity of ownership within the notice area.

\section{ARIZONA}

1. Spacing requirements: Yes. Rule R12-7-107.

(a) Density: Minimum acreage for an oil well is 80 acres. Minimum acreage for a gas well is 640 acres.

(b) Lineal: No oil well shall be located closer than 330 feet from the boundary of drilling unit, nor closer than 330 feet to the shortest center line of drilling unit. Gas well no closer than 1,660 feet from section line.

2. Exceptions: Only after approval by commission following notice and hearing. Rule R12-7-107 $(\mathrm{F})$.

(a) Basis: Topographical or geological conditions, and in order to prevent waste.

(b) Approval: Request public hearing to present evidence of necessity and to give all interested parties a chance to be heard.

\section{Summary (Steve Rauzi)}

Oil and gas rules are found in Title 12, Chapter 7 of the Arizona Administrative Code (A.A.C.). A.A.C. R12-7-107, Well Spacing, specifies the well spacing and acreage dedication requirements in Arizona. The spacing rule was last amended in 1994. A particularly useful aspect of R12-7-107 is that it provides for wide spacing initially and possible in-fill wells, where necessary, to adequately drain a reservoir.

A.A.C. R12-7-107 requires wells drilled for oil to be located on a drilling unit of approximately 80 contiguous acres. They must be at least 330 feet from any boundary of the drilling unit and no closer than 330 feet to the shortest center line of the drilling unit. R12-7-107 requires wells drilled for gas to be located on a drilling unit of approximately 640 contiguous acres and be at least 1,660 feet from any boundary of the drilling unit. These are regular locations.

The Oil and Gas Conservation Commission (OGCC) may grant exceptions to the regular locations administratively if topography prohibits drilling at a regular location. Otherwise, exceptions to the regular locations are granted only after notice and hearing. 
The OGCC may, after notice and hearing, fix different spacing requirements and require lesser or greater acreage for drilling units in any specific oil or gas pool. Since spacing orders are primarily based upon reservoir and fluid characteristics and well completion and production practices, the commission would encourage an operator submitting an application for a spacing order to use seismic data to complement other geologic and engineering data and address horizontal drilling and completion practices. Consequently, A.A.C. R12-7-107 adequately provides for horizontal drilling and the use of seismic data to establish units. The discretion provided by A.A.C. R12-7-107 to the Oil and Gas Conservation Commission to establish special spacing orders is particularly useful.

\section{ARKANSAS}

1. Spacing requirements:

(a) Density: No minimum for oil or gas wells.

(b) Lineal: $\mathbf{2 8 0}$ feet from a governmental division line or lease line or property line for oil or gas wells. (For wildcat wells and wells drilled in fields not covered by field rules.)

2. Exceptions: Yes.

(a) Basis: If a well would be non-productive at normal location or if topographic conditions would create a hazard or an unduly burdensome operation.

(b) Approval: A public hearing must be held and ruling granted by the commission. It can also be granted administratively, with a notice given to the parties having the right to drill in the unit being encroached if no objections are filed within 15 days of publication of notice.

\section{Summary (Grant Black)}

Rule B-3 contained in the Arkansas Oil and Gas Commission (AOGC) general rules and regulations provides that the spacing of wells in proven oil and gas fields or in areas that the commission may designate, shall be covered by special rules for that particular field or area, adopted after notice and hearing.

Drilling units for the production of oil and gas established by the AOGC range, except in extraordinary circumstances, from 10-acre to 640-acre drilling units. 640-acre spacing is the most common drilling unit size for gas, with some 40, 80, 160 and 320-acre units, and 10, 20, 40 and 80 -acre units are commonly formed for oil producing units.

\section{Exploratory Units}

$\S 15-72-302(e)$ of the Arkansas Code is a particularly helpful spacing law that provides that the commission may, after public hearing, establish a drilling unit for an exploratory well to be drilled therein. Any drilling unit determined by the commission to be prospective of oil or gas, may be established when the owners thereof fail to establish a unit voluntarily, provided that persons who own at least an undivided fifty percent (50\%) interest in the unit area agree to drill. 
However, any such order of the commission and drilling unit as established for exploratory purposes there under shall remain in force for a period of no longer than the later of (1) year following the effective date thereof or one (1) year following the cessation of drilling operations or production within the unit, whereupon the order of the commission and the provisions thereof shall automatically terminate.

\section{Exception Locations}

Field rules for individual fields provide for minimum distances from the unit boundary lines. Typical distances from unit boundaries that are normally required are 1,320 feet from the unit boundary of 640-acre units, 660 or 330 feet from the unit boundary of 320-acre units, 660 or 330 feet from the unit boundary of 160-acre units, and 280 feet from the unit boundaries of 80 , 40, 20 and 10-acre units. Exceptions may be granted after notice and hearing with the imposition of a penalty relative to the encroachment footage. Wells drilled within areas not covered by field rules shall be drilled no closer than 280 feet to any property, unit or division line within a governmental section, unless granted an exception by the AOGC.

\section{Seismic}

Seismic evidence is accepted in AOGC hearings and is most frequently used in proceedings to establish exploratory drilling units, where little or no other well data is available.

\section{Horizontal Drilling}

An operator may permit a horizontal well just as any other well. The minimum distance from the unit boundary existing within any field or in areas not covered by field rules would apply to both surface and bottom hold locations of the horizontal well. In cases where unitization has occurred, horizontal wells can be permitted within the unitized area without location restrictions.

\section{CALIFORNIA}

1. Spacing requirements: Yes. (§ 3600-3609)

(a) Density: One well per acre for fields producing after August 14, 1931, or as approved or ordered by the supervisor for pools discovered after January 1, 1974.

(b) Lineal: See $\S 3600-3606.1$ does not apply to fields producing on August 14, 1931. Applies to both oil and gas wells.

2. Exceptions: Yes.

(a) Basis: For drilling islands and developing heavy hydrocarbons that necessitate closer well spacing. (§ 3602.1).

(b) Approval: Through appeal to the state oil and gas supervisor.

Summary (Michael Stettner)

Spacing in California is under three periods. Fields producing before August 14, 1931 
have no spacing requirements, and many fields during the early twenties were developed in town-lot areas. In some fields, such as Long Beach (Signal Hill) and Huntington Beach, it was possible to walk directly from derrick floor to derrick floor. The spacing act enacted in 1931, established the basic one well per acre statewide well spacing and required 100 -foot set back from lease lines, and that these wells be 150 feet apart at the surface. This act was later amended to allow for the subsurface spacing of directionally drilled wells from central drill sites. In 1973, the Legislature enacted a new code to specify that the state oil and gas supervisor may adopt well spacing patterns for new pools discovered after January 1, 1974. Public hearings are required before adoption of a permanent spacing program.

\section{Seismic} units.

Basic spacing is one well per acre. There is no need to use seismic data to establish

\section{Horizontal Drilling}

The spacing laws provide adequately for horizontal drilling. Unlike most other states, California's geology is extremely varied and oil fields exist in a variety of geographical terrain. Consequently, many of the oil and gas wells in California are directionally drilled from locations that are more cost effective and accessible.

\section{Spacing Laws}

Close spacing is allowed for the effective development of heavy hydrocarbon reservoirs. For multiple-pool fields, up to two wells per acre are allowed provided each produces from a separate pool.

\section{California Public Resources Code Spacing Laws}

3600. Except as otherwise provided in this chapter, any well hereafter drilled for oil or gas or hereafter drilled and permitted to produce oil or gas, which is located within 100 feet of an outer boundary of the parcel of land on which the well is situated or within 100 feet of a public street or road or highway dedicated prior to the commencement of drilling of the well or within 150 feet of either a well being drilled or a well there-to-fore drilled, which is producing oil or gas, or a well which has been drilled and is not producing but which is capable of producing oil or gas, is a public nuisance.

3601. Where several contiguous parcels of land in one or different ownership's are operated as a single oil or gas lease or operating unit, the term outer boundary line means the outer boundary line of the lands included in the lease or unit. In determining the contiguity of any such parcels of land, no street, road or alley lying within the lease or unit shall be deemed to interrupt such contiguity.

3602. Where a parcel of land contains one acre or more, but is less than 250 feet in width, there may be drilled on the parcel of land not more than one well to each acre of the area if the surface location of any well or wells is so placed as to be as far from the lateral boundary lines of the parcel of land as the configuration of the surface and the existing improve- 
ments thereon will permit.

3602.1. Where a parcel of land contains one acre or more and the hydrocarbons to be developed are too heavy or viscous to produce by normal means, and the supervisor so determines, the supervisor may approve proposals to drill wells at whatever locations he deems advisable for the purpose of the proper development of such hydrocarbons by the application of pressure, heat or other means for the reduction of oil viscosity and such wells shall not be classed as public nuisances after approval by the supervisor.

3602.2. In determining the area of parcels of land for the purposes of this chapter, the area of the oil and gas mineral estate shall be used exclusively.

3603. For the purposes of this chapter, an alley which intersects or lies within any block or other subdivision unit is not a public street or road.

3604. Each day in which the drilling of any well is carried on or on which it is permitted to produce oil or gas in violation of this chapter is a separate nuisance.

3605. The provisions of this chapter do not apply to any field producing oil or gas on August 14, 1931.

3606. Notwithstanding any other provisions of this chapter, where a parcel of land contains one acre or more and where all or substantially all of the surface of such parcel of land is unavailable for the surface location of wells, there may be drilled or produced not more than one well into each acre of such parcel of land, and the surface location of such well may be located upon property which may or may not contain one acre or more of surface area, and the property upon the surface of which the surface location of such well may be located may or may not be contiguous to such parcel of land; provided:

1. No operator shall construct or maintain any derrick within 150 feet of any other derrick, then standing, of such operator unless approved in advance by the supervisor who may, in granting such approval, attach such conditions as are reasonably necessary to carry out the purposes of this chapter.

2. The surface location of such well, as measured from the center of the hole, shall be not less than 25 feet from an outer boundary of the surface of the property upon which such well is located, and shall be not less than 25 feet from any dedicated public street, road or highway, which is so dedicated and in such public use at the time of the commencement of drilling of such well.

3. The producing interval of such well shall be not less than 75 feet from an outer boundary of the parcel of land into which such producing interval is drilled, and the producing interval of such well shall be not less than 150 feet, as measured horizontally in the same zone, from the producing interval of any other well, which is producing or capable of producing oil or gas. If the parcel of land qualified to be drilled under this section is less than 150 feet in width, the producing interval of such well shall be as far from the lateral boundary lines of the property as is practicable.

To enforce the provisions of this section, the supervisor may require, at the time a supervisor gives approval of notice of intention to drill, redrill or deepen, that a subsurface directional survey be made for such a well, and that a plat of said directional survey be filed with the supervisor within fifteen (15) days of completion. 
3606.1 The 150-foot restriction in $\S 3600$ and elsewhere in this chapter shall apply only to wells drilled and producing from the same zone or pool; provided, however, that the well density shall not exceed one well per acre unless the supervisor shall determine that more than one zone or pool underlies the property; that it is not practical to produce from all of such zones or pools from a single well per acre; and that such other zones or pools are being drained by offset wells. In such cases only, a maximum density of two wells per acre may be approved. These exceptions to the general spacing rule shall apply also to properties qualifying under $\S 3602$ and 3606 .

3607. The prohibition set forth in $\S 3600$ against drilling within 100 feet of any public street or highway shall not apply in the case of any street or highway, which is opened through a field in which drilling was commenced prior to the opening of the street or highway.

3608. Where land aggregating less than one acre is surrounded by other lands, which other lands are subject to an oil and gas lease aggregating one acre or more, and if, under the provisions of $\S 3600$ to 3607 , inclusive, of the Public Resources Code, the drilling or producing of a well on said land is declared to be a public nuisance, said land shall, for oil and gas development purposes and to prevent waste and to protect the oil and gas rights of landowners, be deemed included in said oil and gas lease on said other lands, and shall be subject to all the terms and provisions thereof, when the state oil and gas supervisor has caused to be recorded with the county recorder of the county in which said land aggregating less than one acre is located a declaration as hereinafter provided. A request for inclusion of surrounded land aggregating less than one acre may be filed with the supervisor at any time by either the lessee of such other lands or by the owner or lessee of such surrounded land or the supervisor may act upon his own motion. Before filing such request the lessee of such other lands shall make a reasonable effort to include each parcel of surrounded land, within the oil and gas lease upon such other lands.

There shall be attached to such request a statement which shall set forth the name or names of the record owner or record owners of said land aggregating less than one acre which is to be included in said oil and gas lease on said other lands, the legal description of said land aggregating less than one acre, name of the lessee of the oil and gas lease in which such land is to be included, and a reference to the book and page of the official records of the county recorder where such oil and gas lease is recorded or a reference to the document number and date of recordation of such oil and gas lease. Within 20 days following receipt of such request and attached statement, the supervisor shall cause to be recorded with the county recorder of the county in which said land aggregating less than one acre is located, a declaration, signed by him or his assistant or deputy, that said land is deemed by the provisions of this section to be included in said oil and gas lease on said other lands. Such declaration shall set forth the same information required to be set forth in the statement attached to the request, and a copy thereof shall be mailed or otherwise delivered by the supervisor to the lessee. The county recorder shall accept such declaration for recordation and shall index such declaration in the names of all persons or corporations mentioned therein. From the time of recording thereof in the office of the county recorder, such notice shall impart constructive notice of the contents thereof to all persons dealing with the land therein described.

The owners of the oil and gas mineral rights in said land so deemed included in said oil and gas lease on said other lands, as herein provided, shall thereafter receive in money, based upon the production of oil and gas from the leasehold including said land or lands unitized or pooled therewith, a pro rata share of the landowners' royalty determined 
in accordance with the provisions of said oil and gas lease in the proportion that the area of said land bears to the aggregate of the total area covered by said oil and gas lease including the area of said land or as otherwise provided in said lease; provided further, that said owners of said oil and gas mineral rights in said land shall in no case receive less than their pro rata share determined, as herein provided, of the value of one-eighth part of the oil and gas produced, saved and sold from or allocated to the operating unit comprising said leasehold on said other lands and said land, computed in accordance with the provisions of said oil and gas lease with respect to the computation of landowners' royalty; provided further that upon recordation of the statement by the supervisor, the owners of such oil and gas mineral rights in such land shall also receive a pro rata share of any other benefits thereafter accruing to the owners of the oil and gas mineral rights under the terms of the oil and gas lease on such other lands; and provided further, that without the consent of said owners of said land the lessee or operator of said oil and gas leasehold shall have no right to use the surface of said land nor to use the subsurface thereof down to a depth of 200 feet below the surface thereof.

Where said land aggregating less than one acre is surrounded by lands which are not subject to a single oil and gas lease but is surrounded by lands which are subject to two or more separate oil and gas leases, one or more of which oil or gas leases aggregates one acre or more, then in such event the said land aggregating less than one acre shall, as herein provided, be included within and be joined to that oil and gas lease aggregating one acre or more as to which said parcel of land aggregating less than one acre has the longest common boundary. If there is no longest common boundary, the request shall designate the lease, aggregating one acre or more, into which the parcel aggregating less than one acre shall be included by the declaration of the supervisor; otherwise the supervisor shall make such designation. In determining the contiguity of any parcels of land for the purposes hereof, no road, street or alley shall be deemed to interrupt such contiguity.

3608.1 The owner or operator of any leasehold, into which land has been included under the provisions of $\S 3608$, shall cause to be recorded an appropriate quitclaim to such land in the proper county recorder's office when such leasehold has been terminated.

3609. Notwithstanding any other provisions of this chapter, if the supervisor determines, pursuant to rules and regulations and after a public hearing, that the development of a pool discovered after the effective date of this section for the production of oil and gas or either, requires the adoption of a well-spacing pattern other than that specified in $\S$ 3600 to 3608.1 , inclusive, in order to prevent waste and to increase the ultimate economic recovery of oil or gas, he may adopt a well spacing plan to apply to the surface and subsurface of a designated pool. Such plan shall be applicable to all wells thereafter drilled or redrilled into such pool. Such plan may include a requirement that, as a prerequisite to approval to drill or redrill a well, all or certain specified parcels of land shall be included in a pooling or unit agreement. The supervisor may provide in the rules and regulations for mandatory pooling agreements in connection with the well-spacing order.

\section{COLORADO}

1. Spacing requirements: Minimum density not specific.

(a) Density: Not specific. 
(b) Lineal: Rule 318. Less than 2,500 feet in depth - 200 feet from lease line, 300 feet between wells - one well per governmental quarter-quarter. Greater than 2,500 feet 600 feet from lease lines, 1,200 feet between wells for both oil and gas wells.

2. Exceptions: Yes.

(a) Basis: Geologic, environmental, topographic or archeological conditions, irregular sections or surface conditions.

(b) Approval: Administratively if no objection or receipt of waivers from offset lease owners. Where lease-owner of offset lease is the same as owner of proposed well, waiver must be obtained from offset mineral owners; however, waiver must be reasonable. If waivers cannot be obtained from all parties and no party objects, the operation may apply for a director variance. If parties object, hearing before commission.

\section{Summary (Tricia Beaver)}

\section{Statutory}

$\S 34-60-116$ of the Colorado Oil and Gas Act is the statute that addresses drilling units and pooling interests. There is no statewide spacing in Colorado. After notice and hearing, drilling and spacing units of specified and approximately uniform size and shape may be established by the Colorado Oil and Gas Conservation Commission (COGCC). The commission is authorized to divide any pool into zones and establish drilling units for each zone so that the pool as a whole will be efficiently and economically developed.

No drilling unit shall be smaller than the maximum area that can be efficiently and economically drained by one well. If the commission is unable to determine, based on the evidence introduced at a hearing, the existence of a pool, the appropriate acreage to be included within a drilling unit and the shape of the drilling unit, an exploratory unit may be established. Exploratory units are often best utilized when drilling wells using horizontal technology or based on seismic plays. Permitted well locations or specific setbacks may be designated in an order establishing drilling or exploratory units.

\section{Regulatory}

For wells not subject to drilling units established by the commission, Rule 318 of the Rules and Regulations of the COGCC establishes setbacks for wells drilled greater than 2,500 feet in depth. Wells drilled less than 2,500 feet in depth and a process for seeking exceptions to those setbacks are also covered under Rule 318. Wells drilled greater than 2,500 feet in depth shall be located not less than 600 feet from any lease line and not less than 1,200 feet from any other well in the same formation. Wells drilled less than 2,500 feet in depth shall be located not less than 200 feet from any lease line and not less than 300 feet from any other well in the same formation and only one well per formation shall be allowed in each governmental quarter-quarter unless an exception is obtained. Exceptions due to geologic, environmental, topographic or archaelologic conditions or irregular sections, a surface owner requests, or for other good cause shown may be granted administratively. This is providing that waivers are obtained from the parties toward whom the well is proposed to be moved. If waivers are not obtained but no objections are received, a variance may be administratively granted. If objections are received, the 
commission may hold a hearing to consider the granting of an exception location. Wells drilled using horizontal technology or based on seismic data are subject to this Rule 318.

\section{FLORIDA}

1. Spacing requirements: Yes.

(a) Density: 40 and 160 acres for oil well and 640 acres for gas well.

(b) Lineal: Longest diagonal (of other than a square unit) may not exceed length of diagonal of a square of same size unit by more than $25 \%$ for both oil and gas wells.

2. Exceptions: Yes.

(a) Basis: $10 \%$ of size of unit designated.

(b) Approval: Secretary of the Department of Environmental Protection.

\section{Summary (David Curry)}

\section{Seismic}

Non-routine geologically based units can be created when units based on government survey would likely be unproductive. Seismic data can be used to justify such units.

\section{Horizontal Drilling}

Since Florida's horizontal drilling rules are largely untested, we can not be certain they will prove adequate. They have however, been adequate thus far. Generally, after completion of a successful horizontal test, the newly discovered field would be unitized as soon as practical.

\section{Spacing Laws}

Florida uses routine spacing units based on governmental survey, non-routine units based on geology, temporary units based on setbacks for horizontal wells and field unitization to resolve well spacing problems. All of these methods are necessary and useful since no one method can always be used.

\section{Examples for Other States}

1. Routine spacing - most Florida wells - 160-acre units common to most states.

2. Non routine geologically based units - several wildcats around Florida, none productive.

3. Horizontal setbacks - Sunniland Field, Lake Trafford Field, South Florida.

4. Unitization - Jay Field, Blackjack Creek Field, Raccoon Point Field.

\section{GEORGIA}

1. Spacing requirements: Flexible; to insure public safety at well or to maximize production, 
refers to Rules and Regulations.

(a) Density: Flexible.

(b) Lineal: Flexible.

2. Exceptions: Yes.

(a) Basis: Adequate technical justification.

(b) Approval: By the Director of the Environmental Protection Division.

\section{No narrative response}

\section{IDAHO}

1. Spacing requirements: Yes. General rules are automatic. (Rule 33.)

(a) Density: Generally, every well drilled for oil must be located on a drilling unit consisting of approximately 40 contiguous surface acres contained within the bounds of one governmental quarter-quarter section or lots having one side in common, and being within one governmental quarter section upon which no part is attributed to another well completed or drilling to the same pool. In addition, said drilling unit will not have a side in common with another quarter-quarter section or lot upon which there is a well completed to or drilling to the same pool. Generally, every well drilled for gas must be located on a drilling unit consisting of approximately 640 contiguous surface acres, which will be one governmental section or lots equivalent thereto, upon which no part is attributed to another well completed or drilling to the same pool.

(b) Lineal: Wells drilled for oil will not be located closer than 500 feet to any boundary of the unit and not farther than 500 feet from the shortest center line of the unit. Each well drilled for gas will be located within a square, each side to be 1,660 feet long and parallel to a center line of the section, and the center to coincide with the center of the section.

2. Exceptions: Yes. § 47-321, Idaho Code.

(a) Basis: If well would likely be non-productive or surface conditions will create excessive hazards or cost or other good causes shown by applicant.

(b) Approval: Application to be filed with the commission. Must show reason for exception request and show consent by the owners of all drilling units (established or projected) directly or diagonally offsetting the drilling unit involved with the exception. § 47-321(d), Idaho Code.

\section{No narrative response}

\section{ILLINOIS}

1. Spacing requirements:

(a) Density:

(1) Oil - 10 acres for an oil well in sandstone, 20 acres for an oil well in limestone, 40 acres for an oil well deeper than 4,000 feet. 
(2) Gas - 10 acres for a gas well in a sandstone, 20 acres for a gas well in limestone, 40 acres over 2,000 feet but less than 5,000 feet and 160 acres over 5,000 feet for discovery well offset well spacing set by a hearing.

(b) Lineal: For an oil or gas well not less than 330 feet from the nearest external boundary lines of the drilling unit.

2. Exceptions: Yes.

(a) Basis: Topographical conditions, irregular section, secondary recovery operations, location over mine or geological conditions.

(b) Approval: Administratively after verification of submitted information or by hearing depending on basis stated above.

\section{No narrative response}

\section{INDIANA}

1. Spacing requirements: Yes.

(a) Density:

(1) Oil well -10 acres for sandstone and 20 acres for all other reservoirs except established Trenton.

(2) Gas well - above 1,000 feet same as above and below 1,000 feet, 40 acres.

(b) Lineal:

(1) Oil wells - 330 feet from a property or unit line and 660 feet from another well producing from the same formation.

(2) Gas well - above 1,000 feet same as oil. Below 1,000 feet, 330 feet from a property or unit line and 1,320 feet from another well. Non-commercial gas well - no spacing or unit requirements.

2. Exceptions: Yes.

(a) Basis: When geological and pool conditions justify.

(b) Approval: By hearing. However, public notice is required before permit issuance.

\section{Summary (Mike Nickolaus)}

The Indiana oil and gas statute addressing well spacing and drilling units is IC 14-37. This statute contains the authority to establish well spacing and drilling units. The rule governing spacing and units is 312 IAC 16-5. See the Regulations page of the division's web site located at http://www.state.in.us/dnroil.

The rules require drilling units to be established within the bounds of governmental sections or divisions of governmental sections (i.e. sections, quarter sections or quarter-quarter sections). However, the rules also provide for alternate configurations for irregular or fractional sections, military donations, surveys and other non-conforming survey systems. Additionally, an applicant can petition the Natural Resources Commission to establish non-standard drilling units and well spacing requirements for conservation purposes. 


\section{General Specifications}

The rule establishes minimum setback requirements - minimum distances from boundaries of the unit and between wells capable of production from the same geologic formation. Wells may not be located closer than 330 feet from the boundary of any unconsolidated property line, and the distance between wells is established based on the type and depth of the well as follows:

1. Oil wells regardless of deep: 660 feet between wells.

2. Gas wells less than 1,000 feet deep: 660 feet between wells.

3. Gas wells deeper than 1,000 feet deep: 1,320 feet between wells.

4. The rule also establishes standard drilling unit configurations and sizes as follows:

(a) Oil wells of any depth and gas wells shallower than 1,000 feet completed in sandstone reservoirs require 10-acre drilling units comprised of a quarter-quarter-quarter section of land.

(b) Oil wells of any depth and gas wells shallower than 1,000 feet completed in any other reservoir type requires 20 -acre drilling units comprised of one half of a quarter-quarter section of land.

(c) Gas wells deeper than 1,000 feet completed in any reservoir type require a 40-acre drilling unit comprised of a quarter-quarter section of land.

\section{Standard Exceptions}

In addition to the general specifications noted above there are several standard exceptions to the unit and spacing rules as follows:

1. The division director may grant a $10 \%$ spacing or unit exception without a hearing as long as the exception will not leave isolated tracts of land or create a greater well density than allowed by the rule.

2. The division director may authorize the movement of a well location up to 50 feet to avoid locating the well in an impracticable location.

3. Wells located in an established reservoir of Ordovician age may be located on 5-acre drilling units comprised of one half of a quarter or a quarter-quarter section of land. It may be located no closer than 165 feet to any unconsolidated property boundary and no closer than 330 feet to any other well capable of production from the same reservoir.

4. Class II injection, non-potable water supply and geologic or structure test wells are exempt from the drilling unit and spacing provisions.

5. Non commercial gas wells are exempt from the drilling unit and spacing provisions, but may not be put in a location that would place an existing gas well in violation of the spacing provisions.

\section{Seismic}

Seismic evidence is accepted but infrequently submitted at hearings in support of petitions for unit or spacing exceptions.

\section{Horizontal Drilling}

An operator may permit a horizontal well, like any other well. Although the rules do not 
specifically address horizontal drilling, the division applies the spacing requirements at all points along the horizontal axis of the well within the producing formation. The drilling unit specifications are not adjusted except following a petition and hearing, and the entire horizontal axis of the well within the producing formation must be completely within the boundaries of the established drilling unit and may not be closer than 330 feet to any unconsolidated property boundary.

\section{KANSAS}

1. Spacing requirements: Yes. K.A.R. 82-3-108 and 82-3-312.

(a) Density: 10 acres for oil and gas wells.

(b) Lineal: Gas and oil wells shall be located 330 feet or more from any lease or unit boundary line to qualify for a full allowable. K.A.R. 82-3-207 and 82-3-312.

2. Exceptions: Yes. Oil wells drilled to a depth of less than 2,000 feet in certain counties in eastern Kansas have lineal distance requirement of 165 feet from the nearest lease or unit boundary line. K.A.R. 82-3-108b.

(a) Basis: Application by operator.

(b) Approval: Commission order. Hearing if needed after notice. K.A.R. 82-3-108.

\section{Summary (M. L. Korphage) \\ Well Spacing Requirements and Location Exceptions}

Requirements for standard drilling units for oil and gas wells, location exceptions procedures and special spacing orders are found in the Kansas Corporation Commission (KCC) Conservation Division's general rules and regulations under K.A.R. 82-3-207, K.A.R. 82-3-312, K.A.R. 82-3-108, K.A.R. 82-3-109 and K.A.R. 82-3-110.

\section{Oil Drilling Unit (K.A.R. 82-3-207)}

The standard drilling unit for oil wells is 10 acres. The standard set back for any oil well is 330 feet from any lease or unit boundary. Exceptions to this set back requirement are provided for in K.A.R. 82-3-108, which allows for 165-foot set backs for certain shallow oil wells in specific eastern Kansas counties or well location exceptions for oil wells in other areas upon application to the KCC Conservation Division. K.A.R. 82-3-207 also establishes acreage - attribution unit requirements for oil wells and reduces production allowables in proportion to the acreage attributable to the well if such attribution is less than the standard unit (10 acres in areas with 330-foot set backs and 2.5 acres in areas of 165 -foot set backs).

\section{Gas Allowable and Drilling Unit (K.A.R. 82-3-312)}

The standard drilling unit for gas wells is 10 acres. The standard set back for any gas well is 330 feet from any lease or unit boundary. Exceptions to this set back requirement are provided for in K.A.R. 82-3-108, which allows well location exceptions upon application to the KCC Conservation Division. K.A.R. 82-3-312 also establishes acreage - attribution unit require- 
ments for gas wells and reduces production allowables in proportion to the acreage attributable to the well if such attribution is less than the standard unit (10 acres).

\section{Well Location Exception (K.A.R. 82-3-108)}

This regulation establishes minimum set backs for oil or gas wells at 330 feet from any lease or unit boundary. As stated above, this regulation also establishes minimum set backs for shallow oil wells located in specific eastern Kansas counties. In addition this regulation provides a process for obtaining a well location exception from the applicable set backs, and to the acreage attribution and assigned allowables, when such exceptions are necessary to prevent waste or to protect correlative rights. The regulation defines the content of the location exception application to be filed with the KCC Conservation Division and provides provisions for notice to operators, lessees or unleased mineral rights owners within a $1 / 2$ mile radius of the well for which the exception is sought. A publication of notice is also required. In reviewing applications for location exceptions, the commission may consider operational, geological, geophysical and engineering data submitted by the applicant for the location exception.

\section{Application for Well Spacing, Basic Proration Orders}

(K.A.R. 82-3-109)

This regulation provides a process where interested parties may file an application for or an application for amendments to, a well spacing or basic proration order. The regulation specifies the content of the application, evidence to be provided in support of the application and notice of hearing. It establishes a drilling prohibition or restriction in the area specified in the application once notice of a hearing on the application has been provided by the applicant. In general, evidence to be presented at the hearing may include geologic, geophysical, reservoir data, engineering analysis and other such information the commission may require.

\section{Penalties For Violations of Well Spacing, Basic Proration Orders}

$$
\text { (K.A.R. 82-3-110) }
$$

This regulation provides for penalties in the form of reduced allowables or permanent plugging of oil or gas wells found to be drilled in violation of existing spacing or proration orders.

\section{Seismic}

As noted in discussions of the well location exception process and special well spacing applications geophysical data (seismic) can be presented in support of the application for either location exceptions or spacing orders. Geophysical data (seismic) can also be presented in support of unitization applications, which are heard before the commission as specified under Kansas Statues Annotated (K.S.A.) 55-1301 through 55-1315.

\section{Horizontal Drilling}

Requirements for deviated or horizontal drilling operations are found in the KCC Conservation Division's general rules and regulations under K.A.R. 82-3-103a. 


\section{Deviated Holes, Horizontal Drilling, Notice and Hearing Required}

(K.A.R. 82-3-103a)

This regulation requires that a written notice of intent to drill be filed with the KCC Conservation Division and approved before drilling commences on any hole where the intended deviation from the surface to the top of the producing formation exceeds 7 degrees. In addition, operators of any such intentionally deviated or horizontally drilled well must file an application and provide notice to operators, lessees or unleased mineral rights owners within a $1 / 2$ mile radius of the proposed well. A publication of notice is also required. If no protests are filed, the application is approved administratively with no hearing requirement. The standard set back from any lease or unit boundary must be maintained during the drilling of deviated or horizontal wells as measured from when the well intersects the top of the producing formation. In addition, all points along the horizontal axis in the producing horizon of the well must also maintain the standard set back from the lease or unit boundary. The KCC Conservation Division requires that operators of horizontal wells submit subsurface location surveys to verify bottom hole locations.

\section{KENTUCKY}

1. Spacing requirements: Yes.

(a) Density: 2.88 acres for shallow oil wells in non-coal area; 7.85 acres for shallow oil wells in coal Area: 18.03 acres for shallow gas well spacing.

(b) Deep Wells: As established by Kentucky Oil and Gas Conservation Commission (KOGCC) or in lieu of approved spacing as follows:

(1) 70 acres for oil wells between 4,000-7,000 feet

(2) 281 acres for gas wells between 4,000-7,000 feet

(3) 143 acres for oil wells deeper than 7,000 feet

(4) 574 acres for gas wells deeper than 7,000 feet

(c) Lineal: Oil well (non-coal area and less than 2,000 feet) -400 feet between wells and 200 feet from mineral boundary.

(1) Oil well (coal areas and wells in non-coal area between 2,000 feet and 4,000 feet) 660 feet between wells and 330 feet from mineral boundary in coal producing areas and non-coal areas greater than 2,000 feet.

(2) Gas well - 1,000 feet between wells and 500 feet from mineral boundary for gas wells less than 4,000 feet deep. Varies with depth and geographic area.

2. Exceptions: Yes.

a) Basis: For tracts that are so situated that they have no drillable site.

b) Approval: By notice and hearing.

\section{Summary (Rick Bender)}

The Kentucky oil and gas conservation statute addressing well spacing for shallow wells is 353.610 of the Kentucky Revised Statutes (1960). The statute does not expressly require spacing units, but instead establishes minimum setback requirements from lease boundaries and distance between wells. Minimum distances for wells drilled in the designated coal areas are 
330 feet from the lease line. In the non-coal areas, the minimum distance for a well drilled less than 2,000 feet is 200 feet from the lease line. Below 2,000 feet to a depth of 4,000 feet, the distance is 330 feet as in the coal areas.

A well to be drilled below 4,000 feet or below the Devonian Black Shale in eastern Kentucky is defined as a deep well. The Kentucky oil and gas conservation statute addressing well spacing for deep wells is 353.651 of the Kentucky Revised Statutes (1974). Under this statute, a unit size is established after notice and hearing.

\section{Exception Locations}

Under 353.620 and 353.630 of the Kentucky Revised Statutes, the oil and gas commission may grant exceptions to the setback requirement, allowing wells to be drilled closer to the lease boundaries. KRS 353.620 allows for a variance from the required distance, however, when granted, a like variance is granted to all premises offset and adversely affected by the well. KRS 353.630 allows for compulsory pooling when conditions are met as defined by the statute. Both statutes for exception locations require notice and hearing.

\section{Seismic}

Seismic evidence is not specifically addressed in the Kentucky Revised Statutes. Seismic evidence has been introduced in hearings and is generally accepted as support of petitions for establishing unit size or exception locations.

\section{Horizontal Drilling}

An operator may permit a horizontal well, like any other well. The setback requirements along the horizontal leg in the producing formation for a shallow well are the same as discussed above. The spacing for a horizontal well unit in a deep well can be established by hearing and notice. In either case, shallow or deep, Kentucky statutes allow for unitization of a field or a portion thereof.

\section{LOUISIANA}

1. Spacing requirements:

(a) Density: No minimum acreage requirements for oil or gas wells.

(b) Lineal: Statewide Order No. 29-E - applies and states that wells drilled in search of gas shall not be located closer than 330 feet to any property line nor closer than 2,000 feet to any other well completed in, drilling to or for which a permit shall have been granted to drill to the same pool.

Where Statewide Order No. 29-E is applicable, no spacing shall be required for oil wells drilled in search of oil to depths less than 3,000 feet subsea. Wells drilled in search of oil to depths below 3,000 feet subsea shall not be located closer than 330 feet from any property line nor closer than 900 feet from any other well completed in, drilling to or for which a permit shall have been granted to drill to the same pool.

Statewide Order No. 29-H applicable to new pools has been terminated by State- 
wide Order No. 29-H1. Spacing previously developed under Statewide Order No. 29-H will be regulated by Statewide Order No. 29-E. Any special order that adopted the spacing requirements of Statewide Order No. 29-H has been amended requiring the spacing provisions of Statewide Order 29-E.

2. Exceptions: Yes.

(a) Basis: Refer to Statewide Order No. 29-E.

(b) Approval: By letter setting forth all pertinent facts and reasons why granting the exception is necessary.

\section{Summary (Robert T. Jorden/James Welsh/Mike Killeen)}

Under the Louisiana Conservation Act (La. R.S. 30:1, et seq.) and the regulations thereunder, the spacing of wells and the creation of units are treated separately. This is because wells in Louisiana may be drilled and produced on a lease basis - unit creation is not necessary. In Louisiana, well spacing [the distance from property or unit lines and from other wells in the same pool (reservoir)] is regulated under Statewide Order No. 29-E until special field rules are adopted for the pool. Statewide Order No. 29-E requires, with certain exceptions, that oil and gas wells be no nearer than 330 feet from property and unit lines, and no nearer than 900 feet between oil wells and 2,000 feet between gas wells in the same pool. Most often, special field rules for a pool adopt these same rules. Exceptions to these location distances may be obtained at public hearing but are rarely granted except for substitute unit wells.

\section{Drilling Units}

In the Louisiana Conservation Act, the term, drilling units, is used to designate undrilled units. These units are ones that are being drilled and are producing. It also means any forcepooled unit created by the commissioner of conservation other than a reservoir-wide unit or a deep well unit mentioned below.

In Louisiana, drilling units are created after a public hearing based on legal notice by the commissioner of conservation before, during or after a well is drilled. All separately owned tracts, mineral leases and other property interests in the drilling units are force-pooled and unitized by the special field rule order, which creates them. There is no limit on the size of drilling units created by the commissioner of conservation. The Conservation Act defines a drilling unit as "the maximum area which may be efficiently and economically drained by one well." Recently, a different type of unit called a deep pool unit has been authorized by $\S 5.1$ of the Conservation Act (Act 1094 of 1999), which permits the creation of multiple well units for wells completed below 15,000 feet. The commissioner of conservation, by memorandum dated April 26, 2000, issued a Deep Pool Unit Policy to complement this act. To date, a deep well unit has not been created. It should be noted that drilling units and deep well units do not require that the applicant own or control any particular interest in the mineral rights in the proposed units.

The size of a drilling unit in Louisiana may be as small as one or two acres and as large as 2,000 acres or more. There is no rule as to the shape of such drilling units. In south Louisiana, if there is sufficient well control, drilling units will usually be based on the geological limits of the pool. This is the reason for vast differences in both shape and size of units. In north Louisi- 
ana, drilling units are most often geographical in shape following governmental sections and divisions. The variation between the size and shape of drilling units in north and south Louisiana is not provided for or even mentioned in the Conservation Act or in regulations, which are issued thereunder but probably result from the difference in geological evidence in the two areas.

It is not necessary that a drilling unit is established before or even after a well is drilled wells may be drilled and produced on a lease basis. However, drilling units are established for most productive wells drilled in Louisiana. The most common exceptions involve wells on large tracts with common ownership or wells drilled on voluntary units. Statewide Order No. 29-E provides that a drilling unit or units should be established after four (4) wells have been completed in a pool or one (1) year after the first well is completed in the pool. However, this requirement has not been enforced.

\section{Seismic}

The commissioner of conservation has never considered or used seismic evidence in the creation of drilling units. By memorandum dated April 26, 2000, the commissioner adopted a Seismic Policy, which authorizes the limited use of seismic evidence in unit hearings and sets forth the procedure to be followed, if seismic evidence is to be used. This memorandum has not been used.

\section{Horizontal Drilling}

A horizontal well may be drilled as a lease well or on any drilling unit if the well spacing rules mentioned above are followed. However, in recent years there has been extensive development by horizontal wells of the Austin Chalk, the James Lime and the Saratoga Formation in Louisiana. Different well spacing rules have been obtained for the development of pools in these formations. Well spacing for horizontal wells in the Austin Chalk, the James Lime and the Saratoga Formation, in most pools, permit the wells to be no nearer than 50 feet to the unit lines for the penetration point and terminus of the horizontal leg and no nearer than 1,500 feet to the other unit lines. The drilling units for horizontal wells in these pools range in size from 640 to 2,000 acres or more, depending on the length of the proposed lateral.

Title 43 of the Louisiana Administrative Code, Part XIX, Subpart 7, Chapter 19 (Statewide Order No. 29-E) establishes the spacing requirements for wells drilled in Louisiana. The general requirements are that an oil well should be located more than 330 feet from any property line and 900 feet from any other oil well completed in the same reservoir (pool). Gas wells should be located more than 330 feet from any property line and 2,000 feet from any other gas well completed in the same reservoir (pool).

When a well is permitted to a non-unitized sand as a lease well and does not comply with the spacing provisions of Statewide Order 29-E, a conditional drilling permit is issued that requires the formation of a suitable unit before an allowable will be assigned. When a sand or zone is unitized, there are generally well spacing provisions included in the commissioner's order. If the order does not specifically address spacing requirements, 29-E spacing is assumed.

\section{Exception Locations}

The commissioner of conservation may grant requests for spacing exceptions, as 
provided for in Statewide Order 29-E. Other requests for exceptions to the spacing provisions of Statewide Order 29-E or spacing provisions in field orders, are considered after a ten (10)-day legal notice and a public hearing. Such exceptions are generally granted when a well located in accordance with applicable spacing rules would not be at the optimum position for efficient and economic drainage of the unit or due to topographic conditions.

\section{MARYLAND}

1. Spacing requirements: Yes.

(a) Density: No proration units formed in Maryland for oil - only voluntary units for gas.

(b) Lineal: 2,000 feet from existing gas well, 1,320 feet from existing oil well, 1,000 feet from property line, 1,000 feet from any occupied house, school, church, public building or place of public meeting for both oil and gas wells, 26.19.01.09 (C, D, E, F \& G) and 26.19.08.06, Code of Maryland Regulations (CMR) and § 14-112(a)(b)(c), PLM. Drilling prohibited in the Chesapeake Bay or its tributaries 26.19.01.09(A).

2. Exceptions: Yes. 26.19.01.09 (C, D, E, F and G), CMR.

(a) Basis: No permit will be issued to drill a well within 1,000 feet of the boundary of a tract of land or the boundary of tracts of land included in a pooling agreement or within 1,000 feet from any occupied dwelling house, school, church, public building or place of public meeting unless the permit holder has made a satisfactory written agreement with the oil and gas owner and lessee of such adjacent land or building. The department may issue a permit to drill a well within 1,000 feet of a boundary of a tract of land, if it is impossible to locate a well 1,000 feet or more from the boundaries of the tract.

(b) Approval: Following notice and hearing by the department.

\section{Summary (Edmon Larrimore)}

The Maryland law at Sect 14-112 provides only for a 1,000-foot setback from the property or unleased lands. By regulation, Maryland requires 2,000 feet setback from other producing wells and does not issue a permit within 1,000 feet of an occupied dwelling or church without written permission of the owner. Exceptions may be made to the 1,000-foot unleased setback based upon safety or other topographical concerns.

Directional drilling is permitted but is reviewed on an individual case basis. Ability to drill efficiently must be demonstrated, and the need to protect a structure, road, water body or some feature must be shown. Vertical drilling may not vary more than 3 degrees. Pooling is voluntary, and there is no forced pooling or unitization in Maryland.

\section{MICHIGAN}

1. Spacing requirements: Minimum 40-acre drilling unit conforming to governmental surveyed quarter-quarter section of land. Wells located approximately 1,320 feet apart. R 324.301.

(a) Density: Oil well -40 acres. Gas well -40 acres. R 324.301.

(b) Lineal: Oil well $-1,320$ feet. Gas well $-1,320$ feet. $R 324.301$ (b). 
2. Exceptions: Yes. R 324.301 (2).

(a) Basis: Evidence and testimony.

(b) Approval: By order of supervisor of wells, pursuant to a public hearing pursuant to the voluntary pooling provisions of $R 324.303$.

(c) Pooled on communitized tracts may be developed according to approved alternative spacing and location plans. R 324.303.

\section{Summary (Thomas Wellman)}

Oil and gas well spacing in Michigan is addressed in Rule 301 of Part 615, by the supervisor of wells of the Natural Resources and Environmental Protection Act, 1994 PA 451 (NREPA), as amended. Unless otherwise designated by a special spacing order, Rule 301 provides a general rule for spacing oil and gas wells using 40-acre drilling units, more or less, formed from a governmental quarter-quarter section.

The minimum setback distance of the bottom hole location from the drilling unit boundary is 330 feet. If the bottom hole location of a discovery well is between 330 and 495 feet from the nearest drilling unit boundaries (e.g. in the corner of the unit) it establishes a pattern for subsequent development. Development wells must be located in the same relative location in their drilling units. If a discovery well is in the center of a drilling unit, subsequent development requires a hearing, before the supervisor of wells, to establish a spacing pattern for the field.

\section{Spacing}

Numerous regional and field-wide spacing orders apply to specific formations and areas of the state. Modern spacing orders prescribe drilling units ranging in size from 40 acres for shallower Devonian oil fields, to 80 acres for Silurian oil and gas fields and 640 acres for Ordovician gas fields. Devonian shale gas wells may also be spaced in large tracts called Uniform Spacing Plans to allow for optimum well location and encourage greater well location flexibility with respect to environmental features.

\section{Spacing Exceptions}

Rule 303 provides a mechanism for applicants to obtain an administrative (without a hearing) exception to spacing if they have pooled tracts to form multiples of full drilling units. Rule 303 (2) allows more than one well to be drilled within the proposed drilling unit according to a plan of development, if it satisfies the following criteria:

Persons who pool or communitize the tracts or interests may submit an application to the supervisor to abrogate spacing within the pooled or communitized area. The application shall include a certified copy of the pooling or communitization agreement and the plans for exploration or development. The supervisor may approve the application, if all of the following conditions are satisfied:

(1) Waste is prevented.

(2) The drilling of unnecessary wells is prevented.

(3) A well is not located closer than 330 feet from the pooled or communitized area 
boundary or closer than 660 feet from adjacent wells.

(4) The distance between wells prevents interference.

Rule 303 (3) allows one well to be drilled within the proposed drilling unit, if it satisfies the following criteria:

The lessees and lessors of separate tracts or mineral interests that lie partially or wholly within an area encompassing 2 or more full drilling units may voluntarily pool the tracts or interests to form a development unit for the purpose of receiving a permit for a well as an exception to R 324.301 or special spacing orders adopted pursuant to $\mathrm{R} 324.302$, if the bottom hole location of the well is found by the supervisor to ensure each producer is afforded the opportunity to use his or her just and equitable share of the reservoir energy and to prevent waste, including the drilling of unnecessary wells.

\section{Seismic}

Seismic evidence is accepted and frequently submitted at hearings in support of petitions for exception locations. Likewise, seismic evidence may be used in support of applications for administrative exceptions under Rule 303.

\section{Horizontal Drilling}

An operator may permit a horizontal well, like any other well. If the length of a horizontal well is limited by the size or setback requirements of the drilling unit, the operator frequently requests a spacing exception under R303 (above). In other cases, the operator may petition the supervisor of wells for an exception to established spacing.

\section{Flexibility}

The rules promulgated under Part 615, of the NREPA were substantially revised in 1996. The adoption of Rule 303 and the ability to form Uniform Spacing Plans for Devonian shale gas wells provide a great deal of flexibility to operators to use new technologies by decreasing the regulatory barriers needed to receive spacing exceptions. Equity is preserved in these exception units by requiring all tracts to be pooled. For more information go to the Department of Environmental Quality's Geological Survey Division web site at www.deq.state.mi.us/gsd/.

Pooling is used to describe the bringing together of mineral interests and may be known in other states as unitization or communitization. This is not the same use of the term unitization in Part 617 of NREPA to describe the combination of interests for the efficient operation of a well or field or for secondary recovery.

\section{MISSISSIPPI}

1. Spacing requirements: Yes. Statewide Rules 7 and 8.

(a) Density: Oil well - 40 acres above 12,000 feet and 80 or 160 acres below 12,000 feet. Gas well -320 acres above 12,000 feet and 640 acres below 12,000 feet.

(b) Lineal: Oil well - Statewide Rule 7. Gas well - Statewide Rule 8, unless special field rules authorize exception. 
2. Exceptions: Yes.

(a) Basis: Either by adoption of Special Field Rules, which take precedence over Statewide Rules or by requests for exception to either.

(b) Approval: By notice and hearing before the State Oil and Gas Board.

\section{Summary (John Land McDavid)}

The Mississippi State Oil and Gas Board is established under Mississippi Code Ann. § 53-1-1 to 53-1-47 (1972). Development, production and distribution of oil and gas are provided for in Mississippi Code Ann. § 53-3-1 to 53-3-51 (1972). The size of drilling units is not regulated by statute. $\S 53-1-17(\mathrm{k})$ states the board shall have authority to regulate the spacing of wells and to establish drilling units. §53-3-5 (a), (b) and (c) generally provide for the establishing of rules and regulations for drilling units and for exceptions to the established rules and regulations. Spacing of units and location of wells are covered by statewide rules adopted by the board. Exceptions to statewide rules are granted by the board upon petition and after notice and hearing.

\section{Spacing Units}

The factors, which dictate the size of spacing units in Mississippi, are:

1. Whether the well is an oil or gas well;

2. Whether the well will be drilled to a depth above or below 12, 000 feet; and

3. Whether the well is drilled in Mississippi's Black Warrior Basin or in the remainder of the state.

There is no requirement that units are comprised of governmental quarter-quarter sections or other governmental units based on the United States governmental survey. Drilling units comprised of governmental units have an advantage, in certain circumstances, for acreage tolerance. Unreasonable or extreme unit configurations are controlled by a specified rectangle within which the unit must fit. Statewide rules also deal with the distance of the well from exterior boundaries and from other wells in the same pool. Statewide rules require that the formation of a unit shall not create island acreage.

Statewide Rule 7, which covers the spacing of oil wells, provides:

1. With respect to each pool occurring in the discovery well, the top of which is encountered below a measured depth of 12,000 feet below the surface, and in the Pennsylvanian and older formations with respect to each pool occurring in the discovery well, the top of which is encountered below a measured depth of 3,500 feet below the surface, every oil well: shall be located on a drilling unit consisting of eighty (80) contiguous surface acres or two (2) contiguous governmental quarter-quarter sections containing not less than seventy-two (72) acres or more than eighty-eight (88) acres, upon which no other drilling or producible well is located. The word contiguous as used herein shall mean bordering each other at more than one point.

(a) Any drilling unit not composed of two (2) governmental quarter-quarter sections must be completely encompassed by the perimeter of a rectangle 1,600 feet by 2,725 feet. 
Provided, however, no unit shall be permitted, which will create island acreage;

(b) The well shall be located at least 1,000 feet from every other drilling well or well completed in or producing from the same pool located in conformity with this rule; and

(c) The well shall be located at least 500 feet from every exterior boundary of the drilling unit.

2. However, with respect to each pool occurring in the discovery well, the top of which is encountered below a measured depth of 12,000 feet below the surface, the state oil and gas supervisor may permit 160-acre units for such pools if such unit size will promote and encourage the orderly development of the pool. Every oil well drilled in such pool:

(a) Shall be located on a drilling unit of four (4) contiguous quarter-quarter sections containing not less than 144 nor more than 176 acres, upon which no other well drilling to or producing from same pool is located.

(b) Any drilling unit not composed of four (4) contiguous quarter-quarter sections shall contain 160 surface acres, which must be completely encompassed by the perimeter of a rectangle 2,640 by 3,500 feet provided. However, no unit shall be permitted which will create island acreage.

(c) Each well shall be located at least 1,500 feet from every drilling or producible well from the same pool and not less than 750 feet from every exterior boundary of the drilling unit.

3. With respect to all other pools, every oil well:

(a) Shall be located on a drilling unit consisting of forty (40) contiguous surface acres, or a governmental quarter-quarter section containing not less than thirty-six (36) acres or more than forty-four (44) acres, upon which no other drilling or producible well is located. The word contiguous as used herein shall mean bordering each other at more than one point.

(b) Any drilling unit not a governmental quarter-quarter section must be completely encompassed by the perimeter of a rectangle 1,810 by 1,445 feet. Provided, however, no unit shall be permitted, which will create island acreage?

(c) The well shall be located at least 660 feet from every other drilling well or well completed in or producing from the same pool located in conformity with this rule; and

(d) The well shall be located at least 330 feet from every exterior boundary of the unit.

4. No portion of the drilling unit upon which a well is located shall be attributed, in whole or in part, to any other drilling or producible well in the same pool.

5. If any well drilled in conformity with the provisions of this rule or as an exception thereto, is completed as a gas well, it shall not be produced except for a test period of not exceeding forty-five (45) days or in compliance with applicable special field rules or until authorization has been granted by the board after notice and hearing.

Statewide Rule 8, which covers the spacing of gas wells reads:

1. With respect to each pool occurring in the discovery well, the top of which is encountered below a measured depth of 12,000 feet below the surface, and in the Pennsylvanian and older formations with respect to each pool occurring in the discovery well, the top of which is 
encountered below a measured depth of 3,500 feet below the surface, every gas well:

(a) Shall be located on a drilling unit consisting of

(1) 640 contiguous surface acres; or

(2) A governmental section containing not less than 600 acres or more than 680 acres; or

(3) Sixteen (16) contiguous governmental quarter-quarter sections whose total acreage is not less than 600 acres or more than 680 acres.

In any case, no other well producing from the same pool shall be located on any such unit. The word contiguous as used herein shall mean bordering each other at more than one point.

(b) Any gas-drilling unit formed under section 1(a) of this rule must be completely encompassed by the perimeter of a rectangle 5,580 by 6,245 feet. Provided, however, no unit shall be permitted which will create island acreage.

(c) The well shall be located at least 3,000 feet from every other drilling well or well completed in or producing from the same pool located in conformity with this rule; and

(d) The well shall be located not less than 1,500 feet from every exterior boundary of the drilling unit.

2. With respect to each pool occurring in the Oligocene and younger formations, the top of which is encountered in the discovery well above a measured depth of 5,000 feet below the surface, the State Oil and Gas Supervisor may permit one hundred sixty (160)-acre units for such pools if such unit size will promote and encourage the orderly development of the pool. Every gas well drilled in such pool:

(a) Shall be on a drilling unit consisting of

(1) One hundred sixty (160) contiguous surface acres or

(2) A governmental quarter section containing not less than one hundred forty-four (144) acres or more than one hundred seventy-six (176) acres. In any case, no other well producing from the same pool shall be located on any such unit. The word contiguous as used herein shall mean bordering each other at more than one point.

(b) Any gas-drilling unit formed under $\S 2$ (a) of this Rule must be completely encompassed by the perimeter of a rectangle 2,640 by 3,500 feet. Provided, however, no unit shall be permitted which will create island acreage;

(c) The well shall be located at least fifteen hundred $(1,500)$ feet from every other drilling well or well completed in or producing from the same pool located in conformity with this Rule; and

(d) The well shall be located not less than seven hundred fifty (750) feet from every exterior boundary of the drilling unit.

3. With respect to all other pools, every gas well:

(a) Shall be located on a drilling unit consisting of

(1) 320 contiguous surface acres; or

(2) A governmental half-section containing not less than 300 acres or more than 340 acres; or

(3) Eight (8) contiguous governmental quarter-quarter sections whose total acreage is not less than 300 or more than 340 acres. 
In any case, no other well producing from the same pool shall be located on any such unit. The word contiguous as used herein shall mean bordering each other at more than one point.

(b) Any gas-drilling unit formed under section 2(a) of this rule must be completely encompassed by the perimeter of a rectangle 3,735 by 5,380 feet. Provided, however, no unit shall be permitted which will create island acreage.

(c) The well shall be located at least 1,980 feet from every other drilling well or well completed in or producing from the same pool located in conformity with this rule; and

(d) The well shall be located not less than 990 feet from every exterior boundary of the drilling unit.

4. No portion of the drilling unit upon which a well is located shall be attributed, in whole or in part, to any other well drilling in or producing from the same pool.

5. If any well is completed as a gas well in the gas cap of a pool productive of oil or if any well drilled as a gas well is productive from or completed in an oil pool, it shall not be produced except for a test period not exceeding forty-five (45) days or in compliance with applicable special field rules or until authorization has been granted by the board after notice and hearing.

An Application to Drill (Form No. 2) and establish a drilling unit, which is not an exception to Statewide Rule 7 or 8 or any other statewide rule, is approved administratively (without notice and hearing).

\section{Exceptions}

Statewide Rule 9 provides for exceptions to the spacing rules. Exceptions to any of the statewide rules may be granted for good cause shown upon petition and after notice and hearing.

\section{Seismic}

Seismic evidence is seldom submitted in connection with the formation of units or in obtaining exceptions to statewide spacing rules, however, the introduction of such evidence is not prohibited.

\section{Horizontal Drilling}

There are no specific or express rules for horizontal drilling. Horizontal wells may be drilled on regular spacing units. Rule 14 has to do with deviated holes and requires permission after notice and hearing to intentionally deviate a well except Rule 14 provides that where a unit complies with statewide rules in all respects an administrative permit may be granted for the drilling of a directional well. Exceptions to the spacing rules and other statewide rules are granted for the drilling of horizontal wells upon good cause shown and upon notice and hearing.

\section{MISSOURI}

1. Spacing requirements: Yes. 
(a) Density: (10 CSR 50-2-070)

(1) Oil -40 acres can be exempted if less than 1,200 feet deep to producing formation.

(2) Gas - 640 acres can be exempted if less than 1,500 feet deep to producing formation.

(b) Lineal - 165 feet from lease boundary or property line for an oil well. 234 feet for a gas well.

10 SR 50-2.070. Non-commercial gas well 165 feet from lease line.

2. Exceptions: Yes. 10 CSR 50-2.070.

(a) Basis: To protect against offset drainage from wells drilled before enactment of Chapter 259 RSMO and special project development.

(b) Approval: Upon application to the state geologist, who is the administrator. 10 CSR 502.070.

\section{Summary (Sheri Stoner)}

Missouri's well spacing rules and regulations are administered through 10 CSR 0-2.070.

\section{Oil Wells}

Such wells shall not be located closer than approximately five hundred (500) feet to any boundary line of such a governmental quarter-quarter section, governmental lot corresponding thereto or arbitrarily designated forty (40)-acre tract. They are to be no closer than approximately one thousand $(1,000)$ feet to the nearest well drilling or capable of producing from the same pool on the same lease or unit. If such a governmental quarter-quarter section, governmental lot or arbitrarily designated tract contain less than thirty six (36) acres, no well shall be drilled, except by special order of the council.

Wells whose oil producing formation may be reasonably expected to be less than one thousand two hundred $(1,200)$ feet in depth may be excepted from the forty $(40)$-acre spacing requirement at the discretion of the council. Any well so excepted shall not be drilled closer than approximately one hundred sixty five (165) feet to lease, boundary or property line.

\section{Gas Wells}

1. Not more than one (1) well shall be drilled for gas upon any tract of land other than a governmental section or, in areas not covered by US Public Land Surveys, an arbitrarily designated six hundred forty-acre (640) tract. Such wells shall not be located closer than the approximately two thousand two hundred $(2,200)$ feet to any boundary line of such a governmental section or arbitrarily designated six hundred forty-acre (640) tract, nor closer than approximately four thousand five hundred $(4,500)$ feet to the nearest well drilling to or capable of producing from the same pool on the same lease or unit. Should such a governmental section or arbitrarily designated tract contain less than six hundred (600) acres, no well shall be drilled thereon except by special order of the council.

2. Wells whose gas-producing formations may be reasonably expected to be less than one 
thousand five hundred $(1,500)$ feet in depth may be excepted for the six hundred forty $(640)$ acre spacing requirement at the discretion of the council. No well shall be drilled closer than approximately two hundred thirty four (234) feet from lease, boundary or property line.

\section{Project Development}

Spacing requirements may be waived at the discretion of the council, for all wells required in research or development projects leading to initiation or improvement of methods for the economic recovery of oil or gas by primary, secondary or tertiary processes.

\section{Underground Gas Storage}

Wells drilled expressly for operation of underground gas storage projects is exempt from spacing requirements. No such well shall be drilled closer than approximately three hundred thirty (330) feet to a lease line without written authorization of the state geologist.

\section{Seismic or Horizontal Drilling}

Missouri does not have a specific rule on seismic or horizontal drilling.

\section{MONTANA}

1. Spacing requirements: Yes. Rule 36.22.702.

(a) Density: 40 acres for oil wells less than 6,000 feet deep; 160 acres for wells from 6,001 to 11,000 feet; 320 acres for wells deeper than 11,000 feet. For a gas well, 640 acres.

(b) Lineal: 330 feet from legal subdivision line for wells less than 6,000 feet; 660 feet from quarter section lines for wells 6,001 to 11,000 feet; 660 feet from drilling unit boundaries for wells below 11,000 feet. For gas wells, 990 feet from governmental section lines.

2. Exceptions: Yes. Rule 36.22.702(1).

(a) Basis: For wildcat wells less than 6,000 feet, wells may be moved a maximum of 75 feet closer to quarter-quarter section line, and wells between 6,000 to 11,000 feet may be moved a maximum for 150 feet closer to quarter section lines in extremely rough terrain where it is impractical to move in any other direction but only after inspection by the board representative and subsequent approval by the petroleum engineer or his authorized agent. No tolerance for wells below 11,000 feet or for gas wells.

(b) The board may also grant exceptions to protect correlative rights or to prevent waste. $\S$ 82-11-124, MCA.

(c) Approval: Administrative approval for tolerances described in section (a). Exceptions beyond those tolerances in (a) require notice and hearing.

No narrative response 


\section{NEBRASKA}

1. Spacing requirements: Yes, unless excepted by public hearing. Rule 3.013.

(a) Density: 40 acres for oil or gas well.

(b) Lineal: No closer than 500 feet to 40 -acre legal subdivision line for oil or gas.

2. Exceptions: Yes.

(a) Basis: Topographical, irregular sections or geological considerations.

(b) Approval: Administrative if all owners within 500 feet of proposed well approve or by public hearing. Production may be limited to protect correlative rights.

\section{Summary (William Sydow)}

\section{General}

The general spacing for oil and gas wells is 40 acres. Wells with total depths shallower than 2,500 feet may be drilled within 300 feet of the boundaries of the 40 -acre subdivision. Wells with targets greater than 2,500 feet in depth cannot be located less than 500 feet from the tract boundary. An operator, of course, may apply for field rules, which could allow for larger or smaller spacing units, depending upon the geology and subsequent drainage areas.

\section{Exception Locations}

An exception location is defined as a well that is off-pattern or closer to the tract boundaries than the rules state. The applicable rules are either the general rules or special field rules. Wells located within the boundaries of secondary/tertiary recovery units are exempt from this rule.

The commission will allow exception locations to be drilled as wildcats or development wells. If the working and royalty interest owners of the offsetting acreage are agreeable, the commission staff has authority to approve off-pattern wells after an affidavit has been supplied, so stating, by the operator. The affidavit must state the facts of the necessity for drilling the well in an off-pattern location and that offsetting owners are agreeable. Offset owners always have recourse to ask for proration of production.

If an emergency exists and an affidavit cannot be sworn, an examiner may conduct a hearing and the well authorized and drilled. If the well is successful, a hearing before the commission will be held to determine any applicable production penalty.

\section{Non-Governmental Spacing Units}

Nebraska's rules for individual wells, not in a secondary/tertiary recovery unit, discuss legal subdivisions. Spacing units encompassing portions of two governmental spacing units have never been formed in Nebraska. While rare or non-existent, the commission has the power to form such a unit after a public hearing with the operator supplying sufficient cause and evidence. 


\section{Seismic}

Seismic lines have been submitted, as evidence in several hearings but it is generally never used as an exhibit. Only one three-dimensional seismic survey has ever been acquired in Nebraska. The location that was drilled was an exception location and was approved without hearing. While seismic data may be used as an exploration tool, the commission would ultimately require wells to be drilled to delineate the limits of any field for the purposes of unitization.

\section{Horizontal Drilling}

While there are no specific rules for horizontal wells, there is a rule for directional drilling that has proven to be satisfactory and allows for broad application. The minimum distances from the section lines for standoff at the initial penetration point of the reservoir and at the terminus of the hole are used.

Only six horizontal wells have ever been drilled in Nebraska. The first four were drilled interior to large acreage blocks with common ownership. These did not require pooling of various interests. Two of the six were pooled and spaced on 640-acre units. These two particular wells required public hearings and the subsequent orders before approving the drilling permits. They were both uneconomic.

With the current activity level, there is not a need for horizontal rules. Future wells can be adequately handled under the existing law and rule. The only reason to modify the current rule would be to expedite the approval of drilling permits.

\section{NEVADA}

1. Spacing requirements: Yes.

(a) Density:

(1) Oil well - 5,000 feet or less: 40 acres - not less than 330 feet from boundary of quarter-quarter section.

(2) Oil wells - more than 5,000 feet: 160 acres - not less than 330 feet from boundary of quarter section.

(3) Gas well -5,000 feet or less: 160 acres - not less than 660 feet from boundary of quarter section.

(4) Gas well - more than 5,000 feet: 640 acres - not less than 990 feet from boundary of section.

(b) Lineal: No provision. Determined after hearing.

The spacing requirements do not apply to federal units, working interest ' agreements and areas subject to existing orders.

2. Exceptions: Yes.

(a) Basis: Protection of correlative rights of lessees, location may be nonproductive or topographical conditions.

(b) Approval: By hearing after proper notice and order issued by the division. 


\section{Summary (John Snow)}

The Nevada Revised Statute (NRS) addressing well spacing is NRS 522.040, and the Nevada Administrative Code (NAC) regulating well locations is NAC 522.235. In a proven oil and gas field the spacing of wells will be governed by special rules for each particular field, to be adopted by the Commission on Minerals Resources (CMR) after notice and hearing. In the absence of a special order of the division establishing drilling units or authorizing different densities of wells or patterns of location for particular pools or parts of pools, the following requirements apply:

1. Each well drilled for oil with a projected depth of 5,000 feet or less must be located not less than 330 feet from the outside boundary of a government quarter-quarter section or of a lot, tract or combination of lots or tracts substantially equivalent to a quarter-quarter section as shown by the most recent government survey. Unless the administrator, in his discretion, determines otherwise, only one well may be issued a permit to produce oil from the same reservoir within the same quarter-quarter section.

2. Each well drilled for oil with a projected depth of greater than 5,000 feet must be located not less than 330 feet from the outside boundary of a government quarter section or of a lot, tract or combination of lots or tracts substantially equivalent to a quarter section as shown by the most recent government survey. Unless the administrator, in his discretion, determines otherwise, only one well may be issued a permit to produce oil from the same reservoir within the same quarter section.

3. Each well drilled for gas with a projected depth of 5,000 feet or less must be located not less than 660 feet from the outside boundary of a government quarter section or of a lot, tract or combination of lots or tracts substantially equivalent to a quarter section as shown by the most recent government survey. Unless the administrator, in his discretion, determines otherwise, only one well may be issued a permit to produce gas from the same reservoir within the same quarter section.

4. Each well drilled for gas with a projected depth of greater than 5,000 feet must be located not less than 990 feet from the outside boundary of a government section or of a lot, tract or combination of lots or tracts substantially equivalent to a section as shown by the most recent government survey. Unless the administrator, in his discretion, determines otherwise, only one well may be issued a permit to produce gas from the same reservoir within the same section.

5. The requirements of this section for the location of a well do not apply to:

(a) Federal units.

(b) Wells drilled following a working interest agreement.

(c) Areas subject to existing orders for drilling spacing.

6. The administrator will determine the pattern for the location of wells that are adjacent to an area in which the spacing of wells is prescribed by the division or under application for spacing. There should be sufficient evidence to indicate that the pool or reservoir for which the spacing of wells is or will be prescribed by the division may extend beyond the boundary of the spacing order or application. The uniformity of the pattern of spacing is necessary to ensure an orderly development of the pool. 
7. As used in this section, the term "working interest agreement" means a written agreement entered into by the persons who are responsible for paying the cost of drilling one or more wells and that specifies the location of the well or wells.

\section{Exception Locations of Wells and Well Spacing Orders}

1. Upon proper application, the administrator may approve an exception to NAC 522.235 or to any order of the division establishing the spacing of wells for a pool.

2. An application for an exception must state fully the reasons the exception is necessary or desirable and must be accompanied by a plat showing:

(a) The locations at which an oil or gas well could be drilled in compliance with NAC 522.235 or the applicable order;

(b) The location at which the applicant requests permission to drill; and

(c) The locations at which oil or gas wells have been or could be drilled in accordance with NAC 522.235 or the applicable order:

(1) In a quarter section, for any oil well, regardless of depth or any gas well of 5,000 feet or less; or

(2) In a section, for any gas well greater than 5,000 feet, directly or diagonally adjoining the quarter section or section for which the proposed exception is sought.

3. An exception approved by the administrator does not affect the rights of owners of directly or diagonally adjoining tracts to drill for oil or gas.

\section{Seismic}

Seismic evidence as well as all geologic and reservoir engineering data is considered when evaluating requests for exception locations.

\section{Horizontal Drilling}

Nevada's current spacing regulations do not have a specific provision that addresses horizontal spacing units. Nevada is a frontier exploration state and currently does not have any producing horizontal wells. Exploration units are commonly formed to protect correlative rights, eliminating the need for specific horizontal rules at this time. When the need arises to establish specific horizontal spacing rules to protect correlative rights, the Commission on Minerals will move quickly to adopt rules similar to other states.

\section{NEW MEXICO}

1. Spacing requirements: Yes. Rule 104 or special pool rules. Unless otherwise specified by special pool rules.

(a) Density: 40 acres for an oil well. SE gas: 160 acres to Top Wolfcamp and 320 acres Wolfcamp and older. NW gas: 160 acres to base of the Cretaceous period and 640 
acres for Pennsylvanian. All other areas 160-acre gas.

(b) Lineal: Oil: 330 feet from spacing unit boundary. Gas: 660 feet from spacing unit boundary 10 feet from any quarter/quarter line.

2. Exceptions: Yes.

(a) Basis: When necessary to prevent waste or protect correlative rights. Rule 104F. Waterfloods and pressure maintenance. Rule 701.

(b) Approval: District offices for waterfloods and pressure maintenance. Administrative for other reasons. Any application may be set for hearing.

\section{Summary (Michael Stogner)}

$\S 70-2-11$, NMSA 1978, of the Oil and Gas Act (Act) empowers the New Mexico Oil Conservation Division (division) to prevent waste and to protect correlative rights. $\S 70-2-12$ directs the division to make rules, regulations and orders that:

1. Require wells to be drilled, operated and produced in such a manner as to prevent injury to neighboring properties; and

2. Fix the spacing of wells.

New Mexico, like most states in the lower 48, is grid on the US Public Lands Survey. In 1931, the state geologist adopted this same system for the spacing and locations of wells by requiring oil wells to be assigned 40 -acre tracts, comprising a single quarter-quarter section with wells to be no closer than 330 feet distance from its boundary. As gas production became more prolific and spacing was increased, it was done in a systematic manner. That is 160-acre units were to comprise a single quarter section; 320-acre units were formed by combining two quarter sections within a single section, and 640-acre units to comprise a single section. Compulsory pooling provision assist in keeping this well spacing pattern consistent and orderly, otherwise spacing units would have been formed by mineral leases and ownership alone. This can quickly become hard to manage and result in a very haphazard pattern of development within a pool. New Mexico however has two such pools that have evolved in this manner; prorationing based on acreage serves to keep this pool in check and protects correlative rights.

\section{Seismic}

Assuming unit in this instance refers to spacing unit and not unitization, 3-D seismic and other advanced computer-enhanced geological evaluation programs have recently been utilized in hearings to support a request for a change in well spacing. It has also been used to a lesser degree for the establishment of non-standard spacing and proration units. However, the primary use of this technology is utilized to support location exceptions through both the division's administrative and hearing process.

\section{Horizontal Drilling}

In 1997, the division's directional drilling rules (Division Rule 111) were completely changed and streamlined with horizontal/high angle wellbores in mind. Spacing rules are strictly adhered to for any formation or pool where such a lateral wellbore or multilateral are used. 
Project areas are established through the division's normal drilling or recompletion permitting procedure for such wellbores and are based upon the number of standard spacing or proration units that are developed or traversed by the lateral wellbore or wellbores. Most lateral wellbores are limited only by the size of a unitized or leased area. However, a few project areas through cooperative lease agreements and even one through the compulsory pooling of two spacing units have been formed for such horizontal projects.

\section{Spacing Laws}

Infill drilling in certain pools and formations helps assure the continued orderly development where necessary to further develop/deplete reserves. Also helpful is the ability for operators to seek spacing exceptions on a pool-wide basis by establishing rules that meet the geologic and drainage characteristics of that reservoir. Unitization also provides flexibility by allowing an operator to locate wells almost anywhere provided there is no encroachment to the unit area's outer boundary or to a non-ratifying or non-participating mineral interests within the unit.

\section{Examples for Other States}

1. Routine spacing statewide -40 acres for oil and 160 acres for most wildcat gas.

2. Horizontal/High Angle provisions of Division Rule 111.

3. Regular cooperative industry/division committee participation to study certain aspects of New Mexico's rules.

4. Successful infill development in such areas as the Blanco-Mesaverde Pool, Basin-Dakota Pool and Lusk-Morrow Gas Pool and for deep gas reserves in southeast New Mexico.

5. The division's relaxed procedure towards well location exceptions on a lease basis where applicable, e.g. the Raton basin in northeast New Mexico.

\section{NEW YORK}

1. Spacing requirements: Yes.

(a) Density: 40 acres or in the center of a circle of radius 660 feet for an oil or gas well, subject to change under provision of a spacing order.

(b) Lineal: 660 feet from the boundary line of any lease or unit and 1,320 feet from any other producing well completed or being drilled to the same pool. Wells along the New York/ Pennsylvania state border have a reduced minimum setback distance of 330 feet to meet Pennsylvania's requirements. A spacing order promulgated after a hearing supersedes statewide spacing provisions.

2. Exceptions: Yes.

(a) Basis: Reasonable exceptions to protect correlative rights and prevent waste.

(b) Approval: Typically, by proper application and public hearing. Some exceptions may be granted administratively after proper notice and if no objections are filed. For municipal variances the hearing may be waived where no objection filed by a certain date before the scheduled date of the hearing, no facts are disputed and the department does not object. Production from such well may be adjusted. 
(c) Oil fields or pools discovered, developed and operated before January 1, 1981 are exempt from spacing requirements.

\section{Summary (B. J. Field)}

The New York statute, which addresses well spacing, is Title 5 of the Oil, Gas and Solution Mining Law (Article 23 of the Environmental Conservation Law). It provides that the Department of Environmental Conservation will establish spacing units whenever it finds, after notice and hearing, that the spacing of wells in any field is necessary to prevent waste, provide for greater ultimate recovery of oil or gas or to protect correlative rights. The statute requires that spacing units shall be of approximately uniform size and shape for the entire pool and that no unit shall be smaller than the maximum area that can be efficiently and economically drained by one well. The department is authorized by the statute to grant variances to the requirement for uniformly sized and shaped units and set production allowables where circumstances reasonably require.

The statute does not set specific maximum or minimum unit sizes. However, Part 553, Title 6 of the New York Code of Rules and Regulations (6 NYCRR) establishes a required setback, regardless of unit size, of 660 feet from the lease or unit boundary and 1,320 feet from any other well in the same pool. These setbacks result in 40-acre spacing, referred to in the regulation as statewide spacing. $\S 553.3$ provides for department promulgation, after public hearing, of an order to establish well spacing, which differs from statewide spacing. The regulation states that the department will consider the nature and character of the stratum containing the pool and the fluids contained therein as well as an estimate of the maximum area, which may be drained efficiently and economically by one well. $\S 553.4$ provides for exceptions to statewide spacing or a spacing order and establishment of production allowables to protect correlative rights and prevent waste.

The Division of Mineral Resources (DMN), responsible for implementing the statute and regulation discussed above, will initiate procedures to promulgate a field-wide spacing and integration order in every instance where geologic and engineering analysis indicates that a new field well drains more than the statewide spacing of 40 acres provided by 6 NYCRR 553.1. Through permit conditions, DMN requires production testing to determine drainage area as soon as practicable after completion of any new field well, followed by a proposed production unit within 30 days of concluding the test. Additional new field development prior to a field-wide spacing order is closely monitored by DMN, with the goal of preventing full development of the field before spacing is addressed through notice and hearing as required by law. DMN is currently in the process of refining its procedures for achieving this goal and collecting the technical data necessary to support proposed production units without unduly hindering continued drilling to further define and develop newly discovered fields.

\section{Seismic}

As discussed above, both the statute and regulation call for well spacing to be based on an estimate of the area that can be drained by one well. The regulation further states that the department will consider the nature and character of the stratum containing the pool. Where this can best be accomplished by interpretation and review of seismic data, the department requires that interpreted data be presented to DMN staff. Because of the proprietary nature of seismic 
data, DMN has not, to date, retained seismic data in its files, nor have operators been compelled by the Administrative Law Judge in recent proceedings to enter the data itself into the hearing record. DMN encourages operators to submit at hearing, at a minimum, a map showing an outline of the field as determined by seismic interpretation and the location of seismic lines used to develop the interpretation.

\section{Horizontal Drilling}

DMN technical guidance states that the 660 -foot setback from unleased property must be maintained for the entire wellbore, from surface location to bottom hole location. After a new field is discovered, applications to drill horizontal wells are treated identically to those for vertical wells, with attention paid to the entire length of wellbore which will intersect the productive zone. The statute and regulations provide adequate flexibility to consider spacing issues in light of enhanced well productivity during the review of proposed horizontal or directional wells.

\section{Spacing Laws}

Since DMN considers it appropriate to base well spacing on scientific determination of drainage areas, the lack of specific maximum or minimum unit sizes in the statute is helpful.

\section{Example for Other States}

The New York statute and regulations would provide a good starting point for any state, which determined that reliance on scientific data is more appropriate than pre-determined grids or minimums/maximums.

\section{NORTH CAROLINA}

1. Spacing requirements: No, "upon completion of a discovery well within a new pool or reservoir, the department shall consider and adopt, after public hearing, temporary well spacing and drilling units." As additional reservoir information becomes available, permanent rules and regulations will be adopted including: minimum drilling unit; method of determining pool allowable; method of allocating total allowable; minimum distances from separate leasehold or pooled unit and between wells to the same reservoir.

2. Exceptions: Yes, Rule .0006 (c).

(a) Basis: The basis for such exceptions is topographic conditions, geologic conditions and other pertinent conditions.

(b) Approval: Exceptions are granted if it is shown that more hydrocarbons can be recovered under the leasehold by such exceptions.

\section{No narrative response}




\section{NORTH DAKOTA}

1. Spacing requirements: Within 30 days after oil or gas is discovered in a pool not covered by an order of the commission, a spacing hearing is docketed. In the absence of an order of the commission, the general spacing regulations are as follows:

(a) Density: 40 acres for vertical or directional oil wells drilled and projected to 9,000 feet or less in depth; 160 acres for vertical or directional oil wells drilled or projected to more than 9,000 feet in depth; 160 acres for gas wells.

(b) Lineal: Not less than 500 feet from the drilling unit boundary and 1,000 feet from any well producing from the same pool for vertical or directional oil wells drilled or projected to 9,000 feet or less in depth. Not less than 660 feet from the unit boundary and no more than one well per quarter section for vertical or directional oil wells drilled or projected below 9,000 feet in depth. Not less than 1,000 feet to any unit boundary and 1,500 feet from any well producing from the same pool for gas wells.

(c) Density (horizontal oil wells): 80 acres for horizontal oil wells drilled and projected to a true vertical depth of 9,000 feet or less; 320 acres for horizontal oil wells drilled and projected to a true vertical depth greater than 9,000 feet.

(d) Lineal (horizontal oil wells): Not less than 500 feet from the unit boundary for horizontal oil wells drilled or projected to a true vertical depth of 9,000 feet or less; not less than 660 feet from the unit boundary for horizontal oil wells drilled or projected to a true vertical depth greater than 9,000 feet.

2. Exceptions: Yes.

(a) Basis: Surface conditions require or well at proper location would not produce in paying quantities, also, in order to protect correlative rights, prevent waste or effect greater ultimate recovery of oil and gas.

(b) Approval: By order of the commission after notice and hearing.

\section{Summary (Lynn D. Helms/Bruce Hicks)}

The North Dakota Industrial Commission statute addressing well spacing is from the North Dakota Century Code (NDCC) 38-08-04 part 2. The commission's rule addressing well spacing is from the North Dakota Administrative Code (NDAC) 43-03-02-18.

1. In the absence of an order by the commission setting spacing units for a pool:

(a) Vertical or directional oil wells projected to a true vertical depth of 9,000 feet $(2743.2$ meters) or less shall be drilled upon a governmental quarter-quarter section or equivalent lot, located not less than 500 feet (152.4 meters) to the boundary of such governmental quarter-quarter section or equivalent lot, nor closer than 1,000 feet (304.8 meters) to the nearest well permitted to or capable of producing from the same pool. No more than one well shall be drilled to the same pool on any such governmental quarterquarter section or equivalent lot, except by order of the commission, nor shall any well be drilled on any such governmental quarter-quarter section or equivalent lot containing less than 36 acres ( 14.57 hectares) except by order of the commission. 
(b) Vertical or directional oil wells projected to a true vertical depth greater than 9,000 feet (2743.2 meters) shall be drilled on a governmental quarter section or equivalent lots, located not less than 660 feet (201.17 meters) to the boundary of such governmental quarter section or equivalent lots. No more than one well shall be drilled to the same pool on any such governmental quarter section or equivalent lots, except by order of the commission, nor shall any well be drilled on any such governmental quarter section or equivalent lots containing less than 145 acres (58.68 hectares) except by order of the commission.

2.

(a) Horizontal wells projected to a true vertical depth of 9,000 feet (2743.2 meters) or less, with a horizontal displacement of the well bore drilled at an angle of at least 80 degrees within the productive formation of at least 300 feet (91.4 meters), must be drilled upon a tract described as two adjacent governmental quarter-quarter sections within the same quarter section or equivalent lots, located not less than 500 feet (152.4 meters) to the outside boundary of such tract. No more than one well may be drilled to the same pool on any such tract, except by order of the commission.

(b) Horizontal wells projected to a true vertical depth of more than 9,000 feet (2743.2 meters), with a horizontal displacement of the well bore drilled at an angle of at least 80 degrees within the productive formation of at least 500 feet (152.4 meters), must be drilled upon a tract described as two adjacent governmental quarter sections within the same section or equivalent lots, located not less than 660 feet (201.2 meters) to the outside boundary of such tract. No more than one well may be drilled to the same pool on any such tract, except by order of the commission.

3. No well shall be drilled for gas on a tract of land consisting of a governmental quarter section containing less than 145 acres (58.68 hectares). No well shall be drilled closer than 1,000 feet (304.8 meters) to any boundary line of the tract or closer than 1,500 feet (457.2 meters) to the nearest well, drilling to or capable of producing from the same pool. Provided, that in presently producing gas pools accessible to established gas transportation facilities and not controlled by orders heretofore or hereafter made. No well shall be drilled for gas on a tract consisting of less than 160 surface contiguous acres (64.75 hectares), and which is not substantially in the form of a square, in accordance with the legal subdivisions of the United States public land surveys or a square equivalent to a tract of 160 acres (64.75 hectares). No well shall be drilled closer than 1,000 feet (304.8 meters) to any boundary line of the tract or closer than 1,500 feet (457.2 meters) to a well drilling to or capable of producing from the same pool.

4. Within 30 days or a reasonable time thereafter, following the discovery of oil or gas in a pool not then covered by an order of the commission; a spacing hearing shall be docketed.

Following such hearing the commission shall issue an order prescribing a temporary spacing pattern for the development of the pool. This order shall continue in force for a period of not more than 18 months at the expiration of which time a hearing shall be held. The commission may require the presentation of such evidence as will enable the commission to determine the proper spacing for the pool. During the interim period between the discovery and the issuance of the temporary order, no permits shall be issued for the drilling of an offset well to the discovery well, unless approved by the director. Approval shall be consistent with anticipated spacing for the orderly development of the pool. Any well drilled within 
one mile (1.61 kilometers) of an established field shall conform to the spacing requirements in that field except when it is apparent that the well will not produce from the same common source of supply. In order to assure uniform and orderly development, any well drilled within one mile (1.61 kilometers) of an established field boundary shall conform to the spacing and special field rules for the field. For the purposes of spacing and pooling, the field boundary shall be extended to include the spacing unit for such well and any intervening lands. The foregoing shall not be applicable if it is apparent that the well will not produce from the same common source of supply as wells within the field.

5. If the director denies an application for permit, the director shall advise the applicant immediately of the reasons for denial. The decision of the director may be appealed to the commission.

\section{Non-Governmental Units or Irregular Units}

The commission may establish non-governmental spacing units. Since the regulations provide for units consisting of governmental sections or smaller divisions of a section, the commission must approve non-governmental or irregular units after notice and hearing.

\section{Seismic}

Seismic evidence is accepted and frequently submitted at hearings in support of petitions for exception locations and petitions to establish a non-governmental unit.

\section{Horizontal Drilling}

The North Dakota oil and gas conservation statute addressing well spacing is $\S 38-08-07$ of the North Dakota Century Code. It does not restrict the size of spacing units and provides that spacing units established must be of uniform size and shape for the entire pool. The commission is authorized to divide any pool into zones of separate spacing except when found to be necessary to prevent waste, to avoid the drilling of unnecessary wells or to protect correlative rights.

The statute does not expressly require spacing units to be on governmental sections or divisions of governmental sections (i.e. sections, quarter sections or quarter-quarter sections), but that has been the policy of the commission in the past. Horizontal drilling over the past 10 years and new attributes of 3-D seismic have convinced the commission to be flexible on establishing spacing unit when warranted.

\section{Exception Locations}

If upon application for an exception location, the commission finds that a well drilled at the location prescribed by any applicable rule or order of the commission would not produce in paying quantities, that surface conditions would substantially add to the burden or hazard of such well. If the drilling of such well at a location other than the prescribed location is necessary either to protect correlative rights, to prevent waste or to effect greater ultimate recovery from oil and gas, the commission may enter an order, after notice and hearing permitting the well to be drilled at a location other than that prescribed. It shall include in such order suitable provisions to prevent the production from that well of more than its just and equitable share of the oil and gas 
in the pool.

The application for an exception well location shall set forth the names of the lessees of adjoining properties and the names of any unleased mineral owners of the adjoining properties. The application shall be accompanied by a plat or sketch accurately showing the property for which the exception well location is sought, the location of the proposed well, and all other completed and drilling wells on this property and on the adjoining properties. The applicant or its attorney shall certify that a copy of the application has been sent by certified or registered mail to all lessees and all unleased mineral owners of properties adjoining the tract, which would be affected by the exception location. If the applicant is the lessee of adjoining tracts that would be affected by the exception, the applicant must give notice, as prescribed above, to its lessors of such tracts.

Field rules established by the commission establish minimum setback requirements minimum distances from the boundaries of the unit. That is, on a 40-acre and 160-acre units the well must be 500 feet from the unit boundary; and on 320-acre units, the well must be 660 feet from the unit boundary. Field rules established also require a minimum inter-well setback minimum distance between wells in the same pool. The commission may grant exceptions to both of the setback requirements on exception locations, under these circumstances:

1. A well located in accordance with applicable rules would be noncommercial;

2. A well located in accordance with applicable rules would not be at the optimum position, for the most efficient and economic drainage; and

3. Topographical conditions.

The commission may grant exceptions to the setback requirements allowing wells to be closer to the boundary of the unit after a public hearing during which evidence is presented in support of the exception location. Although the order issued shall include suitable provisions to prevent the production from that well of more than its just and equitable share of the oil and gas in the pool.

\section{Non-Governmental Units or Irregular Units}

The commission may establish non-governmental spacing units. All field rules provide for units consisting of governmental sections or smaller divisions of a section, although the commission may approve non-governmental or irregular units after notice and hearing.

\section{Seismic}

Seismic evidence is accepted and frequently submitted at hearings in support of petitions for exception locations and petitions to establish a non-governmental unit.

\section{Horizontal Drilling}

An operator may permit a horizontal well, like any other well, on a spacing unit. The setback requirements (500 feet for 40-acre and 160-acre units, and 660 feet for 320 -acre units) can be limiting for drilling a horizontal well. Under North Dakota's liberal unitization statute, fields may be unitized to allow any project that substantially increases the ultimate recovery of oil and 
gas from the common source of supply. Horizontal drilling would be considered under such project.

\section{OHIO}

1. Spacing requirements: Rule 1501:9-1-04. No distinction is made between oil wells or gas wells. The general spacing regulations are as follows:

(a) Density:

(1) Wells drilled to a pool from zero to 1,000 feet in depth require a subject tract or drilling unit containing not less than one acre.

(2) Wells drilled to a pool from 1,000 to 2,000 feet in depth require a subject tract or drilling unit containing not less than 10 acres.

(3) Wells drilled to a pool from 2,000 to 4,000 feet require a subject tract or drilling unit containing not less than 20 acres.

(4) Wells drilled to a pool from 4,000 feet or deeper require a subject tract or drilling unit containing not less than 40 acres.

(b) Lineal:

(1) Well must be located not less than 200 feet from any well drilling to, producing from or capable of producing from the same pool.

(2) Well must be located not less than 100 feet from any boundary of the subject tract or drilling unit. (0 to 1,000 feet in depth).

(3) Well must be located not less than 460 feet from any well drilling to, producing from or capable of producing from the same pool.

(4) Wells must be not less than 230 feet from any boundary of the subject tract or drilling unit. (1,000 to 2,000 feet in depth).

(5) Well must be located not less than 600 feet from any well drilling to, producing from or capable of producing from this same pool.

(6) Well must be located not less than 300 feet from any boundary of the subject tract or drilling unit. (2,000 to 4,000 feet in depth).

(7) Well must be located not less than 1,000 feet from any well drilling to, producing from or capable of producing from the same pool.

(8) Well must be located not less than 500 feet from any boundary of the subject tract or drilling unit. (4,000 feet or deeper).

2. Exceptions:

(a) Basis: For offset wells and if an applicant can demonstrate that such exception will protect correlative rights and/or promote conservation by permitting oil and gas to be produced which could not otherwise be produced.

(b) Approval: The chief can grant exceptions. Establishing temporary minimum well spacing near discovery wells. Rule 1501:9-1-04 (D) requires approval of the Technical Advisory Council. 


\section{Summary (Mike McCormac)}

Spacing of Wells

Minimum acreage and distance requirements for a drilling unit are based upon the depth of the proposed formation. Spacing is the same for oil and gas wells.

\begin{tabular}{|cccc|}
\hline Well Depth (ft.) & $\begin{array}{c}\text { Minimum Acreage } \\
\text { per Well }\end{array}$ & $\begin{array}{c}\text { Min. Distance (ft.) } \\
\text { from Property } \\
\text { Boundary }\end{array}$ & $\begin{array}{c}\text { Min. Distance (ft.) } \\
\text { Between Wells in } \\
\text { Same Pool }\end{array}$ \\
\hline $0-1,000$ & 1 & 100 & 200 \\
$1,000-2,000$ & 10 & 230 & 460 \\
$2,000-4,000$ & 20 & 300 & 600 \\
4,000 or deeper & 40 & 500 & 1,000 \\
\hline
\end{tabular}

\section{Temporary Minimum Well Spacing}

The chief may order temporary well spacing for wells in a particular pool or field in an area in the vicinity of a discovery well for the purpose of orderly development of a pool until such time as ultimate spacing is determined. At one time, there were several temporary spacing orders; as of today, they have all been rescinded.

\section{Mandatory Pooling}

In cases where the owner is unable to meet the requirements for drilling a well and has been unable to form a drilling unit on a just and equitable basis, the owner of such tract may make application for a mandatory pooling order. If approved, this includes unleased acreage into the drilling unit.

\section{Drilling Units}

Drilling units may be of any size or shape providing they comply with the minimum requirements and are contiguous. The operator decides the shape and size providing they meet the minimum requirements. Practically, this results in very irregularly shaped units or units' containing several times the minimum acreage.

\section{Seismic}

Spacing laws do not use seismic data to determine drilling units. The exception would be if seismic data were used to present a case under temporary minimum well spacing.

\section{Horizontal Drilling}

There are no special spacing rules for horizontal drilling. Spacing is determined based upon the depth of the borehole. For example, a borehole drilled horizontally at 3,000 feet would require a minimum setback of 300 feet to the drilling unit lines. 


\section{Variances and Infill Drilling}

The chief may grant an acreage or distance variance when an operator is unable to meet the minimum requirements. This is usually between 1 to 10 percent and is on a well-by-well case. Upon evidence from an operator, the chief may also grant exceptions to the acreage and distance between well requirements to allow for the full development of a field.

\section{OKLAHOMA}

1. Spacing requirements: Not mandatory. If desired, upon application, notice (to all entities to participate in production from proposed unit) and hearing.

(a) Density: Typically 10, 20, 40 or 80 acres for oil. Typically, 160, 320 or 640 acres for gas. Hearing can permit drilling additional wells into one unit spacing only.

(b) Lineal: Well to be drilled within center square one-quarter area of square unit or designated square tract constituting one-half of a rectangular unit for an oil or gas well.

(1) Permitted sizes for square units: Wells drilled within a spacing unit must adhere to the following guidelines:

a. $\quad 640$ acres - no closer than 1,320 feet to the unit boundary;

b. 160 acres - no closer than 660 feet to the unit boundary;

c. 40 acres - no closer than 330 feet to the unit boundary; and

d. 10 acres - no closer than 165 feet to the unit boundary.

(2) Permitted sizes for rectangular units: Wells must be drilled according to the well pattern outlined by the commission spacing order, but

a. 320 acre - no closer than 660 feet to the boundary of alternate square drilling tract;

b. 80 acres - no closer than 330 feet to the boundary of alternate square drilling tracts; and

c. 20 acres - no closer than 165 feet to the boundary of alternate square drilling tracts.

2. Exceptions: Yes.

(a) Basis: To prevent waste, protect correlative rights, to encounter the edge of a known producing reservoir or because of surface obstructions.

(b) Approval: Upon application, notice (including written notice to offset operators and working interest parties toward whom the location is to be moved) and hearing. An allowable penalty may be imposed.

\section{Summary (Larry Fiddler)}

The Oklahoma Corporation Commission (OCC) pursuant to 52 Oklahoma Statute (O.S.) 2001 Supplement, $\S 87.1$ maintains authority as a court of record to regulate the spacing and density of oil and gas wells in the state through the issuance of spacing and increased density orders. Following this statute, spacing units are usually from 10 to 640 acres in size, established, as square or rectangular units comprised of subparts of standard governmental sections. For example, a 10-acre unit will be comprised of a quarter, quarter, quarter section, a 320-gas 
unit will be a half section and a 640-gas unit will be a single section. Gas units can be larger than 640 acres if they are located along the state borders or in correction sections along the line where the Oklahoma Panhandle joins the rest of the state. Units are generally 10, 20, 40, 80, 160,320 or 640 acres. Gas units can be any size regardless of depth depending upon the predicted drainage area of the well. Oil units can be no larger than 40 acres from the surface to 4,999 feet, no larger than 80 acres from 5,000 to 9,990 feet and no larger than 160 acres below 9,990 feet. An exception to these depth/size limits was recently enacted through amendment of 52 O.S. $\S 87.1$ to permit reservoir dewatering oil units shallower than 9990 feet no larger than 160 acres. Spacing in Oklahoma is established or modified only through notice and hearing procedures. Personal notice to all owners of mineral rights in the lands covered by an application as well as notice by publication is required to confer jurisdiction.

\section{Location Exceptions}

The permitted well location within any standard square drilling and spacing unit shall be the center of the unit. The permitted well locations within standard rectangular drilling and spacing units shall be the centers of alternate square tracts constituting the units (alternate halves of the units). Provided, however, a well will be deemed drilled at the permitted location if drilled within the following tolerance areas:

1. Not less than 165 feet from the boundary of any standard 10-acre drilling and spacing unit or the proper square 10-acre tract within any standard 20-acre drilling and spacing unit.

2. Not less than 330 feet from the boundary of any standard 40-acre drilling and spacing unit or the proper square 40-acre tract within any standard 80-acre drilling and spacing unit.

3. Not less than 660 feet from the boundary of any standard 160 -acre drilling and spacing unit or the proper square 160-acre tract within any standard 320-acre drilling and spacing unit.

4. Not less than 1,320 feet from the boundary of any standard 640-acre drilling and spacing unit.

The commission does allow for the granting of location exceptions based on geologic and engineering information when necessary to prevent waste or protect correlative rights. A location exception may be granted only after proper application, notice and hearing. Whenever permission is granted to drill a well at a location other than specified by rule, the allowable or production therefrom or both may be adjusted for the protection of the correlative rights of all persons entitled to share in the common source of supply.

\section{Seismic}

The OCC frequently uses seismic data to help make determinations on spacing, location exceptions and increased density hearings.

\section{Horizontal Well}

The commission does allow an operator to permit a horizontal well or horizontal spacing unit. A horizontal wellbore from its point of entry and along any part of the lateral shall be located not closer than the minimum distance as set out below from any other wellbore completed in or drilling to the same common source of supply except by a special order of the commission: 
1. Three hundred feet from any other producible or drilling oil or gas well when drilling to the same common source of supply that is less than 2,500 feet in depth.

2. Six hundred feet from any other producible or drilling oil or gas well when drilling to the same common source of supply that is 2,500 feet or more in depth.

A horizontal wellbore from its point of entry and along any part of the lateral shall be located not less than the minimum tolerance distance from the boundary of the horizontal well unit as follows:

1. Not less than 165 feet from the boundary of any 10,20 or 40 -acre horizontal well unit.

2. Not less than 330 feet from the boundary of any 80 or 160 -acre horizontal well unit.

3. Not less than 660 feet from the boundary of any 320 -acre or 640 -acre horizontal drilling and spacing unit.

\section{OREGON}

1. Spacing requirements: Yes. Rules 632-10-156 and 632-10-157.

(a) Basis: The board will adopt special rules for fields if a hearing is required.

(b) Approval: By the state geologist if no hearing is required and by the governing board of the department if a hearing is required.

2. Exceptions: No

\section{No narrative response}

\section{PENNSYLVANIA}

1. Spacing requirements:

(a) OGA: None.

(b) RCA: Gas wells in workable coal seams must be at least 1,000 feet from any other well and 330 feet from the tract boundary.

(c) OGCL: An operator may apply for a spacing order pursuant to $\S 7$ of the Act. In addition, a well location must be at least 330 feet from the boundary of the tract or unit.

2. Exceptions: RCA: Yes.

(a) Basis: Minimum spacing may be as little as 900 feet where permit applicant and owner of workable coal seam consent; exceptions to 330-foot distance requirement from tract boundary may be granted pursuant to $\S 7$.

(b) Approval: By the Department of Environmental Protection (DEP).

2.1 Exceptions: OGCL: Yes, if the well would not be likely to produce in paying quantities, if there are adverse surface conditions or if coal operators have objected and a well is prohibited in a certain area. $\S 7$. Approval: By the DEP. 


\section{Summary (James Erb)}

The Pennsylvania Code, Chapter 79, Oil and Gas Conservation

Section 79.11(b) - The requested location of the well may not conflict with a spacing or pooling order previously entered or pending before the department, and the requested location shall be at least 330 feet from the nearest outside boundary line of the lease on which it is located.

Section 79.21 - No single application for a spacing order may cover an area exceeding 10 square miles.

The Pennsylvania Oil and Gas Resource Coordination Act 1984-214 Section 7(a) - The minimum distance between gas wells. No permit for a gas well covered by the act may be issued to drill a new gas well or reopen a gas well, which has been plugged in accordance with the Gas Operations Well-Drilling Petroleum and Coal Mining Act. However, unless the proposed gas well is located not less than 1,000 feet from any other well and not less than 330 feet from the boundary of the tract on which the gas is located not less than 1,000 feet from any other well and not less than 330 feet from the boundary of the tract on which the gas well is to be located.

\section{Sections $601.205-$}

The Pennsylvania Oil and Gas Act of 1984, P.L. 1140, No. 233

1. Wells may not be drilled within 200 feet measured horizontally from any existing building or existing water well without the written consent of the owner thereof. Where the distance restriction would deprive the owner of the oil and gas rights of the right to produce or share in the oil or gas underlying said surface tract, the well operator may be granted a variance from said distance restriction upon submission of a plan which shall identify the additional measures, facilities or practices to be employed during well site construction, drilling and operations. The variance, if granted, shall include such additional terms and conditions, as the department shall require insuring the safety and protection of affected persons and property. The provisions may include insurance, bonding and indemnification, as well as technical requirements.

2. No well site may be prepared or well drilled within 100 feet measured horizontally from any stream, spring or body of water as identified on the most current $71 / 2$ minute topographic quadrangle map of the United States Geological Survey or within 100 feet of any wetlands greater than one acre in size. The department may waive such distance restrictions upon submission of a plan, which shall identify the additional measures, facilities or practices to be employed during well site construction, drilling and operations. Such waiver, if granted, shall impose such permit conditions as are necessary to protect the waters of the Commonwealth.

3. The department shall, on making a determination on a well permit, consider the impact of the proposed well on public resources to include, but not be limited to, the following:

(a) Publicly owned parks, forests, gamelands and wildlife area.

(b) National or state scenic rivers.

(c) National natural landmarks.

(d) Habitats of rare and endangered flora and fauna and other critical communities.

(e) Historical and archaeological sites listed on the federal or state list of historical place. 


\section{Seismic}

Pennsylvania's statutes and regulations do not address the use of seismic data to establish spacing units.

\section{Horizontal Drilling}

Horizontal drilling is not addressed in Pennsylvania's statutes and regulations.

\section{SOUTH CAROLINA}

\section{No material available or narrative response received}

\section{SOUTH DAKOTA}

1. Spacing requirements: Yes. Rule 74:10:03:08, 74:10:03:09 and 74:10:03:10.

(a) Density: Oil, 40 acres; gas, 640 acres.

(b) Lineal: Oil well - 500 feet from quarter-quarter boundary and 1,000 feet between wells. Gas well -500 feet from section line and 3,750 feet between wells.

2. Exceptions: Yes. Address request to supervisor.

(a) Basis: Topographic reasons, well at prescribed location would not produce economically or other good cause shown.

(b) Approval: Administratively by the department. Applicant must provide evidence of good cause. Must provide affidavit of service by certified mail to "any person whose property may be affected by the hearing." The department publishes a Notice of Recommendation on the matter in the official county newspaper and the official state newspaper and others. Upon 20 days notice if no objections are filed, the application may be approved. If objections are made, a hearing is required.

\section{Summary (Fred Steece)}

Chapter 49-9 of the South Dakota Codified Laws (SDCL) addresses oil and gas conservation. Well spacing is dealt with in SDCL $\S 45-9-20$ through 45-9-29. These statutes give authority to prevent waste, to avoid the drilling of unnecessary wells and to protect correlative rights. Except where circumstances reasonably require, the spacing units are to be of approximately uniform size and shape. In the interest of preventing waste the board may increase the size of spacing units in the pool or any zone thereof or permit the drilling of additional wells in the pool. The board may even change the size or shape of existing spacing units. The size and shape of the units cannot be smaller than the maximum area efficiently and economically drained by one well. The board order includes provisions to prevent the production of more than a unit's just and equitable share of oil and gas. At the public hearing to establish spacing for a field, temporary spacing units will be set until such time that sufficient evidence is available to set a field's ultimate spacing. Lands may be added to or deleted from an established field as the field 
matures and information becomes available. Wells drilled on spacing units shall have a reasonably uniform pattern but exceptions will be allowed for wells drilled or drilling at the time of the hearing.

In the absence of a spaced field, the statewide spacing for oil wells allowed by the Administrative Rules of South Dakota (ARSD) is one well per governmental quarter-quarter section of land or a governmental lot corresponding thereto. The well must be located not closer than 500 feet from the boundary of the quarter-quarter section or governmental lot, nor closer than 1,000 feet from any well drilling in or producing from the same reservoir. If the spacing unit is smaller than 35 acres, no well can be drilled except with approval of the Department of Environment and Natural Resources after utilizing the Notice of Recommendation procedure (ARSD 74:10:11:01). Likewise, the statewide spacing for gas is one well per governmental section of land. The well must be located not closer than 500 feet from the boundary of the governmental section, nor closer than 3,750 feet from any well drilling in or producing from the same reservoir. If the spacing unit is smaller than 576 acres no well can be drilled except with department approval, using the Notice of Recommendation Procedure. After a discovery of oil or gas, the operator is required to petition the board for a hearing to set a specified spacing pattern. No permits for offset wells will be issued until the hearing is held and the board issues a spacing order.

\section{Exception Locations}

The Department may approve an exception location for any of the following reasons:

1. A well would not produce in paying quantities.

2. Surface conditions would add to the burden or hazard of the well.

3. Good cause, such as geological or geophysical indications of oil or gas.

Application is made to the department for an exception location along with supporting information. After the department has completed its review, a Notice of Recommendation (ARSD $74: 10: 11: 01)$ is published in the official state and county newspapers. The applicant is also required to notify offsetting interest owners by certified mail of the proposed exception location. If no intervention is filed within 20 days of publication, the department's recommendation will be final. If an intervention is filed, a hearing on the matter is scheduled before the Board of Minerals and Environment.

\section{Horizontal Drilling}

The Notice of Recommendation procedure is used to permit directional and horizontal wells. Setback distances for wildcat horizontal wells are 500 feet from the spacing unit boundary. A surface location can vary from the specified setback as long as the horizontal part of the well where it enters the reservoir, shown by a downhole survey, meets the setback requirement. Setback distances for fields are either 500 or 660 feet as stated in the field order. Spacing unit sizes for horizontal wells to date are 320 and 640 acres. Most field orders allow up to two wells per spacing unit. There are no restrictions for direction and distance of horizontal wells in unitized areas.

\section{Seismic}

Maps prepared from seismic data frequently are offered at hearings in South Dakota as 
proof of geologic structure as it relates to trapping mechanisms for the accumulation of oil and gas. Seismic evidence is thus utilized by the Board of Minerals and Environment for establishing fields, unitized areas or for changing spacing in established fields. Seismic information is also used as evidence in support of requests for exception locations, and as evidence in support of requests for horizontal wells in areas not already spaced for horizontal drilling.

\section{TENNESSEE}

1. Spacing requirements: Yes. 1040-2-4 of Rules and Regulations.

(a) Density:

(1) Oil wells - 0-1,000 feet, 10 acres; $1,001-2,000$ feet or to the base of the Devonian Chattanooga Shale, whichever is deeper, 20 acres; more than 2,000 feet or below the base of the Devonian Chattanooga Shale, whichever is deeper, 40 acres. No density requirement for horizontal wells.

(2) Gas Wells - 0-1,000 feet, 10 acres; 1,001-2,000 feet or to the base of the Devonian Chattanooga Shale, whichever is deeper; 20 acres; more than 2,000 feet deep or below the base of the Devonian Chattanooga Shale, whichever is deeper - 5,000 feet or to the top of the Cambrian Conasauga Group, whichever is deeper, 40 acres; more than 5,000 feet deep or below the top of the Cambrian Conasauga Group, whichever is deeper, 160 acres. No density requirement for horizontal wells.

(b) Lineal:

(1) Oil wells - 330 feet or more from any property (lease) or unit line and 660 feet or more from any other well completed in, drilling to or for which a permit shall have been granted to drill to the same pool. No specific well to well distance requirement for horizontal wells.

(2) Gas wells - 0-5,000 feet or to the top of the Cambrian Conasauga Group, whichever is deeper, 330 feet or more from any property (lease) or unit line and 660 feet or more from any other well completed in, drilling to or for which a permit shall have been granted to drill to the same pool; more than 5,000 feet deep or below the top of the Cambrian Conasauga Group, whichever is deeper, 660 feet or more from any property (lease) or unit line and 1,320 feet or more from any other well completed in, drilling to or which a permit shall have been granted to drill to the same pool. No specific well to well distance requirement for horizontal wells.

\section{Exceptions: Yes.}

(a) Basis: For valid geological or topographic reasons.

(b) Approval: Administratively by supervisor, 1040-2-4-.01(k), or by the Oil and Gas Board after public hearing. 1040-2-4-01(k6).

Existing wells may be deepened and produced for oil or gas from whatever zone(s) production may be obtained on the existing permitted unit size.

Spacing of oil and gas wells - Referendum TCA 60-1-106. Oil or gas wells in Overton County: $0-2,500$ feet, 200 feet or more from any property line and 400 feet or more from any other well completed in, drilling to or for which a permit shall have been granted to drill to the same pool. Oil and gas wells in Clay and Pickett Counties: 200 feet or more from any property 
line and 400 feet or more from any other well completed in, drilling to or for which a permit shall have been granted to drill to the same pool.

\section{No narrative response received}

\section{TEXAS}

1. Spacing requirements: Yes. (Rule 37) Statewide 467-1200 feet - spacing 40 acres for oil or gas wells.

(a) Density: Statewide 40 acres. Field rules adopted after hearing may specify different density.

(b) Spacing: Statewide 467-1200 feet. Field rules adopted after hearing may specify different spacing.

(c) Districts 7B, 9 and 7C McCulloch County spacing and density according to depth.

2. Exceptions: Yes.

(a) Basis: Prevention of waste or confiscation.

(b) Approval: By application. Approved without hearing if no protest received after notice or if waivers submitted. Fee: $\$ 50$.

\section{Summary (Steve Gault)}

Statewide Rule 37 establishes well spacing within Texas.

Well spacing in Texas for fields on statewide spacing (no field rules adopted) are minimum 467 feet from lease/pooled unit boundary and minimum 1,200 feet between wells in the same lease and in the same field. These rules are established by average drainage for oil and gas wells, and they are adopted on a statewide basis, with the exception of two Railroad Commission of Texas (RRC) districts, where spacing is based on depth down to 5,000 feet. The spacing in these districts is also $467 / 1,200$ feet. No seismic data is used to establish spacing requirements.

Spacing rules other than statewide rules that have been adopted in fields are established by various methods at hearing. Most often these rules are obtained based on volumetric calculations estimating recoverable oil and gas in the reservoir as well as production decline curves from representative well(s) in the field to estimate production expected from such wells.

Evidence of pressure communication between wells in the field constitutes evidence of acreage being drained, and this data may be used in determining between well spacing and lease line spacing requirements. Applicants requesting spacing other than statewide must prove existing wells are draining at least one-half the distance between two wells. This data also assists in establishing lease line spacing requirements.

Applicants should provide a structure map, an isopach map and $\mathrm{p} / \mathrm{z}$ curves for several wells in the field. RRC forms G-1, Gas Well Pressure Test, Completion or Recompletion Report and Log and G-10 Gas Well Status Report from wells in the field will be reviewed to help establish field rules. 
Statewide Rule 86 governs horizontal wells within Texas.

Horizontal well spacing pursuant to Statewide Rule 86 is similar to Statewide Rule 37. If special horizontal rules have not been established for a field, then statewide spacing rules apply (467 feet from lease line, 1,200 feet between wells on the same lease and in the same field). Statewide Rule 86 does allow for additional acreage assignment pursuant to the length of the drainhole. This is done to increase the allowable for wells and addresses density but not spacing.

Field rules for horizontal wells within a field are established based on the same evidence required to establish standard field rules at a hearing.

Spacing rules are necessary for several reasons. By applying the spacing rules to each operator's wells, all operators from a regulatory standpoint are treated equally by virtue of these rules. Under spacing rules and in conjunction with density and other rules, an operator is afforded its opportunity to recover its fair share of reserves.

When exceptions to spacing rules are needed, notice provisions for exceptions are in place to offer notice to entitled parties in an effort to prevent waste and protect correlative rights.

All acreage that an operator submits with a drilling application via plat and/or completion forms is considered productive, until proven otherwise through a hearing to determine productive acreage. Productive acreage determinations are considered on a field-wide basis and are not required in Texas.

Rule 37 exception applications (statewide and field rule spacing exceptions) are submitted via the Form W-1 drilling application. Lease line spacing exceptions and/or between well spacing exception, notice is provided for in Statewide Rule 37. If waivers cannot be obtained from affected parties, a notice of application is issued. If no protest is received within 21 days for the day of notice, the application is administratively granted. If protest is received, the matter is set for hearing and a notice of hearing is provided to entitled parties. The applicant bears the burden of proof in a Rule 37 exception hearing. The hearing examiner's recommendation is presented to the commissioners for consideration.

\section{UTAH}

1. Spacing requirements: Yes. Statewide location and siting of vertical wells and statewidespacing for horizontal wells.

(a) Vertical well density: In the absence of special orders of the board establishing drilling units or authorizing different well density or location patterns for particular pools or parts thereof, each oil and gas well shall be located in the center of a 40-acre quarter-quarter section or a substantially equivalent lot or tract or combination of lots or tracts as shown by the most recent government survey, with a tolerance of 200 feet in any direction from the center location.

(b) Lineal setbacks for vertical wells: No oil or gas well shall be drilled less than 920 feet from any other well drilling to or capable of producing oil or gas from the same pool.

(c) Horizontal well density: A temporary 640-acre spacing unit consisting of the governmental section in which a horizontal well is located, is established or orderly develop- 
ment of an anticipated pool.

(d) Lineal setbacks for horizontal wells: In the absence of special orders of the board, no portion of the horizontal interval within the potentially productive formation shall be closer than 660 feet to a drilling or spacing unit boundary, federally unitized area boundary, uncommitted tract within a unit or boundary line of a lease which is not committed to the drilling of such a horizontal well. Any horizontal interval shall not be closer than 1,320 feet to any vertical well completed in and producing from the same formation.

2. Exceptions: Yes.

(a) Basis: Geological and/or topographical exceptions.

(b) Approval: Granted administratively providing that evidence of necessity, verification of lease ownership and the written consent from all owners within a 460 -foot radius of the proposed well location or owners of directly or diagonally offsetting drilling units are received by the division.

\section{Summary (John Baza)}

In Utah, the Board of Oil, Gas and Mining consists of 7 citizen members appointed by the governor, regulate well spacing. The board is a policy making body for the Division of Oil, Gas and Mining, which administers and implements the rules, orders and policies of the board. According to Utah statute (Utah Code, Title 40, Chapter 6), "the board has the authority to regulate ... the spacing and location of wells." Also included is "the board may order the establishment of drilling units for any pool."

\section{Standard Well Location and Siting}

A well in Utah that is proposed for drilling in an area where there is no board order previously establishing drilling units will fall under the requirements of Rule R649-3-2, Location and Siting of Vertical Wells and Statewide Spacing for Horizontal Wells. This rule allows an oil or gas well to be located in the center of a 40 -acre quarter-quarter section or equivalent combination of lots or tracts. There is a tolerance for locating the well in the center of a quarter-quarter section of 200 feet in the north, south, east or west direction, creating a square drilling window of 400 feet on each side within a quarter-quarter section. Note that this does not mean that newly drilled wells are spaced on 40-acre parcels, it only allows for properly locating a well within a quarterquarter section of land. Once the well is drilled, completed and producing, it is then necessary for a well operator to request a hearing before the Board of Oil, Gas and Mining in order to establish appropriately sized drilling units for the purpose of spacing additional wells to be drilled to the same pool.

\section{Well Spacing}

Utah statute prescribes specific requirements for establishment of drilling units as follows:

1. Only one well may be drilled for production within each drilling unit, unless the board modifies an existing order establishing drilling units.

2. A drilling unit may not be smaller than the maximum area that can be efficiently and economically drained by one well. 
3. Each drilling unit within a pool shall be of uniform size and shape, unless granted an exception based on geologic, geographic or other factors.

Board orders establishing drilling units are promulgated following a public hearing at which evidence and testimony are presented to justify establishment of drilling units. The board may consider any and all representations by well operators, interest owners, members of the public or division staff during such hearings. Once established, drilling units are in effect for a pool until suspended or rescinded by the board again through a public hearing process.

\section{Exception Locations}

The board has promulgated Rule R649-3-3, Exception to Location and Siting of Wells, which allows the division administrative authority to grant an exception to the locating and siting requirements of Rule R649-3-2 (the statewide location and siting rule) or any order of the board if the following conditions are met:

1. The operator shall submit written application for the exception.

2. The operator shall obtain and provide evidence of written consent from all the owners of oil and gas affected by the exception (based on specific radius from the proposed wellbore or within offset drilling units).

3. The operator shall state fully the reasons why such an exception is necessary.

4. The operator shall provide a plat showing both the location where a well could be drilled in compliance with rules or orders, and the location where the applicant is requesting approval to drill.

5. The operator shall provide the names of all owners who are indicated in requirement number 2.

\section{Seismic}

There is no preclusion from utilizing seismic data in determining the size and shape of drilling units, and such data is occasionally submitted and considered during the public hearing process in the course of establishing drilling units.

\section{Horizontal Drilling}

Unlike vertical wells, horizontal wells do have specific requirements for spacing stated in Rule R649-3-2 as follows:

1. In the absence of special orders of the board governing horizontal well spacing, no portion of the horizontal interval within a well shall be closer than 660 feet to a drilling unit boundary, a federally unitized area boundary, an uncommitted tract within a unit, or the boundary of a lease not committed to the drilling of the horizontal well.

2. The surface location for a horizontal well may be located anywhere on the same mineral lease.

3. Any horizontal interval shall not be closer than 1,320 feet to a vertical well completed in and producing from the same formation.

4. A temporary 640-acre spacing unit, consisting of the governmental section in which the horizontal well is located, is established for that well.

5. The operator shall provide notice of application to drill to all owners within the temporary 640acre spacing unit. In order to convert the temporary 640 -acre spacing unit for a horizontal well into a permanent drilling unit, the operator must petition the board for a hearing similar to 
establishment of any other drilling unit.

\section{VIRGINIA}

1. Spacing requirements: Yes.

In the absence of field rules established by the Virginia Gas and Oil Board, statewide spacing, based on minimum distance between wells, is as follows:

(a) For oil: Not within 1250 feet of another well completed in the same pool and not within 625 feet of the boundary of acreage supporting the well.

(b) For gas: Not within 2500 feet of another well completed in the same pool and not within 1250 feet of the boundary of acreage supporting the well.

(c) For coalbed methane wells: Not within 1000 feet of another coalbed methane well and not within 500 feet of the boundary of acreage supporting the well.

(d) For coalbed methane wells located in the gob: Not within 500 feet of another well completed in the gob and not within 250 feet of the boundary of acreage supporting the well.

2. Exceptions: Yes.

(a) Basis: The Virginia Gas and Oil Board hears unique testimony regarding each application for exception and renders a decision based on that testimony.

(b) Approval: All exceptions to statewide spacing must be approved by the Board and detailed in an order issued by the Board.

\section{Summary (Bob Wilson)}

Statewide spacing of gas and oil wells in Virginia is mandated by $\S 45.1-361.17$ of the Code of Virginia. The requirements are based entirely on the distance from wells, which are completed in the same pool, or, in the case of coalbed methane drilling, the distance from any other coalbed methane well. Spacing units based on acreage are not defined in the Code. In addition to spacing requirements, oil wells and coalbed methane wells which are located within 2500 feet of any existing well are subject to objection by coal owners, and if a location within the 2500 feet cannot be agreed upon the permit is not issued (\$45.1-361.12).

Exceptions to statewide spacing can only be granted by the Virginia Gas and Oil Board and must be approved prior to drilling. The request for exception must appear on the Board's published docket, and the applicant must directly notify all gas, oil, coal and mineral owners in the unit to be drilled. Spacing exceptions are most often requested and granted for reasons related to topography, mining activity or infill drilling of stranded (island) acreage.

Any gas or oil owner can apply to the Board for the establishment of field rules, or the Board may consider such rules on its own motion. A hearing is scheduled and operators are required to present evidence concerning geology, drainage, potential production and allowables. Field rules will define the boundaries of field areas, formations which are subject to production, the size and shape of drilling units, the size of interior drilling windows, minimum distances from other wells in the field and production allowables. Almost all of Virginia's coalbed methane production is under field rules mandating either 60 - or 80 -acre units. 
Seismic information is not specifically mentioned in the gas and oil laws or regulations, and most of Virginia's existing development activity does not benefit from seismic. Seismic data would be accepted by the Board as supporting evidence for spacing exceptions or field rules.

Neither the Virginia statutes nor the regulations specifically address horizontal drilling. Such drilling would have to meet the same requirements regarding spacing distances and acreage setback, as do conventional wells. Alternately, as outlined above, the Board has authority to establish field rules under any scenario, including horizontal drilling. To date, no horizontal drilling has occurred in the state.

\section{WASHINGTON}

1. Spacing requirements: Yes. Not smaller than the maximum area that can be efficiently drained by one well. Because we have no production, specific limits have never been set.

(a) Density: Not greater than 160 acres for oil or 640 acres for gas.

(b) Lineal: Not closer than 500 feet to lease boundary line.

2. Exceptions:

(a) Basis: Department rules that prescribed location would not produce in paying quantities or that surface conditions would add a burden or hazard.

(b) Approval: From the department.

\section{No narrative response}

\section{WEST VIRGINIA}

1. Spacing requirements: General rule: deep wells, 3,000 feet from wells producing from same formation; shallow wells, none.

(a) Density: Maximum - 640 acres for gas wells and 160 acres for oil wells in a unit.

(b) Lineal: Deep wells only 3,000 feet from wells producing from the same formation except by special field rules; none for shallow wells for gas or oil.

2. Exceptions: Yes.

(a) Basis: Economic, geological or topographic or reservoir necessity.

(b) Approval: By application, hearing and order.

\section{Summary (Mike Lewis)}

Well spacing requirements in West Virginia are only applicable to deep wells and coalbed methane wells. The respective statutes and rules that specify those requirements are West 
Virginia Code, Chapter 22C, Article 9, Rule 39CSR1-4.2 and Chapter 22, Article 21. Deep wells are defined in West Virginia as any well drilled and completed at or below the uppermost member of the Onondaga Group, which is generally about 6,000 feet deep in West Virginia. There are no spacing requirements for shallow oil and gas wells.

Deep wells are required to maintain a 3,000-foot spacing between wells capable of producing from the objective pool and a 400-foot setback distance from the lease or unit boundary. Seismic data is not specifically promoted for use in establishing units but may be submitted for use in granting exception locations or establishing special field rules. West Virginia rule does require directional surveys of all deep wells, which must be run every 500 feet or every bit change, whichever is less, but no more frequently than every 250 feet. Such requirements for directional surveys should provide adequately any deviated or horizontal drilling.

Coalbed methane wells are required to maintain a 1,600-foot spacing from the location of an existing well for which a permit application is on file, unless all owners and operators of any affected coal seams agree in writing. A 100-foot setback from the outside boundary of the coal tract from which the coalbed methane is or will be produced is required. Generally, seismic data is not applicable to coalbed methane wells. The horizontal wells drilled for coalbed methane development has been practiced in West Virginia, however has not been a particular issue. Should significant additional horizontal drilling take place in the state, issues could likely arise on spacing and drainage that the law does not adequately address?

\section{WYOMING}

1. Spacing requirements: Yes.

(a) Density: 40 acres for an oil well; 40 and 160 acres for a gas well; 40 and 80 acres for a coalbed methane well.

(b) Lineal: For an oil well, not closer than 460 feet to the exterior boundaries of a 40 -acre subdivision. Same for a gas well or a coalbed methane well, center of NE/4 or SW/4 with 200 feet of tolerance on 40 acres and the center of a 160-acre tract with 200 feet of tolerance. Chapter III, Section 2.

(c) Horizontal wells, no closer than 660 feet to unit boundary or 1,320 feet from any vertical well completed in the same zone. Temporary 640-acre spacing. Certain areas have alternate spacing patterns. Requires notice in one-half (1/2) mile area.

2. Exceptions: Yes.

(a) Basis: Geologic or topographic.

(b) Approval: Administratively in the absence of any objection, by commission order should there be an objection. Chapter III, Section 3 and Chapter V, Section 16.

\section{Summary (Don Likwartz)}

The Wyoming Oil and Gas Conservation statute addressing well spacing is $\S 30-5-109$ of the Wyoming Statutes (1999). In the absence of a commission order establishing drilling units or 
authorizing different well density or location patterns, each oil and gas well must be located in the center of a forty (40)-acre governmental quarter-quarter section or lot or tract or combination of lots or tracts substantially equivalent thereto.

\section{Location of Wells}

The rules of the State Oil and Gas Conservation Commission establish minimum setback requirements - minimum distances from the boundaries of the unit. For a 40-acre unit, the well can have a tolerance of 200 feet in any direction from the center location (a window 400 feet square). In addition, no oil or gas well can be drilled less than 920 feet from any other well drilling or capable of producing from the same pool.

\section{Horizontal Wells}

In the absence of a special spacing order, no portion of the horizontal interval within the potentially productive formation can be closer than 660 feet to a drilling or spacing unit boundary, federal unit boundary, uncommitted tract within a unit or boundary line of a lease not committed to the drilling of the horizontal well.

Any horizontal interval can not be closer than 1,320 feet to any vertical well completed in and producing from the same formation. A temporary 640-acre spacing unit is established for the orderly development of the anticipated pool.

\section{Exception Locations}

The supervisor can approve, as an administrative matter, exceptions to vertical and horizontal well locations and setbacks. The application must state fully the reasons why such an exception is necessary and must be accompanied by a plat showing the location requested plus the locations at which oil or gas wells have been or could be drilled directly or diagonally offsetting the proposed exception. If any operator in the surrounding area protests the proposed exception location, the matter is set for hearing before the commission.

\section{ALBERTA CANADA}

Summary (Jim Dilay)

\section{Seismic}

Seismic data is often used in applications and hearings to support a request for a change in well spacing. It is particularly useful in assessing the potential impact of a proposed well spacing change on an offset mineral right owner.

\section{Horizontal Drilling}

Horizontal wells are initially subject to the same drilling spacing unit and target area provisions as vertical wells. However, if an operator wishes to drill a horizontal well across two or 
more laterally adjoining drilling spacing units of common mineral right ownership, he may do so without making an application to this board. An off target penalty may be applied if any portion of the productive section of the wellbore encroaches on the offset mineral right owner. Where an operator requires additional flexibility for placement of horizontal wells, it may apply for the suspension of drilling spacing unit and target area provisions for holdings (areas of common mineral right ownership) or unitized areas. In place of the normal spacing provisions, an operator will establish a buffer zone and, if necessary, a minimum interwell distance and a maximum well density restriction.

\section{Spacing Laws}

The ability to suspend drilling spacing unit and target area provisions in holdings and unitized areas provide an operator with maximum flexibility to develop its mineral rights. In essence, an operator can place its well bores anywhere within these areas as long as there is no encroachment on the offset mineral right owners. Most of the high density drilling in Alberta occurs in a holding or unit.

\section{Spacing Regulations}

Part 4 of the Oil and Gas Conservation Regulations (regulations) addresses well spacing regulations in Alberta. $\S 5.190$ to 5.220 deal with the establishment of holdings that are also used to define spacing requirements. Drilling spacing units (DSU) and target areas are defined using the Dominion Land Survey System. Normal DSU size for oil is one-quarter section (160 acres) and normal DSU size for gas is one section (640 acres). As will be discussed later, these DSUs have defined target areas as described in Part 4 of the regulations. Applications are made in accordance with the above regulations to reduce the DSU size and/or vary the target areas.

\section{Reduced Spacing}

Applications are generally made to reduce the normal spacing for oil from one-quarter section to two legal subdivisions (LSD)(80 acres) or one LSD (40 acres). Normal spacing for gas is generally reduced from one section to one-half section (320 acres) or one-quarter section. These reduced DSU sizes have defined target areas as outlined in Part 4 of the regulations and in the attached ID 94-2. Reduced spacing is primarily used to improve oil or gas recovery where the need for additional well bores is based on the density of the crude or specific reservoir characteristics. However, reduced spacing can also be used to accelerate depletion of a gas or oil pool provided equity and conservation of the resource are not jeopardized.

\section{Target Areas}

Target areas and off-target penalty factors for wells drilled outside the target area are described in Schedule 14 of the regulations and in ID 94-2 This includes target areas and offtarget penalty factors for both normal and reduced spacing. The target areas for normal quarter section oil spacing are generally the NE LSD in agricultural areas (to accommodate farming operations) and a central area 200 meters $(\mathrm{m})$ from the DSU boundary in non-agricultural areas. For normal one section gas spacing, the target area is a central area $300 \mathrm{~m}$ from the DSU boundary. As movement is made outside the target area, a well can have a penalty factor of $0.75,0.50$ or 0.25 applied to its allowable. See the attached regulations/ID for target areas and 
off-target penalty factors for DSUs under normal and reduced spacing. For wells drilled outside their defined target area, an off-target penalty is only applied after an equity complaint is received from a negatively affected offset mineral right owner (see ID 94-2). The spacing regulations also provide for a First Well Policy that permits the first well in a new pool to be drilled outside it has prescribed target area without incurring an off-target penalty. The purpose of this policy is to reward those operators willing to take the risk of drilling an exploratory well.

\section{Holdings}

The EUB uses holdings to redefine spacing rules for larger tracts of land. Part 4 of the regulations is suspended and a holding issued with the newly defined spacing rules for that area. These redefined rules will provide for a buffer zone (distance from the holding boundary in which production cannot take place without the risk of an off target penalty), and where necessary, an interwell distance and a well density restriction (e.g. one well per quarter section). The key conditions of a holding are that the area be made up of whole laterally adjoining DSUs comprising common mineral right ownership. The ownership must be common at both the lessor and lessee levels. Holdings are a useful tool for redefining well spacing rules to optimize recovery in certain geological and topographical environments where drilling to specific targets area is not practical. Examples of this would be drilling locations determined by 3-D seismic and surface locations in the foothills of the Province of Alberta. They are also a mechanism used to facilitate the drilling of horizontal wells. In holdings, horizontal wells can be drilled on the optimum trajectory and through multiple DSUs without regard for DSU or target area boundaries.

\section{Extracts from Oil and Gas Conservation Regulation - Part 4 Drilling Spacing Units and Target Areas Drilling Spacing Unit $\mathbf{- 4 . 0 1 0}$}

\footnotetext{
Attachments:

1. Part 4 of the Oil and Gas Conservation Regulation

2. $\S 5.190$ to 5.220 of the Oil and Gas Conservation Regulation

3. Interim Directive ID 94-2
}

Note: Schedule 14 of the Oil and Gas Conservation Regulation is not attached, as it is the same as Figures 1 to 4 of Interim Directive ID 94-2 
1. The drilling spacing unit for a well is the surface area of the drilling spacing unit and

(a) The subsurface vertically beneath that area or

(b) Where the drilling spacing unit is prescribed with respect to a specified pool, geological formation, member or zone, the pool, geological formation, member or zone vertically beneath that area.

2. A drilling spacing unit does not include the area of a road allowance.

AR $151 / 71$ s4.010;374/91; 112/98

\section{Normal Drilling Spacing Units $\mathbf{- 4 . 0 2 0}$}

1. The normal drilling spacing unit for an oil well is one-quarter section.

2. The normal drilling spacing unit for a gas well is one section.

3. Repealed AR $144 / 96$ s 10.

AR 151/71 s4.020; 295/78; 469/78; 374/91; 144/96

\section{Target Areas $\mathbf{- 4 . 0 3 0}$}

1. The target area for those wells drilled or to be drilled in the area of the province outlined and mark 1 on schedule 13 is as follows:

(a) If the drilling spacing unit is one section, the target area shall be the central part of the section;

(b) If the drilling spacing unit is one quarter section, the target area shall be the central part of the quarter section;

(c) If the drilling spacing unit is one legal subdivision, the target area shall be the central part of the legal subdivision.

2. The target areas for those wells drilled or to be drilled in the area of the province outlined and marked 2 on schedule 13 shall be within the drilling spacing unit, as follows:

(a) If the drilling spacing unit is one section, the target area shall be the central part of the section;

(b) If the drilling spacing unit is one half section, target area shall consist of legal subdivision 6 or 16 ;

(c) If the drilling spacing unit is one quarter section, the target area shall consist of legal subdivision $6,8,14$ or 16 ;

(d) If the drilling spacing unit is 2 legal subdivisions, the target area shall consist of the north-west quarter of the south-west or north-east legal subdivision of the quarter section;

(e) If the drilling spacing unit consists of one legal subdivision, the target area shall consist of the northwest quarter of the legal subdivision.

3. Legal subdivisions shall be divided into quarters by lines described as follows:

(a) Each east-west line shall be parallel to the south boundary of the legal subdivision and 
shall pass through a point on the east boundary of the legal subdivision, 200 meters north of the south-east corner of the legal subdivision;

(b) Each north-south line shall be parallel to the east boundary of the legal subdivision and shall pass through a point on the south boundary of the legal subdivision, 200 meters west of the southeast corner of the legal subdivision.

AR 151/71 s4.030; 264/74; 374/91; $12 / 98$

\subsection{5}

Repealed AR 374/91 s2.

\section{Special Drilling Spacing Units -4.040}

1. Notwithstanding sections 4.020 and 4.030 , the board may prescribe special drilling spacing units which may differ from normal drilling spacing units in size, shape or target area.

2. An application for an order pursuant to subsection (1) shall conform to the provisions of section 15.160 concerning such applications.

3. The board shall not grant an application for an order pursuant to subsection (1) that would reduce the size of drilling spacing units to less than the size of normal drilling spacing units unless the applicant shows that:

(a) Improved recovery will be obtained,

(b) Additional wells are necessary to provide capacity to drain the pool at a reasonable rate that will not adversely affect the recovery from the pool,

(c) The drilling spacing units would be in a pool in a substantial part of which there are drilling spacing units of such reduced size or

(d) In a gas field, increased deliver-ability is desirable.

4. The board may prescribe for an approved oil sands scheme or after publication of notice, for an experimental scheme

(a) Special drilling spacing units as to size, shape and target area or

(b) An area not having any specific drilling spacing units as to size, shape or target area within which wells may be drilled.

AR 151/71 s4.040; 374/91

\subsection{0}

1. Any person proposing to drill a well in a fractional section shall apply to the board for a special drilling spacing unit if the proposed drilling spacing unit differs in area from a normal drilling spacing unit by more than 5 per cent.

2. If the board by order declares a fractional section to be a drilling spacing unit, the board may apply either a production penalty based on the ratio of the area that the fractional section drilling spacing unit bears to a normal drilling spacing unit or an off-target penalty.

AR 151/71s4.050; 374/91 


\section{Off-Target Penalties $\mathbf{- 4 . 0 6 0}$}

1. Where the board has prescribed a special drilling spacing unit, it may prescribe a factor to be applied in reduction of the base allowable of the well if the well is not completed within its target area.

2. Notwithstanding any other provision of this section, where a well is off-target, the board may specify that the off-target penalty factor prescribed for the well pursuant to $\S 4.070$ shall not apply, or may be modified or changed, subject to such terms and conditions as the board may prescribe.

3. If a drilling spacing unit exists that is smaller than one quarter legal subdivision, but is similar in configuration as to shape and target area as to the larger drilling spacing units and where an off-target well exists in the smaller drilling spacing unit, the board, in order to determine the off-target penalty factor, may use and adapt the figures referred to in Schedule 14 to fit the boundary and area of the smaller drilling spacing unit.

4. If a well is completed within its target area, its base allowable shall not be reduced because of its location within its drilling spacing unit.

5. Where a well is spudded on or after April 1,1994 and is the first well in a new pool, the offtarget penalty factor prescribed for the well under $\S 4.070$ shall not apply.

6. For the purposes of this section,

(a) Capable, when the term is used in connection with a first well, means

(b) An oil well that is placed on production within 6 months of the spud date and

(c) A gas well that is completed and a suitable test has demonstrated to the board's satisfaction that the well has the ability to produce gas at commercial rates on a sustained basis;

(d) First well means the well in a new pool with the earliest spud date that is capable of production.

AR 151/71s4.060; 350/87; 374/91;226/93; 12/98

\section{Central Target Areas - Off-Target Penalty -4.070}

1. If a well is completed outside of its target area, its base allowable shall be reduced by a penalty factor determined in accordance with Schedule 14.

2. The point at which the off-target penalty factor is determined is the minimum horizontal distance, measured in meters, from any portion of the well bore within the oil or gas productive part of the producing pool to the nearest boundary of the drilling spacing unit.

3. Notwithstanding subsection (1) a well drilled before April 1, 1994 with an off-target penalty that is less than the off-target penalty factor determined by schedule 14 , shall retain its current penalty factor.

AR 151/71s4.070; 69/72; 2/76; 202/76; 250/77; 295/78; 469/78; 229/79; 267/82; 374/91; 12/98

\subsection{0}




\subsection{0}

1. If the board, by order or regulation, changes the drilling spacing unit so that a well in the drilling spacing unit that was on-target before the issuance of the order or regulation, is offtarget, the base allowable shall not be reduced because of its location within the drilling spacing unit unless the board otherwise directs.

2. Where any well was spudded on or before January 1,1992, it shall not become off-target nor have its off-target penalty changed due to the change in regulations.

AR 374/91 s3

\section{Extract from Part 5 of the Oil and Gas Conservation Regulation Establishment of Holdings - $\mathbf{5 . 1 9 0}$}

The board, on application and by order, may establish holdings.

$A R 217 / 88$ s5

\subsection{0}

A holding shall contain only:

1. A single drilling spacing unit or

2. Whole, contiguous drilling spacing units of common ownership.

AR217/88s5;226/93

\subsection{0}

The board may specify in an order establishing a holding any terms and conditions respecting the establishment, continuation and termination of the holding that it considers appropriate in the circumstances.

$A R 217 / 88$ s5

\subsection{0}

The board may, on application or on its own motion, where a holding fails to meet the requirements of $\S 5.200$ or the terms and conditions specified in an order establishing the holding,

1. Vary the area of the holding or any term or condition contained in the order establishing the holding by amending the order or

2. Rescind the order.

AR217/88 


\section{Interim Directive ID 94-2 \\ Revisions To Oil And Gas Well Spacing Administration \\ Background}

The oil and gas well spacing regulations and policy have received considerable review and some significant changes are appropriate. Extensive consultation with the Canadian Association of Petroleum Producers, the Small Explorers and Producers Association of Canada and the Alberta Department of Energy has taken place. The Energy Resources Conservation Board (board) will implement the changes summarized in the following paragraphs and in Attachments 1 through 3 on April 1, 1994.

\section{First Well in a Pool}

The optimum geologic location to drill the first well into a pool is often outside the existing target area. The board receives many applications to change target areas for first wells. Most operators apply before drilling to ensure on-target status and to avoid an off-target penalty that may result from subsequent pool development. These applications can alert competitors to the possible play and intervention may be filed resulting in long and costly delays. This, in effect, penalizes the company that takes the initiative to explore for a new pool. Accordingly, it is considered appropriate to establish a policy that recognizes those companies willing to take the risk associated with drilling exploratory wells.

Effective April 1, 1994, the board will not impose an off-target penalty on the first well in a pool. This policy will be reviewed periodically to ensure that benefits received by industry justify the administrative resources expended by the board. Should it be evident the policy is being abused or is unmanageable it may be rescinded or, alternately, a special charge may be introduced to deal with the resolution of such disputes. Details of the policy are described in Attachment 1 and apply to oil and gas wells.

\section{Off-Target Penalty Surveillance}

The change from prorated allowables in oil pools to an environment where rate controls are administered primarily for conservation purposes led the board to conclude that its role in monitoring off-target wells and lease-line drainage requires revision. The current policy of automatically applying off-target penalties in Maximum Rate Limitation (MRL) administered oil pools can result in the imposition of penalties when protection of correlative rights is not an issue. In addition, the increased use of holdings and miscellaneous orders to facilitate drilling of optimum geologic locations during pool development has resulted in fewer off-target wells.

Most oil wells do not have rate limitations because they are in pools subject to good production practice (GPP). The monitoring of off-target wells in GPP pools has been the responsibility of operators in the pools, with the onus on an affected party to bring equity concerns to the board. With approximately 75 percent of pools now on GPP, industry is presently responsible for much of the off-target surveillance.

Under the revised policy, the board will no longer automatically apply off-target penalties. It will require industry to monitor its respective oil and gas pools for off-target wells and bring 
equity concerns to the board using the procedures and policy outlined in Attachment 2.

\section{Off-Target Penalty Determination}

Off-target penalty factors are presently calculated using the formulas outlined in Part 4 of the Oil and Gas Conservation Regulations. Part 4 contains some nine pages of off-target penalty calculations and text, which are complicated and confusing to the user. The board has replaced the current penalty calculations with simplified figures that show specific off-target areas and the assigned penalty factors. The new method to determine an off-target penalty is shown in Attachment 3, Figures 1 through 4. It should be noted that the new method applies to wells spudded on or after April 1, 1994. Off-target wells spudded before April 1, 1994 will continue to have their offtarget penalties calculated in accordance with present regulations. The appropriate changes will be made to the Oil and Gas Conservation Regulations at a later date. Questions regarding this interim directive should be directed to the board's oil department.

\section{G. Berndtsson, P.Eng. Board Member}

\section{Attachment 1 to ERCB ID 94-2 First Well in a Pool Policy}

1. The first well policy is effective April 1, 1994 and applies to a well spudded on or after this date.

2. The first well in an oil pool is defined as the well with the earliest spud date that is capable of oil production and that commences oil production within 6 months $^{1}$ of the spud date.

3. A capable oil well is a well that is placed on production.

4. The first well in a gas pool is the well with the earliest spud date that is capable of gas production.

5. A gas well is considered to be capable when it is completed and a suitable test has demonstrated to the board's satisfaction that the well has the ability to produce gas at a commercial rate on a sustained basis.

6. The establishment of the first well designation will be initiated when a well of competitive ownership becomes capable and a request to apply the off-target penalty is made to the board. Note that the request to apply an off-target penalty shall contain the information, which justifies the application of the penalty. Until that occurs, the off-target well will produce without penalty in accordance with the off-target well policy presented on Attachment 2.

7. Upon a request to apply an off-target penalty, the board will review pool delineation using all available relevant information such as geological and pressure data. Where the well in question is deemed to be the first well in the pool, the off-target penalty will not be applied.

8. In the event that a well does not qualify for first well status, the well will be subject to an offtarget penalty effective the first day of the month following the date a request is received by the board to apply the penalty.

9. Where pools containing a well with first well status are coalesced, only one well will retain its first well status. However, the new pool will not be reviewed for first well status until a request is made to apply an off-target penalty. Until then, all wells with first well' status will produce without penalty.

\footnotetext{
${ }^{1}$ Where a well is not capable, within 6 months because it is required to comply with unique or area specific regulations, an extension may be requested.
} 


\section{Attachment 2 to ERCB ID 94-2 Off-Target Well Surveillance}

Effective April 1, 1994, industry will be responsible for off-target well surveillance. After this date, an off-target penalty factor will be applied to a new well being placed on production only upon successful request from a competitive operator. This shift to industry will require operators to monitor mineral leases offsetting their lands for off-target wells. Specifically, industry is required to make the initial assessment as to whether a well is off-target, and if off-target, whether application of an off-target penalty is warranted. To do this, an operator needs to know the following information:

1. Vertical well: the coordinates of the well's surface location,

2. Deviated or horizontal well: the coordinates of the well's surface and bottomhole locations,

3. The well spacing for the area of interest,

4. The general guidelines the board will be following in applying an off-target penalty and directional survey information, if applicable.

Information on well coordinates, well spacing orders, spud date and pool status (MRL/ GPP) is available from the board's information services. In addition, a daily listing of new wells licensed is available at the main floor reception desk.

\section{Procedure for Initiating an Off-Target Penalty}

1. Using the well's surface and bottom-hole coordinates and applicable well spacing orders, determine if the well is outside its designated target area.

2. Using the following general guidelines, determine whether an off-target penalty should be applied.

3. If application of an off-target penalty is warranted, submit a letter to the board, with a copy to the operator of the off-target well, requesting that an off-target penalty be applied.

\section{Guidelines for Applying Off-Target Penalty}

The board will apply the following general guidelines in determining if an off-target penalty should be applied:

1. Where the well is off-target towards a competitor's land containing a well producing from the same pool, application of the off-target penalty would be automatic.

2. Where the well is off-target away from a competitor's lands containing a well producing from the same pool, the off-target penalty would not normally be applied.

3. An off-target penalty factor for a well would not normally be initiated by a operator who is in a second, third or fourth line offset drilling spacing unit (DSU) without substantiating data proving inequitable drainage.

4. Notwithstanding points 2 and 3, the board may apply the off-target penalty where a well has gained access to a reservoir because of its off-target location.

5. The base rate for an off-target oil well will take into account the allowable administration of the pool. Where the pool is on MRL administration, the penalty factor would be applied to the well's MRL. In GPP oil pools, the board would consider the capabilities of the off-target well, wells in the immediate area and possibly other wells in the pool. Both parties will be provided 
with an opportunity to table input regarding the appropriate well rate.

6. For a gas well, the off-target penalty will be applied against its Qmax, as defined in $\S 10.300$ of the Oil and Gas Conservation Regulations.

7. Operators are reminded that normally only one well may be produced from each pool in a DSU. Failure to comply with this requirement will result in the assignment of overproduction plus any overproduction penalties to the DSU.

\section{Attachment 3 to ERCB ID 94-2 Off-Target Penalty Determination}

Wells spudded after April 1, 1994, shall have the off-target penalty factors determined in accordance with the attached figures. Please note that the numbers defining the width of the offtarget bands represent subsurface distances normally calculated at porosity top of the producing horizon, for vertical wells. For directionally drilled and horizontal wellbores, the actual location of the wellbore in the producing horizon is considered.

Please note a DSU does not include the area of any provincial road allowance. 
Appendix 5 


\section{RESOLUTION 01.126 \\ On U.S. EPA's Establishment of Electronic Reporting}

WHEREAS, the United States Environmental Protection Agency (EPA) has published a proposed rule in the Federal Register (66-FR-46162-46195) to establish electronic reporting and recordkeeping requirements, known as Cross-Media Electronic Reporting and Recordkeeping Rule (CROMERRR); and,

WHEREAS, CROMERRR could affect all 40 CFR programs including those EPA-approved state 1425 programs and EPA 1422 programs; and,

WHEREAS, CROMERRR could require such programs to modify the EPA-approved state programs if they are to accept electronic reports and allow electronic recordkeeping; and,

WHEREAS, CROMERRR could not "grandfather" existing programs; and,

WHEREAS, CROMERRR could require states to implement a variety of potentially expensive and onerous provisions; and,

WHEREAS, the Interstate Oil and Gas Compact Commission (IOGCC) recognizes the potential value of electronic recordkeeping, but is concerned about the potential costs to implement CROMERRR;

NOW, THEREFORE, BE IT RESOLVED that the IOGCC finds CROMERRR could require states to implement costly electronic reporting and recordkeeping requirements that discourage the use of electronic filing and recordkeeping; and,

BE IT FURTHER RESOLVED, that the IOGCC requests that EPA withdraw CROMERRR to provide an opportunity for review and restructuring in cooperation with the states and other stakeholders. 


\section{ACTION PLAN \\ RESOLUTION 01.126 \\ On U.S. EPA's Establishment Of Electronic Reporting}

1. Send copies of the resolution to all IOGCC governors, official representatives and all directors of member state oil and gas divisions.

2. Send copies of the resolution to President George W. Bush, Vice President Dick Cheney and EPA Director Christie Todd Whitman.

3. IOGCC staff would coordinate efforts to withdraw the rule with NGA, ECOS and other appropriate organizations.

4. Urge all IOGCC states to review the rulemaking and file comments with respect to the rule, sharing those comments with the IOGCC.

5. IOGCC will seek dialogue with EPA on the issue. 
Appendix 6 


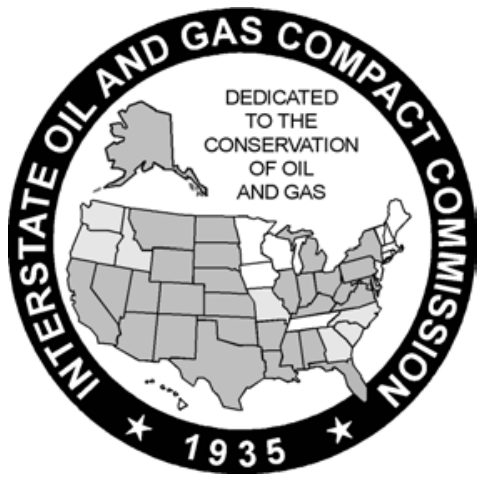

\title{
Interstate Oil and Gas Compact Commission
}

\author{
Bentonite Plugging Subcommittee
}

Report to the Environmental and Safety Committee

Evaluation of Compressed Sodium Bentonite for Use in Plugging and Abandoning Oil \& Gas Wells 


\section{Bentonite Plugging Study Subcommittee Members of the IOGCC Environmental and Safety Committee}

\section{Co Chairmen}

Michael W. Schmidt

Deputy Director, OCC Oil \& Gas Conservation Div.

P.O. Box 52000

Oklahoma City, OK 73152-2000

m.schmidt@occmail.occ.state.ok.us

James W. Collins

President, J.W.C. \& Associates

159 Oakview Drive

Cranberry Township, PA 16066

jwcconsulting@aol.com

\section{Members}

John R. Baza

Associate Director, Oil \& Gas

DNR-Div of Oil, Gas and Mining

P.O. Box 145801

Salt Lake City, UT 84114-5801

jbaza@state.ut.us

Stan Belieu

UIC Director/Petroleum Engineer

Oil \& Gas Conservation Comm.

P.O. Box 399

Sidney, NE 69162

sbelieu@hamilton.net

Rick Bender

Director, DMM B Division of Oil \& Gas

P.O. Box 2244

Frankfort, KY 40601

rick.bender@mail.state.ky.us

James E. Erb

Dir., Bur of Oil \& Gas Management

Dept. of Environmental Protection

P.O. Box 8785 5th Floor, RCSOB

Harrisburg, PA 17105-8765

jerb@state.pa.us 
Richard Ezeanyim, Chief Engineer

Oil Conservation Division, EMNRD

1220 S. St Francis Drive

Santa Fe, NM 87504

rezeanyim@state.nm.us

Sam Farris, Technology Transfer Coordinator

OK Marginal Well Commission

1218-B West Rock Creek Road

Norman, OK 73069

sfarris@mhs.oklaosf.state.ok.us

William F. Guerard, Jr.

State Oil \& Gas Supervisor

DEC-DOG \& Geothermal Res.

$801 \mathrm{~K}$ Street, 20th Floor, MS 20

Sacramento, CA 95814-3530

bguerard@,consrv.ca.gov

John T. King

Supervisor B Petroleum Engineering Section

Public Service Commission

P.O. Box 30221

Lansing, MI 48909-7721

john.t.king@cis.state.mi.us

Charles C. Ross

Deputy Director, Field Operations

Texas Railroad Commission

1701 North Congress

Austin, TX 78711-2967

charles.ross@,rrc.state.tx.us

Barry R. Salsbury

Chief Operating Officer

Chevron Abandonment Services

935 Gravier

New Orleans, LA 70112

barrysalsbury@chevrontexaco.com

Robert F. Van Voorhees

Attorney

Bryan Cave, LLP

700 13th Street, NW, Ste 700

Washington, DC 20005-3960

rfvanvoorhees@bryancave.com 
Bob Blalock

Western Regional Manager

Benterra Corporation

4900 California Ave. Suite A135

Bakersfield, CA 93309

bbbl@,chevrontexaco.com

Liz Fajen

Executive Director

OK Marginal Well Commission

1218-B West Rock Creek Road

Norman, OK 73069

lfajen@mhs.oklaosf.state.ok.us

Vance LeBeau

Manager Field Operations

Oklahoma Corporation Commission

P.O. Box 52000-2000

Oklahoma City, OK 73152-3127

v.lebeau@,occmail.occ.state.ok.us 


\title{
Table of Contents
}

\subsection{Executive Summary}

\subsection{Procedures, Standards and Guidelines}

2.1 Material Specifications and Selection

2.2 Plug Characteristics

2.3 Design Specifications

2.3.1 Base

2.3.2 Plug Length

2.3.3 Plug Volume

2.4 Verification of Plug Locations

2.5 Hydration Fluid Specifications

\subsection{Technical Questions and Answers}

3.1 How can correct plug placement be assured?

3.2 What are the relative cost differences between compressed bentonite and cement?

3.3 How long does it take for a bentonite plug to hydrate?

3.4 What happens if a bentonite plug dehydrates/rehydrates?

3.5 Will a bentonite plug hydrate in salt saturated fluid?

3.6 When should a bentonite plug not be used?

3.7 What is the compressive strength of a bentonite plug?

3.8 What does gas influx into the well do to a bentonite plug?

3.9 What are the permeability differences between bentonite and cement plugs?

\subsection{Regulatory Barriers}
4.1 California
4.2 Kentucky
4.3 Nebraska
4.4 New Mexico
4.5 Ohio
4.6 Oklahoma
4.7 Pennsylvania
4.8 Utah
4.9 Texas

\subsection{Pilot Projects}

\author{
5.1 California Pilot \\ 5.1.1 Purpose \\ 5.1.2 Scope \\ 5.1.3 Findings \\ 5.2 New Mexico Pilot \\ 5.2.1 Purpose \\ 5.2.2 Scope \\ 5.2.3 Findings
}


5.3 Oklahoma Pilot

5.3.1 Purpose

5.3.2 Scope

5.3.3 Findings

5.4 Texas Pilot

5.4.1 Purpose

5.4.2 Scope

5.4.3 Findings

6.0 Findings and Conclusions

Appendix A; Questions and Answers

Appendix B; References

Appendix C; Example Well Diagram

Appendix D; Photos

Appendix E; Plug Length Curves

Appendix F; Operation Guidelines for Compressed Sodium Bentonite Well Plugging Operations, California DOGGR

Appendix G; Operation Guidelines for Compressed Sodium Bentonite Well Plugging Operations, New Mexico Oil Conservation Division, EMNRD 


\subsection{Executive Summary}

In May 2001 the IOGCC Environmental and Safety Committee created the Bentonite Subcommittee to investigate the viability of using highly compressed sodium bentonite nodules to plug and abandon oil and gas wells.

The subcommittee's task was to determine if compressed sodium bentonite was a viable alternative to cement in well plugging operations and, if so, what technical issues or regulatory barriers exist that would prevent the use of compressed sodium bentonite as a plugging agent and, if so, how those barriers could be eliminated. This report addresses these issues and concerns presented to the Environmental and Safety Committee. A draft of this report was presented to the Environmental and Safety Committee at the December 2001 Annual IOGCC Meeting in Santa Fe, NM.

The report describes several types of well completions and the generic well plugging processes using compressed sodium bentonite as the plugging agent and outlines standards and guidelines for use and design specifications. Plug characteristics, plug hydration, and pilot studies are discussed. The subcommittee also surveyed its member states as to any existing regulatory barriers to the use of sodium bentonite as a plugging agent in those states. Responses to questions from subcommittee members are also included in Appendix A.

The subcommittee finds that compressed sodium bentonite is a viable alternative for use in most typical oil and gas well plugging and abandonment procedures. The process provides a nearly impermeable, permanent plug that can be easily drilled out should the need arise for future use of the wellbore and, depending on wellbore conditions, reduces the cost involved by eliminating the need for servicing rigs, trucks, and equipment normally used in plugging operations. However, certain wellbore conditions will prohibit the use of compressed sodium 
bentonite. These conditions include, but are not limited to, the presence of high saline fluids, downhole obstacles, high wellbore pressures, and highly deviated wellbores.

It should be noted that ChevronTexaco has patented this product and the product is being marketed under the name of "Zonite". Benterra Corporation, a subsidiary of ChevronTexaco, is the marketing agent and well plugger performing the pilot projects. ChevronTexaco is attempting to license out the use of this product to other companies to make the product more available for use and to increase the competitiveness of the market. 


\subsection{Procedures, Standards and Guidelines}

The American Petroleum Institute, in their report entitled "Environmental Guidance Document: Well Abandonment and Inactive Well Practices for U. S. Petroleum and Production Operations", states that well plugging and abandonment procedures are done to achieve the following results:

- Isolate hydrocarbon-bearing zones and formations

- Isolate high-pressure and other anomalous zones

- $\quad$ Protect freshwater-bearing (groundwater) zones

- $\quad$ Protect public safety and the environment

Achieving the above criteria is essential whether plugging with conventional cement or other approved or accepted plugging agents, such as compressed sodium bentonite. A typical problem associated with conventional cement plugging procedures is the cement curing improperly or irregularly due to gas cutting, water channeling or dilution. Also, casing degradation or collapse, collapse of the wellbore, seismic events, and other downhole changes may cause deterioration of the cement plug over time.

Compressed sodium bentonite has the following advantages when compared to cement as a well sealing medium:

Flexibility (an ability to adjust to changes in wellbore conditions due to casing failure, geologic movement, and other downhole changes while maintaining a viable seal, i.e., a "living plug").

Lower permeability coefficient.

May result in reduced equipment use, expense, and logistics (i.e., surface pour, no pumping equipment necessary for many applications). 
May impede or eliminate gas migration due to its swelling capability and may work well at trapping and shutting off gas and gas migration.

Ease of reentry or drill out should the need arise.

Compressed sodium bentonite has the following disadvantages when compared to cement as a well sealing medium:

$>$ Inability to be pumped (depth, deviation, and pressure considerations).

$>$ Inability to be squeezed behind casing and or around downhole obstacles.

$>$ Possibility of bridging during placement due to improper application rate.

Hydration fluid salinity limitation.

$>$ Well control concerns (lack of tubing/pipe in hole for control purposes).

Most of these disadvantages may be mitigated with proper care and further research. For instance, the proper application rate reduces the likelihood of downhole bridging. Also, most wells being plugged and abandoned are at the end of their life cycle and have little, if any, remaining reservoir pressure. This in itself greatly reduces the chance of losing well control. However, in some areas up hole formations may exhibit pressures that may cause loss of well control. It is recommended that a hydraulic wellhead valve be installed during application. The proper placement of a compressed sodium bentonite plug depends on gravitational fall to an artificial base. If the well is flowing, the use of compressed sodium bentonite as a plugging agent would be limited. Wells can still be plugged under flowing conditions using compressed sodium bentonite as long as the weight of the material exceeds the pounds per square inch (psi) force of the fluid flow. The effects of high salinity fluids on the hydration of compressed sodium bentonite are being tested but as of yet the results indicate that the presence of such fluids will 
inhibit the proper hydration of compressed sodium and cause plug failure. This is been proved during several of the pilot projects.

Concerns have also been expressed about the compressive strength of a hydrated sodium bentonite plug. Compressive strength is a measurement of a material's ability to withstand a compressive load without breaking or shearing and thus is an indicator of a structure's durability. A standard cement plug will have a compressive strength between 3,000 and 4,000 psi; the compressive strength of a hydrated sodium bentonite plug is approximately 175 psi. A hydrated sodium bentonite plug does not have the load-bearing capacity of a cement plug but the primary purpose of a plugging agent is not to support a load; it is to create an effective permeability barrier. However, any plugging agent must be able to withstand any pressure exerted by the upward migration of formation fluids under pressure (another form of load) without losing integrity. Testing continues in the pilot projects as to the ability of a hydrated compressed sodium bentonite plug to withstand this type of load.

2.1 Material Specifications and Selection - Historically, sodium bentonite has been known as an excellent plugging material due to its expansion characteristics. The material specifications of the sodium bentonite reviewed in this report met the following criteria:

* The specific gravity of the dry product was 2.0 or greater.

* The $\mathrm{pH}$ was between 6 and 12 .

* The chemical composition make-up was approximately $63 \% \mathrm{SiO}_{2}, 21 \% \mathrm{Al}_{2} \mathrm{O}_{3}$, and $16 \%$ other.

Sodium bentonite meeting the above material specifications has undergone extensive research and testing. Any substantial variations from this material composition should be 
reviewed and approved by the regulatory authority prior to its use and application in oil and gas well plugging operations.

2.2 Plug Characteristics - The following table shows the characteristics of compressed sodium bentonite in comparison to the properties of typical abandonment-grade cement.

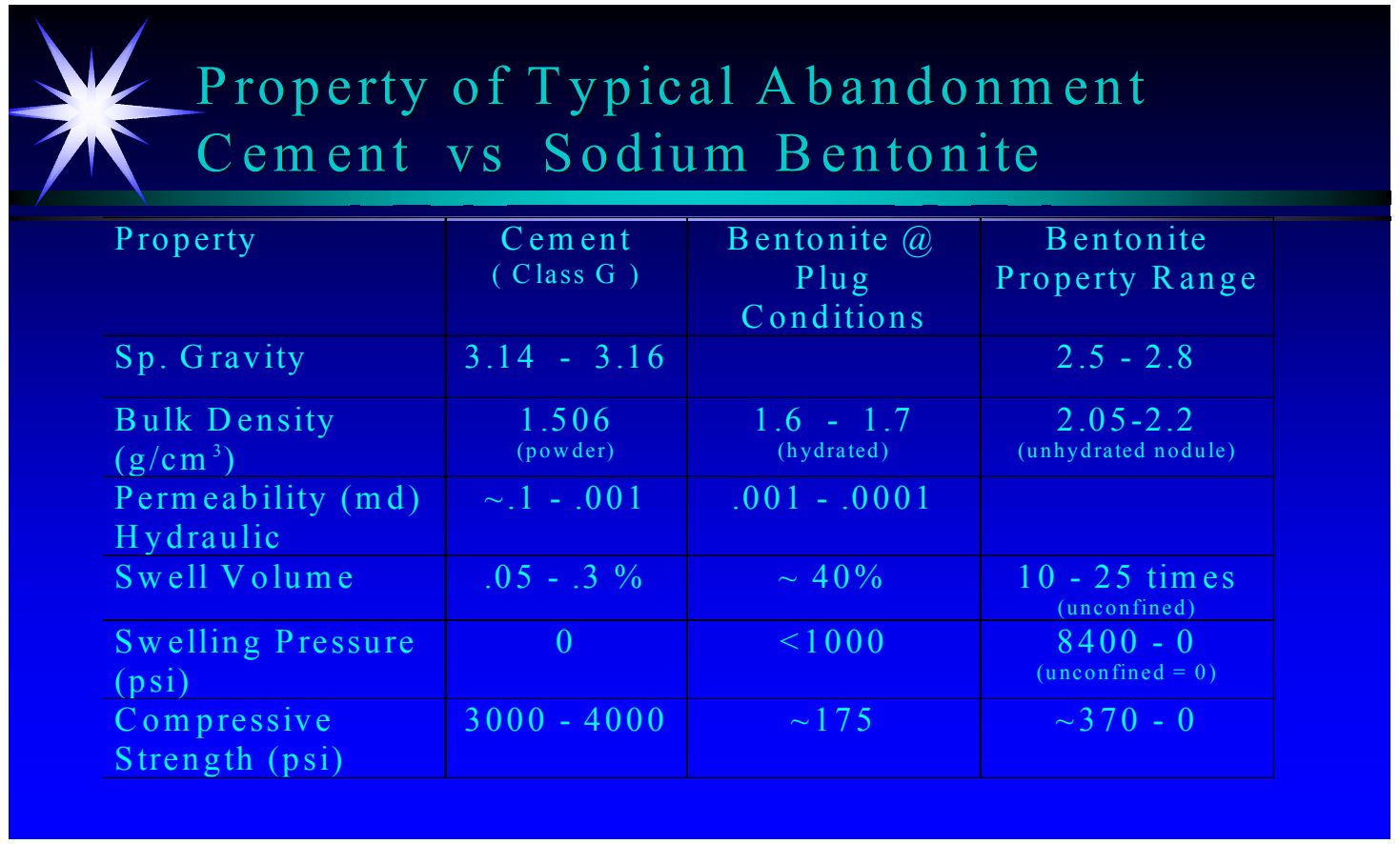

To achieve the minimum desired permeability level $(<0.1 \mathrm{md})$, the density of a hydrated plug must meet a minimum threshold of $1 \frac{1}{2} \mathrm{~g} / \mathrm{cm}^{3}$. The permeability of a hydrated sodium bentonite plug is inversely proportional to the hydrated plug's density. In other words, the more dense the plug, the less permeable it is. Compressed sodium bentonite with a density of 2.1 $\mathrm{g} / \mathrm{cm}^{3}$ will yield a hydrated plug having a density of $1.66 \mathrm{~g} / \mathrm{cm}^{3}$ at $40 \%$ water saturation. At this density, hydraulic permeability will be between $0.001 \mathrm{md}$ to $0.0001 \mathrm{md}$.

The following calculation can be used to determine the density of a hydrated plug.

$$
\gamma \mathrm{P}=(1-\varphi)(\gamma \mathrm{B})+\varphi(\gamma \mathrm{W})
$$

Where: 
$\gamma \mathrm{P}=$ Calculated density of the hydrated plug.

$\gamma \mathrm{B}=$ Density of the compressed sodium bentonite nodule, pellet, or flake.

$\varphi=$ Percentage of the bulk volume not occupied by the un-hydrated bentonite nodule, pellet or flake (i.e. the "void volume").

$\gamma \mathrm{W}=$ Density of the hydration water.

Example: Sodium bentonite nodules with a density of $2.1 \mathrm{~g} / \mathrm{cm}^{3}$ are used to form a plug in fresh water. The packing efficiency is estimated to result in 60 percent of the bulk volume consisting of bentonite solids and 40 percent of the bulk volume to consist of fresh water. The calculation yields:

$$
\begin{aligned}
& \gamma \mathrm{P}=(1-0.4)(2.1)+(.4)(1.0) \\
& \gamma \mathrm{P}=1.26+0.4 \\
& \gamma \mathrm{P}=1.66 \mathrm{gm} / \mathrm{cm}^{3}, \text { the density of the hydrated plug. }
\end{aligned}
$$

It should be noted that the sodium bentonite plug densities and permeability are based upon measured and observed levels of partial hydration based on the packing efficiency and available pore space for the hydrating fluid. While all indications are that this ideal level of hydration occurs in practice, improper conditions may allow further hydration yielding plug densities of $1.55 \mathrm{~g} / \mathrm{cm}^{3}$ at $50 \%$ water saturation, $1.44 \mathrm{~g} / \mathrm{cm}^{3}$ at $60 \%$ water saturation, and 1.33 $\mathrm{g} / \mathrm{cm}^{3}$ at $70 \%$ water saturation with all variations in between.

2.3 Design Specifications - The design specification for use of compressed sodium bentonite as a plugging agent must address a base for the initial plug placement, plug length to withstand the anticipated differential pressures, and plug volume.

2.3.1 Base $-\mathrm{A}$ base is required for the initial placement of sodium bentonite plugs to initiate bridging and the top of the base must be verifiable. 
The following materials have been used successfully as base materials:

- Gravel

- Sand

- Bridge plugs

- Cementing wiper plugs

- Natural fill or bottom of hole

2.3.2 Plug Length - Three factors determine the appropriate length of the compressed sodium bentonite plug, pressure, wellbore size, and friction. The appropriate plug length is determined from the amount of differential pressure each plug will encounter. The greater the differential pressure, the greater the plug length required. Wellbore size and friction factor also determines effective plug length. Determination of required plug length is easily calculated by use of a plug length diagram similar to Figure 2. Additional diagrams for 7 " and $85 \%$ " casing are found in Appendix E.

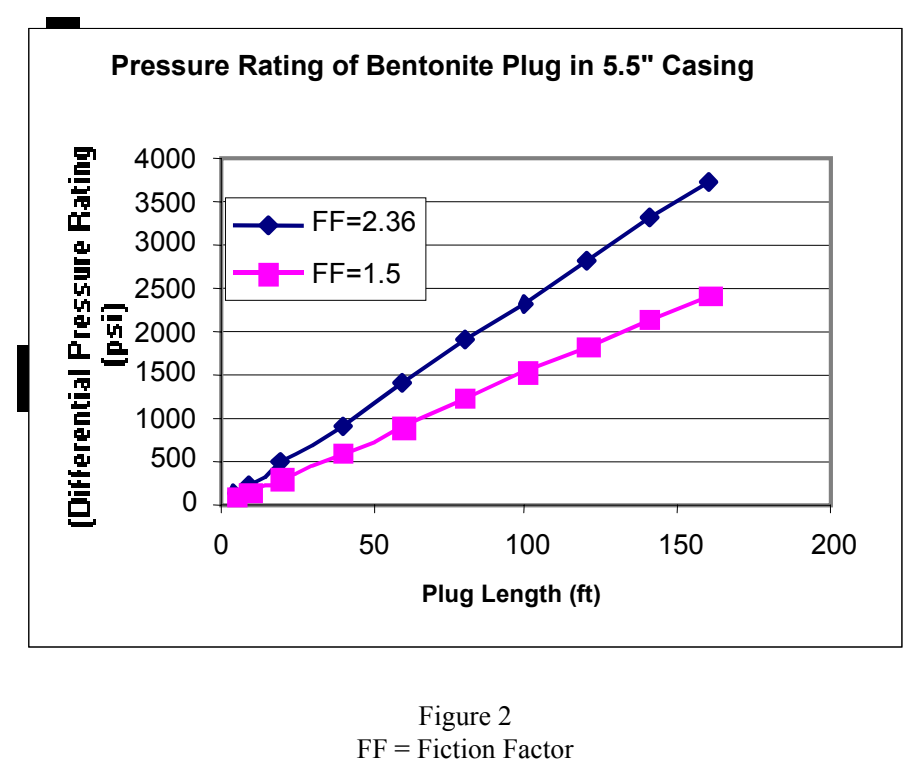


Since a hydrated compressed bentonite plug is essentially impermeable, the pressure limitation of a plug is the pressure it can withstand without dislodging from the casing wall or wellbore and moving up or down the wellbore. The greater the differential pressure, the greater the plug length required. Friction, generated by the swelling pressure of the compressed bentonite against the casing wall, is what keeps the plug in place. The frictional resistance increases proportionally with the length of the plug. The longer the plug, the greater the frictional resistance and the less likely it is to dislodge. In many cases, the wellbore or casing may contain materials that inherently decrease friction factors, such as oil and/or emulsions, reducing the dislodgement pressure. It is recommended that the plug length include a safety factor of $10 \%$ to $15 \%$. The dislodgment pressure decreases as casing or wellbore diameter increases.

Friction factors for hydrated compressed bentonite plugs have been measured in the laboratory using plugs from 4 to 6 inches in diameter and up to 15 feet in length. Towler and Ehlers at the University of Wyoming and Lutenegger and DeGroot at the University of Massachusetts performed these types of tests.

Using the friction factors determined in the laboratory, a 100 -foot plug in $5 \frac{1}{2}$ inch casing should withstand a differential pressure of 1,500 to 2,300 psi. A 100-foot plug in 7-inch casing should withstand pressures between 1,200 and 1,800 psi. In $85 / 8$ " casing a 100 -foot plug should withstand pressures between 1,000 and 1,500 psi. These determinations represent ratings when pressure is applied from below the plug. The ratings are $10 \%$ to $20 \%$ lower when pressure is applied from above. Pressure Rating Charts for 7" and 85/8" casing are found in Appendix E: Plug Length Curves. 
The New Mexico and Texas pilot projects are evaluating the dislodgment pressures of plugs installed in actual wellbores.

2.3.3 Plug Volume - The plug volume is calculated on the bulk volume occupied by the dry compressed sodium bentonite plugging material within a specified casing size.

Example: A 100 foot plug set within 7-inch (26 pounds per foot) casing using compressed sodium bentonite nodules. The capacity of 100 feet of casing is $\left(100 \mathrm{ft}\left(0.2148 \mathrm{ft}^{3} / \mathrm{ft}\right)\right.$ $=21.48$ cubic feet.

2.4 Verification of Plug Locations - The state regulatory authority may require that the bottom and top of each plug be verified. Verification can be done by use of a slick line, other wire line devices, other generally accepted measuring devices, or tubing.

2.5 Hydration Fluid Specifications - Compressed sodium bentonite has been shown to hydrate in fresh water and formation waters with chlorides less than 12,000 mg/l and temperatures less than $420^{\circ} \mathrm{F}$. Hydration characteristics with fluids containing chlorides greater than $12,000 \mathrm{mg} / \mathrm{l}$ are being evaluated. Hydration fluid characteristics may alter the effectiveness and efficiency of the hydrated plug. 


\subsection{Technical Questions and Answers}

Questions regarding the use of compressed sodium bentonite as a plugging agent were received from eight states. These questions are summarized below. The specific questions and answers are included in Appendix A.

\subsection{How can correct plug placement be assured?}

Any generally accepted measuring device, such as a slick line, may verify placement of the plug. Waiting time is not necessary, as hydration of the compressed sodium bentonite will commence immediately upon contact with water. The plug will adhere to the casing walls rapidly. The recommended procedure for compressed sodium bentonite plugging operations is:

1. Approval from the appropriate state regulatory representative as to the depth and length (volume) of each plug. This approval will include authorization to remove any casing or the perforation or cavity shot used to isolate any hydrocarbon-bearing, salt water-bearing, or fresh water-bearing formations. (A cavity shot is a procedure that removes a 10 to 20 foot section of casing by explosive devises to expose the annulus of the wellbore.)

2. Verification of the placement of the base of the plug by a generally accepted measuring device (the appropriate state regulatory personnel may require this process to be witnessed).

3. Placement of the calculated volume of material in the wellbore.

4. Verification of the placement of the top of the plug by a generally accepted measuring device (the appropriate state regulatory personnel may require this process to be witnessed).

5. Verification that the hydration fluid level remains above the top of the plug until the 
plug has hydrated.

\subsection{What are the relative cost differences between compressed sodium bentonite and} cement?

The cost advantage to using a compressed sodium bentonite plug will vary significantly by application. SPE Paper 66496 addressed this based on the results of the field pilot conducted in California in 2000. Quoting from the SPE Paper, "With the elimination of coiled tubing units, pump trucks and bulk units, along with other process improvements, anticipated cost savings using sodium bentonite are estimated at $20 \%$ to $40 \%$ over traditional experience."

\subsection{How long does it take for a compressed sodium bentonite plug to hydrate?}

Compressed sodium bentonite will generally hydrate within 18 to 48 hours depending on temperature and hydration fluid. It may take several weeks for a hydrated plug to become fully homogeneous and reach equilibrium with the wellbore environment.

\subsection{What happens if a compressed sodium bentonite plug dehydrates/rehydrates?}

Dehydration or desiccation of hydrated sodium bentonite is assumed to occur only when exposure to the atmosphere promotes evaporation. Once hydrated and encased in a well buried below the surface, the potential exposure is eliminated. There are some concerns about sodium bentonite plugs placed in vadose zones (surface plugs) dehydrating. One of sodium bentonite's inherent strengths is its long-term stability in terms of geologic time.

In their Sandia National Laboratories report, Jaak Daemen and Chongwei Ran wrote, "Oscarson et al (1990) compared the swelling pressures and hydraulic conductivity of processed and unprocessed bentonite to identify the longevity of the bentonite seal."...'Unprocessed bentonite maintains a significantly high swelling capacity and low permeability after millions of 
years of water erosion, thermal alteration, loading and unloading. Its latent swelling characteristics do not diminish with time."

\subsection{Will a compressed sodium bentonite plug hydrate in salt saturated fluid?}

Test data indicates the plugs will hydrate; however, the properties of such a plug have not been fully determined but appear to be inadequate for a competent well plug. Fresh water is preferred since the sodium bentonite swells more, and hydrates faster. Fresh water was the hydrating medium used in tests to determine plug properties. Produced water containing less than $12,000 \mathrm{ppm}$ chloride forms an acceptable, hydraulically solid plug. Additional testing is required before using this method with high chloride content water as the hydration fluid.

\subsection{When should a compressed sodium bentonite plug not be used?}

Currently, the only known conditions that would prohibit the use of compressed sodium bentonite plugs are conditions that would require filling casing annular spacing, squeezing into a formation, or where downhole obstacles impede the fall of the pellet preventing the proper placement of the plug. The presence of high saline fluid will prohibit the use of compressed sodium bentonite. Depth and deviation limitations on placement are still being evaluated. The vast majority of wells requiring abandonment are less than 5,000 feet and are ideal candidates for highly compressed sodium bentonite. The compressed nodules are designed to fall through a column of water without prematurely forming a plastic mass, bridging off the wellbore.

\subsection{What is the compressive strength of a compressed sodium bentonite plug?}

The compressive strength of a hydrated compressed sodium bentonite plug is approximately 175 psi, which is low when compared to cement. However, a high compressive strength is not required for many wells being plugged. The value of a compressed sodium 
bentonite plug is that it is essentially impermeable, remains pliable and will expand to fill voids while retaining its sealing properties.

\subsection{What does gas influx into the well do to a compressed sodium bentonite plug?}

A plug using compressed sodium bentonite as the sealing agent has shown in tests to effectively seal off gas influx without channeling as is commonly found when cement is used as the sealing agent. This is due to the swelling characteristic of bentonite as it is hydrated. Dr. Roland Pusch, a noted expert on nuclear repository borehole sealing, addressed the gas influx issue as follows: "A number of gas percolation experiments have been made using hydrogen, nitrogen and helium. In these tests, plugs of compacted bentonite and mixtures of bentonite and 'ballast' sand/silt have been exposed to successively increased gas pressure for recording critical threshold conditions. The penetration mode has been identified and modeled. The understanding of mechanisms and conditions for gas penetration of plugs of smectitec materials is concluded to be satisfactory for the nuclear industry."

Pusch and Hokmark (1990) concluded through modeling that the macroscopic hydraulic conductivity to gas appears to be of the same order of magnitude as that of water, i.e., about $10^{-13}$ $\mathrm{m} / \mathrm{s}$ for dry densities of about 1.7 to $1.8 \mathrm{~g} / \mathrm{cm}^{3}$.

\subsection{What are the permeability differences between compressed sodium bentonite}

\section{and cement plugs?}

In a paper prepared by Sandia National Laboratories, Jaak Daemen and Chongwei Ran wrote, "Bentonite has excellent sealing performance and has been selected as a principal sealing component for numerous nuclear waste repositories. Bentonite has an extremely low hydraulic conductivity, is self-healing and has good chemical stability that would provide effective longterm sealing. Bentonite can penetrate rock fractures by either viscous flow or expansion. 
Bentonite suspensions can form barriers at low solids concentrations. Bentonite can generate swelling pressure when water or brine penetrates the clay. Swelling of the seals increases the internal supporting pressure in the shaft and fractures and should accelerate healing of any disturbed rock zone. Swelling of bentonite also can assist in sealing fractures caused by structural damage or by rock block displacement by self-penetration into the fractures; it should also help in obtaining tightness between seals and host materials." They also mention that the permeability of dense bentonite is about $10^{-3} \mathrm{md}$.

One of the hydrated plugs was cored in the California pilot, well \#2-7, Section 25D. The permeability measured from the core was $1.4 \times 10^{-3} \mathrm{md}$. The permeability of typical cements used for plugging operations range from $1 \times 10^{-1}$ to $1 \times 10^{-3} \mathrm{md}$. The major difference is not in the permeability coefficient itself but in the rigidity of the plug once formed. Cement plugs become rigid and are subject to micro annuli and fractures that may result in the migration of fluids around or through the plug. The swelling capacity and plasticity of the sodium bentonite plug prevent micro annuli and fractures, thus reducing the likelihood of fluid migration. 


\subsection{Regulatory Barriers}

Members of the Bentonite Subcommittee analyzed their state plugging regulations to see if there were barriers to the use of compressed sodium bentonite nodules for plugging oil and gas wells. Where barriers exist, committee members discussed the options that would be available to eliminate these barriers. This section summarizes these discussions.

4.1 California - Some regulatory change needed.

Current California rules provide for "or as approved" regarding alternate plugging materials but not processes. Regulatory changes will be needed to remove the mud as the required hole fluid.

4.2 Kansas - Some regulatory change needed.

Current Kansas rules specify the use of cement for well plugging operations.

4.3 Kentucky - Some regulatory change needed.

Kentucky rules allow for "cement or other suitable material" in coal producing regions. In noncoal producing regions only cement is allowed.

4.4 Nebraska - No regulatory change needed.

4.5 New Mexico - No regulatory change needed.

Current New Mexico language allows for "other approved material".

4.6 Ohio - No regulatory change needed.

4.7 Oklahoma - Some regulatory change needed.

The Oklahoma Corporation Commission amended its well plugging rules effective July 1, 2002, to allow the use of alternate well plugging procedures and or material (plugging agents) approved by the appropriate regulatory personnel at the Commission.

4.8 Pennsylvania - No regulatory change needed.

Current rules provide for alternate processes and materials. 
4.9 Utah - No regulatory change needed.

The current Utah rules state "or as approved" which allows a variance as long as it meets the basic plugging requirements.

4.10 Texas - Some regulatory change needed.

Current Texas regulations specify the use of API cement for well plugging. Texas needs to amend the rules to allow for alternate materials and processes. 


\subsection{Pilot Projects}

Pilot Projects were conducted or are being conducted in four states: California, New Mexico, Oklahoma, and Texas. The following is a brief description of each project including the project's purpose, scope, and findings.

\subsection{California Pilot}

On March 15, 2000, a 19-well pilot project was commenced on Chevron leases in Coalinga, California, with the approval of the California Division of Oil, Gas and Geothermal Resources (DOGGR).

5.1.1 Purpose - The objectives of the pilot were to assess the following:

- Could compressed sodium bentonite nodules be effectively placed at depth?

- Would the compressed sodium bentonite nodules hydrate to form an impermeable plug?

- What permeability characteristics would the hydrated plugs exhibit?

- What verification and witnessing procedures were required?

- Could cost savings be realized?

5.1.2 Scope - The pilot project originally entailed 19 wells, consisting of producers, cyclic wells and water injection wells, ranging in depth between 605 feet and 3,405 feet. Two and three plug designs, both with and without fresh water present, and with and without cement behind pipe were required for the wells. All pilot designs used either gravel or bridge plugs as a base, and all designs used lease water as the hydration hole fluid.

5.1.3 Findings - The major conclusions of the pilot were: 
- Compressed sodium bentonite can be successfully placed in wells and hydrated to form an impermeable plug in oil and gas wells (sample results demonstrated a water permeability of $0.0014 \mathrm{md})$

- The compressed sodium bentonite nodules could be hydrated using produced water as the hole fluid $(6,000$ to $12,000 \mathrm{mg} / \mathrm{L}$ chlorides $)$

- Oil-in-water or an oil column does not impede the ability of the compressed sodium bentonite to form a plug

- Hydration of the compressed sodium bentonite nodules is accelerated with increasing temperatures

- Wells abandoned with compressed sodium bentonite can be reentered using a softformation drilling assembly

- Cost savings could be achieved through use of the compressed sodium bentonite nodules

The initial 19-well program was carried out to test application procedures for compressed sodium bentonite. During the project, a number of problems developed and the program was expanded to include more than 100 wells to further refine the process. After about 100 wells were plugged, no defined application process had been developed. The DOGGR called for an industry peer review to obtain broader input into the process. The peer review resulted in Operational Guidelines (Appendix F) being developed to fulfill regulatory requirements. More than 500 additional wells have been abandoned using compressed sodium bentonite since approval of the guidance document. 


\subsection{New Mexico Pilot}

In September 2001 through March 2002, a 25 well pilot project was conducted on Chevron leases in Lea County New Mexico with the approval of the New Mexico OCD.

5.2.1 Purpose - The purpose of the New Mexico pilot project was to demonstrate that:

- Bentonite can be accurately placed in the wellbore without bridging.

- Bentonite plugs stay in place.

- Bentonite plugs will withstand differential pressure without dislodging.

- Bentonite plugs are impermeable.

- Bentonite plugs can be placed in wellbores not cemented to surface.

- The process is safe and environmentally friendly.

- The process is cost competitive with conventional cement abandonments.

5.2.2 Scope - Twenty- five wells were abandoned in the Lea County, New Mexico area under the direction of the OCD District 1 supervision of Chris Williams, Gary Wink and Paul Kautz. The wells included oil wells, gas wells and water source wells. Plugs were set as deep as 4300 ' within casing sizes ranging from $4 \frac{1}{2}$ " to $95 / 8$ ". Twelve wells had production casing cemented to surface requiring only bentonite plugs to be set inside the casing. The other thirteen wells were not cemented to surface. Of these, bentonite was placed behind pipe in 4 wells by cutting and pulling the production casing. In 3 other wells, bentonite was placed behind pipe by shooting a cavity shot. Six wells required cement to be squeezed or circulated behind the casing, resulting in several hybrid cement/bentonite abandonments. The average well required 4 to 5 separate plugs.

5.2.3 Findings - As part of the pilot protocol, many of the wells were not initially plugged all the way to the surface to allow better monitoring of the downhole conditions. No 
plug leaks were detected. Plug placement was extremely successful. Of the 112 plugs set, only 1 bridged prematurely. Plugs did not dislodge unless a significant differential pressure was applied before these were fully hydrated. In three wells, the bottom hole pressure was overestimated, resulting in a plug that was too short to withstand the differential pressure applied by a full column of water in the well bore. As the pilot progressed, the placement issues were better understood and successfully addressed. Full hydrostatic head plus 500 psi was applied to several plugs while attempting to circulate wells.

The plugs have shown no signs of being permeable. This was demonstrated in many low-pressure wells by setting the bottom plugs and then filling the well bore with water to apply a differential pressure to the plug. The permeability (to water) of one of the plugs was measured by CORE Laboratories and was determined to be $1.04 \times 10^{-3}$ millidarcies. The plugs have also shown an excellent capability to shut off gas migration. In one well, after the bottom plug was set and the well was filled with water, the well would build to 120 psig of gas pressure in a short amount of time and gas bubbles could be seen. Casing damage was suspected in a historically high pressure/low volume gas zone above the bottom plug. A bentonite plug was placed above the suspected source zone and the gas was immediately shut off.

Nine cavity shots were performed and the wire line became stuck in the first 2 attempts. Operational modifications were made to correct this and the shots were successfully completed. Four of the nine cavity shots were completed with cement or by pulling casing in response to a variety of mechanical issues. These included a well that flowed water after the cavity shot, a well where the casing parted above the cavity shot and a well where it appeared that multiple annuli were uncemented and in communication with the surface during testing after the cavity shot. 
Five casing pulls were attempted and successfully completed on four of the five wells. The failed operation involved a well drilled with cable tools in 1937 and the casing would not come free of the wellhead.

The pilot work required minimal use of well servicing units and very little handling of fluids in pits resulting in very safe and clean operations.

In response to the success of the pilot, the New Mexico OCD District 1 staff approved a "Bentonite Plugging Operational Guidelines" on May 14, 2002, which allows the use of compressed sodium bentonite under specific conditions.

\subsection{Oklahoma Pilot}

In September 2001, six wells were plugged and abandoned in Oklahoma with the approval of the Oklahoma Corporation Commission and the EPA. All six wells were orphan wells. Four of the wells were located in Logan County, just north of Oklahoma City and the other two were located near Lake Oologah, north of Tulsa.

5.3.1 Purpose - The purpose of the Oklahoma pilot project was to demonstrate the bentonite plugging process to the OCC and the EPA. This work was conducted under the supervision of Mike Schmidt, Vance LeBeau, Larry Adams and Mike McChesney of the OCC, and Jackie Fowler, the Lake Oologah EPA representative. In addition, the demonstration was scheduled to coincide with a meeting of the IOGCC bentonite plugging sub-committee in Oklahoma City. The focus areas were to demonstrate that:

- The bentonite can be accurately placed in the wellbore without bridging.

- The bentonite plugs can be placed in wellbores not cemented to surface.

- The process is safe and environmentally friendly. 
5.3.2 Scope - The four Logan County wells all had free (not cemented) $4 \frac{1}{2}$ " casing set between 2,300 feet and 3,300 feet. The wells required a bottom plug, a plug at the surface casing shoe, and a surface plug. After a bottom plug was set, the $4 \frac{1}{2}$ " casing was cut and pulled from below the surface casing shoe and plugs were placed across the shoe and at the surface. The two Lake Oologah wells were both 6" boreholes approximately 375 feet deep. The plugging design called for the wells to be filled with bentonite from total depth to surface and then hydrated with fresh water.

5.3.3 Findings - The bentonite was placed in all wells without bridging. Casing was successfully pulled on the four Logan County wells. The only problem encountered was some hole sloughing between the surface shoe and the casing stub between the time the casing was pulled and the bentonite was placed. Subsequent wells were cut deeper to allow for this contingency. The IOGCC Bentonite Plugging Subcommittee witnessed the completion of a shoe plug and the start of the surface plug on one well.

The first Lake Oologah well was plugged by filling the wellbore with 79 cubic feet of bentonite from total depth to surface in a matter of $2^{1 / 2}$ hours. The second wellbore had a very large open hole section in the bottom of the well, estimated at 36" in diameter by at least 5' long. Eighty cubic feet of bentonite was placed in the well and only 18' of wellbore was filled. The plug in this well was completed at a later date.

The plugging operations on all six wells were completed in about a week's time with no safety or environmental incidents.

\subsection{Texas Pilot}


The Texas pilot project commenced in February 2002 and consists of 19 wells in the West Texas area involving three different operators. Demonstrations may be conducted in other RRC districts at a later date.

5.4.1 Purpose - The purpose of the Texas pilot project is to demonstrate the bentonite plugging process to the Texas Railroad Commission. The work is being performed under the supervision of Charles Ross, Mark Henkhaus, Don Horner and Danny Miles of the RRC. Pilot objectives are to demonstrate that:

- The bentonite can be accurately placed in the wellbore without bridging.

- The bentonite plugs stay in place.

- The bentonite plugs will withstand differential pressure from below when place above a pressurized producing formation.

- The bentonite plugs are impermeable.

- The bentonite plugs can be placed in wellbores not cemented to surface.

- The salinity of hydration water affects the plug properties.

- The process is safe and environmentally friendly.

- That the process is cost competitive with conventional cement abandonments.

5.4.2 Scope - The 19 wells range in depths from 2,740 feet to 5,990 feet with casing sizes as small as $3 \frac{1}{2}$ ". This will extend operating parameters for bentonite plugs in terms of depth and minimum casing diameter. Several wells will have bottom plugs in place and then the water will be swabbed from the well bores to allow reservoir fluids to apply differential pressure from below the plugs.

5.4.3 Findings - As of July 1, 2002, 15 of the 19 wells have been worked on. One well was dropped from the pilot project because an influx of formation fluid prevented lowering of the 
chloride concentration in the wellbore to an acceptable level of less than $12,000 \mathrm{ppm}$. Six of the 15 have been completely plugged to surface with no problems encountered. Two bridges have occurred in wells with $5^{1 / 2}$ " casing. Attempts to plug one of the wells with $3^{1 / 2}$ " casing has been unsuccessful using the first generation bentonite nodules. One inch diameter spherical nodules are being developed and will be tested in this well.

The most rigorous testing in the Texas pilot involves measuring bottom hole pressure in several wells, setting and hydrating the bentonite plugs, and then swabbing the fluid out of the well bore to apply differential pressure to the plug with highly saline reservoir fluids. This has been attempted in five wells to date. Three of the plugs have held "tight" since early April. Two others have held "tight" since early June. One of these plugs failed initially. The failure was traced back to operation procedures during setting of the plug that resulted in the plug being hydrated with high chloride formation water. The plug was reset and hydrated with fresh water No casing pulls or cavity shots have been attempted to date. 


\subsection{Findings and Conclusions}

A substantial amount of literature and research exists regarding the use of compressed sodium bentonite as a wellbore-sealing agent. The Subcommittee reviewed numerous reports and papers on the subject written by experts on the subject. The Subcommittee witnessed a plugging operation in Oklahoma, in addition to reviewing the status of the various pilot programs. Procedures and standards were reviewed and developed to specify material and plug specifications. Plug placement, hydration and plug integrity were demonstrated in the field and laboratory environments.

The Subcommittee concludes that the physical characteristics of a compressed sodium bentonite plug meet or surpass the standards typically set for plugging material. Added benefits to the use of compressed sodium bentonite include the plug's ability to self heal and the ease of re-entry, if necessary. The use of compressed sodium bentonite is not applicable in every situation. For example, the material cannot be squeezed past obstacles (fish) in the wellbore. Also, because the use of this material to plug oil and gas wells is relatively new, the actual limitations to its use are still being determined. Evaluation of depth and deviation restrictions is ongoing. The effects of high salinity fluids on the hydration of compressed sodium bentonite are likewise being tested and, until more data becomes available, it is recommended that states allowing the use of compressed sodium bentonite as a plugging agent establish some limitation regarding its use in highly saline environments. However, the subcommittee has determined that the material can be placed at specific depths and that plug locations and volumes can be verified. Certain regulatory barriers exist from state to state, with some states requiring regulatory change prior to use. 
In general, the Subcommittee finds that the use of compressed sodium bentonite to plug and abandon oil and gas wells is a viable alternative to conventional cement in certain conditions. Depending upon well conditions, the process can provide cost savings while also providing an impermeable, permanent plug that can be easily drilled out should the need arise for future use of the wellbore. 


\section{Appendix A - Questions \& Answers from State Regulators (organized by general category)}

\section{Field Operations/Placement}

1. How can assurance be provided that placement of the plug is correct?

Placement of the plug can be verified by slick line tag soon after the bentonite has been placed. No wait time is necessary as hydration of the bentonite will commence once contacted with water and will adhere to the casing walls rapidly. It is recommended that the procedure for sodium bentonite plugging operations follow these steps: 1) approved program/plan for placement and field operations. 2) Slick line tag of the base of the plug with witness by regulatory personnel if desired. 3) Volume of required material is calculated and placed in the well. 4) Slick line tag of the top of plug with witness by regulatory personnel if desired (no wait time is required to assure proper placement).

2. Bentonite may have limited application for specific situations, rather than broad usage.

Sodium bentonite in fact does have broad application and uses as discussed in the pilot report and previous answers. Bentonite has been laboratory and field tested in a number of environments (freshwater, saline, oily, high temperature, gas) and well types.

3. We need to develop some clear guidelines regarding method of placement, wait times, allowable parameters (temperature, hole fluid composition and salinity, bottom hole pressures, etc.) and squeeze/cavity shot criteria.

The pilot projects have allowed identification of process optimization and better understanding of nodule characteristics. Some of these optimizations and recommended practices are provided in the pilot report. Recommended application boundaries are included in Section IV of the pilot report. A recommended procedure for DOGGR verification is included in the answer to question 12 .

4. Because of the probability of serious objections from established service companies, there is a need for an outside peer review of the process before approving the general use of these nodules.

The approval of individual well programs and witnessing procedures allows any state regulatory group the ability to verify that the new technology is being properly applied. The formation of an ad hoc committee comprised of operators, service companies and state and federal agencies to act as an advisory body for the development of field guidelines pertaining to the use of sodium bentonite as a plugging alternative has been established.

5. What are the cost/benefit ratio analysis (advantages and disadvantages) of bentonite plugs as compared to regular cement plugs?

On strictly the cost side, the cost advantage to using a bentonite plug will vary significantly by application. Cost savings will be significant in wells with good cement jobs behind the casing strings. In wells that require cavity shots or pipe pulling, the savings will be less. SPE paper 66496 addressed this based on the results of the field pilot conducted in California last year. Quoting from the SPE paper, "With the elimination of coiled tubing units, pump trucks and bulk units, along with other process improvements, anticipated cost savings using sodium bentonite are estimated at $20 \%$ to $40 \%$ over traditional experience." 
6. Advantages we see to Bentonite Plugs

\begin{tabular}{lcc}
$\begin{array}{l}\text { Relative Performance Comparison of Abandonment Cement and Sodium } \\
\text { Property }\end{array}$ & $\begin{array}{c}\text { Bentonite } \\
\text { Cement }\end{array}$ & $\begin{array}{r}\text { Bentonite } \\
\text { XXX }\end{array}$ \\
\hline $\begin{array}{l}\text { Low Permeability } \\
\text { Low Risk to: }\end{array}$ & $\mathrm{X}$ & $\mathrm{XXX}$ \\
Seismic Subsidence & $\mathrm{X}$ & $\mathrm{XXX}$ \\
Casing Deterioration & $\mathrm{X}$ & $\mathrm{XXX}$ \\
Gas Micro-annuli & $\mathrm{X}$ & $\mathrm{XXX}$ \\
Ease of Well Re-entry & $\mathrm{XXX}$ (With additives) & Tested to 340 F \\
High Temp. Stability & $\mathrm{XXX}$ & $?$ \\
Deep \& Deviated Well & & $\mathrm{XXX}$ \\
Plasticity & &
\end{tabular}

7. Have similar pilot tests been run in other states? Which states and what are the results? Has any state changed their rules as a result?

California approved a similar pilot test and it was conducted last year. Texas, Oklahoma, and New Mexico also conducted pilot programs.

The California pilot was successful as evidenced by the California Division of Oil, Gas and Geothermal Resources (DOGGR) issuing a set of Bentonite Plugging Guidelines (Appendix F) as operational field rules applicable to shallow, low-pressure wells located in the San Joaquin Valley. These rules became effective on August 16, 2001. The basic regulations in California do not require a change to use bentonite plugs instead of cement, but regulatory change will be required to substitute fresh water for mud as a spacer fluid. California does not anticipate allowing water as a spacer at this time. As of August 2001, approximately 300 wells have been plugged in California using highly compressed sodium bentonite nodules.

8. Is the bentonite placed on top of a bridge plug?

A bridge plug may be used but is not required. A slick line and a sinker bar are used to push a rubber wiper plug (with a hole drilled in it) to establish a base for the plug. Experience shows that the wiper plug is a sufficient obstruction to cause the material to bridge.

9. Can the bentonite plug be used in open hole as well as in casing?

Yes. The use of compressed sodium bentonite provides an excellent application for abandoning wells with casing or in open hole below casing. Sodium bentonite develops swelling pressure when water or brine penetrates the clay and, according to Dr. Pusch, will penetrate rock fractures either by viscous flow or by expansion. In fact, sodium bentonite is an approved sealing material in many states for numerous applications in open holes, such as shot holes, water wells and monitoring wells.

10. I have heard the bentonite process referred to as a temporary plugging process. Is it being applied in any area as only a temporary process?

The use of highly compressed sodium bentonite nodules is a permanent plugging process, but wells plugged in this manner can be easily re-entered and can easily be used as a temporary plugging process.

11. Does lithology have to be taken into consideration when setting bentonite plugs?

No more so than with a conventional cement abandonment. If zonal isolation is desired, the bentonite plug should be placed across the confining barrier, i.e., caprock. 
12. If they have to go in and circulate the wellbore clean and also displace the brine with fresh water, where are the savings going to be. If the savings are small, why switch to using bentonite at all?

If a well has been abandoned with the tubing removed, the cost savings of using compressed sodium bentonite are quickly diminished. If the well has tubing in-place, cost savings may still be realized since the service unit is only required during the fluid displacement and tubing and casing (if removed) removal processes. During a cement plugging procedure, the service unit and a pump truck are required throughout the entire process. The elimination of the pump truck and the partial elimination of some service unit time should result in some cost savings.

\section{How do you space bentonite plugs over multiple zones?}

The number of zones requiring isolation and the length between those zones determines an abandonment procedure. For example, a plug at the top of the lowermost zone and a plug across the next higher zone can accomplish the isolation of two producing zones. Depending on length between the two intervals (within 300 feet), the design may simply call for one long plug across both zones. The technical design requires no communication between zones. If the zones are close together, the economics may determine that one long plug is preferred over placing a series of closely spaced shorter plugs.

14. Have you found any type of formations or conditions under which a bentonite plug cannot or should not be used?

A bentonite plug is-not appropriate when squeezing is mandated, an obstacle prevents the proper plug placement, an annulus needs to be filled, or when the well is under flowing conditions. Bentonite also has limited use with cavity shots due to limited expansion and inability to lift into annular space. Depth and deviation limitations on placement are still being tested, however, the vast majority of wells requiring abandonment (i.e. $<7,500$ feet) are ideal candidates for highly compressed sodium bentonite. The compressed nodules are designed to fall through a column of fluid without prematurely hydrating. It is this delay in hydration that allows the material to be placed at the specified depth. The deeper the well, the longer the time the nodule is suspended in fluid and the greater the potential for bridging. This potential is mitigated, however, by slowing the rate of pour.

\section{Well-depth and wellbore deviation}

While wells up to 7,500 feet have been abandoned using this method, there is no proven depth or deviation limitation. The placement method utilized in the process is gravity feed, so there is likely a barrier somewhere between a well that is completely vertical and one that is completely horizontal. Bentonite nodules were successfully placed recently at a depth of 7,500 feet through $5 \frac{1}{2}$ " inch casing, for a water shutoff test in New Mexico. The fluid level in this well was at 4,000 feet.

\section{Casing size}

There are no known technical limits to casing size as long as the casing is larger than the sodium bentonite material. Casing sizes for the New Mexico pilot have ranged from 51/2" to $95 / 8$ ". Four of the wells in the Oklahoma pilot have $4 \frac{1}{2}$ " casing and plugs will be set at 3,300 feet. One of the wells to be proposed for the Texas pilot has $3 \frac{1}{2}$ " casing at 3,200 feet. While there is likely a placement depth limitation for each casing size, these limitations have not been encountered. The upcoming work in $4 \frac{1}{2}$ " and $3 \frac{1}{2}$ " casing may provide some additional data. 
17. Status of wellbore between time pulling unit leaves well and bentonite-plugging operations begin.

Ideally, the plugging process will commence immediately after the pulling unit leaves. However, many wells have been placed in a temporary abandoned status (often for years) prior to the actual plugging procedure commencing. Each state has developed rules for placing wells in a temporary abandonment or "idle" status. These same rules should be adhered to during the time frame between when the service unit leaves and the compressed sodium bentonite procedure begins, especially if any substantial time should lapse between the two operations.

18. Well control. Salvage operations.

There should be little difference between bentonite and cement salvage operations. Any tubular goods that are salvageable during a cement plugging procedure are salvageable during a compressed sodium bentonite plugging procedure. Well control may be an issue however with the compressed sodium bentonite procedure. Since this procedure is conducted from a surface pour relying on gravity flow for proper plug placement, the well must not exhibit any fluid flow that may inhibit plug placement. Generally, wells that are being plugged are at the end of their life cycle and have little, if any, remaining reservoir pressure that would impede the gravity flow of the compressed sodium bentonite and proper plug placement. However, if casing is pulled, other zones may be exposed that may exhibit pressures that may impede proper plug placement or threaten well control. In any case, proper safety measures should be addressed and a wellhead valve installed to shut-in the well should it start to flow.

19. Documentation of test.

Once the wells for the Texas pilot have been selected, the objectives for the pilot will need to be agreed on by the RRC and the operators. An implementation and testing protocol will then be prepared for the pilot project that outlines what tests will be conducted on which wells over which timeframe.

\section{Mechanical limitations}

There are no known mechanical limitations.

21. One of the concerns identified in the study was that of placement.

Pilots in several states have shown that highly compressed sodium bentonite nodules have been successfully placed downhole at the desired depth to the maximum depth of 5,000 feet.

\section{Well control}

Since sodium bentonite is placed in the wellbore by pouring the pellets from the surface, the wellbore must be stable before the well can be worked on. For wells with open perforations and pressure, the well will be killed with fresh water and a pump truck. A full opening gate valve can be used to shut the well in at surface in the event the wellbore becomes unstable.

\section{Wellbore conditions and job preparation}

Before application of the bentonite, the wellbore needs to be clear of all obstructions to the proposed base of the bottom bentonite plug. No other preparation is required beyond ensuring the wellbore is stable and contains fluids that are compatible with hydration of the bentonite.

24. Method for calculating volume to obtain fill requirements and placement verification. 
The plugs are spotted by causing the bentonite to bridge on (a) the bottom of the hole, (b) a cementing wiper plug, (c) a mechanical bridge plug or (d) the casing stub when casing has been cut and pulled. The bridging device is set and the depth is confirmed by wireline measurement. A volume of bentonite is then poured from surface and the wellbore fill is verified by wireline measurement to confirm that the material went to the proper depth without bridging. The storage bins on the deployment truck are calibrated in cubic feet, so it is a relatively easy process to estimate how much bentonite has been placed and then confirm the placement with wireline measurement. Pouring the bentonite at a rate appropriate for the casing size minimizes up-hole bridging problems. Smaller casing requires a slower pour rate

25. Placement opposite uncemented casing that would require a cement squeeze using conventional plugging methods.

The bentonite nodules cannot be squeezed through perforations like cement. It has been shown that in a densely perforated piece of pipe, the bentonite will grow out through the perforations; however, at this time, the physical properties of the bentonite seal outside of the pipe have not been measured. This will be the subject of future research. At present, the alternatives to squeezing are to either shoot a cavity shot (removal of 10 feet of casing with an explosive charge) or pull casing from the well. Since a 360-degree radial contact with the surface of the formation can be assured through either method, these alternatives will provide a superior seal when compared to squeezing cement. Cavity shots are used in California but are the least desirable abandonment technique. Both cavity-shots and pipe pulling were tested in New Mexico and Texas.

26. In the past, I had heard that Ohio allows, or had recently allowed, well plugging with "clay". My information was that they had undesirable results. Do you know anything about this?

Ohio allows the use of native clays in limited areas.

27. Placement Procedures

Well Control.

Wellbore conditions \& job preparation.

Method of placement to ensure plug is properly spotted, and bridging problems are minimized.

Rate of application, measurement system.

Placement opposite uncemented casing that would require a cement squeeze using conventional plugging methods.

Method for calculation volume to obtain fill requirements and placement verification.

Well Control - Since surface pouring places sodium bentonite, the wellbore must be stable before this method can be used. For wells with open perforations and pressure, the well will be killed with fresh water and a pump truck. A hydraulically operated, full opening, full opening gate valve of sufficient pressure rating should be in place to shut the well in at surface in the event the wellbore becomes unstable.

Wellbore conditions \& job preparation - Prior to the application of sodium bentonite, the wellbore needs to be free of all obstructions to the proposed base of the plug. No other preparation is required beyond ensuring the wellbore is stable and contains fluids that are compatible with hydration of the sodium bentonite.

Method of placement to ensure plug is properly spotted, and bridging problems are minimized. 
The plugs are spotted by causing the bentonite to bridge on (a) the bottom of the hole, (b) a cementing wiper plug, (c) a mechanical bridge plug, or (d) the casing stub when casing has been cut and pulled. The bridging device is set and the depth is confirmed by wireline measurement. A volume of bentonite is then poured from surface and the wellbore fill is verified by wireline measurement to confirm that the material went to the proper depth without bridging. The storage bins on the deployment truck are calibrated in cubic feet, so it is a relatively easy process to estimate how much bentonite has been placed and then confirm the placement with wireline measurement. Pouring the bentonite at a rate appropriate for the casing size minimizes up-hole bridging problems. Smaller casing requires a slower pour rate.

Rate of application, measurement system.

During the New Mexico pilot project, the sodium bentonite was poured at a rate of approximately 0.5 cubic feet per minute in 7 " casing and 0.3 cubic feet per minute in $5 \frac{1}{2}$ " casing.

Method for calculating volume to obtain fill requirements and placement verification. -

The volume necessary to determine fill requirements and placement verification are the same volumetric calculations used to determine volumetric capacity of casing and tubing.

Placement opposite uncemented casing that would require a cement squeeze using conventional plugging methods - The sodium bentonite nodules cannot be squeezed through perforations like cement. At present, the alternatives to squeezing are to either shoot a cavity shot (removal of 10 feet of casing with an explosive charge) or pull casing from the well. Since a 360degree radial contact with the surface of the formation can be assured through either method, these alternatives will provide a superior seal when compared to squeezing cement. Cavity shots are quite common in California and both cavity shots but are not the preferred method of accomplishing zone isolation during plugging. Pipe pulling was tested in New Mexico and Oklahoma.

\section{Proper Hydration}

28. What happens to a sodium bentonite plug that dehydrates after time (i.e., no source of water in or near the casing)?

Tests indicate that the bentonite shrinks and becomes a brittle, crumbly mass. This could be a concern when plugging occurs above the water table.

Dehydration or desiccation of hydrated bentonite only occurs when exposure to atmosphere promotes evaporation. Once hydrated and encased in a well buried below surface, the potential exposure is eliminated. Holes in casing do provide means for communication with bentonite within the casing; however, moisture-rich (although not necessarily producible) environments are prevalent at depth.

29. In addition, what happens when a plug rehydrates?

Sodium bentonite will readily rehydrate when exposed to water.

30. What outward pressure does hydrated sodium bentonite nodules place on thin-walled casing? Can it rupture the casing?

For the densities found in compressed sodium plugs, swelling pressures should range from $100 \mathrm{psi}$ to around $500 \mathrm{psi}$. There are no data or practical applications that suggest significant enough pressures are exerted to damage pipe.

31. There needs to be more field-testing to determine how the nodules react to salt water, oil, 


\section{high temperatures and H2S. Would the displacement of existing wellbore fluids with fresh water result in more consistent results?}

Although new to the oil industry, the use of sodium bentonite as a sealant has been researched for several decades. More than 11,000 references have been identified concerning its application. A significant body of research pertaining to bentonite hydration in saline, oily, high temperature and $\mathrm{H}_{2} \mathrm{~S}$ environments exists. During the implementation of the California pilot, some of the effects of temperature on bentonite hydration were experienced. Laboratory experiments were conducted to understand better the temperature effects. Laboratory experiments were conducted in Houston and Bakersfield to understand the effects of salinity on bentonite hydration. These tests are summarized in Section IV of the pilot report. Tests conducted as part of the pilot indicate that bentonite will hydrate in saturated hydrogen sulfide water. However, bentonite-swelling capacity appears to be affected by the presence of $\mathrm{H}_{2} \mathrm{~S}$. Laboratory experiments on the hydration of bentonite in oily environments were conducted. The discussion is provided in the pilot report. Additionally, the 19 wells abandoned in Coalinga all revealed the presence of oil within them. Based on standing water columns at surface observed in most of the wells, bentonite's ability to hydrate in oily environments is demonstrated.

\section{Under what circumstances can a hydrated bentonite plug dehydrate? What are the} consequences of a dehydrated bentonite plug?

Per Dr. Daeman of the University of Nevada, "I see no reason why a hydrated bentonite plug inside a casing should dehydrate absent heat and oxygen. There have been some studies in the nuclear waste programs on this, and as I remember it, this was not perceived as a major or even significant problem. At least some of the nuclear waste studies that I am aware of were conducted at very high temperatures (hundreds of degrees), to simulate the effect of nearby nuclear waste, and thus any corrosion reactions that took place were (intentionally) greatly accelerated. One of the great benefits of bentonite as a sealing material is that it is self-healing. Even when it dehydrates, it can rehydrate indefinitely, or repeatedly. However, it is difficult to visualize conditions deep in a borehole, especially inside a casing, where dehydration would occur."

Dr. Degroot of the University of Massachusetts reports that, "The major mechanism that causes bentonite to dehydrate is water evaporation from the bentonite upon exposure to air of sufficiently low relative humidity. In the absence of air, the bentonite will not dehydrate. For the proposed application, the hydrated bentonite will not lose water to the surrounding formation soil/rock because the casing provides a relatively impervious hydraulic barrier preventing the migration of hydration water away from the bentonite. Furthermore, even if the casing suffered significant deterioration over time, the bentonite seal will still retain most of its hydration water since its capillary tension is very high compared to other common soils and porous rock (Lambe and Whitman 1968)."

Dehydration likewise should not occur in open hole environments.

\section{Will the plugs hydrate in salt water?}

Our testing indicates they will; however, fresh water is preferable since the sodium bentonite swells more and hydrates faster in fresh water.

\section{Will the sodium bentonite hydrate properly and give the predicted yields in the heavy} brines

found in most Michigan wellbores?

Further research is being conducted concerning the characteristics of sodium bentonite hydrated using a high chloride hydration fluid. Until this research is concluded with the analysis 
indicating that a competent plug is formed, it is recommended that the wellbore fluid be replaced with fresh water for hydration purposes.

35. How long does it take the sodium bentonite to hydrate and make a seal?

Sodium bentonite will generally hydrate within 18 to 48 hours depending on temperature and hydration fluid.

\section{Interaction/compatibility with fluid systems}

Technical experts have addressed the issues of salt-water contamination, $\mathrm{H}_{2} \mathrm{~S}$ influences and chemical/ hydrocarbon compatibility. Dr. Daeman of the University of Nevada states, "The first basic line of defense is the low permeability. If bentonite borehole seals can be emplaced with low permeability, other permeates (e.g. hydrocarbons, brine) are highly unlikely to penetrate, and therefore react with the bentonite."

Dr. Degroot of the University of Massachusetts reports that, "The key factor that results from these studies is that a high solids content bentonite plug, hydrated with fresh water, cannot undergo changes in its basic fabric, even when exposed to chemicals. Because of the high solids content of the seal the individual bentonite particles do not have room to reorient themselves and thus no appreciable change in fabric and thus permeability will occur. To have a molecule of fluid at the bottom of the 100-foot seal move to the top of the seal in 100 years would take a bottom pressure of approximately 8,000 psi."

Dr. Daeman also states. "What is needed to have any significant interactions is penetration, not simply contact. Hence the critical importance of initial low permeability. With respect to salty water or brine, the evidence is rather clear - as long as the plugs are well confined, any deterioration is likely to be insignificant. The picture is less clear with respect to hydrocarbons. Although a fairly large number of tests have been conducted on bentonite with organic solvents (primarily to study its performance as a landfill, waste containment liner), few studies are available on hydrocarbons as such. Available results suggest that negative effects on well-confined bentonite (e.g. emplaced in a borehole) should be minor. With hydrocarbons, tested primarily for landfills or waste containment lagoons or similar structures it appears that the permeability tends to increase somewhat, maybe of the order of one to two orders of magnitude, which given the extremely low permeability you start out with should not be a significant deterrent against the use of bentonite. Most of this test work however was not done with crude oil."

According to Dr. Degroot, "The bentonite seal will not deteriorate significantly upon contact with chemical liquids such as oily, salt or brine water over a period of time because the proposed application uses a high solids content bentonite seal that is hydrated with fresh water."

A test was run to evaluate the impact of $\mathrm{H}_{2} \mathrm{~S}$. A sodium bentonite nodule was immersed in a jar of fresh water and at the same time, another was immersed in saturated hydrogen sulfide water. Both nodules hydrated, but the nodule in $\mathrm{H}_{2} \mathrm{~S}$ water swelled about $70 \%$ as much as the nodule in the fresh water. Their conclusion was that "...bentonite will hydrate in saturated hydrogen sulfide water. However, its swelling capacity appears to be affected by the presence of $\mathrm{H}_{2} \mathrm{~S}$.”

37. If they don't go in and circulate the oil and gas out of a well will the sodium bentonite hydrate at all?

Yes, see response to question number 36.

38. Many wellbores have other hydrocarbon reservoirs in them which have not been produced 
because the permeability's are too low (i.e., the Berea Sand), and some of these (AICarb) are highly over pressured. These reservoirs are still at virgin pressure and will flow some oil and gas resulting in a coating on the bentonite preventing hydration. To prevent this a heavy hydraulic head has to be maintained to hold the oil in the formation. Wouldn't this prohibit the use of fresh water for hydration?

No. Plugs hydrated with fresh water can be designed with sufficient length to resist overpressured reservoir.

\section{Type fluid/material between plugs.}

Water is the preferred fluid for hydrating the sodium bentonite plugs and is therefore the preferred spacer material for the plugs. In most cases, water will provide an adequate hydrostatic head to prevent the entry of fluids into the wellbore. Water is also effective for displacing reservoir fluids back into the reservoir or light hydrocarbons to the surface. One of the main objectives is to protect fresh water, using water for this purpose is recommended. Since mechanical devices are used to support the bentonite plugs while they hydrate, a high viscosity fluid is not needed for this purpose. California has determined that while water may be an adequate spacer material in some situations, mud is considered to be a superior spacer material.

40. Dehydration concerns

See response to question numbers 28 and 32.

41. Identify/develop bentonite technical specifications (material composition and chemical/physical properties) and nodule size/shape.

The material should be specified as highly compressed sodium bentonite nodules. The approximate chemical makeup is $63 \% \mathrm{SIO}_{2}$ plus $21 \% \mathrm{AL}_{2} \mathrm{O}_{3}$ and $16 \%$ other (typically referred to as Wyoming sodium bentonite). No additives may be used with the bentonite. A minimum specific gravity of 2 should be specified for the dry nodule and a specific gravity of 1.5 should be used for a hydrated plug. The material should have a pH between 6 and 12 .

\section{Strength of the plug}

42. How good is bentonite plug in high temperature, oily, and H2S environments?

See response to question numbers 31 and 36.

43. Are bentonite nodules, by themselves, allowable if pressure competency is an issue?

Yes, once placed, and exposed to water, sodium bentonite will hydrate and exert a pressure of 100 to 500 psi on the casing or the formation.

44. What differential pressures are the plugs good for?

The differential pressure for 100 foot plugs are as follows:

1. A 100-foot plug in 51/2" casing should withstand a differential pressure of 1,500 - 2,300 psi.

2. A 100-foot plug in 7" casing should hold 1,200 - 1,800 psi.

3. A 100 -foot plug $85 / 8$ " casing should hold $1,000-1,500 \mathrm{psi}$.

45. If the bentonite hydrates better with fresh water than with brine and we do displace the brine with fresh water to get an adequate plugging, will the fluid column be heavy enough to hold the pressures in the reservoir? 
The plug should hold the differential pressures listed in the answer to question number 42 above.

46. Pressure Limitations?

Since a hydrated sodium bentonite plug is essentially impermeable, the pressure limitation of a plug is the pressure it can withstand without dislodging from the casing wall and moving up or down the wellbore. Friction, generated by the swelling pressure of the sodium bentonite against the casing wall, is what keeps the plug in place. Therefore, the longer the plug, the greater the dislodgment pressure. The dislodgment pressure decreases as casing size increases.

Friction factors for hydrated sodium bentonite plugs have been measured in the laboratory using plugs from 4" to 6" in diameter and up to 15 ' in length. Testing was performed by both Towler and Ehlers at the University of Wyoming and Lutenegger and DeGroot at the University of Massachusetts. The results of these tests are the pressure factors listed in the answer to question number 44 . These represent ratings when pressure is applied from below the plug. The ratings are $10 \%$ to $20 \%$ lower when pressure is applied from the top of the plug.

The dislodgment pressures for plugs installed in actual wellbores are currently being evaluated as part of the New Mexico pilot project.

47. Will a bentonite plug, which is essentially a water based mixture that never sets up into a crystalline matrix, hold the pressures of a charged formation? The reservoir pressure will eventually approach the original reservoir pressures. I would think it would behave as water and allow the oil and gas to migrate right through it?

See response to question number 36. A plug set with sodium bentonite using the recommended packing and hydration fluid does not dissolve into a watery substance, but a dense near impermeable substance that will swell to fill any void in space as long as a hydration fluid is available. This should prevent any gas migration.

\section{Compressive strength}

48. What is the compressive strength and permeability of the bentonite plugs?

The compressive strength of bentonite ranges, approximately from 175 to 365 psi based on water saturation. This is compared to a range of 500 to 4,000 psi for typical cements.

Since the supporting of casing strings is not the primary focus in abandoning wells, more significant than compressive strength in this application is bentonite's sealing, low permeability, and plasticity qualities.

In a paper prepared by Sandia National Laboratories, Jaak Daemen and Chongwei Ran wrote, "Bentonite has excellent sealing performance and has been selected as a principal sealing component for numerous nuclear waste repositories. Bentonite has an extremely low hydraulic conductivity, is self-healing and has good chemical stability that would provide effective longterm sealing. Bentonite can penetrate rock fractures by either viscous flow or expansion. Bentonite suspensions can form barriers at low solids concentrations. Bentonite can generate swelling pressure when water or brine penetrates the clay. Swelling of the seals increases the internal supporting pressure in the shaft and fractures and should accelerate healing of any

disturbed rock zone. Swelling of bentonite also can assist in sealing fractures caused by structural damage or by rock block displacement by self-penetration into the fractures; it should also help in obtaining tightness between seals and host materials."

49. What is the compressive strength of bentonite plugs, and can it rupture the casing? 
For well abandonments, the most important property for a plug to have is low permeability, as opposed to compressive strength. The hydrated bentonite has relatively little compressive strength. The above-mentioned SPE paper (66496) shows the compressive strength at $174-69$ psi.

The parameter important for casing rupture would be what the literature refers to as swelling pressure. Roland Pusch, in his paper, Swelling Pressure of Highly Compacted Bentonite, 1980, notes that the bulk density of the bentonite, temperature and to a lesser degree, the hydration media, affects swelling pressure of bentonite. Pusch documented pressures ranging from as little as $115 \mathrm{psi}$ to as much as 8,410 psi for sodium bentonite, depending on density and temperature.

For the densities found in the plugs, swelling pressures should range from $100 \mathrm{psi}$ to around 500 psi. There has been no documentation of bentonite plugs rupturing or damaging pipe.

Compressive strength is a measure of cement quality, with sodium bentonite it is not. A compressive strength requirement for a sodium bentonite plug should be considered not applicable as guidance-criteria, and will be one of the modifications needed in existing regulations.

50. What is the compressive strength of the plug?

See response to questions number 48 and 49.

51. What influences the compressive strength of the bentonite plug?

Density of the hydrated plug is the primary determinant of compressive strength. The hydrated density of a sodium bentonite plug should be approximately $1.7 \mathrm{~g} / \mathrm{cm}^{3}$.

52. Pennsylvania regulations require a minimum compressive strength of 350 psi. Can this be consistently maintained using a bentonite plug?

No it cannot be consistently maintained. The primary advantages of a sodium bentonite plug are its plasticity, its ability to heal itself, and its low permeability coefficient. In this regard, compressive strength is not an essential attribute for plug effectiveness.

53. Identify/develop comparative specs with cement. Compressive strength, performance under differential pressure conditions, bonding (shear and hydraulic).

Since the supporting of casing strings is not the primary focus in abandoning wells, the most important property for a plug to have is low permeability, as opposed to compressive strength. The hydrated sodium bentonite has relatively little compressive strength and ranges, from 175 - 365 psi based on water saturation. This compares to a range of $500-4,000$ psi for typical cements. Compressive strength is a measure of cement quality, with sodium bentonite it is not. A compressive strength requirement for a sodium bentonite plug should not be applicable as a guidance criteria or specification. Permeability should be the main determinant of plug effectiveness.

For performance under differential pressure conditions and bonding (shear and hydraulic), please see the above response to the question on pressure limitations (see questions number 36, 46 and 48).

54. Performance under differential pressure conditions, bonding (shear and hydraulic) Please see the above response to the question on pressure limitations (see questions number 36, 46 and 48). 


\section{Permeability/Durability of the plug}

55. After hydration, how difficult is it to clean out a bentonite plug if it fails or is misplaced? How will failure be determined?

Drilling out a sodium bentonite plug is accomplished very quickly using a basic rotary assembly. Plug depth verification, with the use of a wire line, determines if the sodium bentonite plug is set at the proper depth.

\section{Qualities of drilling mud over formation fluids in the wellbore to control vertical migrations.}

The plug must provide zonal isolation. Oil/gas entry is only a concern between zones, not within zones. Drilling mud does not meet the permeability requirements for zonal isolation. The conclusion of the US EPA research document (EPA/600-R-98/075) titled Potential for Underground Sources of Drinking Water through Mud-Plugged Wells: An Experiment Appraisal regarding mud as a plugging media is "Drilling mud in glass tubes settled, so as to separate into two fractions: drilling mud denser than 9 pounds per gallon, overlaid by water that contained very small amounts of clay. Separation of drilling mud into two fractions continued throughout the longest test - 850 days."

\section{How long will a sodium bentonite plug last?}

A sodium bentonite plug will last millions of years. According to Dr. Daeman of the University of Nevada, "In all probability the hydrated bentonite plugs will last extremely long." The main argument for this is that sodium bentonite is the residual product of weathering alteration of volcanic rocks. Therefore, in many geological environments, sodium bentonite has demonstrated extreme longevity. This, in fact, is the main reason why sodium bentonite has been selected as the prime sealing material for nuclear waste repositories in Canada, Sweden, Switzerland, Japan and Germany. It now also appears extremely likely that sodium bentonite will be a major sealing material for Waste Isolation Pilot Plant (WIPP) near Carlsbad, New Mexico facility for disposal of Department of Defense (DOD) nuclear waste.

The factors that affect longevity can be considered primarily to be permeability or hydraulic conductivity; geochemical stability (i.e. what effects might interact with groundwater, host rock etc.); and mechanical stability (i.e. is there a risk that sodium bentonite borehole seals could be mechanically displaced).

It may be worthwhile quoting from a study for the Canadian nuclear waste disposal program. "Research on the longevity of potential sodium bentonite based barrier materials is an important part of the Canadian Nuclear Fuel Waste Management Program. Valuable information on the long-term effectiveness of sodium bentonite barriers can be obtained by examining the properties of unprocessed sodium bentonite from natural deposits. The data indicates that the unprocessed sodium bentonite clay maintains an acceptably high swelling capacity and low permeability for millions of years after disposition." (Oscarson et al, 1990).

Dr. Degroot of the University of Massachusetts says, "The seal material should not deteriorate with age. A high solids content bentonite plug hydrated with fresh water and that remains hydrated should last indefinitely."

Ogden and Ruff from Colorado State University state on strength testing, "Bentonite is an end product of the weathering of rock and is assumed to be stable over geologic time periods."

\section{Micro Annuli}

58. Surface pours of cement are not allowed in casing less than 5 inches in diameter. To what 
extent is bridging a concern, and does the diameter limitation apply to bentonite nodule plugging?

Bridging is a significant concern as identified in referenced literature. Effort should be taken to ensure an appropriate pouring rate is utilized per well diameter, as well as appropriate nodule size and shape. Tagging the top of the plug before hydration will verify successful placement without bridging.

59. Drilling mud can help seal micro annuli or prevent fluid/gas entry if casing corrodes, or is otherwise damaged.

The bentonite in drilling mud does provide some of these described characteristics, however, it is the function of the plug to fully seal the wellbore. Micro annuli are the result of an incompetent plug. Highly compressed sodium bentonite has been field proven to seal gas wells without forming micro annuli (DOGGR Coast Range Well No. 5). Additionally the plug must provide zonal isolation. Oil/gas entry is only a concern between zones, not within zones.

Wells are circulated with various liquids to prepare the well for the primary cement job. Attempts to remove drilling mud filter cake in order to gain good cement bonding are included in typical primary cementing job procedures. Additionally, compressed sodium bentonite retains latent swelling capacity that allows it to adjust to changing borehole conditions that occur over time.

60. How does sodium bentonite react to gas channeling?

Dr. Roland Pusch, a noted expert on nuclear repository borehole sealing, addressed this issue as follows: "A number of gas percolation experiments have been made using hydrogen, nitrogen and helium. In these tests, plugs of compacted bentonite and mixtures of bentonite and 'ballast' sand/silt have been exposed to successively increased gas pressure for recording critical threshold conditions. The penetration mode has been identified and modeled. The understanding of mechanisms and conditions for gas penetration of plugs of smectitec materials is concluded to be satisfactory for the nuclear industry."

Pusch and Hokmark (1990) concluded through modeling that the macroscopic hydraulic conductivity to gas appears to be of the same order of magnitude as that of water, i.e., approximately $10^{-13} \mathrm{~m} / \mathrm{s}$ for dry densities of about 1.7 to $1.8 \mathrm{~g} / \mathrm{cm}^{3}$.

\section{Has this been experienced?}

There have been many successes reported using highly compressed sodium bentonite to prevent gas channeling in wells.

In November 2000, the California Division of Oil, Gas and Geothermal Resources abandoned an orphan well Coast Range \#5 that was leaking water and gas. This well had been conventionally abandoned using cement several months earlier with funds from the state's orphan well program. The abandonment failed. The well was replugged using compressed sodium bentonite. The Division of Oil, Gas and Geothermal Resources chose to leave the wellhead uncapped in order to observe and monitor the bentonite plug. To date, the well has not been capped and continues to be monitored. No leaks have occurred.

Additionally in 1999 and 2000, research was conducted at the US EPA Mechanical Integrity Testing Facility near Ada, Oklahoma, to evaluate the effectiveness of bentonite plugs to resist high pressures of both water and air. Two tests were run, one over a 9-month period and the other over a 5 -week period. The results showed that sodium bentonite is very effective for containing pressures up to 1,500 psi while exposed to air, water or brine.

\section{CAVITY SHOTS/ PERFORATIONS}


62. Sodium bentonite nodules cannot be squeezed through perforations, so how effective is the job when a cavity shot or a milled casing window is used? Does that mean bentonite used may be limited to cavity shots or milled windows rather than perforating and squeezing to plug annuli?

Sodium bentonite may be an effective plugging agent when it is used in combination with a cavity shot or a milled casing window. Cavity shots often require significant penetration or lifting of the plugging agent into the annular space. When this is required, sodium bentonite would not be the appropriate plugging agent to use. Sodium bentonite should not be used to plug annuli through a perforating and squeezing procedure.

As provided in the body of the pilot report while describing expected hydration observations, Roland Pusch, Ph.D., University of Lulea, Sweden, stated, "In the course of water saturation, the particle aggregates expand and most of the inter-aggregate voids will be filled by a clay gel formed by the expanding aggregates. Eventually, a condition of considerable isotropy and homogeneity with respect to the orientation and spacing of the montmorillonite particles will be reached at moderate and high densities."

Jaak Daemen and Chongwei Ran added, "Bentonite is a highly plastic swelling clay material." For this reason, a cavity shot or milling operation is recommended at this time. Review of cavity shot film indicates that once detonated, ample casing and formation exposure is provided to ensure 360-degree placement in the annuli.

California has conducted tests, and continues to conduct tests, determining the adequacy of sodium bentonite as a plugging material in combination with cavity shots. The are several factors involved including configuration of the cavity shot itself, the need for squeezing/pumping plugging material into uncemented annuli, the ability of the sodium bentonite to swell into the entire cavity adequately, and the pressure competency of the bentonite inside the cavity shot, considering that the dynamics are different from a sodium bentonite plug inside competent casing. California considers that sodium bentonite plugging is acceptable in combination with some, but not all, cavity shot abandonment plugs.

63. The use of pea gravel allows channeling of fluids. Do partially hydrated bentonite nodules allow channeling? If pea gravel is used with bentonite plugs, why can't it be used with cement plugs?

Sodium bentonite will continue to hydrate as long a fluid is available. Some channeling will be experienced initially until the sodium bentonite hydrates sufficiently. Once hydrated sufficiently, sodium bentonite will not allow channeling. Experiments conducted during the pilot indicate that partially hydrated sodium bentonite provides a barrier to fluid migration. The plastic, adhesive tendencies of sodium bentonite cause the development of a bond with the casing walls and each other without the nodule being fully hydrated. Dark spots, or eyes, are reflective of a lack of complete nodule hydration. The sodium bentonite also seals the pore throats of the pea gravel and/or formation where contact exists.

Nodule shape and process implementation are key to ensuring adequate water availability for hydration. Coring activities and wellhead removals conducted in the Coalinga field indicate that hydration has developed to the point where the plugs are hydraulically solid.

Sodium bentonite maintains a significantly high swelling capacity and low permeability after millions of years of water erosion, thermal alteration, loading and unloading.

Consult with the local (state) regulatory authority to determine the appropriateness of the use of pea gravel during a typical cement plugging procedure.

64. Can the bentonite nodules be squeezed through perforations in the hole, since sodium montmorillonite can swell up to 6 to 10 times its original volume? 
No, the nodules cannot be squeezed through perforations like cement. In a densely perforated piece of pipe, the bentonite will grow out through the perforations. However, at this time a measurement of the physical properties of the bentonite seal outside of the pipe has not been completed. This will be the subject of future research. At present, the alternative to squeezing is to either shoot a cavity shot or pull casing. Either of these two alternatives will provide a superior seal when compared to squeezing, since we can obtain 360-degree radial contact with the surface of the formation.

65. If casing cannot be recovered and is perforated, can the bentonite plug be squeezed through the perforations in place of cement?

No, the nodules cannot be squeezed through perforations like cement. The preferential method for abandoning wells with casing with no cement behind pipe is to perform a cavity shot. The bentonite nodules fill the void space created by the cavity shot and seal the annular space.

66. Other Issues

Type fluid/material between plugs. Status of wellbore between time pulling unit leaves well and bentonite-plugging operations begin.

Well control. Salvage operations.

Documentation of test

Type fluid/material between plugs - Some regulatory authorities may allow water to be used as the fluid type/material between the plugs while other regulatory authorities may require pea gravel, drilling mud or other spacing materials. Water is the preferred fluid for hydrating sodium bentonite plugs and thus, regardless of the spacing agent used, an adequate amount of water must be available for the compressed sodium bentonite to hydrate sufficiently to for a constituted plug. Since mechanical devices are used to support the bentonite plugs while they hydrate, a high viscosity fluid is not needed for this purpose. California considers mud to be a superior spacer material.

Status of wellbore between time pulling unit leaves well and bentonite plugging operations begin - The wellbore will remain in idle status between the time when the pulling unit leaves and the bentonite abandonment begins. If the well has rods and/or tubing in it, a pulling unit will be used to remove the equipment from the well. An appropriate wellhead pack off device will be installed to prevent endangerment to health and safety and the environment until the application of the sodium bentonite nodules.

Well control. Salvage operations - See the previous response for a discussion on well control. There should be little difference in salvage operations between sodium bentonite and cement abandonments. A method is needed; however, to establish a base for sodium bentonite plugs in open hole sections. This would allow casing to be pulled from as deep as possible and then a sodium bentonite plug could be placed up-hole. Currently, the casing stub is used as the base for a bentonite plug when the casing is cut and pulled. 


\section{Appendix B; References}

“Abandoned Wells", paper by Maurice James, January 2000

"Bentonite as a Waste Isolation Pilot Plant Shaft Sealing Material", Contractor report, SAND 96-1968

Unlimited Release UC-721, Jaak Deamen and Chongwei Ran, University of Nevada-Reno, 12/96

"Bentonite Well Plugging Technique", from Field Applications publication by RMOTC, 2/98.

"Cement Sheath Stress Failure", SPE 20453, Goodwin and Crook, 9/90.

"Comments from Dr. Roland Pusch to Craig Gardner regarding Well Abandonment, Compressed

Bentonite Questions", Ideon Research Center, SE-22370, Lund, Sweden, 5/2000.

"Comments on Petro-Plug's Proposed Procedure for Sealing Abandoned Oil Wells", prepared for

Maurice James by David DeGroot (UMASS at Amherst), 3/14/98.

"Coalinga, California Pilot", Technical Report on the Utilization of Sodium Bentonite in the

Abandonment of Oil Field Wells, WZI Inc., Bakersfield, CA., July 2000.

"Design and Construction of a Prehydrated Sand-Bentonite Liner to Contain Brine", M.D. Haug, Barbour and Longval, 1988.

"Evaluation of Dispersion Characteristics of Bentonite with Application to Design of Containment

Transport Barriers", DeGroot et al, 8/98.

"Experiments in Subsurface Applications of Bentonite in Montana", Wheaton et al., 1994.

"Friction Factors for Hydrated Bentonite Plugs". SPE 38347, Towler \& Ehlers, 5/97.

"Geosynthetic Clay Liners Permeated with Chemical Solutions and Leachates", Journal of Geotechnical and Geoenvironmental Engineering, Ruhl \& Daniel, 4/97.

"Handbook on Well Plugging and Abandonment", Pennwell Publishing Company, Dwight K. Smith, 1993.

"Hydraulic Conductivity of Compacted Bentonite-Sand Mixtures", Canadian Geotechnical Journal, Volume 29, Number 3, Kenney et al., June 1992.

"Hydraulic Conductivity Tests on Compacted Clay", Journal of Geotechnical Engineering, Boynton, S. S. \& Daniel, D. E., 1985.

Letter and Report to Maurice James from Jerry Thornhill (Consultant) providing results from USEPA's

Robert S. Kerr Environmental Research Center's Mechanical Integrity Testing Facility near Ada,

Oklahoma.

Letter of Support to Maurice James from Clark Turner (Director, NPR sites in Colorado, Utah and

Wyoming), 1/8/98.

Letter to Gordon Fassett (Wyoming State Engineer) from Don Lamborn (Environmental Specialist) at the Pittsburgh \& Midgway Coal Mining Co. (a Chevron Company).

Letter to Maurice James from Jaak Daemen (Professor and Chair of Department of Mining Engineering at University of Nevada-Reno), 3/22/98.

Letter to Maurice James from R. Odell (Consulting Geologist, Minerals Scout of Rocky Mountain Scout), $8 / 22 / 99$.

"Material Specifications, Appendix 12-A A RCRA Permit for the U. S. Department of Energy's Waste Isolation Pilot Plant, Carlsbad, NM, 2000.

"Mineral Water Interactions and Their Influence on the Physical Behavior of Highly Compacted

Bentonite", Canadian Geotechnical Journal, R. Pusch, 1982.

"New Abandonment Technology New materials and Placement Techniques", SPE Paper 66496, J.

Englehardt, M. J. Wilson, F. Woody, 2001.

"Petro-Plug Project Test Results, RMOTC, Tyler, 1/5/98.

"Plugging of the C-1 \& C-2 Monitor Wells-1 Area", Memorandum from L. A. Sessions to G. A. Johnson, $1 / 14 / 97$.

Practice for Waste Disposal 1987, Proceedings of a Specialty Conference, Ho, Y.A., June15-17, 1987.

Predicting Hydraulic Conductivity of Clay Liners, David E. Daniel.

"Preliminary Report on Longevity of Montmorillonite Clay Under Repository-Related Conditions", 
Roland Pusch, December, 1990.

"Report of Pressure Tests, Plugging Simulations", Accord Technologies, Ehlers, 3/99.

"Report of Well Test", Accord Group Inc., Ehlers, 10/27/97.

"Report-Axial Shear Strength Testing of Bentonite Water Well Annulus Seals", State University, Ogden \& Ruff, Fall 1989.

"Soft Sell Project Preliminary Results from the Coalinga Abandonment Pilot", Chevron Environmental Management Company.

"State of the Art Evaluation of Repository Sealing Materials and Techniques", Materials Research Society, Grirk, P. 1988.

"Sustained Casing Pressure in Offshore Producing Wells", OTC 11029, Bourgoyne et al., 5/99.

"Swelling Pressure of Highly Compacted Bentonite", Roland Pusch, August, 1980.

"Technical Note", Accord Group Inc., Ehlers, 10/29/97.

"The Effects of Brine Containment on the Properties of Fine Grained Soils". Geotechnical Practice for Waste Disposal, Proceedings of a Specialty Conference, Ho, Y. A. 6/15-17/87.

"The Impact of a $\mathrm{NaCl}$ Brine on the Behavior of Compacted Fine Grained Soil", University of Windsor, Department of Civil Engineering, Ridley, K. J./ D. , Bewtra, J. K. and Mccorquodale, J. A., 1983.

"Using Coarse Ground Bentonite to Plug Abandoned Holes", Melvyn James, in WWJ, 6/96. 


\section{Appendix C; Example Well Diagrams and Procedures}

The following well diagrams show how different well completions are plugged with compressed sodium bentonite nodules.

C1 - Plugging Procedure when Casing is Cut and Pulled - Canning \#2 is located in Logan County, Oklahoma. The long string is cut to accommodate a plug across the bottom of the surface casing.

C2 - Plugging Procedure when Casing Annulus is Filled with Cement - McElroy, J. T., Cons. \#847 is located in Upton County, Texas. Both surface and production casing are cemented to the surface. Plugs are set in the production casing.

C3 - Plugging Procedure when Casing Annulus is Void of Cement - Harry Leonard (NCTD) \#11 is located in Lee County, New Mexico. In this well, "cavity shots" are used instead of "squeeze cementing" to set two plugs outside the production casing. 
C-1

Cut and Pull Casing 


\begin{tabular}{l}
$\begin{array}{l}\text { Well Name: } \\
\text { API Number } \\
\text { Coordinates: } \\
\text { S- T - R } \\
\begin{array}{l}\text { County / State: } \\
\text { Drilled: }\end{array}\end{array}$ \\
RKB = $\quad \frac{\frac{\text { Canning }}{2230^{\prime}}}{\frac{\text { Leg } 3}{1986}}$ \\
\hline $\begin{array}{l}\text { Formation Tops } \\
\text { Base of FW at 290' } \\
\text { (assumed) }\end{array}$
\end{tabular}

Canning \# 2

083-22949

- T17N - R1W

ogan, Oklahoma

986

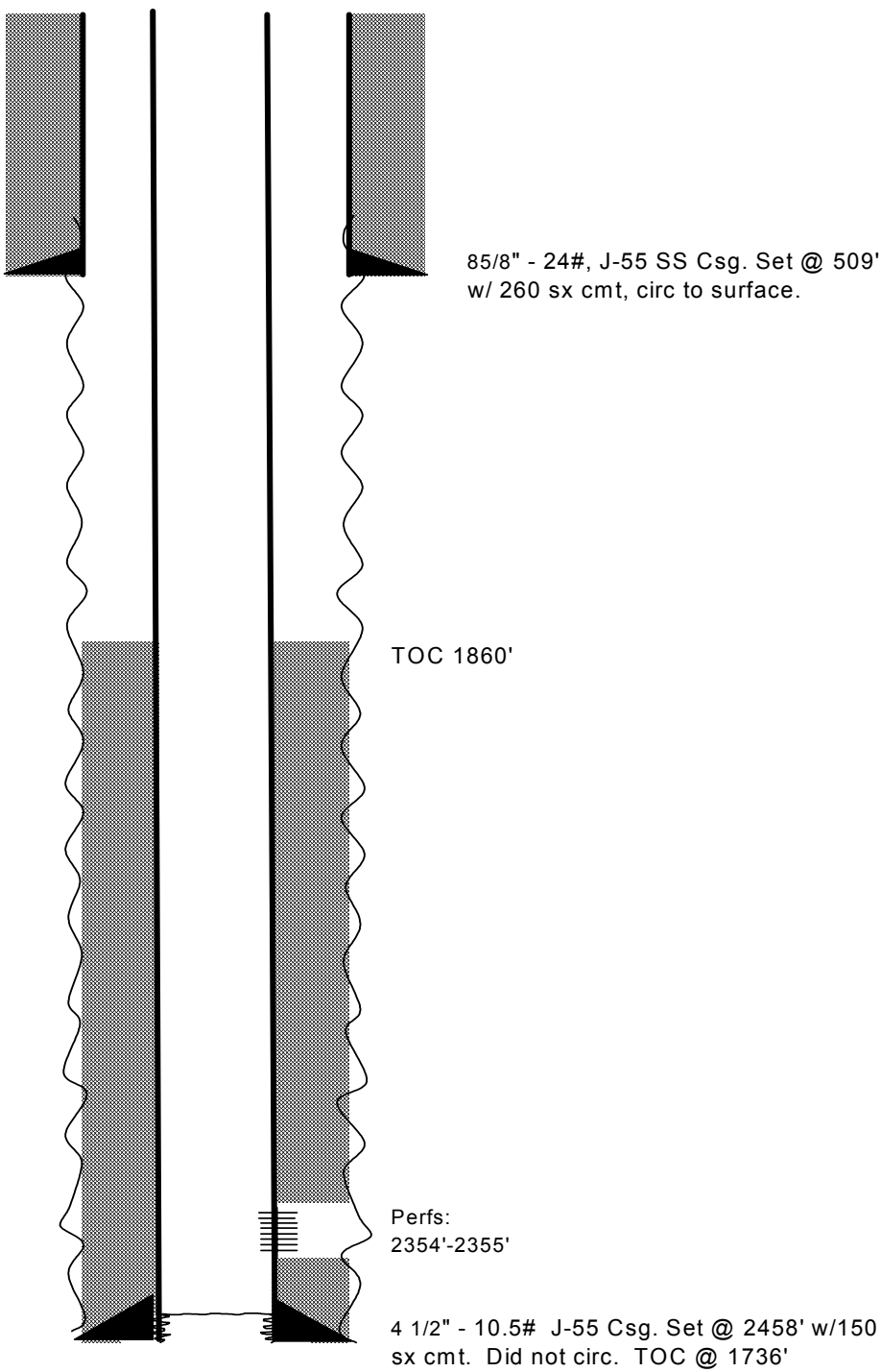

TD @ 2429
Operator: OCC

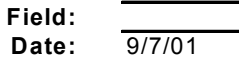

By: $\mathrm{MCB}$
85/8" - 24\#, J-55 SS Csg. Set @ 509' w/ $260 \mathrm{sx} \mathrm{cmt}$, circ to surface. sx cmt. Did not circ. TOC @ 1736 


$\begin{array}{llll}\text { Well Name: } & \text { Canning } \# 2 & \text { Operator: } & \text { OCC } \\ \text { API Number: } & \text { 083-22949 } & \text { Field: } & \\ \text { Coordinates: } & 2230 \text { ' FSL \& 2310' FWL } & \text { Date: } & 9 / 7 / 01 \\ \text { S }- \text { T }- \text { R } & \text { Sec } 31-\text { T17N }- \text { R1W } & \text { By: } & \text { MCB } \\ \text { County / State: } & \text { Logan, Oklahoma } & & \\ \text { Drilled: } & 1986 & & \end{array}$

\section{Provide Appropriate Notification to OCC of Pending Operations}

1. MI Genie equip. Hold pre-job safety mtg. And spot equipment. Check 41/2" csg and $85 / 8$ " x 41/2" annulus for pressure.

2. ND WH equip and install well control equip.

3. Pull and lay down rods and tubing and clean out wellbore to OCC requirements.

4. Pump cement wiper plug to 2330 ' with fresh water. Confirm depth with slickline or sandline.

5. NU WH and RDMO Genie equip

6. MI equip. Hold pre-job safety meeting and spot equipment. Check $4 \frac{1}{2}$ " annulus for pressure.

7. ND WH equip and install well control equip.

8. Check wiper plug depth w/ SL @ 2330’. Record FL.

9. Surface pour $9 \mathrm{cu} \mathrm{ft}$ of compressed sodium bentonite to set 100' btm plug from 2330' - 2230'. Set plug in stages. Check w/ SL to assure bridges are not occurring and required plug height is achieved. Pour at rate that minimizes potential to bridge. After setting plug, add water as necessary to assure hydration of plug. Wait 24 hours for plug to hydrate and then fill casing with freshwater.

10. Push cored 41/2” wiper plug to 570 ' with sinker bar.

11. Remove well control equip and NU WH equip to secure well. RDMO.

12. MI Key Energy. Hold pre-job safety mtg and RU equipment. Check $4 \frac{1}{2}$ " csg and $8 \frac{5}{8}$ " x 41/2" annulus for pressure.

13. Install $4 \frac{1}{2} "$ pull joint and attempt to work pipe free of slips.

14. RU wireline and cut casing at 559”. RD wireline and circulate hole w/freshwater prior to pulling csg.

15. $\mathrm{PO} \mathrm{OH}$ and lay down casing

16. NU wellhead. RDMO Key.

17. MI equip. Hold pre-job safety meeting and spot equipment. Check $8 \%$ " for pressure.

18. Surface pour $60 \mathrm{cu} \mathrm{ft}$ of Compressed sodium bentonite to set 100' in-out plug from 459' - 559'. Set plug in stages. Check w/SL to assure bridges are not occurring and required plug height is achieved. Pour at rate that minimizes potential to bridge. After setting plug, add water as necessary to assure hydration.

19. Push $8 \%$ " "wiper plug to 30 ' w/ slickline.

20. Fill casing with compressed sodium bentonite to 3' below GL ( $10 \mathrm{cu} \mathrm{ft})$. After setting plug, add water as necessary to assure hydration.

21. Remove well control equip. secure WH and RD equip.

22. Turn over to OCC for any surface remediation work. 
WELL PLANNING SHEET

PROPOSED ABANDONMENT

\begin{tabular}{|c|c|c|}
\hline $\begin{array}{l}\text { Well Nan } \\
\text { API Num } \\
\text { Coordin } \\
\text { S - T - R } \\
\text { County I } \\
\text { Drilled: }\end{array}$ & e: & $\begin{array}{l}\frac{\text { Cannin }}{083-22} \\
\text { Sec 31 } \\
\text { Logan, } \\
1986\end{array}$ \\
\hline RKB = & $?$ & \\
\hline \multicolumn{3}{|c|}{$\begin{array}{l}\text { Formation Tops } \\
\text { Base of FW at 290' } \\
\text { (assumed) }\end{array}$} \\
\hline
\end{tabular}

\begin{aligned} & $\begin{array}{c}\text { Operator: } \\ \text { Field: } \\ \text { Date: } \\ \text { By: }\end{array} \\ &$\hline MCB \end{aligned}

lahoma

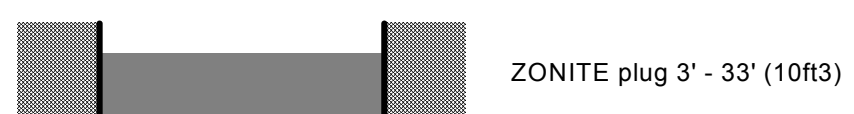

Wiper Plug @ 33'
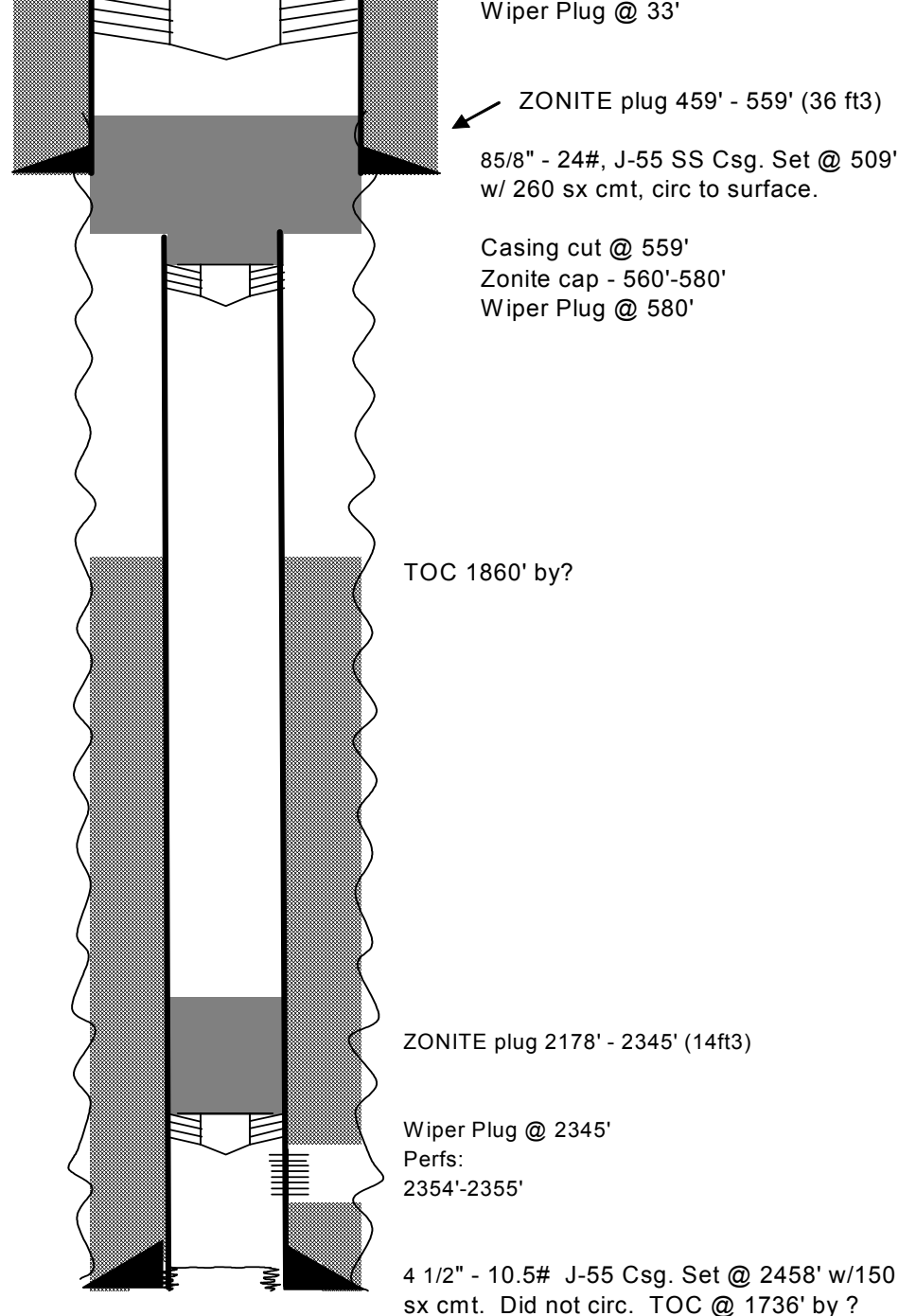

TD @ 2429'

sx cmt. Did not circ. TOC @ 1736' by? 
C-2

Cement Behind Pipe 
$\begin{array}{ll}\text { WELL NAME: } & \text { McEIroy, J.T., Cons. \# 847 } \\ \text { API NUMBER } & \frac{42-461-30491 \text { (RRC Lease \# }}{4161)} \\ \text { COORDINATES: } & \frac{1650^{\prime} \text { FNL \& 330' FEL }}{\text { SEC/TWN/RNG: }} \\ \text { S189-BLK F, CCSD \& RGNG RR Survey } \\ \text { DRILLED: } & \frac{3.5 \text { miles SE from Crane }}{1975}\end{array}$

KB $12^{\prime}$

\begin{tabular}{|lr|}
\hline \multicolumn{2}{|c|}{ Formation Tops: } \\
\hline Fresh Water & $650^{\prime}$ \\
\hline Rustler & $1000^{\prime}$ \\
\hline Yates & $2000^{\prime}$ \\
\hline Queen & $2400^{\prime}$ \\
\hline & \\
\hline
\end{tabular}

$\begin{array}{ll}\text { OPERATOR: } & \text { Chevron } \\ \text { COUNTY/STATE: } & \frac{\text { Upton, TX District 8 }}{\text { DATE: }} \\ \text { BY: } & \frac{\text { CRS }}{\text { CRS101 }} \\ \text { ELEVATION: } & \underline{2641^{\prime} \text { GL }}\end{array}$

Casing Size $85 / 8 "$ Wt. 28.55\#

Set @ 535' w/100 s $\overline{x \mathrm{cmt}}$

Cemented to surface

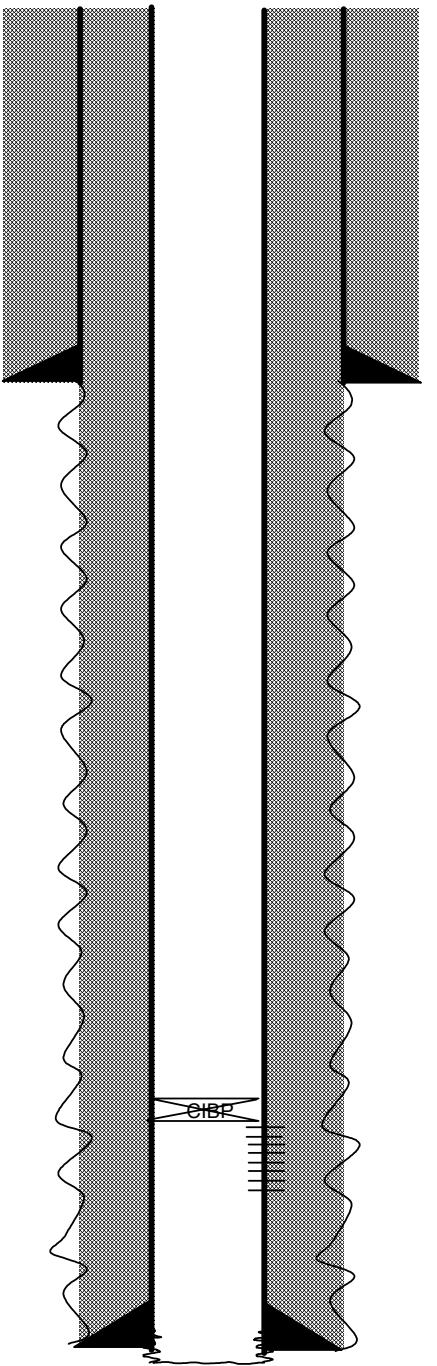

PBTD @ 3200'

TD @ 3550'
Perfs 3268' - 3438'

Casing Size 5 1/2" Wt. 15.5\#

Set @ 3538' w/ 600 sx $\overline{c m t .}$ 


$\begin{array}{llll}\text { Well Name: } & \text { McElroy, J. T., Cons \# 847 } & \text { Operator: } & \text { Chevron } \\ \text { API Number: } & \text { 42-461-30491 (RCC Lease \# 04161) } & \text { Field: } & \text { Upton, TX District } 8 \\ \text { Coordinates: } & \text { 1650' FNL \& 330' FEL } & \text { Date: } & \text { 10/17/2001 } \\ \text { SEC/TWN/RNG: } & \text { S189-BLKF, CCSD \& RGNG RR Survey } & \text { By: } & \text { MCB }\end{array}$

\section{Provide RRC with at least 4 hours Notification of Pending Operations Confirm that well contains fresh water. If not, circulate well with fresh water.}

1. Hold pre-job safety mtg. and spot equipment. Check $5 \frac{1}{2}$ " $\operatorname{csg}$ and $85 / 8$ " x 51/2" annulus for pressure.

2. ND WH equip and install well control equip.

3. Make trip w/ SB on slickline and check PBTD @ 3200’. Record FL.

4. Surface pour $14 \mathrm{cu} \mathrm{ft}$ of compressed sodium bentonite to set 100' bottom plug from 3100' - 3200'. Set plug in stages, checking $\mathrm{w} / \mathrm{SL}$ to assure bridges are not occurring and required plug height is achieved. Pour at rate that minimizes potential to bridge. After setting plug, add water as necessary to assure hydration of plug.

5. Insert and push 51/2" wiper plug to 2450 ' w/ slickline. Set 100' (14 cu ft) compressed sodium bentonite Queen Plug from 2350 ' -2450 ', using precautions as in Step 4 . Add water if necessary to hydrate plug.

6. Insert and push 51/2" wiper plug to 2050' w/ slickline. Set 100' (14 cu ft) compressed sodium bentonite Yates Plug from 1950 ' - 2050', using precautions as in Step 4. Add water if necessary to hydrate plug.

7. Insert and push 51/2” wiper plug to 1050 ' w/ slickline. Set 100' (14 cu ft) compressed sodium bentonite Rustler Plug from 950' - 1050', using precautions as in Step 4. Add water if necessary to hydrate plug.

8. Insert and push 51/2" wiper plug to 700' w/ slickline. Set $215^{\prime}$ (30 cu ft) compressed sodium bentonite Shoe/Fresh Water Plug from $485^{\prime}-700$ ', using precautions as in Step 4. Add water if necessary to hydrate plug.

9. Insert and push 51/2" wiper plug to 13 ' w/ slickline. Set 10' (2 cu ft) compressed sodium bentonite Surface Plug from 3' - 13', using precautions as in Step 4. Add water if necessary to hydrate plug.

10. Remove well control equip. secure WH and RD equip.

11. Allow 48 hours for compressed sodium bentonite to hydrate, remove WH, cut off casings 3' below GL.

12. Install dry hole marker stamped w/ required well identification, 4” OD x 4' above GL.

13. Complete any surface remediation work. 


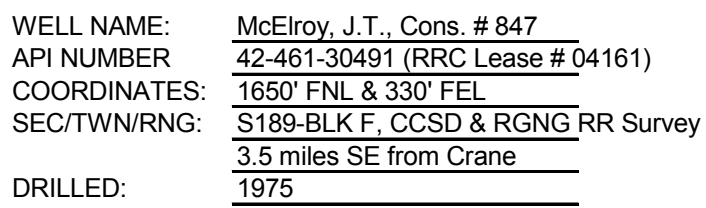

KB 12'

$\begin{array}{ll}\text { OPERATOR: } & \text { Chevron } \\ \text { COUNTYISTATE: } & \frac{\text { Upton, TX District } 8}{10 / 15 / 01} \\ \text { DATE: } & \frac{\text { MCB }}{2641^{\prime} \mathrm{GL}} \\ \text { BY: } & \end{array}$

Surface Plug @ 3' - 13' (2 cu ft Zonite)

Wiper Plug @ 13'

Casing Size $85 / 8 "$ Wt. 28.55\#

Set @ $53 \overline{5}$ w/ $100 \mathrm{sx \textrm {cmt }}$

Cemented to surface

Wiper Plug @ 700

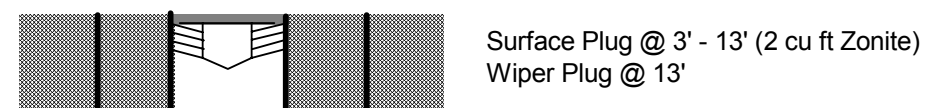

\begin{tabular}{|lr|}
\hline \multicolumn{2}{|c|}{ Formation Tops: } \\
\hline Fresh Water $650^{\prime}$ \\
\hline Rustler & $1000^{\prime}$ \\
\hline Yates & $2000^{\prime}$ \\
\hline Queen & $2400^{\prime}$ \\
\hline & \\
\hline
\end{tabular}

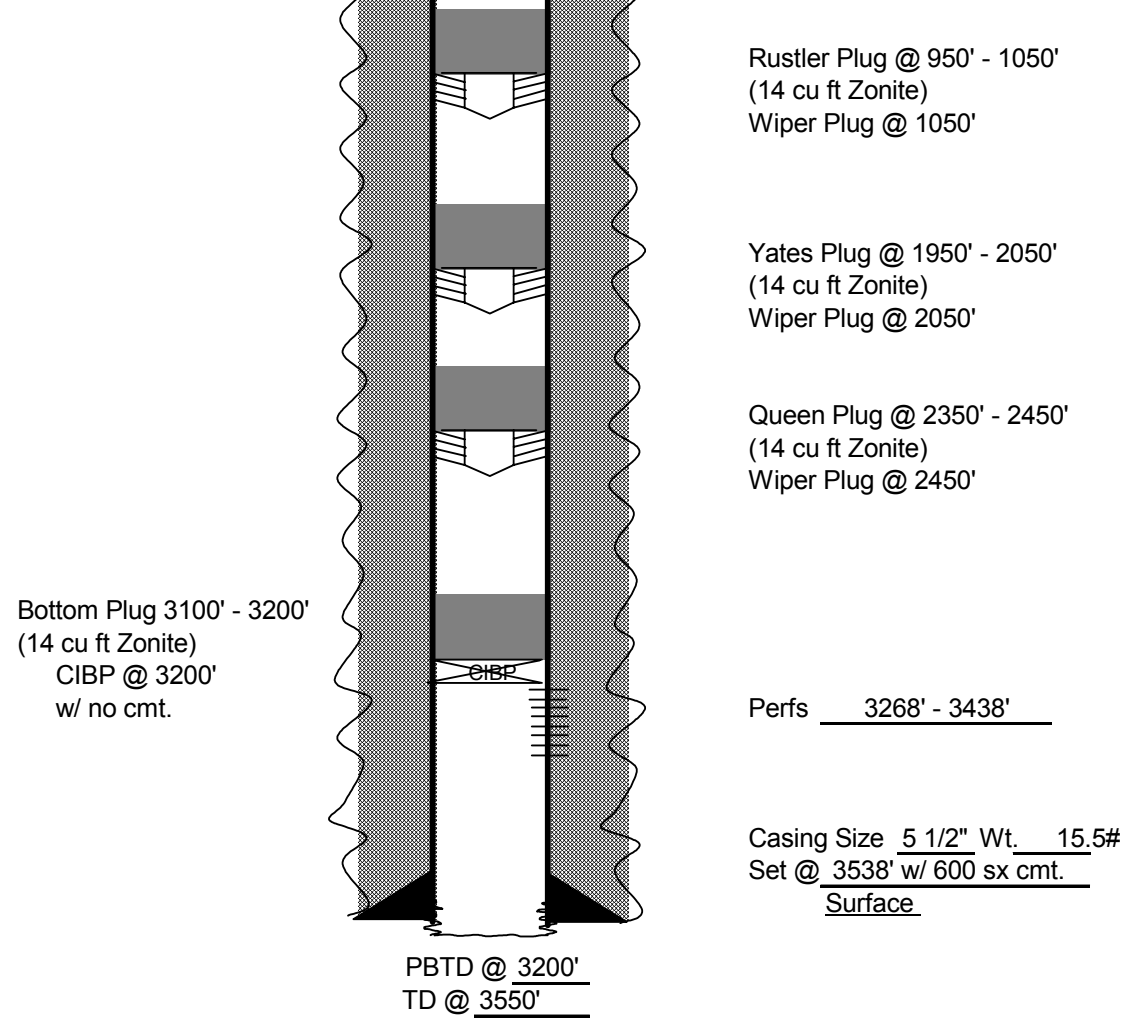


C-3

No Cement Behind Pipe 
WELL PLANNING SHEET

Existing Configuration

Well Name: $\quad$ Harry Leonard (NCT-D) \#11

API Number $\quad 30-025-08761$

Coordinates: $\quad 1980 \mathrm{FNL} \& 1980 \mathrm{FEL}$

S - T - R

County / State:

Drilled:

Lea, NM

1959

RKB =

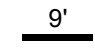

Formation Tops

Anhydrite/Rustler

T/Salt (Per Paul Kautz)

B/Salt

Yates

7 Rivers

Queen

1558

$1655^{\prime}$

$2970^{\prime}$

$3127^{\prime}$

$3340^{\prime}$

3744
Unit J

(2)

-

(1)

$\begin{aligned} \text { Operator: } & \text { Chevron } \\ \text { Field: } & \text { Eunice S. (Y7RQ) } \\ \text { Date: } & 8 / 24 / 01 \\ \text { By: } & \text { DCD }\end{aligned}$

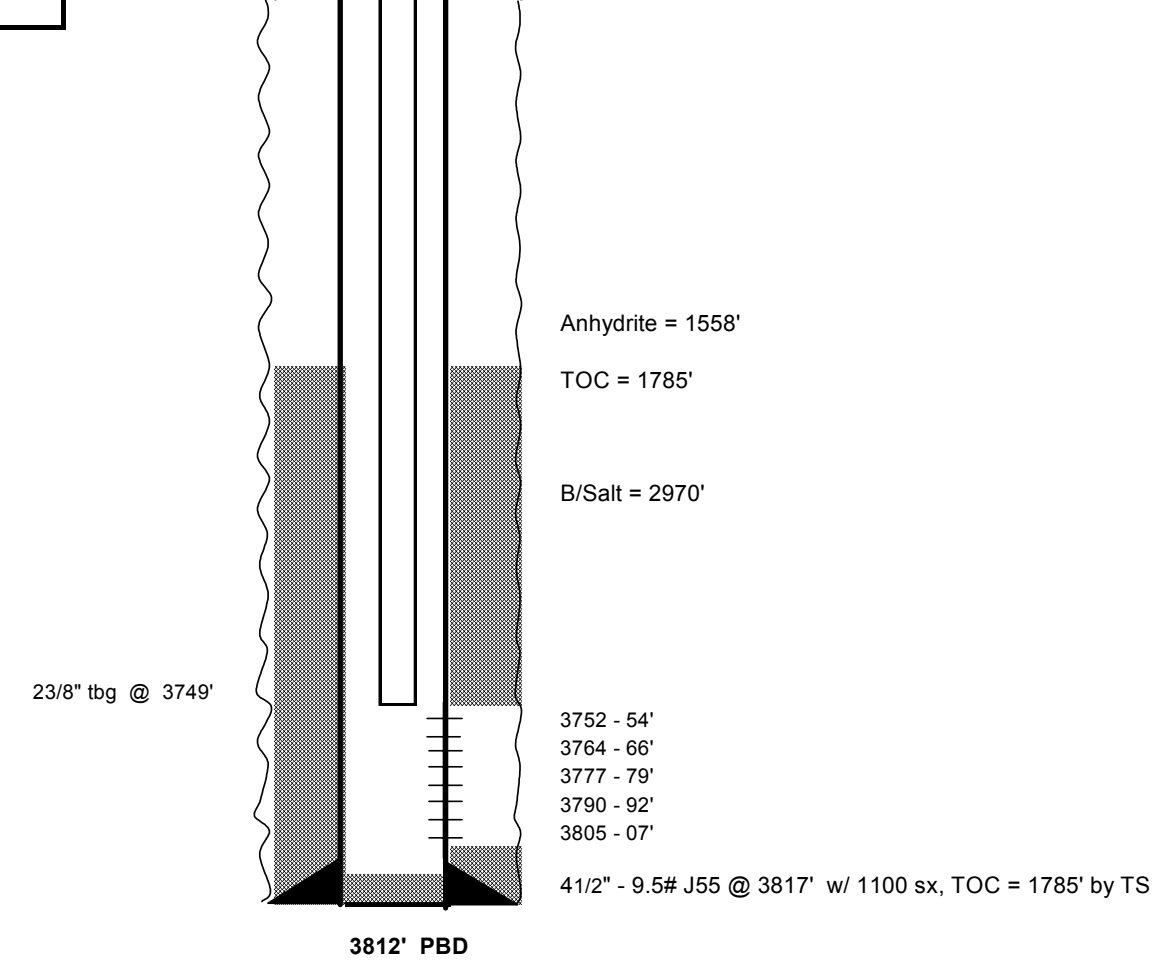

3818' TD 


$\begin{array}{llll}\text { Well Name: } & \text { Harry Leonard (NCT-D) \# 1 } & \text { Operator: } & \text { Chevron } \\ \text { API Number: } & \text { 30-025-08761 } & \text { Field: } & \text { Eumont (Y7RQ) } \\ \text { Coordinates: } & 1980 \text { ' FNL \& 1980' FEL } & \text { Date: } & 8 / 4 / 2001 \\ \text { S - T - R } & \text { Sec 3-T22S - R36E } & \text { By: } & \text { DCD } \\ \text { County / State: } & \text { Lee, New Mexico } & \\ \text { Drilled: } & 1944 & \\ & \text { Provide 24 hr Notification to NMOCD of Pending Operations } \\ & \text { Note: Assure that tubing has been pulled before moving in. }\end{array}$

1. MI equip. Hold pre-job safety mtg. And spot equipment. Check 41/2" csg and 85/8” x 41/2" annulus for pressure.

2. ND WH equip and install well control equip.

3. Check btm w/SL, 3812' PBD. Calculate Fluid Level in well. Record FL. Displace wellbore fluids w/2x fluid volume of freshwater. Note: no wiper plug is needed for the bottom plug.

4. Surface pour $15 \mathrm{cu} \mathrm{ft}$ of compressed sodium bentonite to set 160 ' btm plug from 3652' - 3812' PBD. Set plug in stages, check w/ SL to assure bridges are not occurring and required plug height is achieved. Pour at rate that minimizes potential to bridge, pour rate will be slower for this $4 \frac{1}{2}$ " casing. After setting plug, add water as necessary to assure hydration of plug. Remove well control equip and NU WH equip to secure well.

5. Move off location and wait at least overnight for plug to hydrate. Assure that an adequate fluid level is maintained to hydrate plug.

6. MI equip. Hold pre-job safety mtg and RU equipment. Check $4 \frac{1}{2}$ " csg and $85 / 8$ " x $4 \frac{1}{2}$ " annulus for pressure and install well control equip. Check top of plug w/slickline and record FL.

7. Push cored 41/2" wiper plug to 3020', 50' below B/Salt. Pour $9 \mathrm{cu} f \mathrm{ft}$ of compressed sodium bentonite and establish plug from 2920 ' - 3020' to cover base of salt. Use pouring precautions as in Step 4 and add freshwater to assure hydration of plug.

8. Insert 41/2" wiper plug (cored to allow fluid bypass) into csg and push to 1608 ' w/ slickline. Cap w/ 20' of compressed sodium bentonite ( $\sim 2 \mathrm{cu} \mathrm{ft})$. Fill casing w/freshwater to approximately 500 ' from surface to prep for cavity shot.

9. Perform cavity shot (removal of 10' of casing) at top of Rustler/Anhydrite - 1558' - 1568'. Check btm with SL after shot.

10. Pour compressed sodium bentonite and establish plug from 1468' -1568 '. Volume of compressed sodium bentonite estimated to be $12-15 \mathrm{cu} \mathrm{ft}$. Use pouring precautions as in Step 4 to assure proper placement of plug and required height is achieved. Fill casing with freshwater to hydrate plug and prep for second cavity shot.

11. Push cored $4 \frac{1}{2}{ }^{\prime \prime}$ wiper plug to $449^{\prime}$ w/ slickline. Cap w/20' of compressed sodium bentonite ( $\left.2 \mathrm{cu} \mathrm{ft}\right)$.

12. Perform cavity shot at $399^{\prime}-409^{\prime}$.

13. Pour compressed sodium bentonite and establish plug from 309' $-409^{\prime}$. Volume of compressed sodium bentonite estimated to be $12 \mathrm{cu} \mathrm{ft}$. Use pouring precautions as in Step 4 to assure proper placement of plug and required height is achieved.

14. Push $4 \frac{1}{2}$ ” wiper plug to 30 ' w/ slickline.

15. Fill casing w/compressed sodium bentonite to 3' below GL $(\sim 2.5 \mathrm{cu} \mathrm{ft})$.

16. Remove well control equip. secure WH and RD equip.

17. Allow 48 hours for compressed sodium bentonite to hydrate, remove WH, cut off casings 3' below GL. Also attempt to bridge $85 / 8$ " $\times 4 \frac{1 / 2 "}{2}$ annulus with compressed sodium bentonite before capping well.

18. Install dry hole marker stamped w/ required well identification, 4” OD x 4' above GL. 
WELL PLANNING SHEET

Proposed P\&A

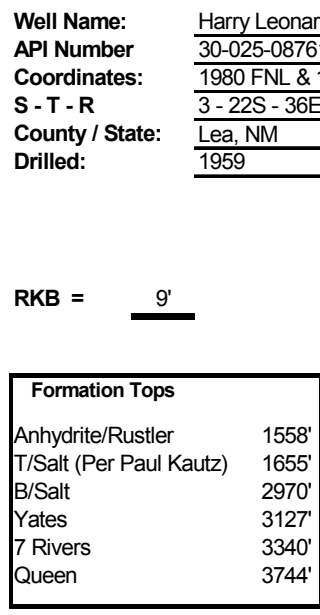

Operator: Chevron

Field: $\quad$ Eunice S. (Y7RQ)

Date: $8 / 24 / 01$

By:

DCD

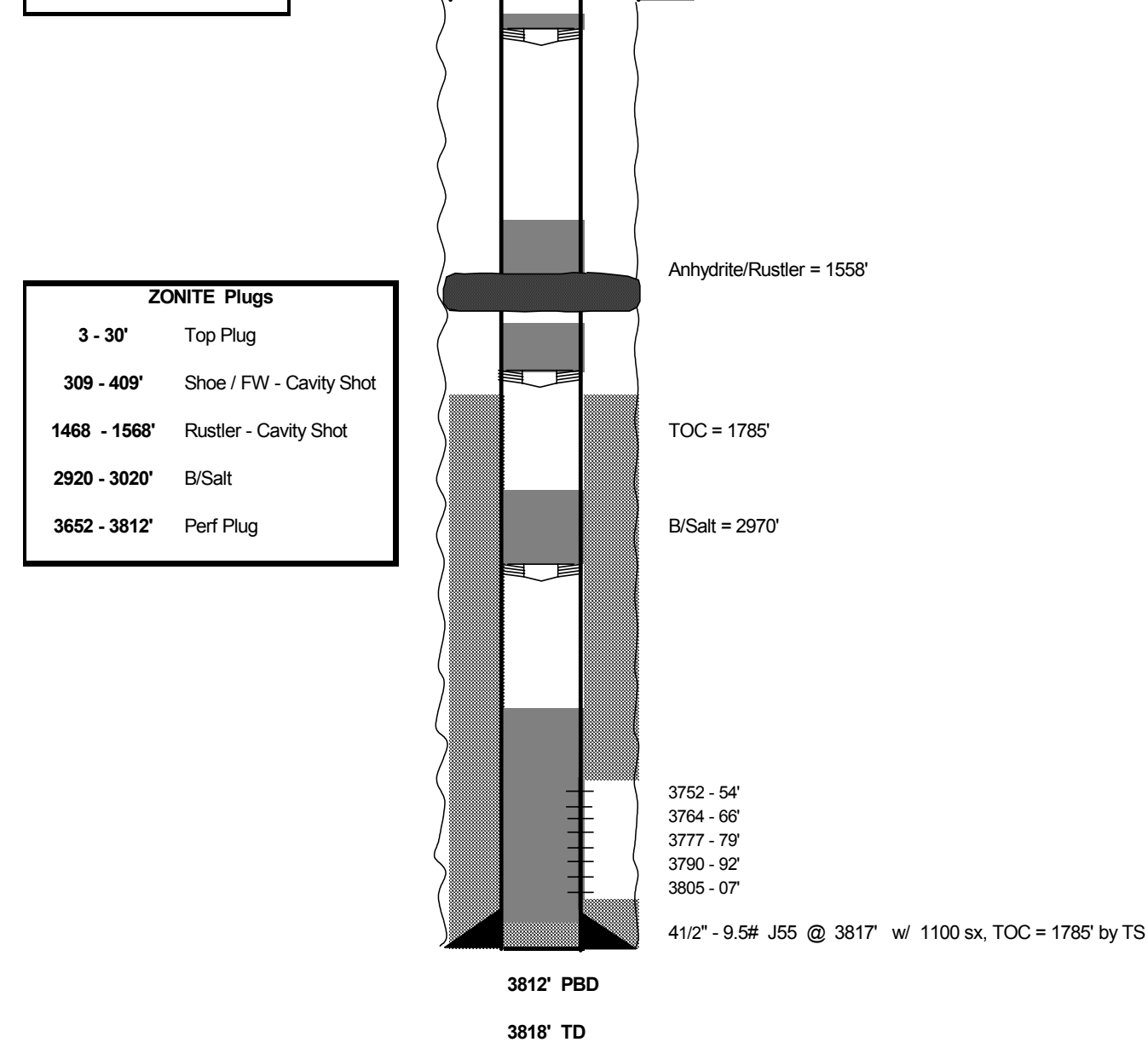




\section{Appendix D; Photos}

\section{Appendix D; Placement and Hydration Photos}

\section{Placement \& Hydration}

Placement and hydration were two important issues addressed at the Oklahoma City Meeting of the Bentonite Plugging Study Subcommittee. Placement was viewed of a compressed sodium bentonite plug in a well in Logan County, OK. Hydration was demonstrated by viewing a compressed sodium bentonite plug that was formed in a 6" clear plastic tube. The subcommittee requested photos be taken to show the plug formation timing. The photos show the placement techniques witnessed during the subcommittee meeting in Oklahoma City and the formation of a compressed sodium bentonite plug. 


\section{Placement}

This photo shows the technician holding the wiper plug that will be placed down hole to form a base for the compressed bentonite plug. He is explaining how the plug will be placed.

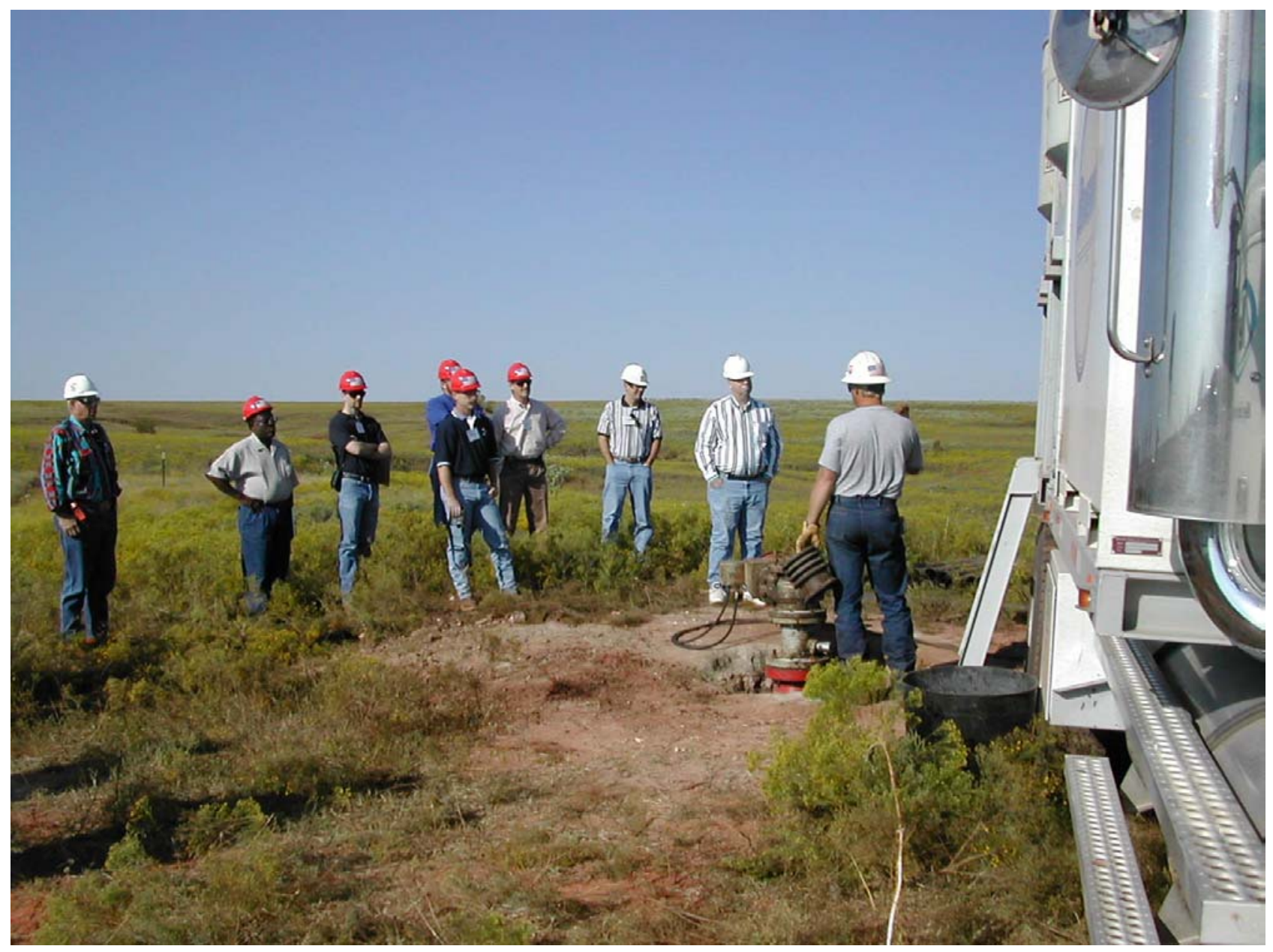


This photo shows the slick line being used to pushing the plug to the desired depth.

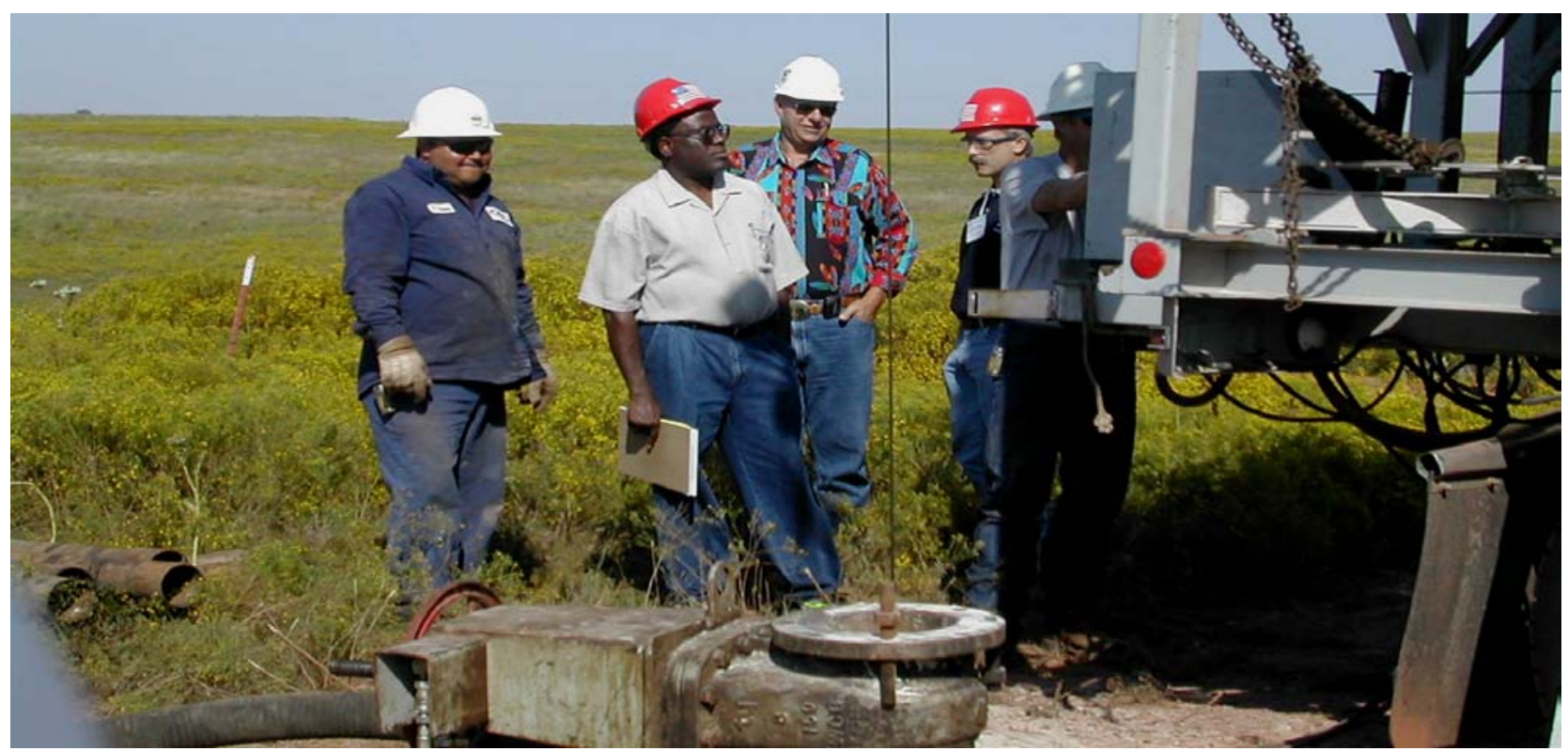

The next three photos demonstrate the surface pour of the compressed sodium bentonite nodules.

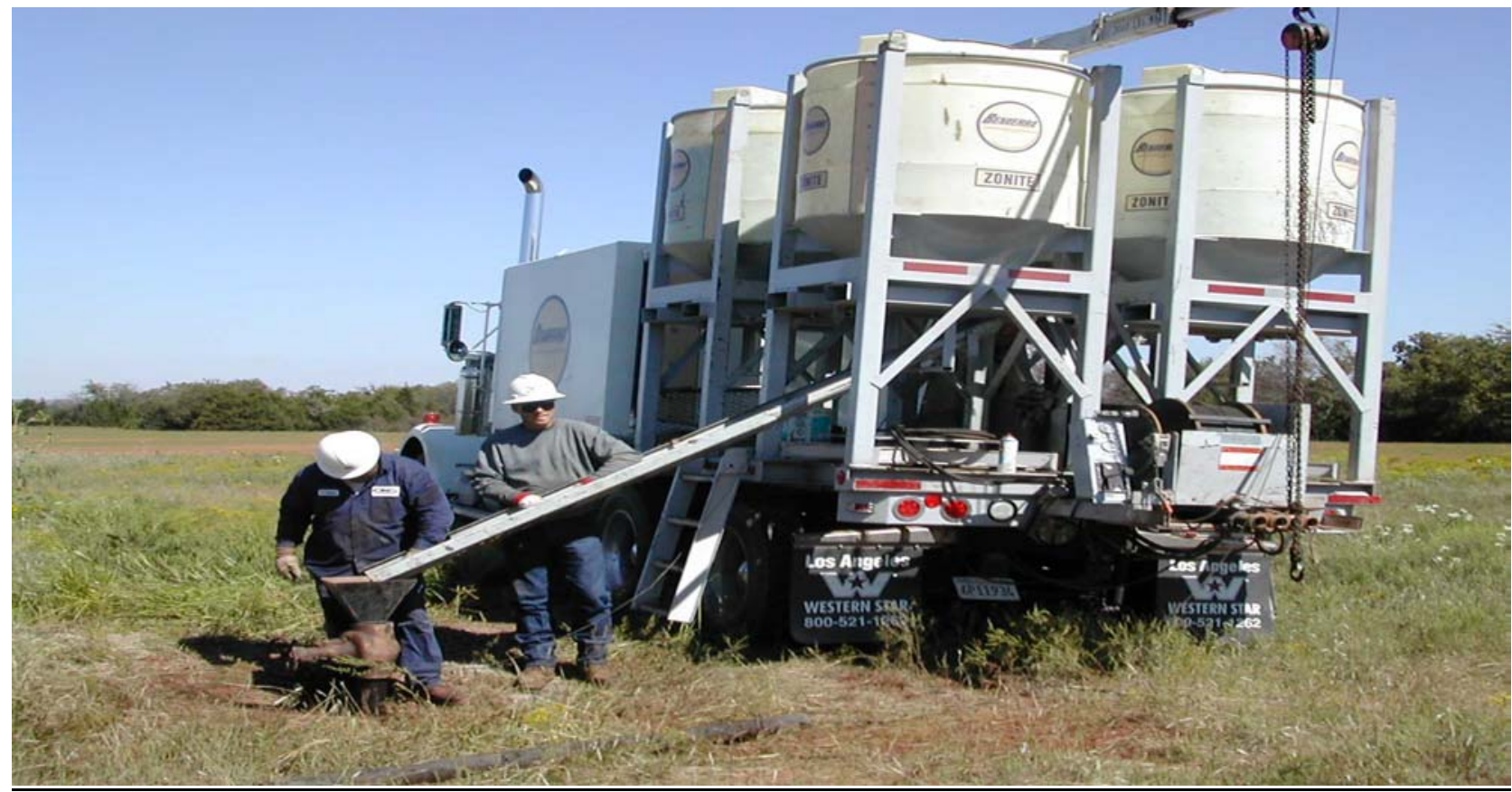



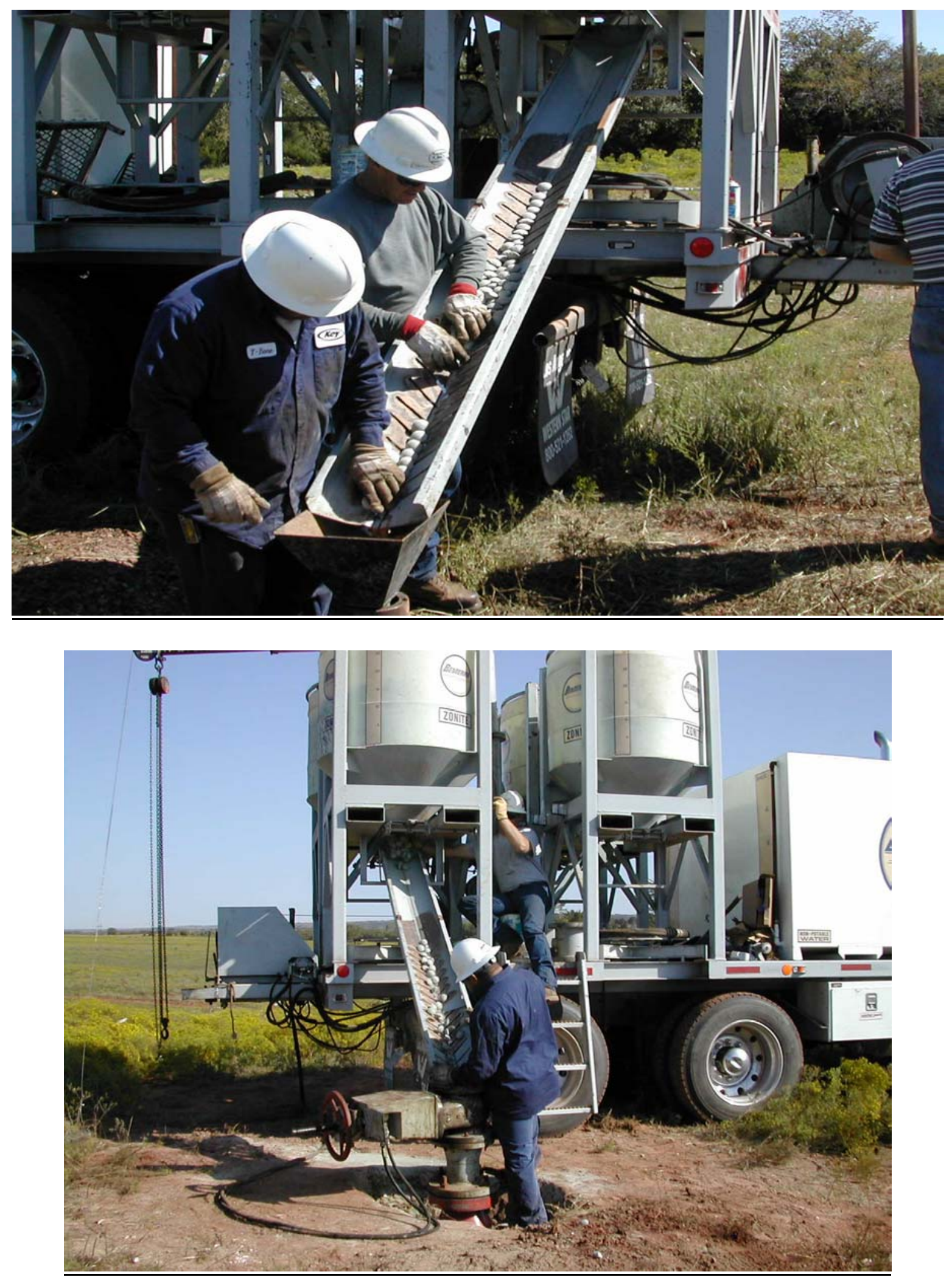


\section{HYDRATION}

Compressed sodium bentonite nodules were placed inside a 6" clear plastic tube and filled with fresh water about 2" above the top of the nodules, as requested by the IOGCC Bentonite Subcommittee. The following photos were taken at timed intervals of 1 to 96 hours to show the hydration process of compressed sodium bentonite.

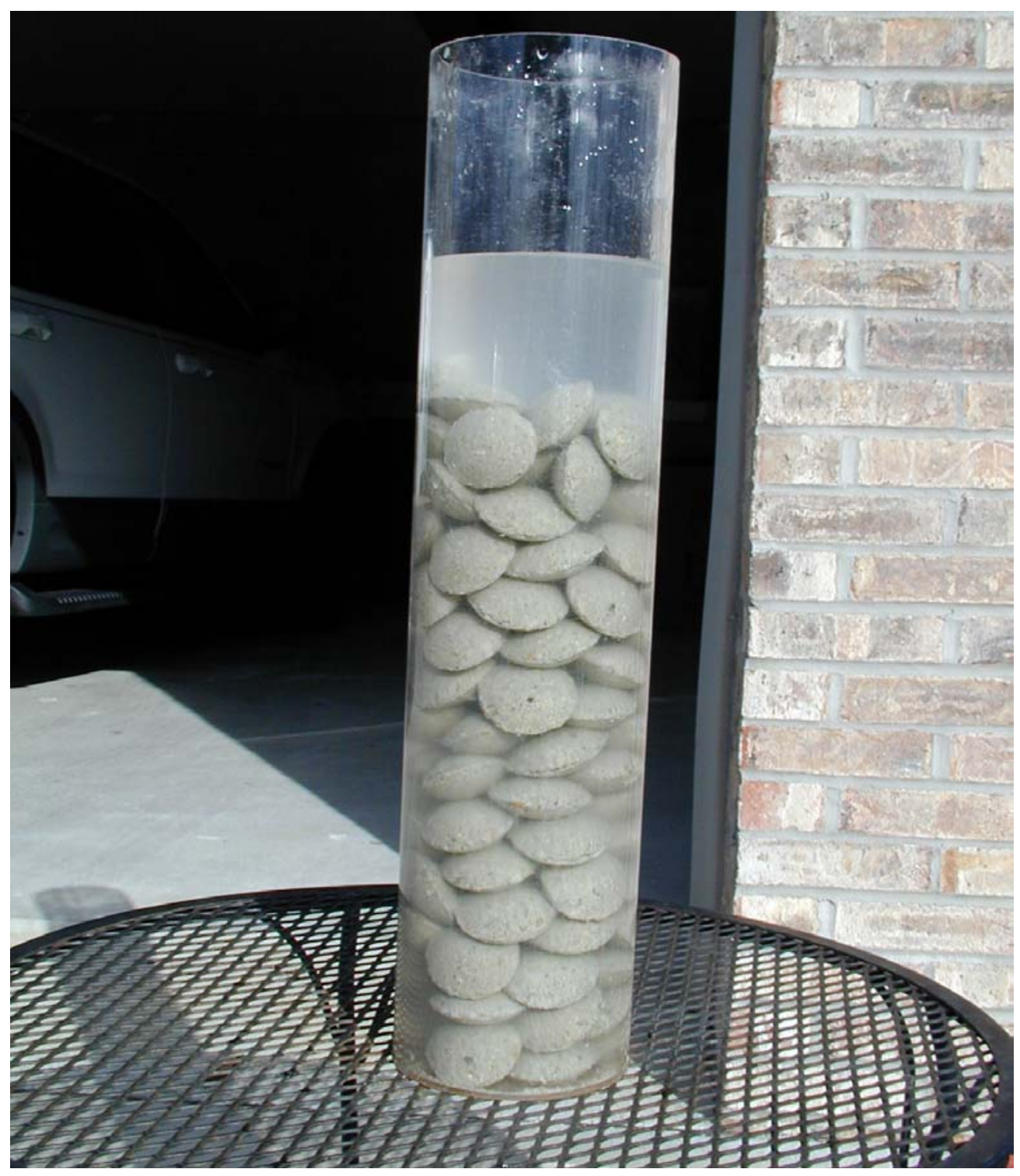


The top of the water and the top of the nodules were also marked.

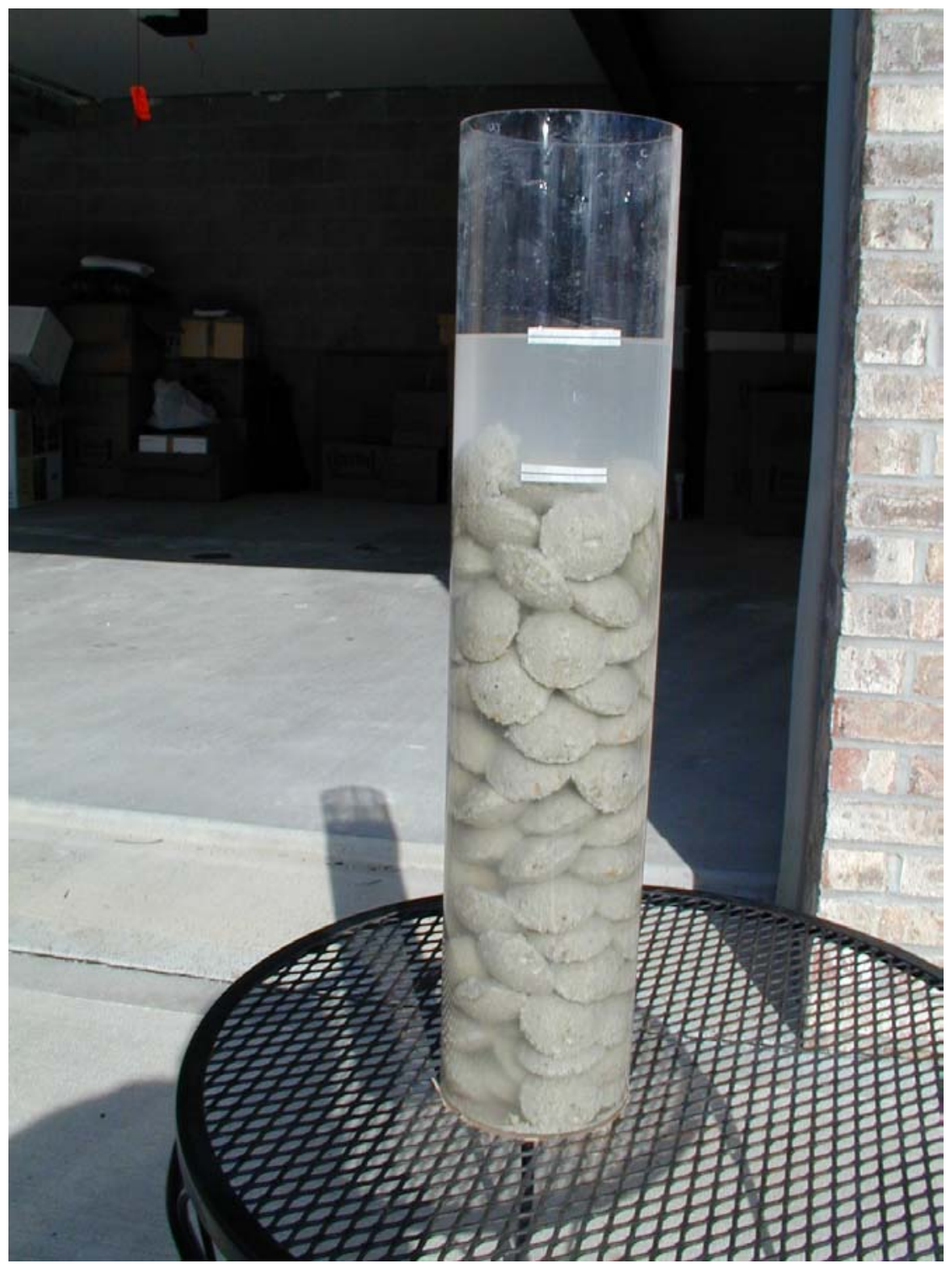


Note the cavity at the bottom of the column. The cavity area will be photographed over time to see if the nodules expand into the cavity.

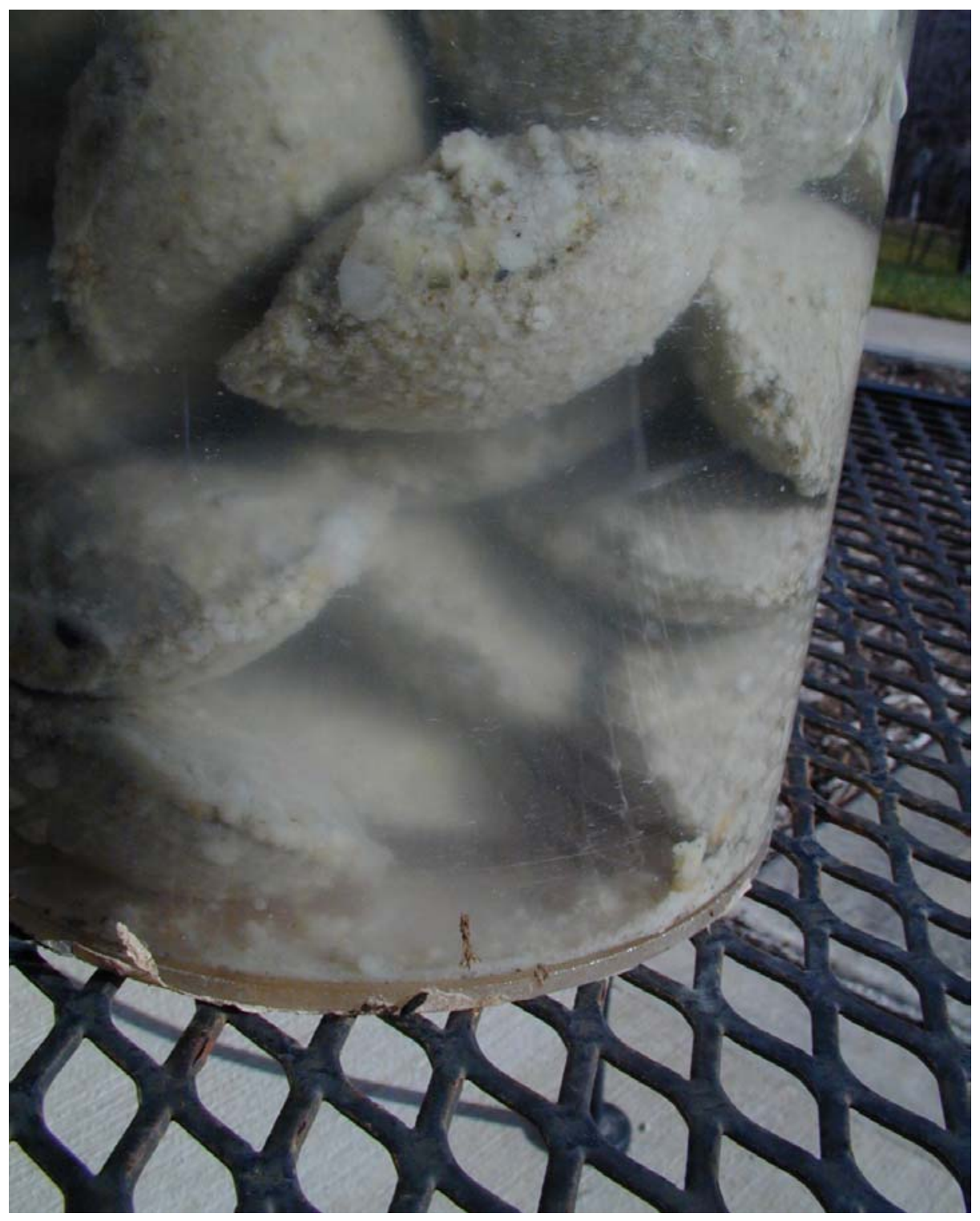


The following pictures were taken at 1,2,3,4,5,21,24 and 96 hour intervals.

Photos of the cavity at the bottom of the tube were taken to examine the cavity size as hydration occurred.

\section{Hour}

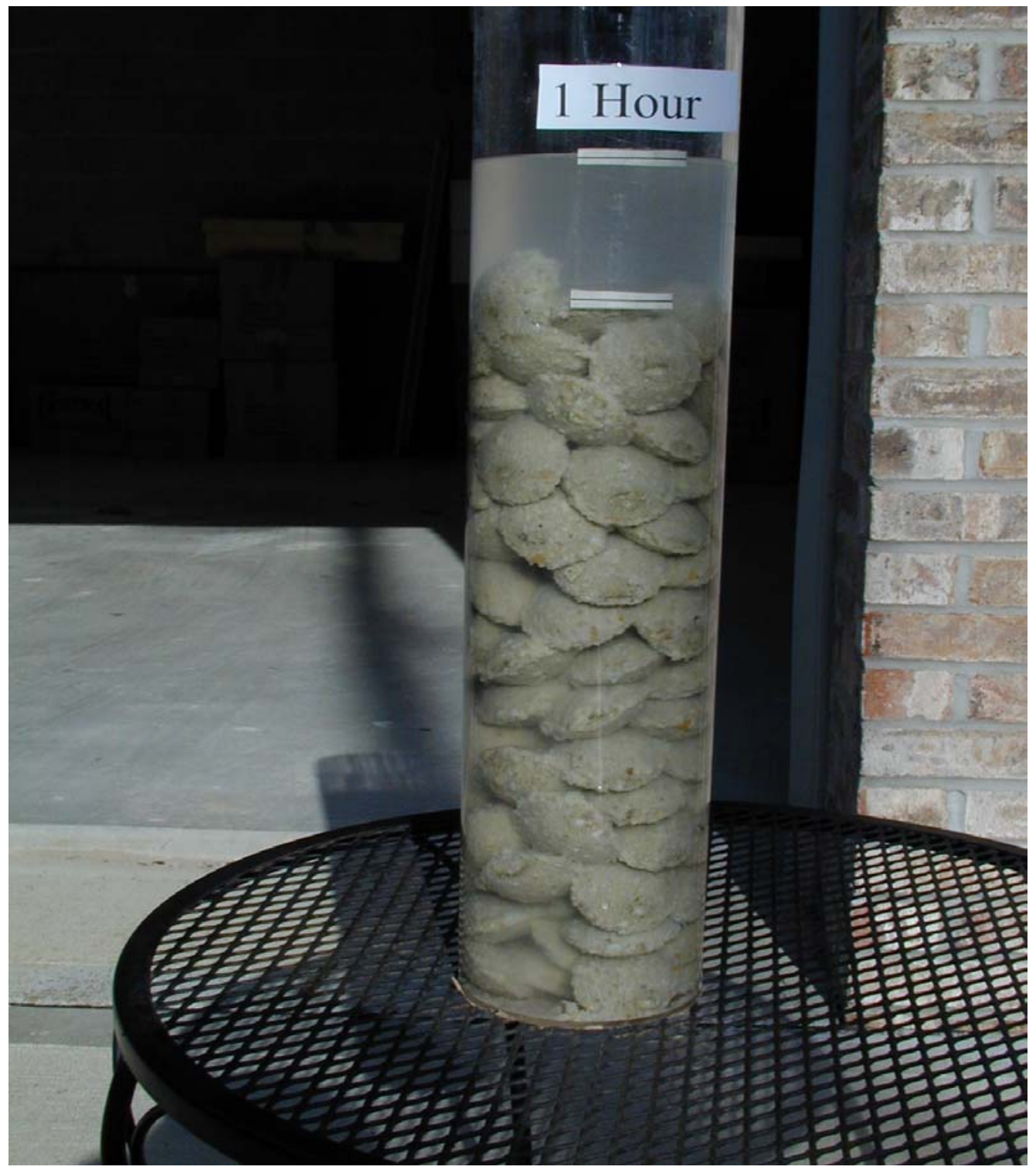


1 Hour Cavity

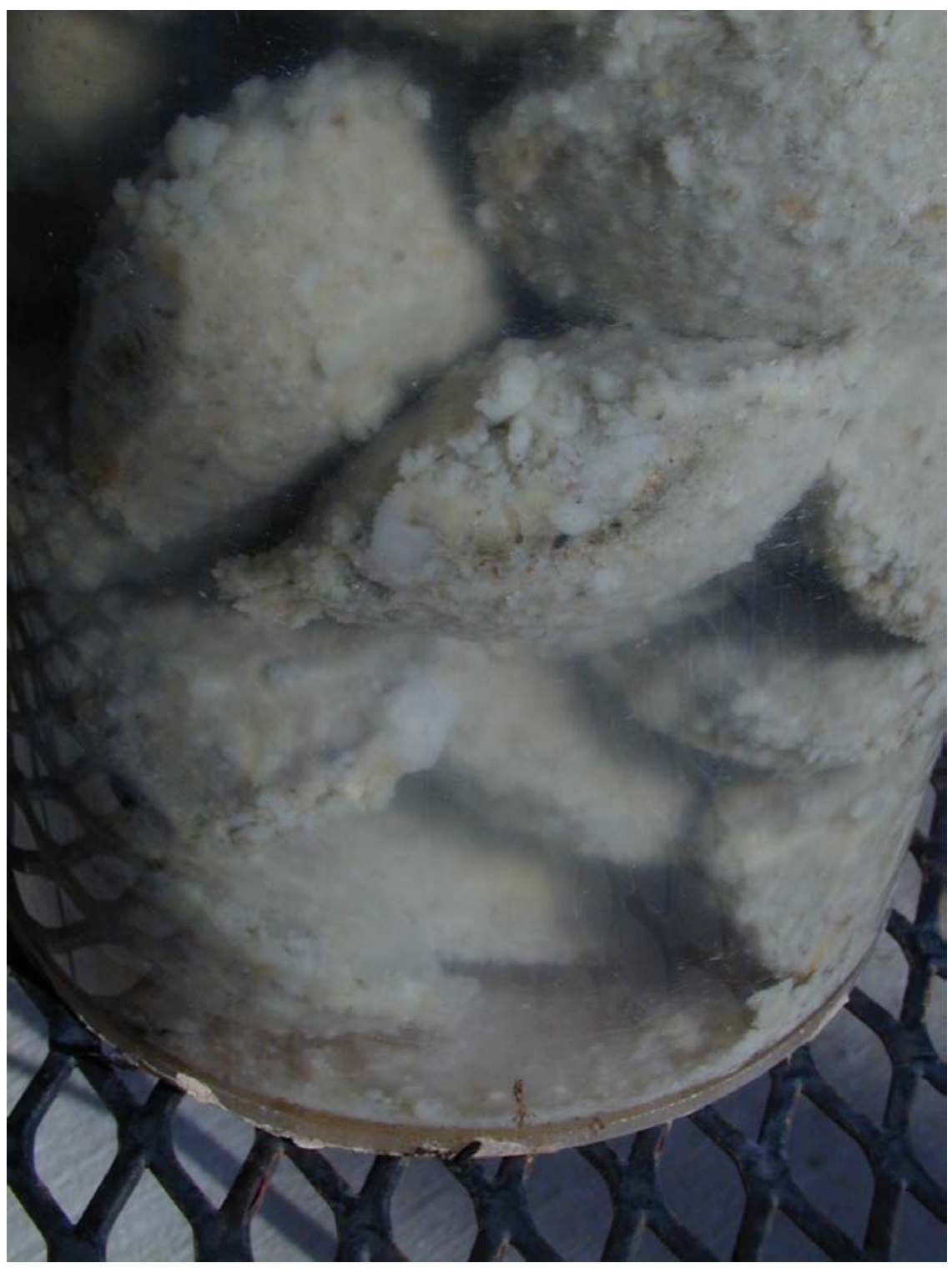


2 Hours

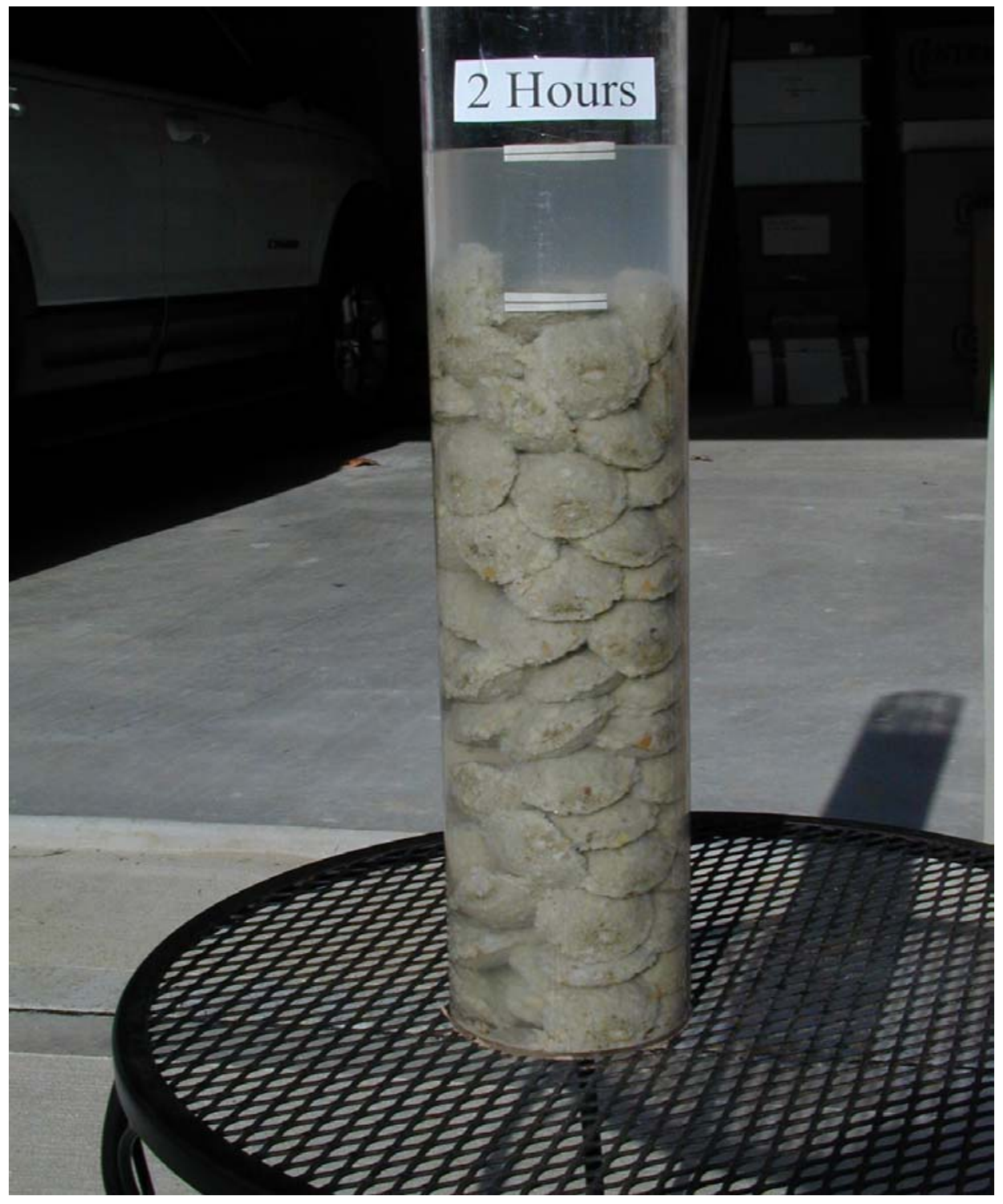


2-Hour Cavity

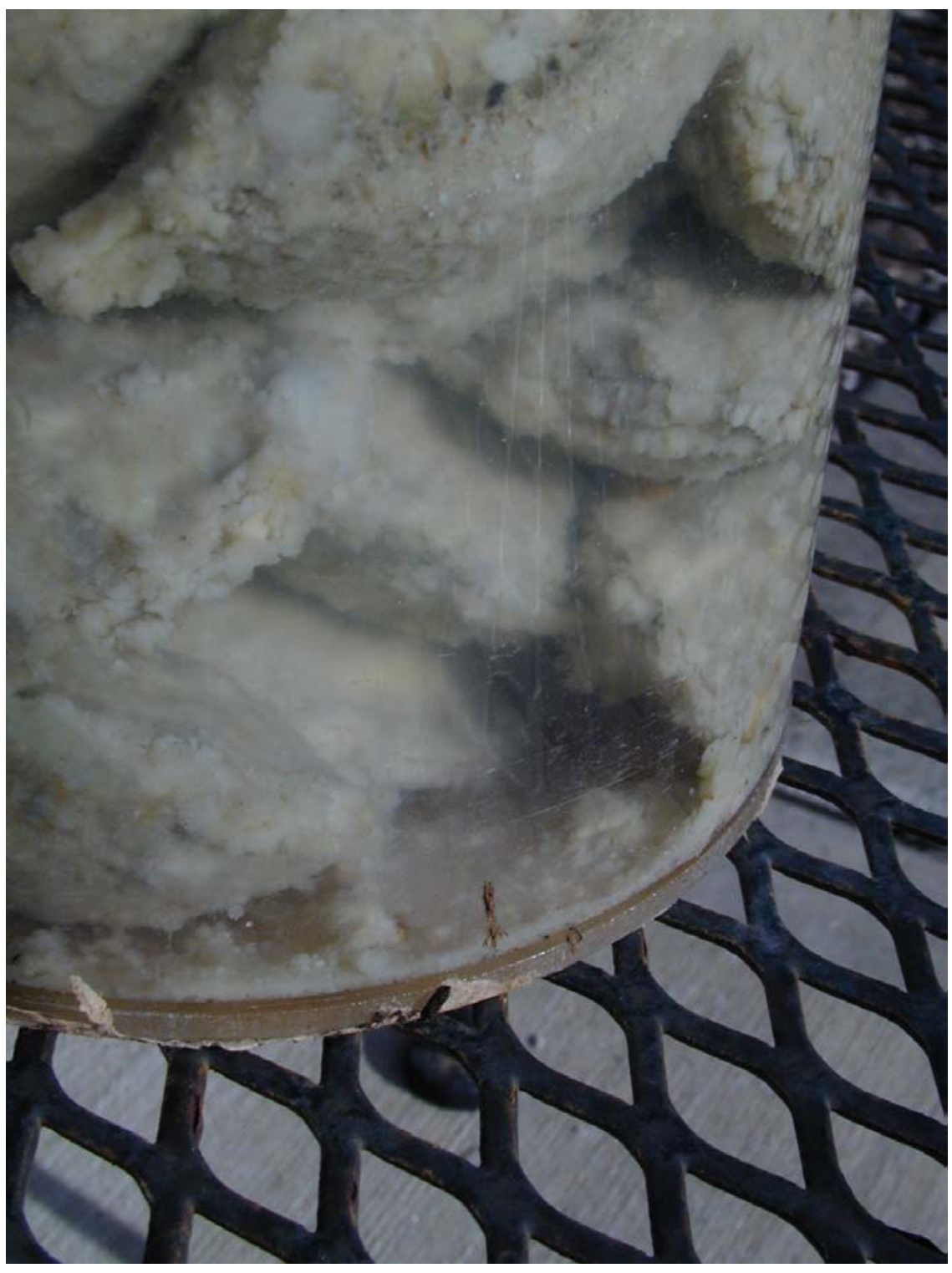


3 Hours

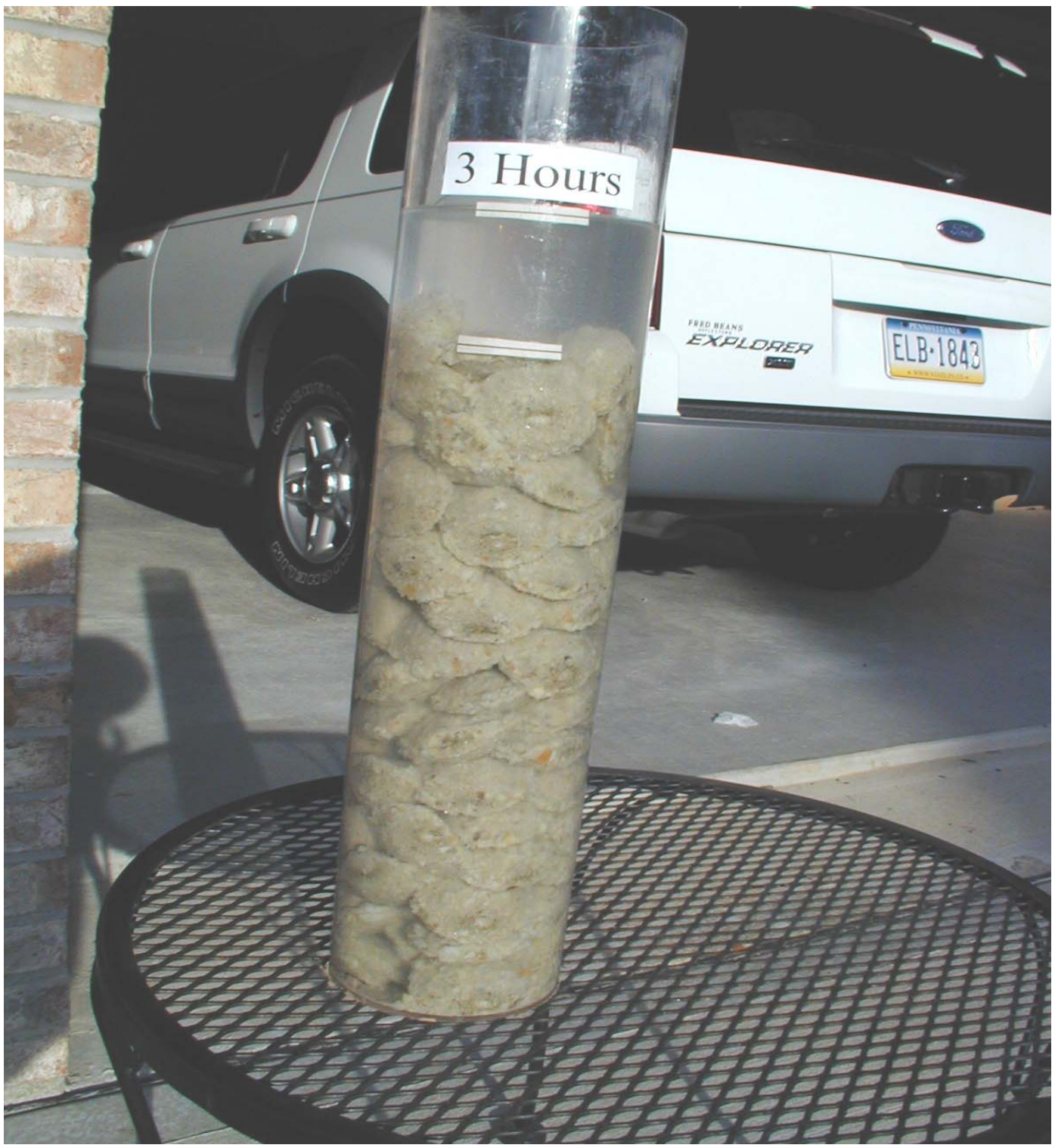




\section{3-Hour Cavity}

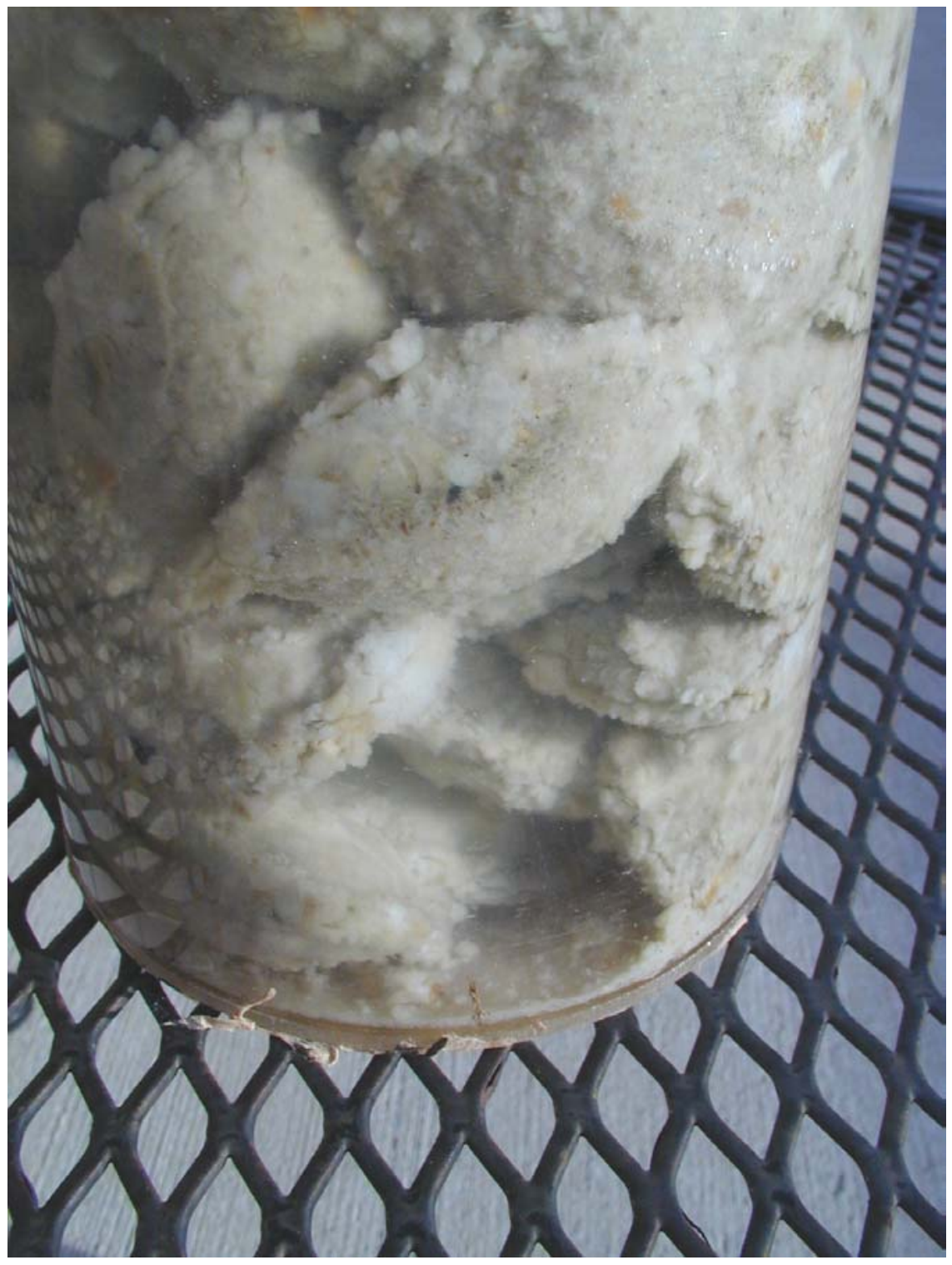




\section{Hours}

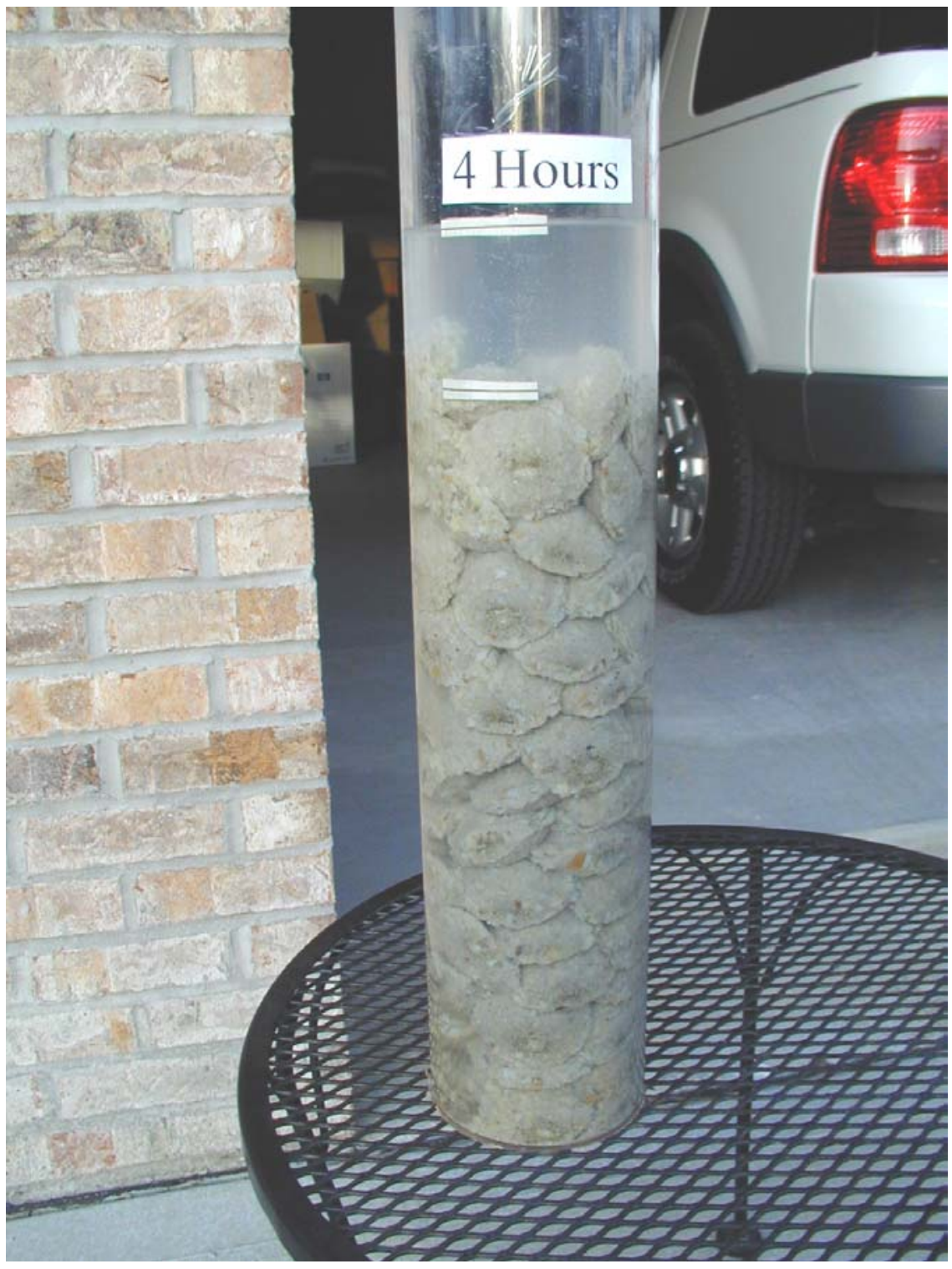




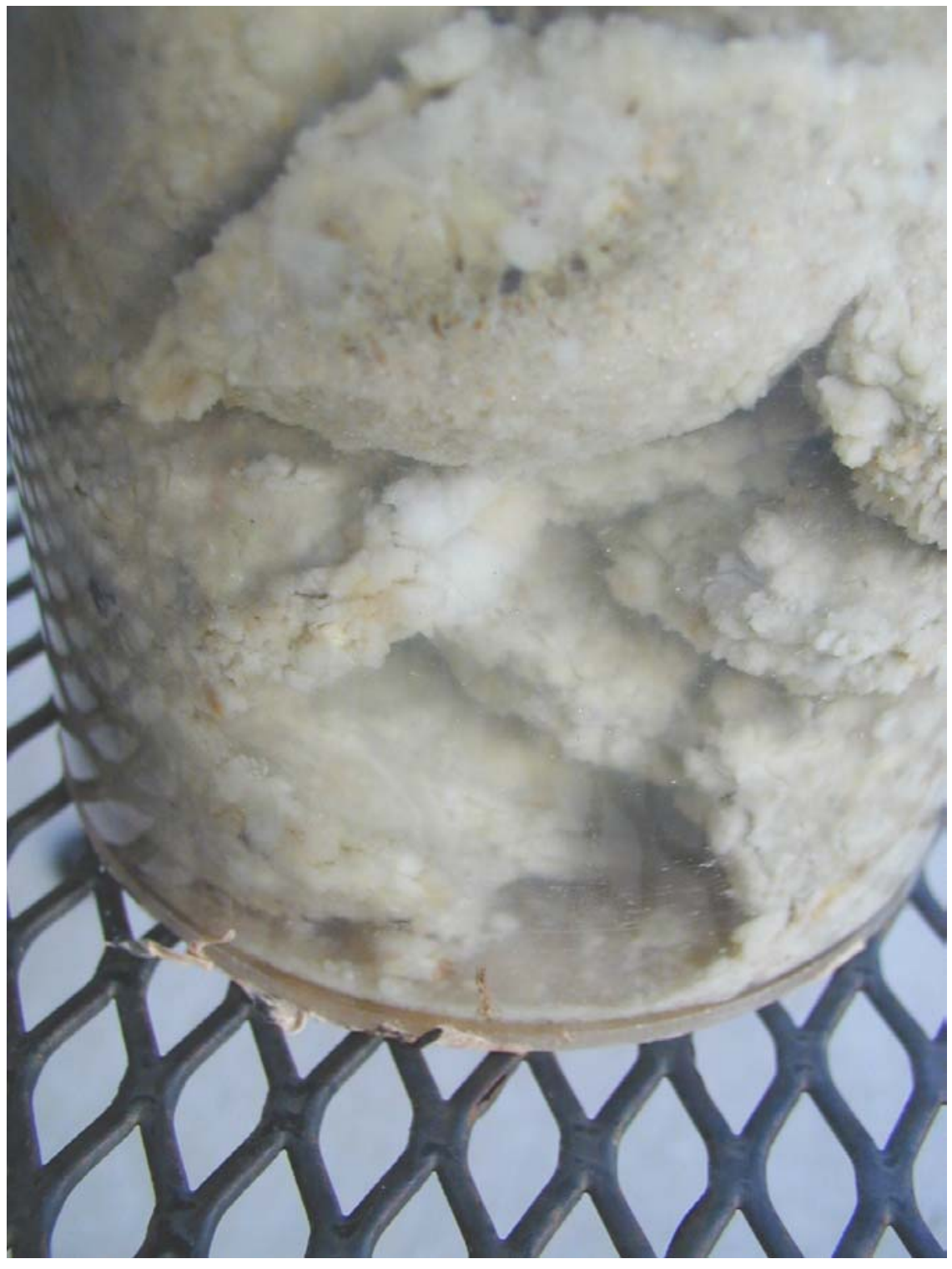




\section{Hours}

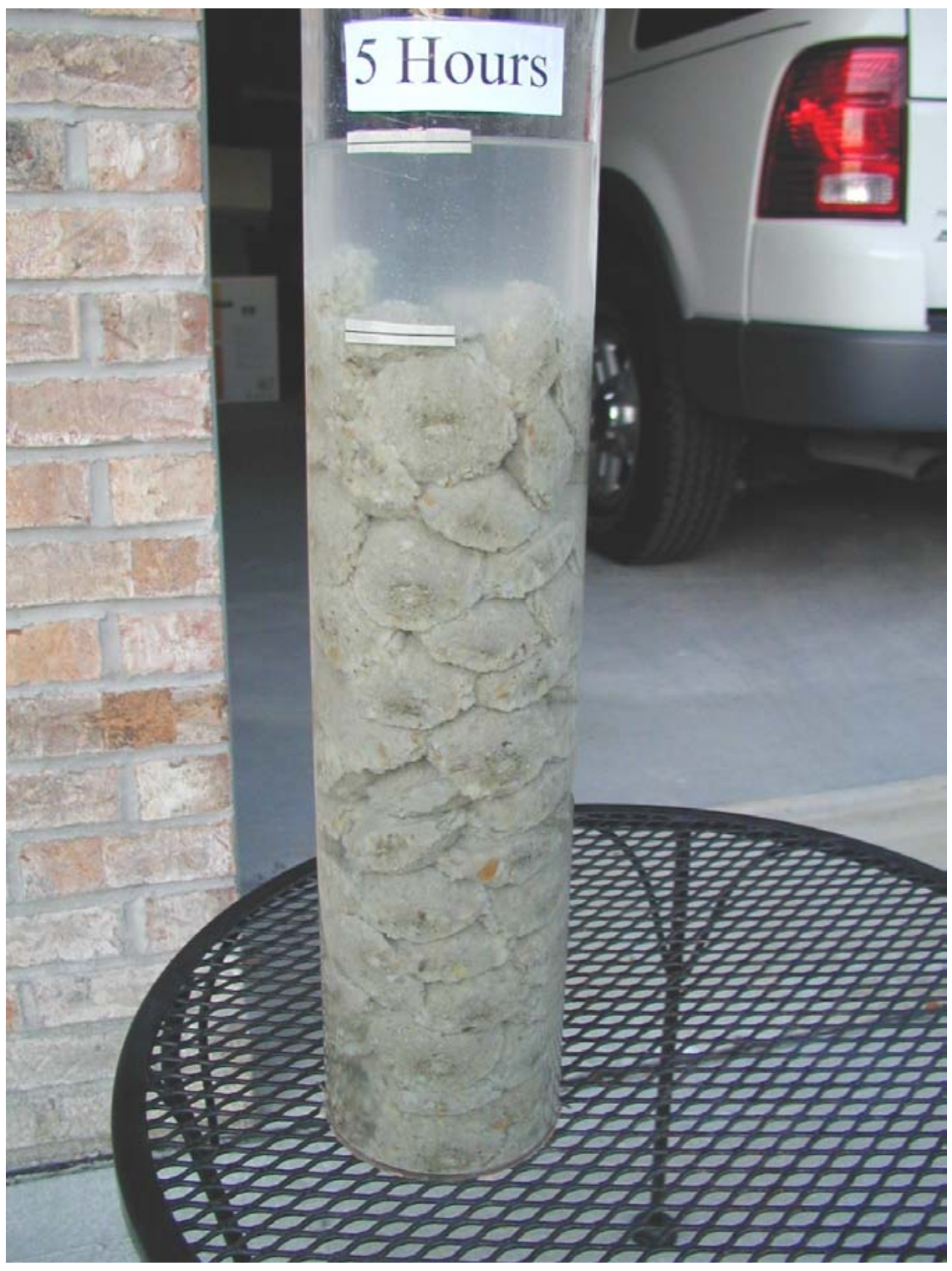




\section{Hour Cavity}

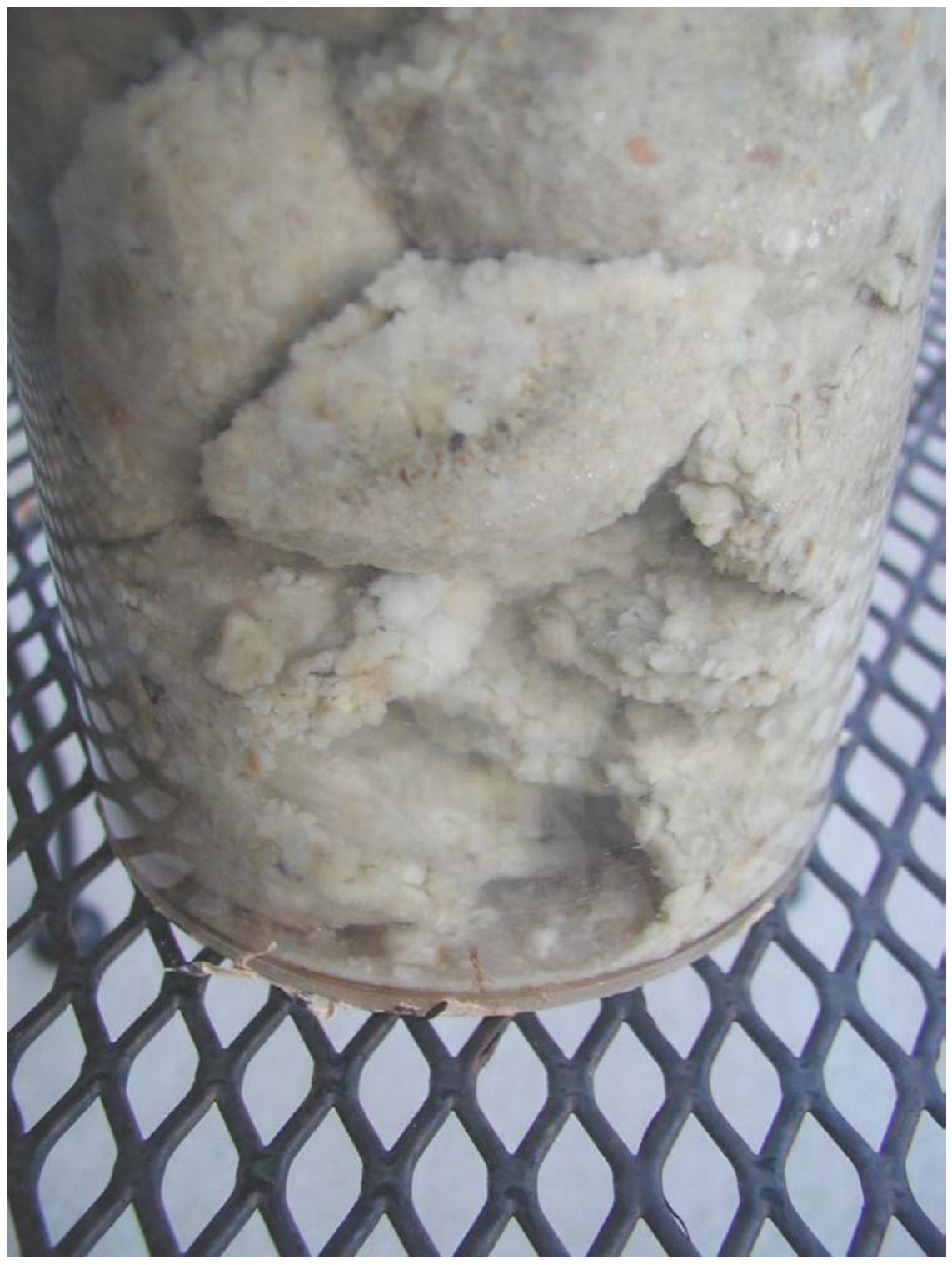




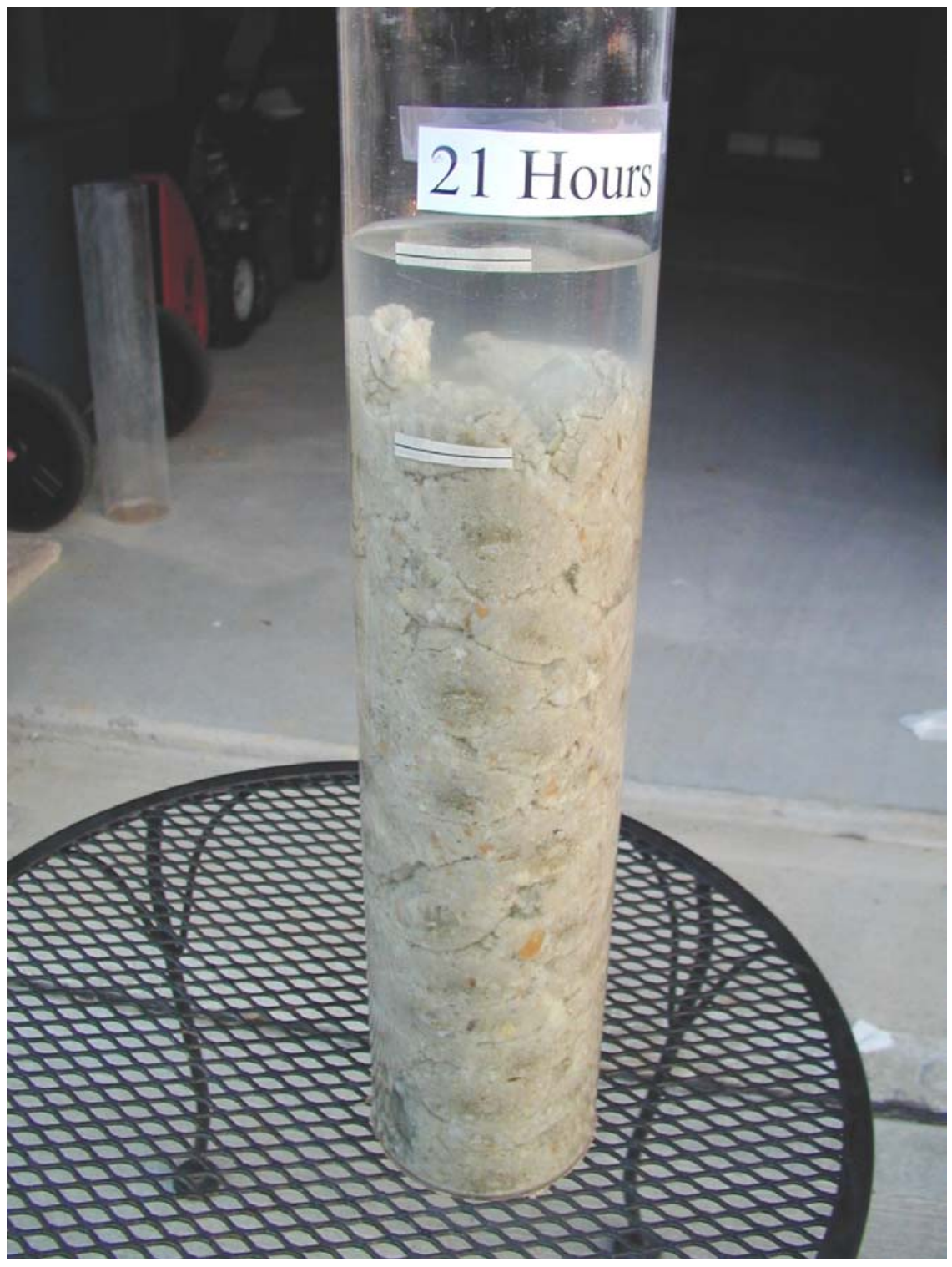




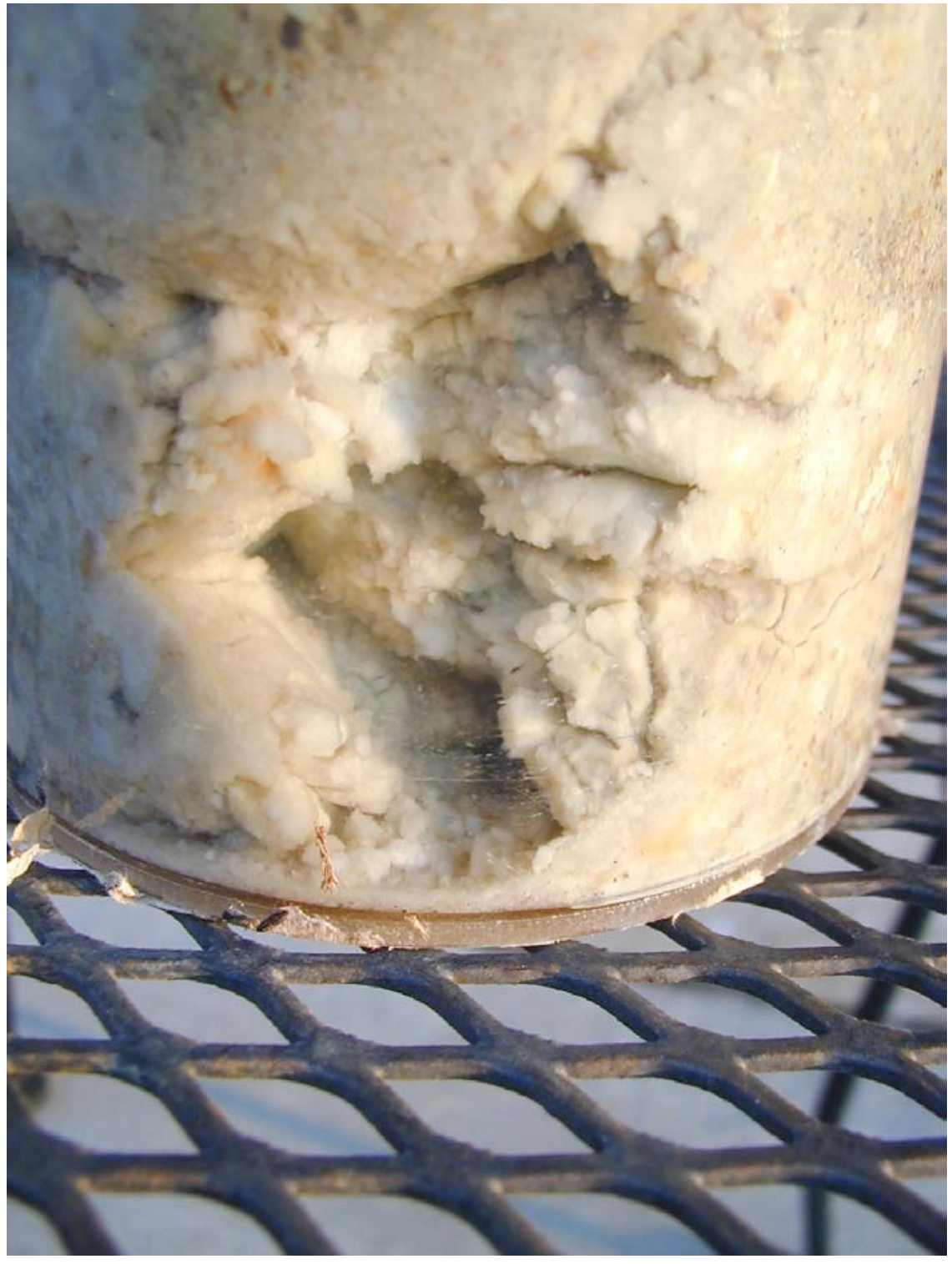




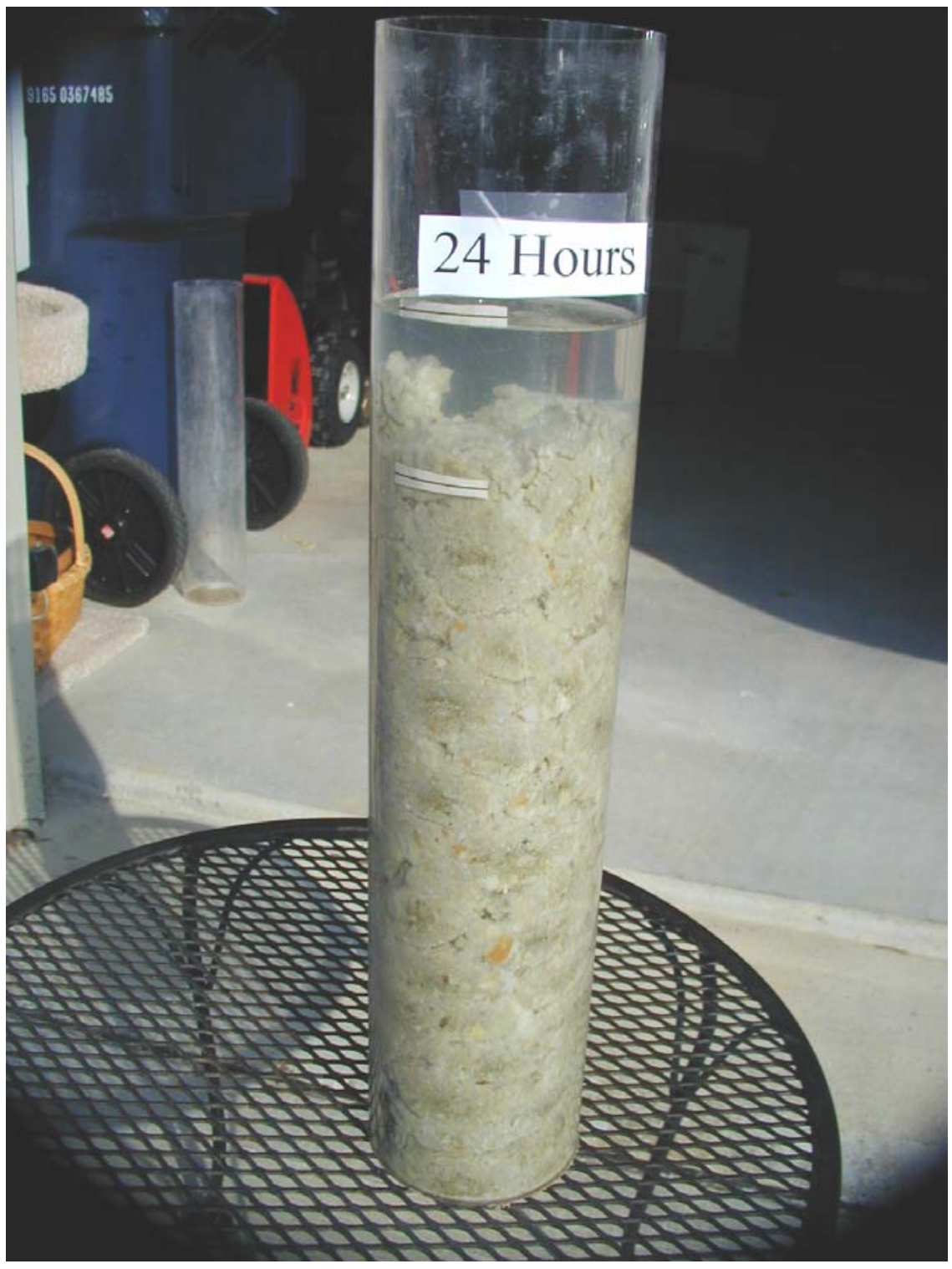


24-Hour Cavity

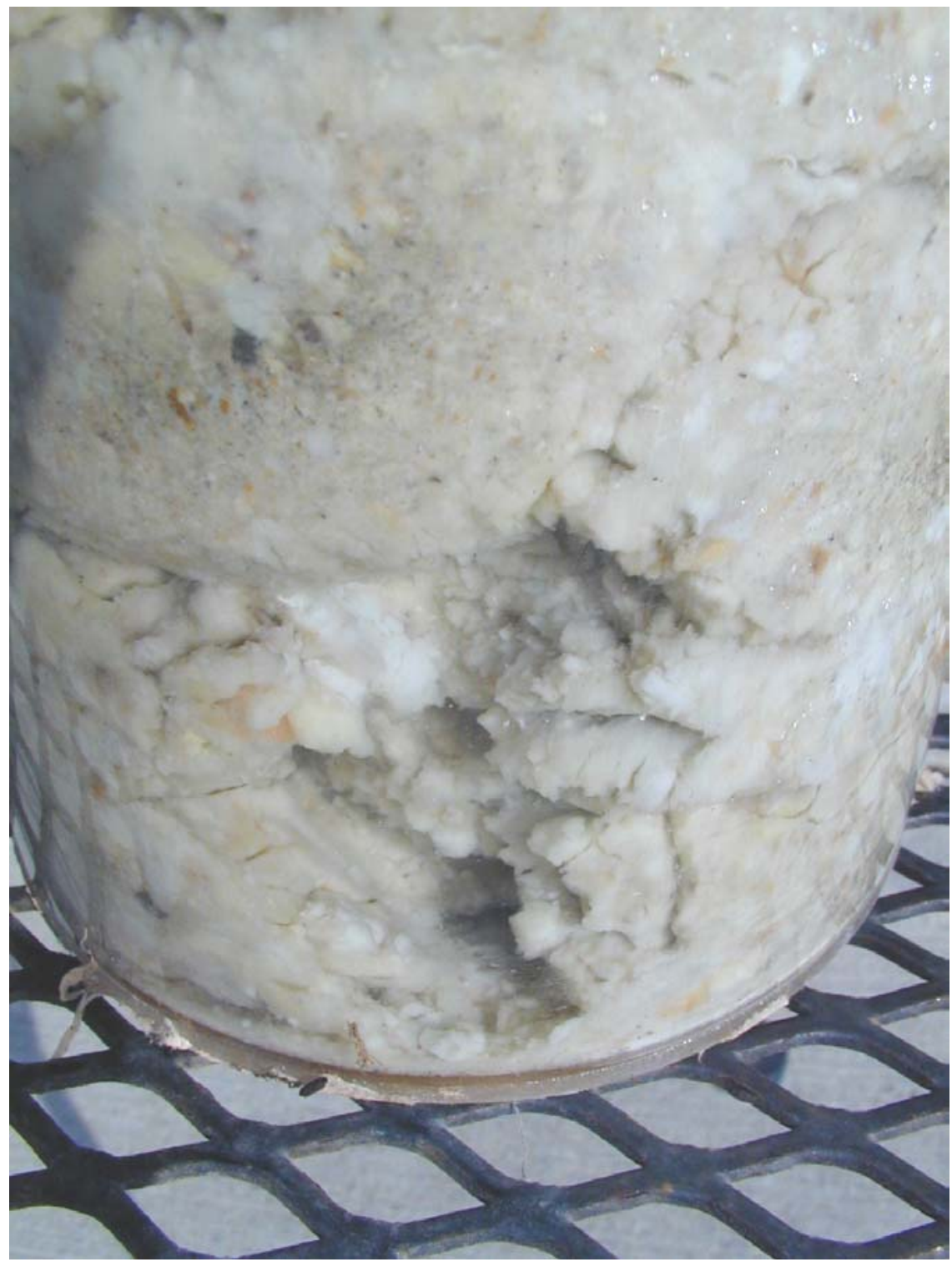


96 Hours

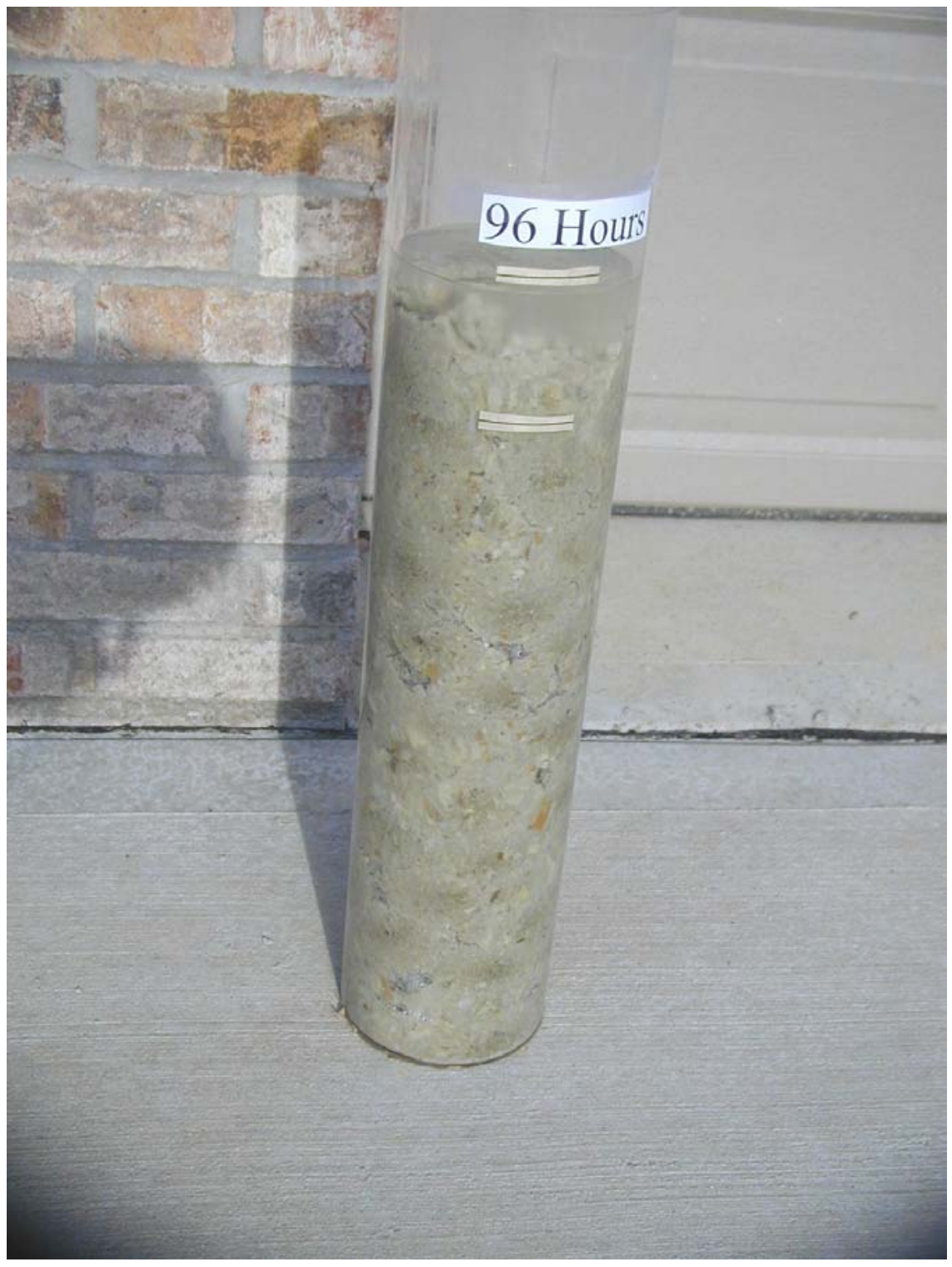


96-Hour Cavity

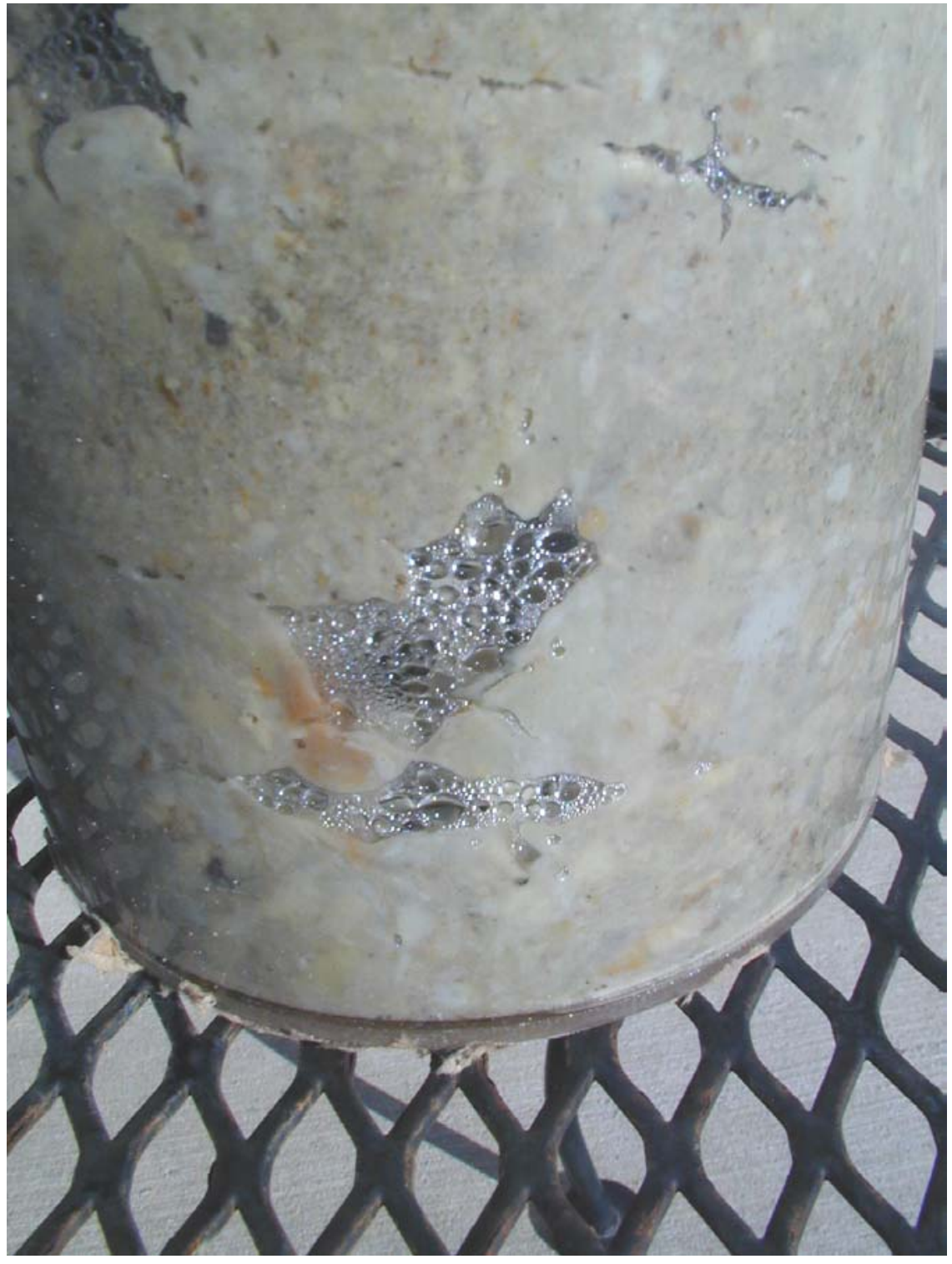


The following photographs document an in-situ demonstration of compressed sodium bentonite as a plugging agent in oil and gas well abandonments. The demonstration was conducted at the request of the California Division of Oil, Gas and Geothermal Resources, the Bakersfield office of the U. S. Bureau of Land Management, and the Conservation Committee of California Oil \& Gas Producers- Bentonite Subcommittee.

The purpose of the demonstration was to show that the compressed sodium bentonite nodules could be placed at specific depths and would hydrate throughout the length of the plug. The project followed a protocol approved by the California division of Oil, Gas and Geothermal Resources. It was conducted at the Chevron well \#9-8A in Section 31E in the Midway Sunset Field near Taft, California. The demonstration was initiated on May 24, 2001 and concluded on July 3, 2001.

It demonstration consisted of:

1) running a string of pipe into an existing wellbore to 1320 feet;

2) surface pouring compressed sodium bentonite nodules to set a bottom plug from 1315 feet to 1165 feet and to set a 100 foot surface plug within the pipe;

3) hydrating the material with lease water;

4) waiting 30 days;

5) retrieving the plugged pipe from the hole

6) viewing the plug material at the pipe disconnection points; and

7) cutting one joint of the pipe at approximate midpoint of the bottom plug to determine if the plug had uniformly hydrated.

One or more representatives of the California Division of Oil, Gas, and Geothermal Resources witnessed all Segments of the demonstration. The demonstration showed that compressed sodium bentonite nodules can be placed at specific depths and will uniformly hydrate at both zonal and surface locations. 


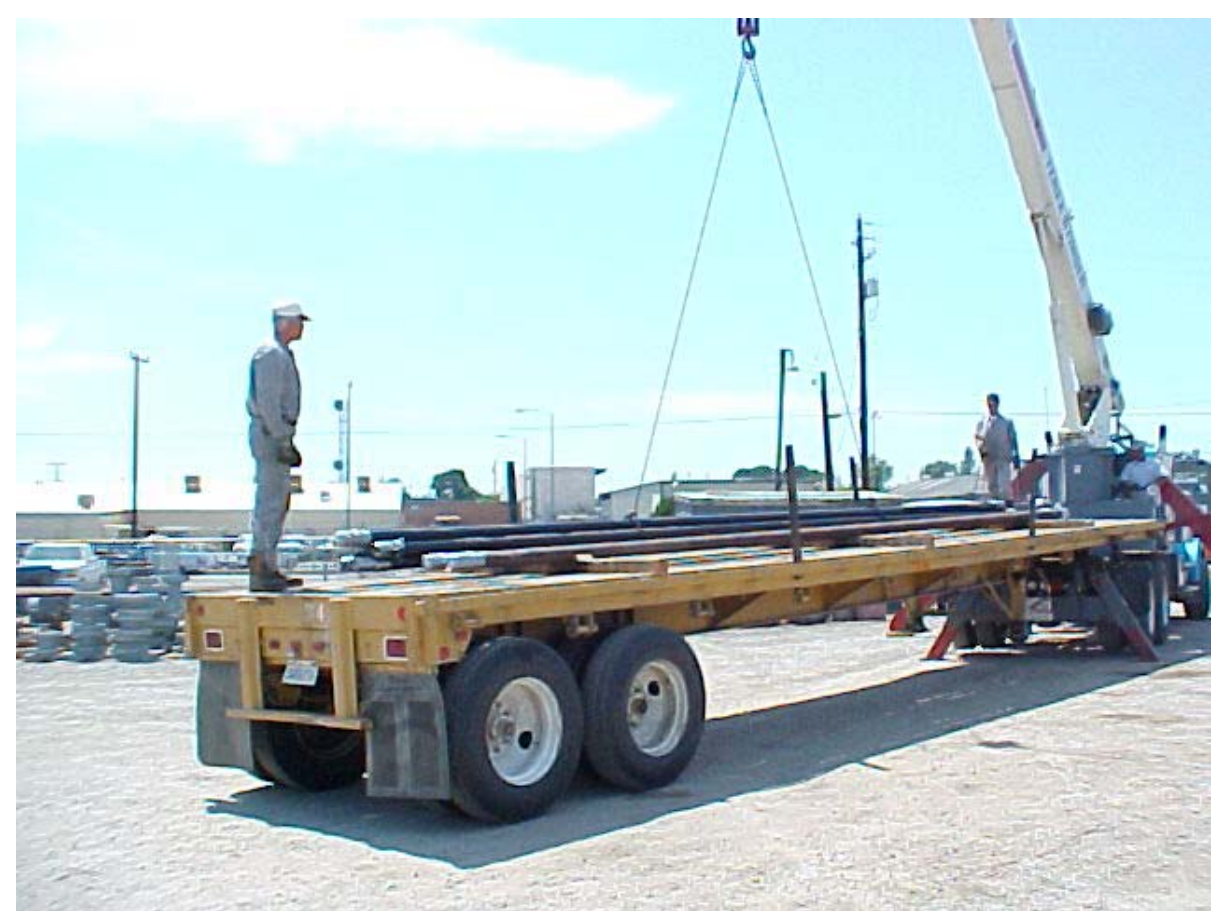

The pulled bentonite-filled casing being offloaded in Bakersfield

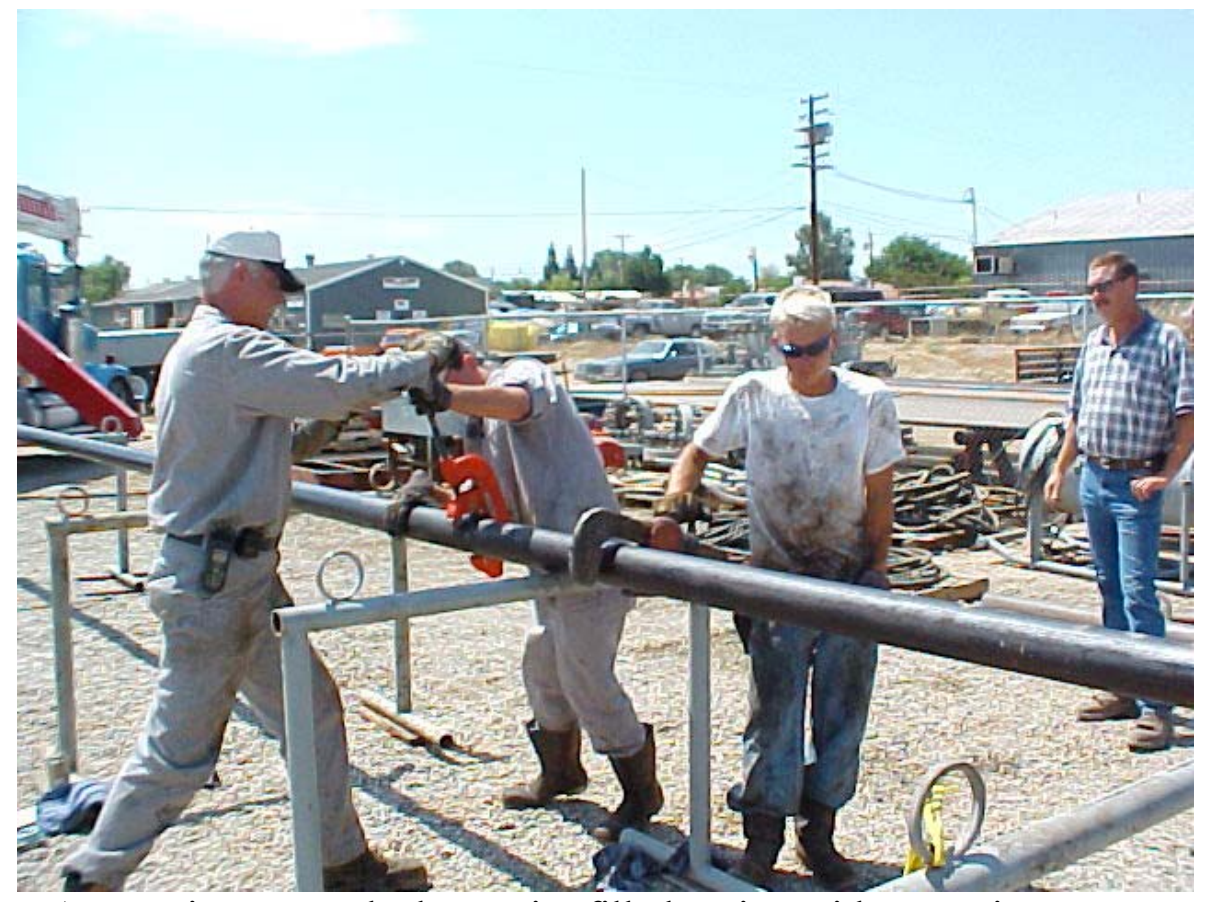

Attempting to cut the bentonite-filled casing with a rotating cutter. 


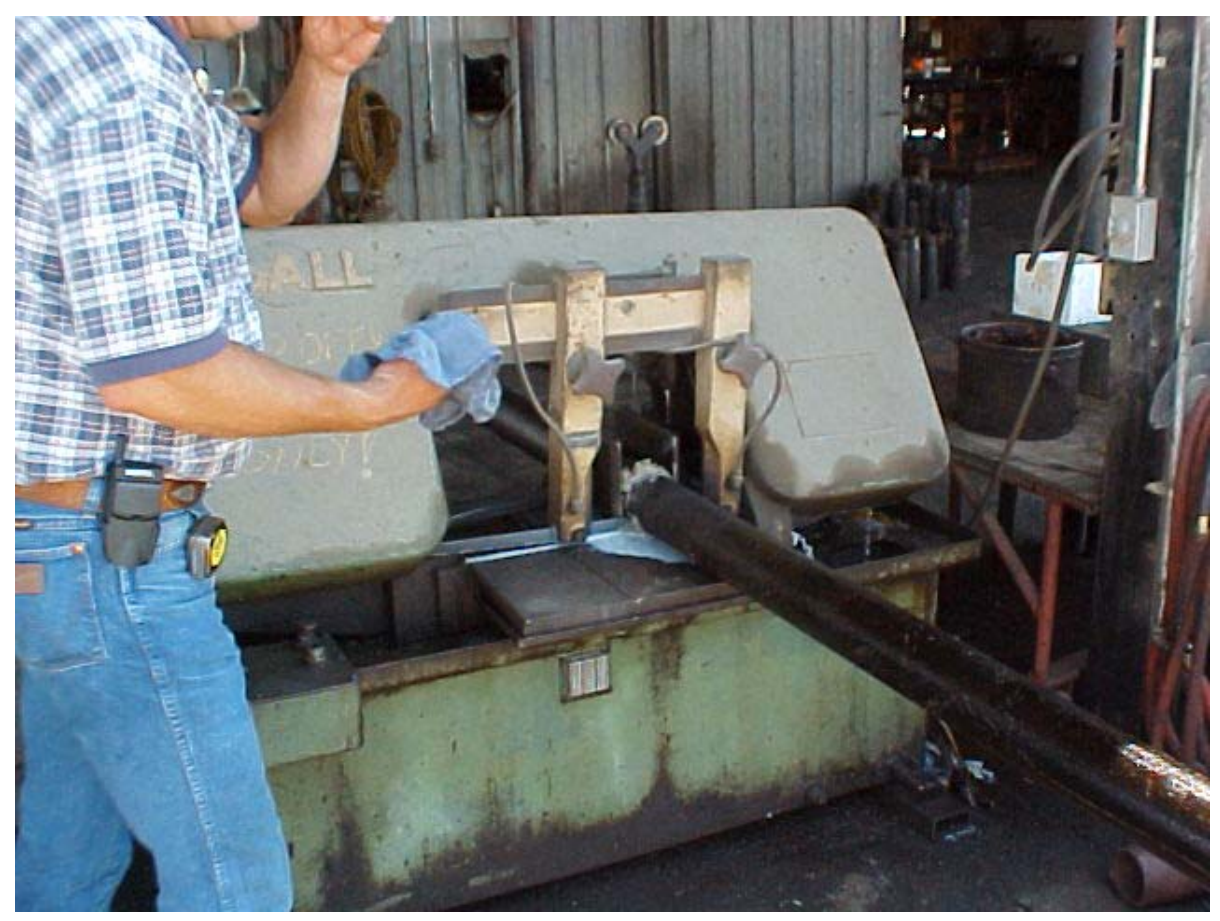

Cutting the bentonite-filled casing with the band saw.

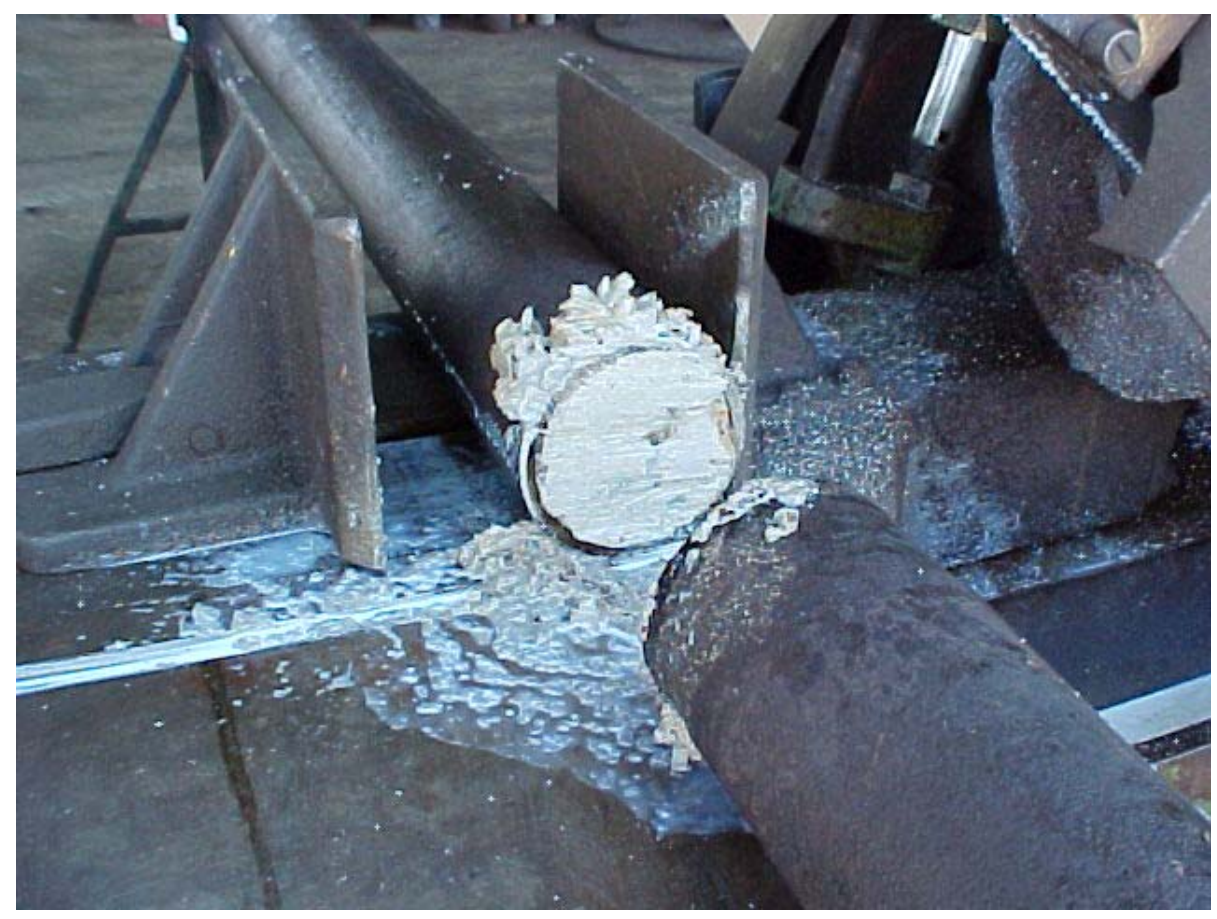

The bentonite-filled casing immediately after cutting. 


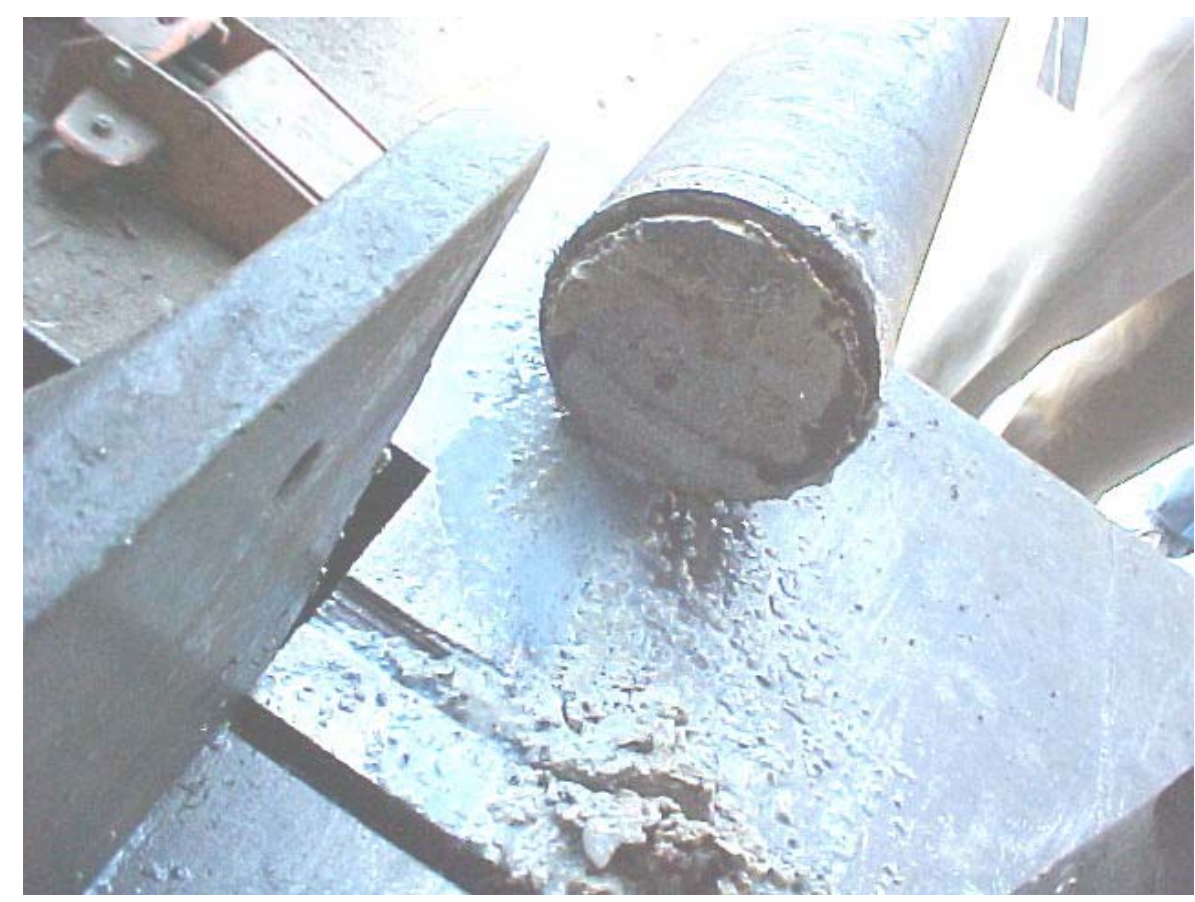

After a couple of minutes the bentonite is extruding from the casing

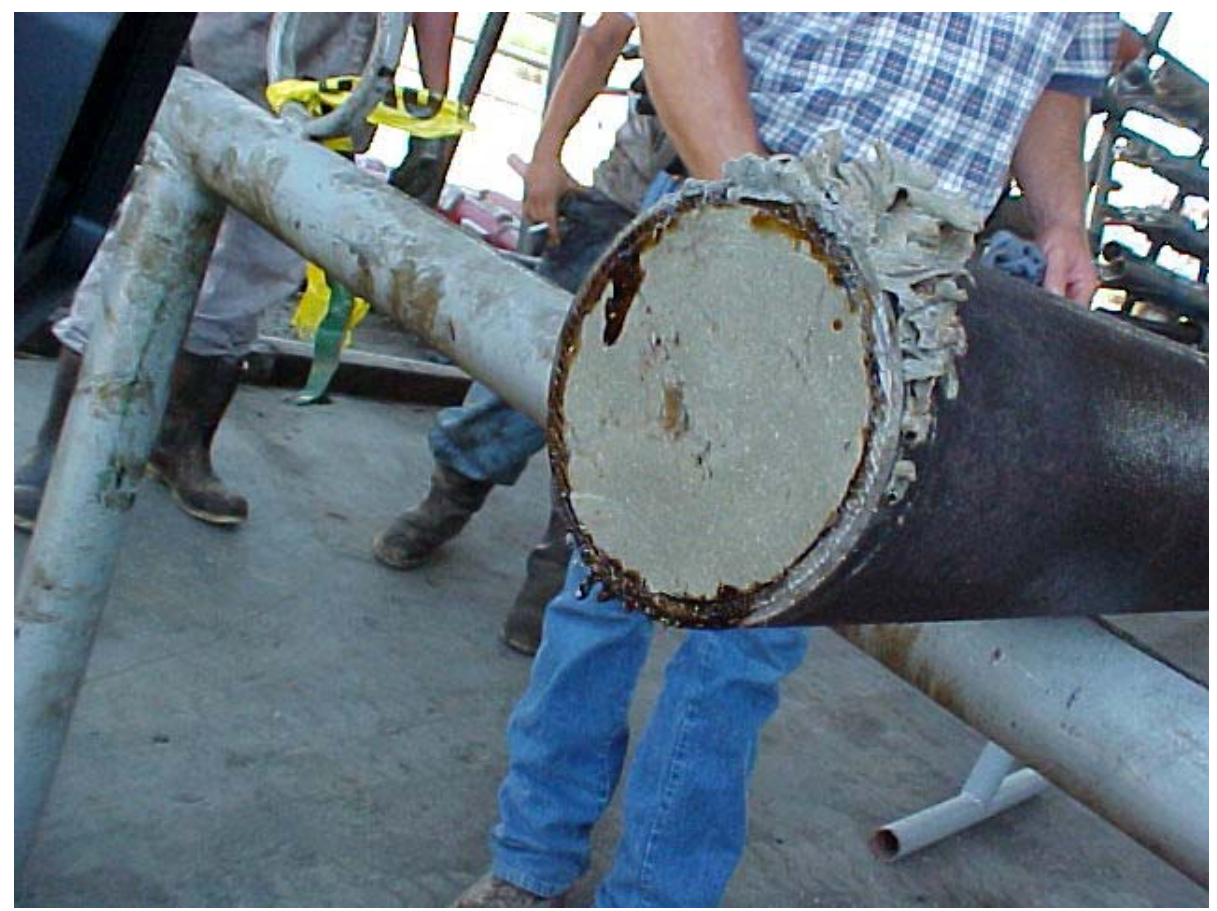

Showing some slight extruding and some oil staining from the casing wall 


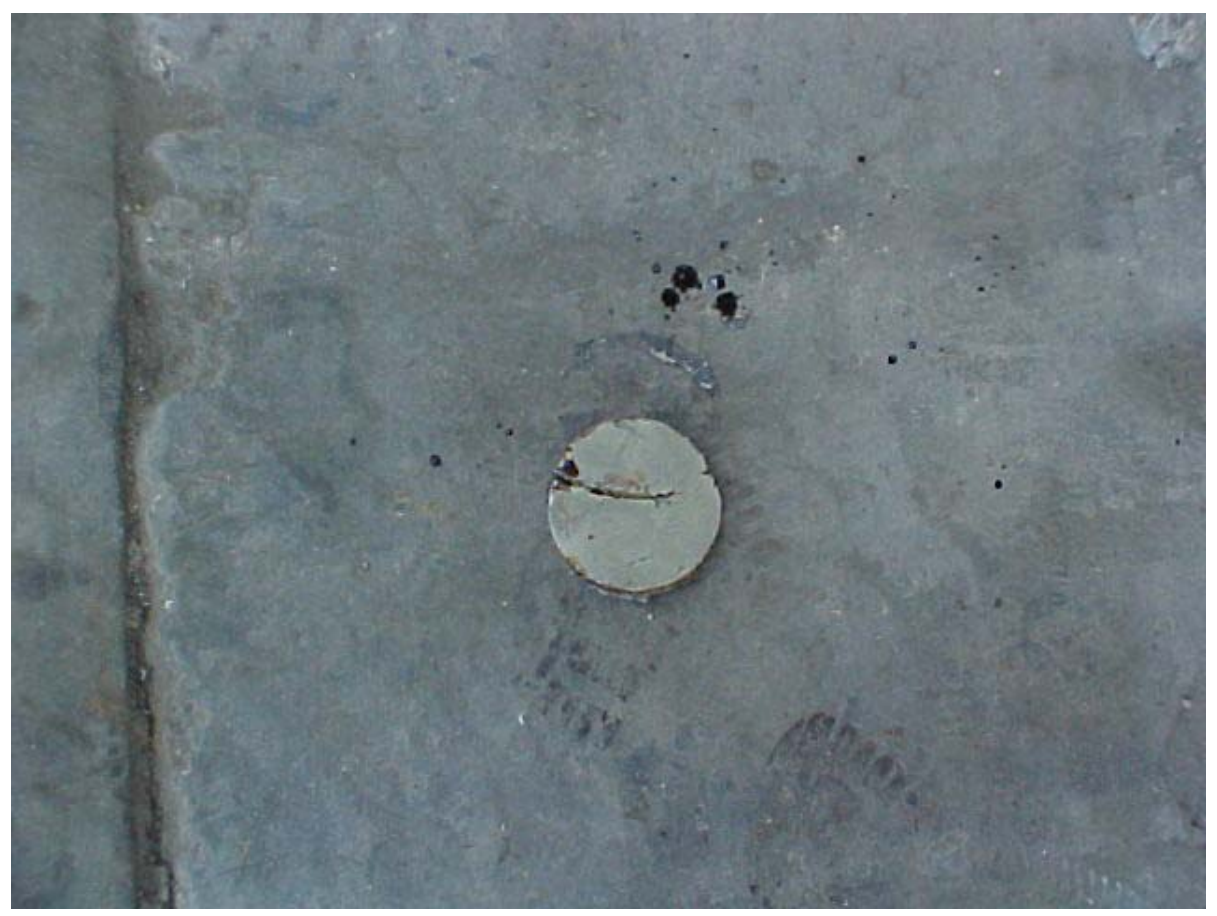

A cookie like slab cut from the extruded bentonite

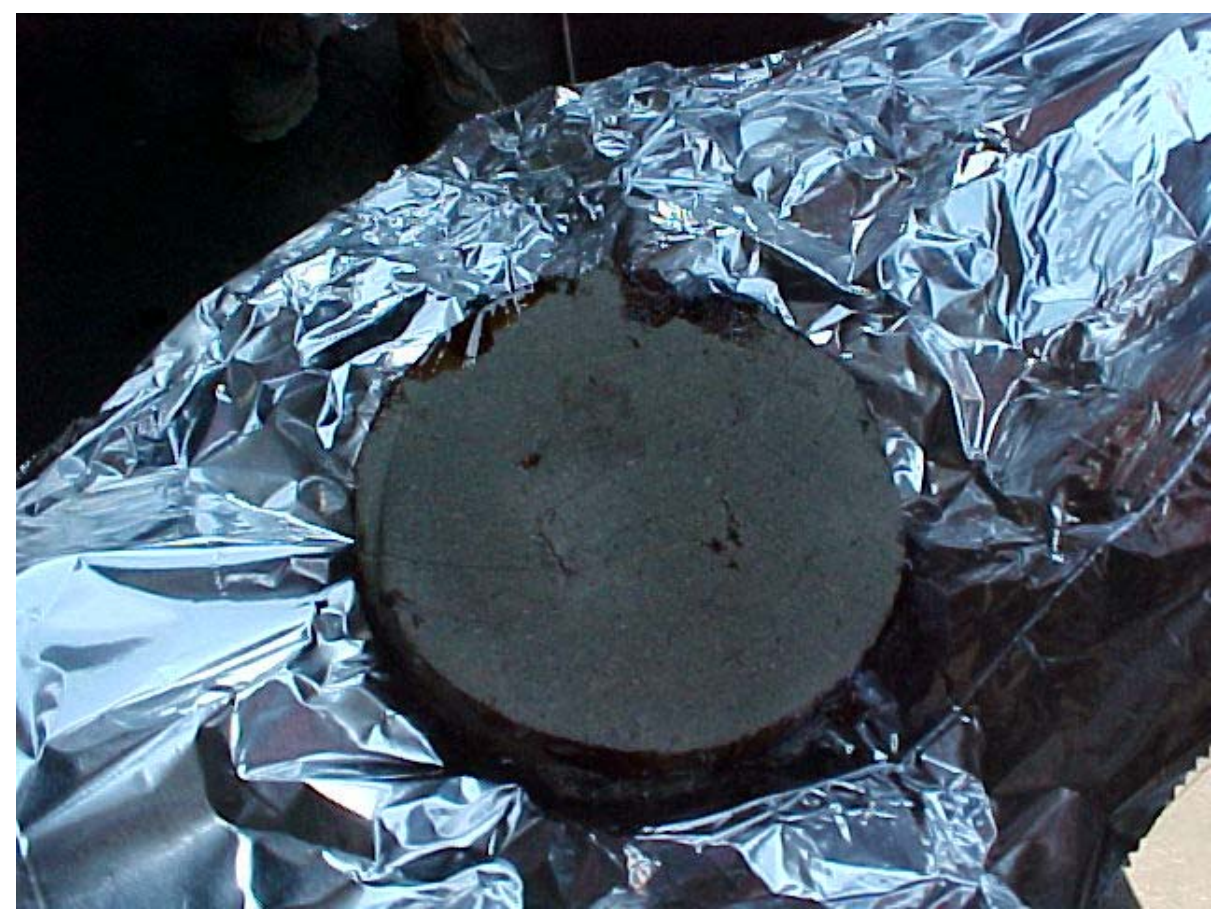

A slab cut from the extruded bentonite 


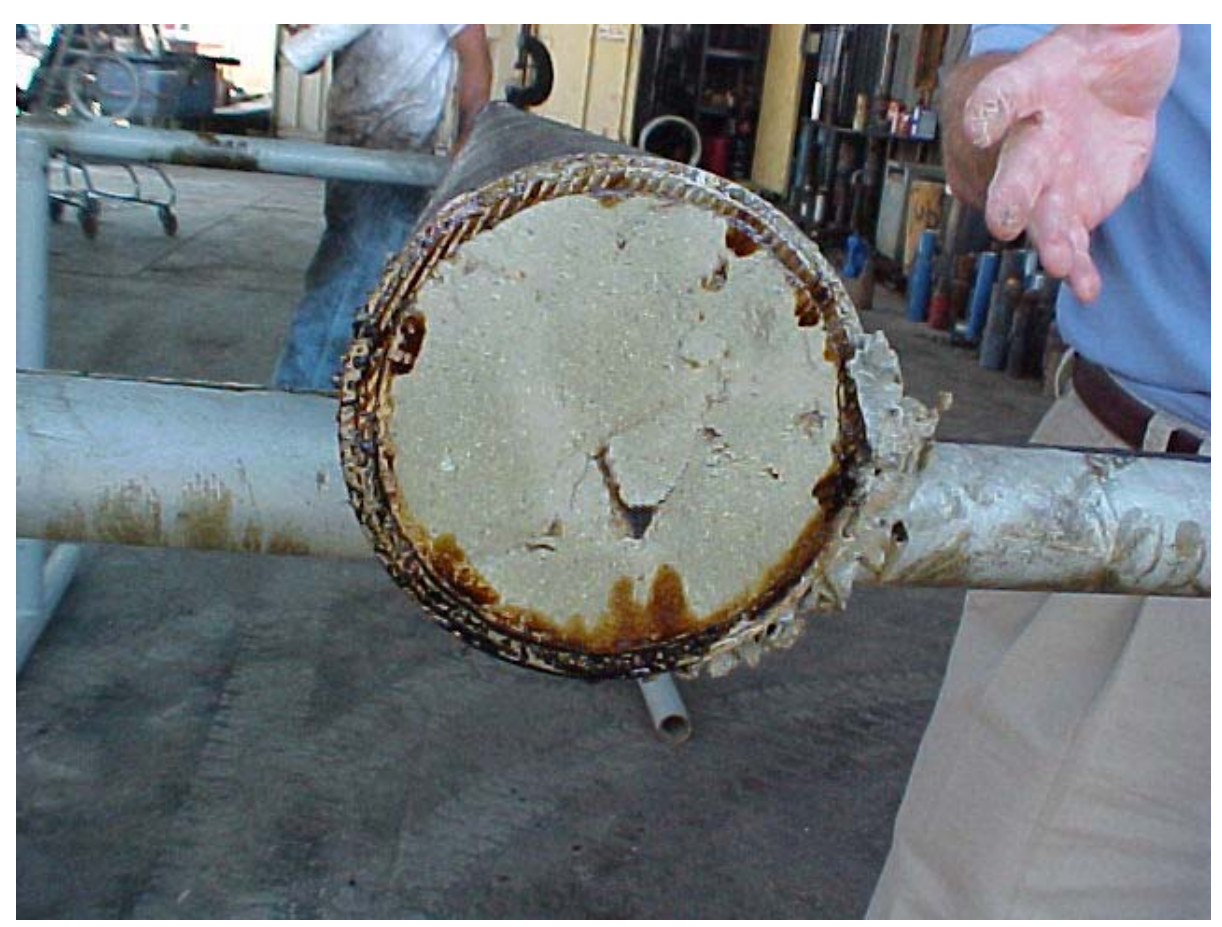

A cross section view of the bentonite in the casing

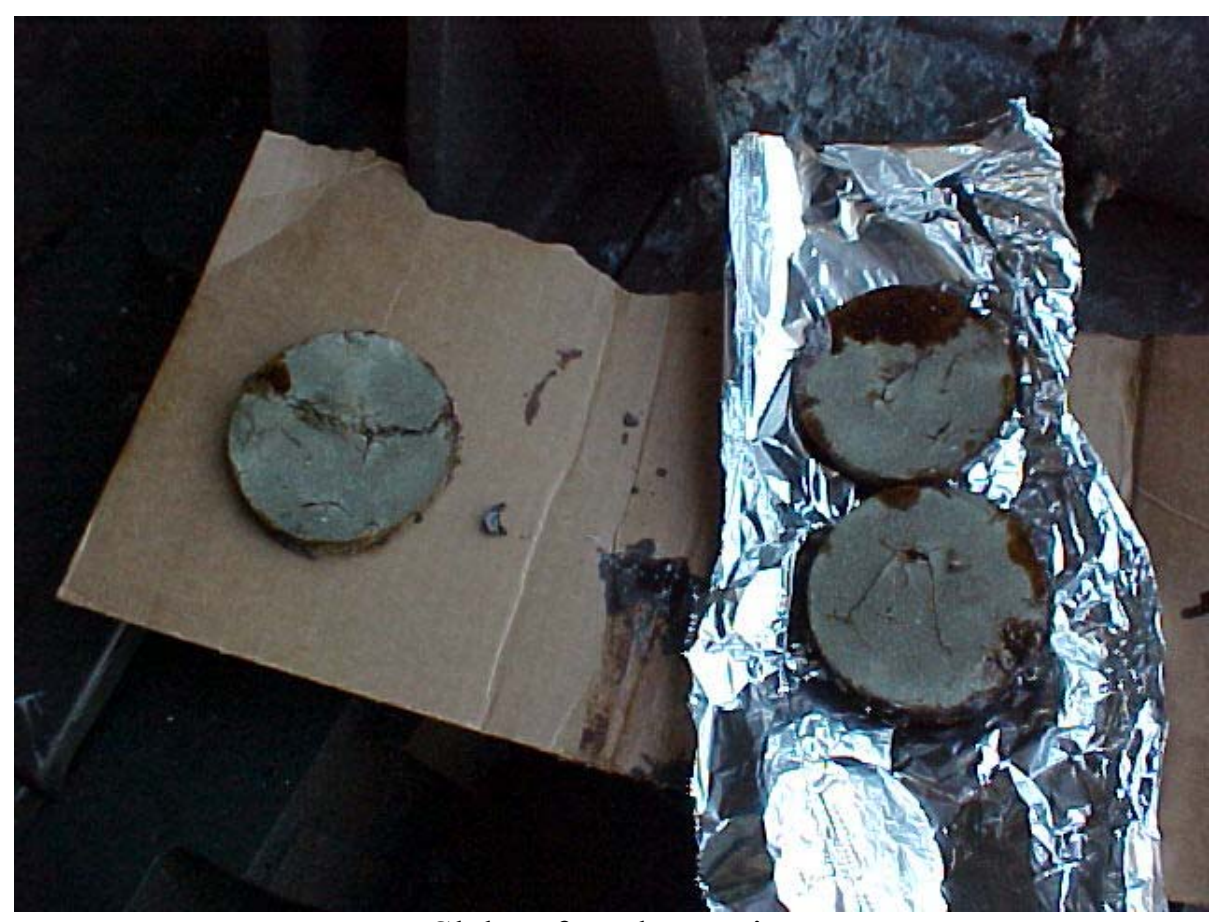

Slabs of cut bentonite 


\section{Appendix E: Plug Length Curves}
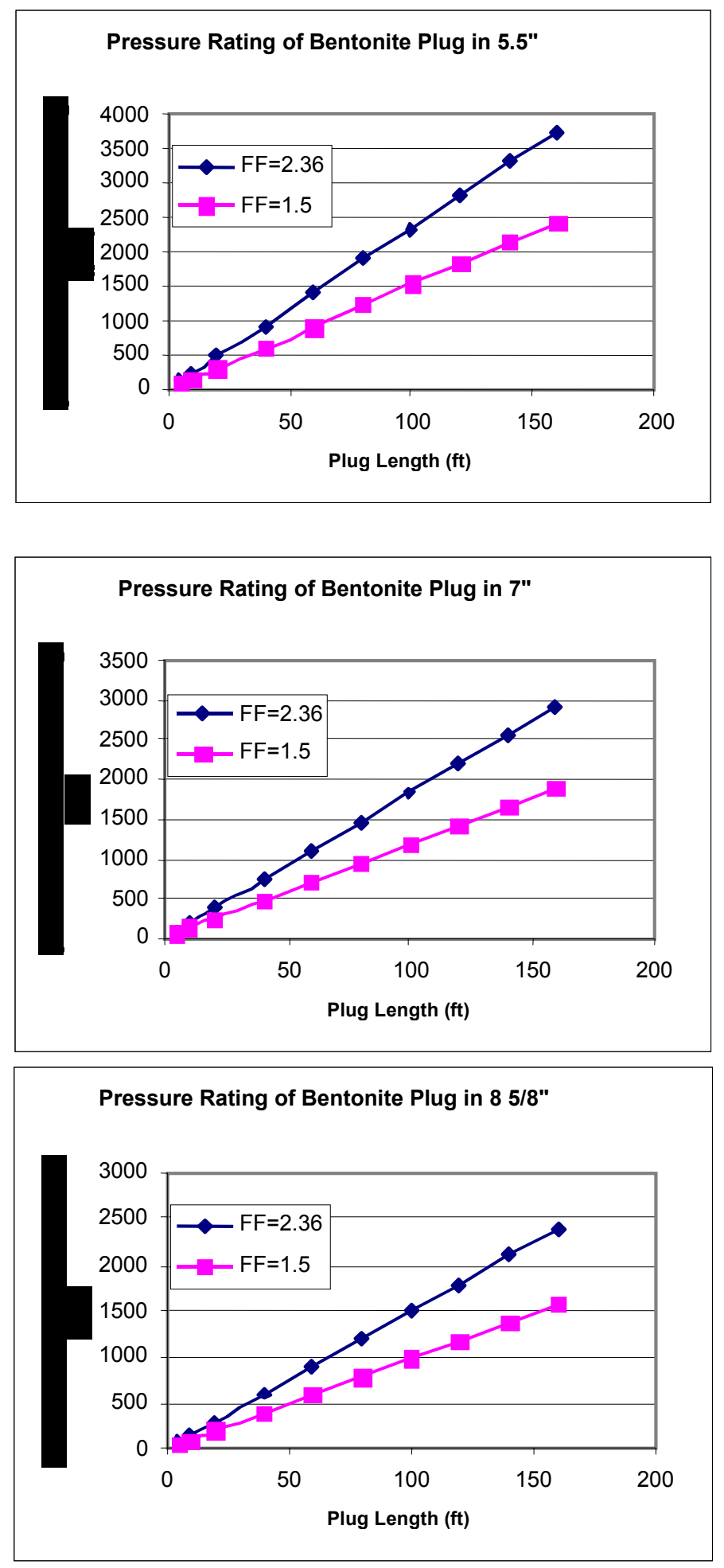


\title{
Appendix F; Operation Guidelines for Compressed Sodium Bentonite Well Plugging Operations, California DOGGR
}

\section{DIVISION OF OIL, GAS, AND GEOTHERMAL RESOURCES}

\author{
Bentonite Plugging Guidelines \\ Operational Field Rules
}

\begin{abstract}
February 22, 2002
Following are guidelines for sodium bentonite plugging operations. These guidelines are applicable as field rules in the Bakersfield and Coalinga districts and are subject to change, as the use of bentonite for plugging evolves.
\end{abstract}

\section{RESTRICTIONS}

1. Well plugging programs requiring a squeeze job may not use bentonite as the squeeze material.

2. Bentonite may not be used in wellbores greater than 4,000 feet deep (ED) or having a zone pressure differential that is 500 psi greater than an upper zone without prior evaluation and consideration by this Division.

3. Bentonite may not be used in wells with greater than $20^{\circ}$ deviation without prior evaluation and approval by this Division.

4. Any bentonite plug that has bridged above the intended interval must be drilled out.

\section{CONDITIONS}

1. The bentonite itself must consist of sodium bentonite exhibiting a minimum specific gravity of 2.0 (dry)/ 1.5 (hydrated), a pH between 6 and 12, and a chemical makeup approximately $63 \% \mathrm{SiO} 2,21 \% \mathrm{Al} 2 \mathrm{O} 3$, and $16 \%$ other. No additives may be used with the bentonite.

2. Bentonite must be in compressed form. Flake or powdered bentonite may not be used without further study and prior approval of the Division.

3. Bentonite size/shape (using samples) must be preapproved by the appropriate District Deputy.

4. Proper weight or volume indicators must be utilized to determine bentonite dry weight prior to placement in the wellbore.

5. The bulk density conversion factors will be furnished to the Division prior to commencing operations.

6. Wellbores must be cleaned out to at least 25 feet into the uppermost set of effective perforations.

7. Spacer material will be based upon zonal isolation requirements subject to approval by the Division. If water is used as a spacer material across a zone, the water shall be compatible with the water of the zone. If water is used across a zone defined as US 
Drinking Waters, than the TDS of the water shall not exceed the TDS of the water of the zone. If gravel is used as spacer, gravel size may not exceed $3 / 4$ ".

8. Previously approved spacer or base materials may be allowed across the perforations to within 25 feet of the upper perforation, or perforation that is open below a casing shoe. In wells with multiple-zone completions, each zone must be separated by a bentonite plug.

9. Wellbores must be flushed with one hole-volume minimum prior to the placement of bentonite or gravel. The purpose of flushing is to remove contamination, primarily oil, from the wellbore. Circulation may be required. "Bradenhead flushing" is never acceptable.

10. Rate and method for delivery of bentonite and gravel into the wellbore must be in a manner such that the potential for bridging is kept to a minimum, and so that proper volumetric calculations can be made prior to placement.

11. The location of all bentonite plugs shall be witnessed. Generally, the plug can be tagged by "stacking out" with a coiled tubing rig. All coiled tubing rigs will have a weight indicator. Plug tops may also be verified using tubing or bailer. Other methods may be approved by the Supervisor.

12. Downhole bentonite plugs must extend a minimum of 100 lineal feet. The surface plug must be at least 25 lineal feet.

13. Water will be added to the wellbore until all bentonite plugs are properly hydrated. Generally, a fluid level must be maintained over a bentonite plug for a minimum of 4 hours.

14. Wells must be equipped with adequate BOPE as specified in the permit.

15. If plugging is required in a wellbore with uncemented casing, a 10-foot section (minimum) cavity shot shall be placed opposite a competent shale or formation and a bentonite plug shall be placed across the entire cavity shot section.

16. A minimum 20 lineal foot bentonite plug shall be placed directly below the base of any proposed cavity shot prior to detonation of the shot.

\section{RECOMMENDATIONS}

1. Bentonite is temperature sensitive and may prematurely hydrate in wellbore fluids exceeding $120^{\circ} \mathrm{F}$.

2. Bentonite has not been used in casing/tubing less than 2-7/8" OD. 


\title{
Appendix G; Operation Guidelines for Compressed Sodium Bentonite Well Plugging Operations New Mexico Oil Conservation Division, EMNRD
}

\section{New Mexico Energy, Minerals and Natural Resources Department Oil Conservation Division}

\author{
Bentonite Plugging Guidelines \\ Operational Field Rules - March 25, 2002
}

Following are guidelines for plugging operations using sodium bentonite. These guidelines are applicable as field rules in the OCD Districts and are subject to change, as the use of bentonite for plugging evolves.

\section{$\underline{\text { RESTRICTIONS }}$}

1. Well plugging programs requiring a squeeze job (down past junk) may not use bentonite.

2. Bentonite may not be used in wellbores greater than 6,500 feet deep or having a zone pressure differential that is 1500 psi greater than an upper zone without prior evaluation and consideration by the District staff.

3. Bentonite may not be used in wells with greater than $20^{\circ}$ deviation without prior evaluation and approval by the District staff.

4. Any bentonite plug that has bridged above the intended interval must be drilled out, unless an exception is granted by the District staff.

5. Bentonite may not be used to plug wells with casing smaller than 3.5 inches O.D. unless approved by the District staff.

\section{CONDITIONS}

1. The bentonite must consist of sodium bentonite exhibiting a minimum specific gravity of 2.0 (dry)/1.5 (hydrated), a pH between 6 and 12, and sodium bentonite with a chemical makeup of approximately $63 \% \mathrm{SiO} 2,21 \% \mathrm{Al} 2 \mathrm{O} 3$, and $16 \%$ other. No additives may be used with the bentonite, unless approved by the District 1 staff.

2. Bentonite must be in compressed form. Flake or powdered bentonite may not be used without further study and prior approval of the District staff.

3. Bentonite size/shape (using samples) must be pre-approved by the District 1 staff.

4. The hydrating and spacer fluid shall be water with a chloride content of 12,000 ppm or less.

5. The wellbore shall be prepared for plugging by displacing or circulating with water of the quality specified in condition 4, unless the well was previously TA'd and water with less than 12,000 ppm chloride was placed in the well.

6. The depths at which bentonite plugs shall be placed will follow the District guidelines for the setting of cement plugs.

7. Bentonite plugs may be supported by natural fill, a bridge plug, wiper plug or other similar device approved by the District staff. 
8. Rate and method for delivery of bentonite into the wellbore must be such that the potential for bridging is kept to a minimum and proper volumetric calculations can be made during placement.

9. The location of all bentonite plugs shall be verified. Such location can be verified using tubing, bailer, or wireline sinker bar. Other methods may be approved by the District staff.

10. Bentonite plugs must extend a minimum of 100 linear feet, but in any case shall be of sufficient length to contain the maximum anticipated inter-zonal pressures. The surface plug must be at least 60 linear feet.

11. Water $(12,000 \mathrm{ppm}$ chloride or less) will be added to the wellbore until the bentonite plug is properly hydrated.

12. Well control must be maintained throughout the plugging operations.

13. If plugging is required in a wellbore with uncemented casing, either:

A. A 10-foot section (minimum) cavity shot shall be placed opposite a shale or competent formation where local experience, a caliper log or other similar device does not indicate areas of washout. A minimum 20 linear foot bentonite plug shall be placed with the base of the plug at least 50 feet below the base of any proposed cavity shot prior to detonation of the shot. A bentonite plug shall be placed across the entire cavity shot section and a minimum of 90 feet above the shot inside casing; or,

B. The uncemented casing shall be cut and pulled from the well at an appropriate depth and bentonite plugs shall be set in open hole or within cemented casing. 
Appendix 7 


\title{
IOGCC MEETING ON \\ LONG-TERM STORAGE OF $\mathrm{CO}_{2}$ IN GEOLOGIC FORMATIONS
}

July 17-19, 2002

\author{
Alta, Utah
}

Workshop Report 


\section{Purpose of the Workshop}

Although the science of climate change is evolving, there is growing interest both within industry and government in the possible opportunities for the long-term geologic sequestration of $\mathrm{CO}_{2}$, the predominant greenhouse gas targeted in the Kyoto Accords. Geologic sequestration is expected to store $\mathrm{CO}_{2}$ in oil and gas reservoirs (producing and depleted), unmineable coal seams, and other geologic strata (like saline aquifers). Any geologic sequestration activities will have to be regulated, ideally at the state-level, by building upon existing regulations governing injection of $\mathrm{CO}_{2}$ for enhanced recovery of oil and natural gas.

The U.S. Department of Energy (DOE) Carbon Sequestration Program is actively pursuing R\&D related to greenhouse gas (GHG) mitigation strategies. Geological sequestration of $\mathrm{CO}_{2}$ is a major thrust within the DOE program. In recognition of the regulatory uncertainty surrounding geological sequestration, DOE felt it important to co-sponsor a meeting to explore this topic, and is very interested in encouraging state-initiated regulatory initiatives in this area. The Interstate Oil and Gas Compact Commission (IOGCC) agreed to co-sponsor the meeting, and to assemble a group of State Oil and Gas Directors and State Geologists to participate.

The meeting took place in Alta, Utah on July 17-19, 2002. The objective of the meeting was to explore the issue of geologic $\mathrm{CO}_{2}$ sequestration and assess the interest of the states, through the IOGCC, in undertaking the development of model state regulations for the geologic sequestration of $\mathrm{CO}_{2}$. The meeting agenda and attendee list are included in the attachments.

The first part of the workshop consisted of various background presentations that described current issues associated with climate change and $\mathrm{CO}_{2}$ sequestration, DOE programs related to developing and demonstrating $\mathrm{CO}_{2}$ capture and sequestration technology, and public and private sector views on $\mathrm{CO}_{2}$ sequestration, its potential, and the challenges it faces.

Copies of all presentations given at the workshop can be accessed at: http://www.iogcc.state.ok.us/ISSUES/CO2\%20Sequestration/co2sequestration.htm.

In the second part of the workshop, representatives from 14 oil and gas producing states, including state geologists and regulators responsible for oil and gas industry activities, discussed issues and concerns regarding regulation of $\mathrm{CO}_{2}$ sequestration activities, and developed a proposed action plan for the states, through the IOGCC, to take a proactive position on the issue. 


\section{Workshop Activities}

\section{WEDNESDAY, JULY 17, 2002 - Opening Reception and Dinner}

Dave Thomas of Advanced Resources International (ARI) gave a presentation entitled Climate Change: A Challenging Opportunity for Industry and Government. In this presentation, Dr. Thomas discussed the current issues associated with GHG emissions and their potential contribution to global climate change and presented data that support the possible linkage between atmospheric $\mathrm{CO}_{2}$ concentration and global warming. He discussed the various options available for reducing emissions of $\mathrm{CO}_{2}$, and highlighted the potential of $\mathrm{CO}_{2}$ capture and storage as a viable near-term option and demonstrated that $\mathrm{CO}_{2}$ injection into oil and gas reservoirs is an established commercial activity. Dr. Thomas made a case for a proactive, state-initiated effort towards bringing regulatory stability to future potential sequestration activities. He also provided references to sources of information for those wishing to explore this issue further. (Resource List Attached to this report.)

This presentation stimulated considerable debate among participants concerning the issue of global warming and the potential economic implications associated with aggressive efforts to address this problem, whether perceived or real. The general consensus was that, whether you believe in global warming or not, $\mathrm{CO}_{2}$ injection in oil and gas fields is currently taking place, and injection and sequestration of $\mathrm{CO}_{2}$ into these fields could contribute to productive activity in oil and gas producing states. This alone, in their opinion, warrants the careful review and consideration by state agencies responsible for regulating oil and gas activities in the states, and the state geologists that are likely to play a key role in advising the process of developing future regulatory requirements.

\section{THURDAY, JULY 18, 2002}

Thursday morning began with participant introductions and a welcome by Lowell Braxton, the Director of the Division of Oil, Gas, and Mining for the State of Utah. Christine Hansen, Executive Director of the IOGCC and Scott Klara, Program Manager for Carbon Sequestration at the DOE/National Energy Technology Laboratory (NETL), welcomed everyone and set the context for the meeting.

Dave Beecy, the Director of the Office of Environmental Systems in the DOE Office of Fossil Energy, began the morning session with a presentation of the policy drivers currently influencing DOE's activities addressing potential global climate change concerns. He talked about current Administration's global climate change initiatives, and the Administration's goals for addressing emissions of GHGs. He described the current role of the Office of Fossil Energy in addressing these issues, focusing on the objectives and the $\mathrm{R} \& \mathrm{D}$ activities related to $\mathrm{CO}_{2}$ sequestration. Particular emphasis was given to the role of public-private partnerships and the critical importance of regional approaches for addressing the challenges and opportunities associated with $\mathrm{CO}_{2}$ sequestration.

Scott Klara of DOE/NETL, followed with a presentation that described some of the major drivers influencing DOE's strategies for reducing emissions of GHGs. Mr. Klara described DOE's focus on the near-term opportunities associated with $\mathrm{CO}_{2}$ sequestration, and the important role that regional partnerships, public-private sector collaboration, and integrated technology demonstration efforts will have on ensuring program success. He talked about the current goals of the $\mathrm{CO}_{2}$ sequestration $\mathrm{R} \& \mathrm{D}$ program, gave an overview of historical and anticipated future 
R\&D budgets, and highlighted some of the key program areas and activities currently underway and planned.

Craig Lewis of ChevronTexaco spoke on behalf of the public-private joint Carbon Capture R\&D Project. The Carbon Capture Project (CCP) is a \$25 million research project supported by eight companies and three governments focused on resolving technical issues and demonstrating the feasibility of carbon sequestration in oil and gas reservoirs. Mr. Lewis gave a brief overview of the CCP and its goals and objectives. In particular, he described the chronology of activities to date conducted by the CCP's Storage, Monitoring, and Verification (SMV) team. He described the key technical issues that the SMV team are addressing, and gave a brief description of the projects conducted to date or currently underway. Particular emphasis was given to the information and technical issues being addressed that could impact the development of regulatory guidelines for $\mathrm{CO}_{2}$ sequestration activities.

Steve Seni of the Texas Railroad Commission provided a brief overview of current regulatory activity associated with $\mathrm{CO}_{2}$-based enhanced oil recovery (EOR) operations in the state of Texas. Mr. Seni informed the meeting participants that there are approximately 52,000 permitted injection wells in Texas, of which, over 10,000 are permitted to inject $\mathrm{CO}_{2}$, and about 8,000 currently inject $\mathrm{CO}_{2}$ exclusively. Almost all of these wells are in the Permian Basin of West Texas. He stated that about $0.36 \mathrm{Tcf}$ of $\mathrm{CO}_{2}$ is currently injected into oilfields annually, amounting to about $1 \mathrm{Bcf} /$ day. Nearly all of the $\mathrm{CO}_{2}$ currently injected comes from natural $\mathrm{CO}_{2}$ fields in primarily in Colorado.

Mr. Seni stated that the current costs of $\mathrm{CO}_{2}$ injected into oil fields is about $\$ 0.60-\$ 0.65 / \mathrm{Mcf}$ of $\mathrm{CO}_{2}$, with about half being transportation costs. Typical injection costs are approximately $\$ 0.50$ per barrel of incremental oil recovered. Factoring in both injection and $\mathrm{CO}_{2}$ costs, typical costs of $\mathrm{CO}_{2}$ injection are approximately $\$ 4 / \mathrm{Bbl}$, with considerable variation in this from field-to-field.

Mr. Seni noted that $\mathrm{CO}_{2}$ and water injection wells in the state are subject to essentially the same permitting requirements. Wells injecting $\mathrm{H}_{2} \mathrm{~S}$ have slightly different requirements, essentially adding incremental requirements associated with emergency planning, response, and public notification. Mr. Seni made the point that what we eventually call $\mathrm{CO}_{2}$ sequestration (disposal vs. storage or use for enhanced recovery) will be critical in determining which regulatory authority in the state has jurisdiction.

Jack Ford of the New Mexico Energy, Minerals, and Natural Resources Department, Oil Conservation Division, talked about the experiences of permitting $\mathrm{CO}_{2}$ injection wells in New Mexico. In New Mexico, $\mathrm{CO}_{2}$ injection wells and production wells are permitted in a manner similar to all other wells drilled in the state. Like Texas, New Mexico permits $\mathrm{CO}_{2}$ injection wells under its state Underground Injection Control (UIC) program. For the most part, $\mathrm{CO}_{2}$ is treated by the state as a commodity, not as a waste. He made the point that the infrastructure for transporting and distributing $\mathrm{CO}_{2}$ in the state is currently limited. Mr. Ford provided some information on several pilot $\mathrm{CO}_{2}$ injection projects in New Mexico, and described, in one case, associated issues related to injection of gases containing $\mathrm{H}_{2} \mathrm{~S}$. Mr. Ford also talked briefly about state experiences in regulating natural gas and LPG storage, and talked about possible parallels between this and $\mathrm{CO}_{2}$ storage.

After a working lunch, the afternoon session began with a Panel Discussion entitled Technical and Other Considerations For Long Term Storage of $\mathrm{CO}_{2}$ in Geologic Formations. Vello Kuuskraa of ARI chaired this panel. The members of the panel and the perspectives they provided were: 
- Craig Lewis, ChevronTexaco: Major Producer's Perspectives

- Steve Melzer, Independent Consultant: Independent Producer's $/ \mathrm{CO}_{2}$ Provider's Perspectives

- Russell Martin, Kinder-Morgan $\mathrm{CO}_{2}$ Company: $\mathrm{CO}_{2}$ Provider Perspectives

- Hugh Guthrie, U.S. DOE: Federal Government Perspectives

- Charlie Mankin, Oklahoma Geological Survey: State Government Perspectives

- Vello Kuuskraa, ARI (Chair) -- Overview of $\mathrm{CO}_{2}$ Sequestration Economics

The panel members were asked to address the following questions in their presentations:

- What is your (the stakeholders that you represent) specific interest and potential role in long-term storage of $\mathrm{CO}_{2}$ in geologic formations?

- What barriers currently exist that may impede your role in combining additional oil and gas recovery with long-term storage of $\mathrm{CO}_{2}$ ?

- What set of actions, including additional information, technology development, field demonstrations, and market-based incentives, would best enable you (and the stakeholders you represent) to fully participate in long-term storage of $\mathrm{CO}_{2}$ and associated gases and products in geologic formations?

- How could the IOGCC best assist in supporting increased energy production, the economic use of depleted geologic structures, and maximum, safe long-term storage of $\mathrm{CO}_{2}$ ?

Craig Lewis, a Senior Staff Research Scientist in the Energy Research Technology Company of ChevronTexaco, provided ChevronTexaco's climate change initiatives and perspectives on geologic storage. In general, ChevronTexaco's climate change objectives are:

- Reducing emissions of GHGs and increasing energy efficiency

- Investing in research, development and improved technology

- Pursuing business opportunities in promising innovative energy technologies

- Supporting flexible and economically sound policies and mechanisms that protect the environment.

ChevronTexaco's perspectives highlighted industry's excellent safety performance, demonstrated in $80 \mathrm{CO}_{2} / \mathrm{EOR}$ fields globally, and in 750 natural gas storage fields in the US and the European Union. They believe that $\mathrm{CO}_{2}$ should not be considered a "hazardous waste." Their position is that there are multiple technology efforts globally to respond to the technical challenges, that industry is working with governments to respond to technical challenges, and that industry can effectively demonstrate that risk of leakage can be made acceptable, or that leakage could be effectively remediated if it occurs. They believe that $\mathrm{CO}_{2}$ injection wells should be classified as Class II wells, just like any well currently permitted for oil, gas, or EOR operations. Finally, Mr. Lewis provided ChevronTexaco's perspectives on each of the questions posed to the panel members.

Steve Melzer, a geological engineer and consultant from Midland, Texas represented independent producer perspectives on $\mathrm{CO}_{2}$ storage. Mr. Melzer made the point that $\mathrm{CO}_{2}$ storage can be addressed in terms of three sub-industries: (1) the extension of existing $\mathrm{CO}_{2}$ flooding (currently a relatively mature sub-industry), (2) the application of enhanced coal bed methane (ECBM) processes (today a relatively immature sub-industry), and (3) the long-term "disposal" 
of $\mathrm{CO}_{2}$ (today a non-existent industry). This discussion raised an important question concerning the use of the term "disposal," with the connation that "disposal" may in many states require a different set of standards and regulatory considerations than that which would apply for storage or injection for enhanced recovery.

Mr. Melzer provided an overview of the current economics of $\mathrm{CO}_{2}$ injection in oil fields. $\mathrm{He}$ talked about the main parameters that can impact $\mathrm{CO}_{2}$ flooding economics. He talked about the need for economic incentives to encourage operators to consider $\mathrm{CO}_{2}$ injection for $\mathrm{EOR}$, and highlighted what he considered to be some of the necessary characteristics of possible incentives. $\mathrm{He}$ also presented some emerging concepts for thinking about $\mathrm{CO}_{2}$ storage as a business concern. In particular, he described $\mathrm{CO}_{2}$ injection activities as representing three phases of operations:

- An active injection/flooding phase, represented by that corresponding to existing $\mathrm{CO}_{2}$ flooding operations for EOR.

- $\mathrm{A} \mathrm{CO}_{2}$ "soaking" phase, which could present business opportunities for "new" hybrid environmental/flooding companies, that would involve long periods of injection and storage interspersed with brief periods of incremental production.

- A final "shut in" phase, which would require long-term state supervision and monitoring.

This caused some discussion about revisions of how these phases might be considered and described (discussed in more detail below).

Finally, Mr. Melzer raised some important issues associated with relative surface and mineral ownership rights pertaining to long-term $\mathrm{CO}_{2}$ storage, especially at the point where some value gets applied to stored $\mathrm{CO}_{2}$ (i.e., it becomes an economic commodity). In Mr. Melzer's opinion, legal issues associated with the allocation of ownership rights may require resolution before longterm $\mathrm{CO}_{2}$ storage becomes a widespread operation.

Russell Martin, Vice President for Business Development for Kinder-Morgan $\mathrm{CO}_{2}$ Company, presented his company's perspectives on $\mathrm{CO}_{2}$ storage as a current commercial provider of $\mathrm{CO}_{2}$. Mr. Martin called his company the largest $\mathrm{CO}_{2}$ company in the world, with a business perspective focused exclusively on providing $\mathrm{CO}_{2}$ for oil and gas field injection operations. Mr. Russell described Kinder-Morgan's current operations in the western U.S. (targeting EOR operations in West Texas), and potential opportunities the company is considering in California and the North Sea. He noted that since the early 1980 s, over 380 million tones of purchased $\mathrm{CO}_{2}$ have been injected into oil fields in West Texas, resulting in over 620 million barrels of incremental oil recovered. Mr. Martin described the factors currently influencing EOR economics, and thus the value and market opportunities for $\mathrm{CO}_{2}$ as a commodity to enhance oil and gas recovery. $\mathrm{He}$ highlighted the need for economic incentives to stimulate companies to consider $\mathrm{CO}_{2}$ injection and establish it as a viable, long-term approach for sequestrating $\mathrm{CO}_{2}$.

Hugh Guthrie, a Senior Advisor for DOE/NETL, provided his perspectives on opportunities for $\mathrm{CO}_{2}$ sequestration. Mr. Guthrie focused many of his comments on the site-specific nature of $\mathrm{CO}_{2}$ sequestration issues, and commented that the participation of the state geologists was key to resolving site-specific issues. In this regard, he described the need for regional partnerships, and provided some perspectives on how these may be structured to address these critical issues. Moreover, he highlighted how the economics of long-term $\mathrm{CO}_{2}$ storage will be critically dependent on the relative regional interdependencies between potential sources of anthropogenic $\mathrm{CO}_{2}$, and possible sinks in oil and gas fields and unmineable coal seams. Finally, Mr. Guthrie described the delicate balance that needs to be managed on this issue, with the interplay of 
technical, economic, political, and regulatory considerations. He likened this to an Alexander Calder mobile, and that addressing this balance is critically dependent on extensive collaboration between industry, government, and academia.

Charles J. Mankin, Director of the Oklahoma Geological Survey and the Sarkeys Energy Center at the University of Oklahoma, represented a state's perspectives. Mr. Mankin stated that in the U.S., a large portion of the $\mathrm{CO}_{2}$ would be produced from industrial activity within the same states that it will be stored. He noted that the capture, transportation, and retention of $\mathrm{CO}_{2}$ would require significant development of infrastructure. He noted that the number of sites where secure retention can be achieved might be limited, but that more is known about the geology of oil and gas fields than any other place where long-term storage may be considered. In his opinion, areas of high $\mathrm{CO}_{2}$ generation often do not have sites for secure retention.

Mr. Mankin described what he terms the "dilemma of retention," noting that the retention of $\mathrm{CO}_{2}$ is essentially forever, and that sites used for $\mathrm{CO}_{2}$ retention must be selected with that perspective in mind. Moreover, he noted that considering alternative uses for such sites will require serious creative thinking, and that mistakes could be very costly. However, he also noted that from challenges come opportunities, that $\mathrm{CO}_{2}$ is a valuable gas for EOR, and that there are many large oil fields discovered early in this century that were poorly developed. He noted that several such fields in Oklahoma have recovery factors of less than 20 percent, leaving behind on the order of 100 million barrels of remaining oil in place as the target for $\mathrm{CO}_{2}$-based $\mathrm{EOR}$. Using $\mathrm{CO}_{2}$ to recover crude oil from selected fields, nonetheless, would meet the requirement of removing $\mathrm{CO}_{2}$ from the atmosphere and, in his opinion, would generate revenue at the same time from incremental production. Moreover, this process would permit an early effort to remove $\mathrm{CO}_{2}$ from the atmosphere while considering final retention.

Mr. Mankin concluded that although the role of $\mathrm{CO}_{2}$ in global warming seems to be an accepted fact, in his opinion, the issues related to global warming are not yet sufficiently characterized to confidently recommend the most appropriate actions. Moreover, he noted that the alternative to global warming, namely global cooling, might present more serious challenges for the human race than expected.

Vello Kuuskraa of ARI concluded the session by summarizing the comments by the other panelists and presented a review of $\mathrm{CO}_{2}$ sequestration economics. He noted that the oil and gas industry offers significant opportunities for "value added" sequestration of $\mathrm{CO}_{2}$, but that the full capture of this opportunity requires: (1) lower cost $\mathrm{CO}_{2}$ capture technology; (2) R\&D plus field demonstrations for geologic sequestration; (3) clear market value for reducing $\mathrm{CO}_{2}$ emissions; and, (4) tax credits or other incentives for sequestering $\mathrm{CO}_{2}$. Mr. Kuuskraa presented two case studies - one for EOR, and the other for ECBM recovery, that highlighted the critical role that economic incentives will play in making long-term $\mathrm{CO}_{2}$ storage in oil and gas fields and unmineable coal seams a reality. However, with performance-based incentives and technology, he showed that geologic formations have the potential for storing considerable volumes of $\mathrm{CO}_{2}$ in the 2005 to 2050 timeframe, while providing additional domestic oil and gas production, reducing atmospheric $\mathrm{CO}_{2}$, and possibly encouraging the development of $\mathrm{CO}_{2}$ sequestration business units.

\section{State Workshop}

The second part of the workshop began with Christine Hansen, Executive Director of the IOGCC, presenting her perspectives on the purpose and expectations for this part of the workshop. In this session, the representatives from 14 oil and gas producing states participated in a facilitated 
discussion focused on the issues, barriers, and opportunities associated with a possible stateinitiated effort to develop and/or promote regulatory guidelines for $\mathrm{CO}_{2}$ sequestration.

Prior to the meeting, participants were provided a list of some of the possible topics for consideration in this session:

- How might regulatory requirements for the long-term sequestration of $\mathrm{CO}_{2}$ differ from current requirements for gas $/ \mathrm{CO}_{2}$ injection and gas storage?

- Should the IOGCC develop recommended state regulatory guidelines?

- How will state requirements support verification needs of state GHG emission reduction registries?

- Would further field unitization be required?

- What, if any, additional studies, information, demonstrations, etc. may be required?

- What stakeholders must be considered?

$\circ \quad$ Oil and gas producers, coal, transportation, industry in general

- Other $\mathrm{CO}_{2}$ producers / emitters

- Mineral right owners (royalty owners)

- Surface right owners (landowners)

- Government agencies

- Environmental groups (NGOs)

- Society at large.

- What set of geologic options should be included in any guidelines/regulatory framework? Currently producing oil and gas fields

Unmineable coal seams

Depleted oil and gas fields

Deep saline aquifers.

A summary of the discussion in this first session, facilitated by Bill LeMay and Dave Thomas, is provided below.

An issue for some of the state regulators was whether or not they would have the regulatory authority to oversee sequestration activities. For the most part, to the extent the $\mathrm{CO}_{2}$ injection/sequestration was associated with oil and gas recovery operations, general regulatory jurisdiction would not be an issue. However, at the point that sequestration became perceived as "disposal", and the $\mathrm{CO}_{2}$ became a "waste" rather than a commodity or component of production, regulatory jurisdiction could become more of a debatable issue.

This discussion led to defining oil and gas production with subsequent sequestration as possibly consisting of five phases:

- $\quad$ Primary production (first few years - up to 10 years?)

- Secondary production using waterflooding or other stimulation methods (Could be 10 30 years beyond primary?)

- Tertiary production - EOR - generally $\mathrm{CO}_{2}$ flooding as one of the most successful techniques. (Perhaps 20-50 years beyond secondary.)

- Soaking Phase EOR - $\mathrm{CO}_{2}$ storage with periodic production to recover additional oil and supplemental $\mathrm{CO}_{2}$ injection. (50-100 years beyond tertiary?)

- Storage - surface operations cease with minimal monitoring - indefinite duration. This also led the discussion to the issue of how the injected $\mathrm{CO}_{2}$ may be classified - i.e., is it to be classified as a commodity or waste? 
- If it has value for purposes of enhancing oil and natural gas recovery then it would appear to be a commodity. As such, the state corporation commissions or oil and gas commissions/agencies would likely have regulatory authority.

- If is merely a waste stream requiring disposal, then it may be more appropriate for state environmental agencies to have regulatory authority.

If the $\mathrm{CO}_{2}$ is considered a commodity (i.e., it has a value), then regulatory authority may have to weigh in on the issue of how value is allocated, or at least, how value is determined. (For example, if the value of the $\mathrm{CO}_{2}$ is in the fact that it is permanently sequestered, then some verification of that permanence would be required.)

On the other hand, if the $\mathrm{CO}_{2}$ is considered a waste, the same issues may need to be addressed, though now concerned with potential liability rather than allocated value.

One concern was how regulatory requirements may shift based on the phase in a reservoir's life:

- May shift from commodity to waste when the operations shift from EOR to storage.

- Plugged reservoirs defined as "storage" rather than disposal may be key.

The consensus of the participants at the meeting was that existing oil and gas regulations may be very important in the short-to-mid term as a starting point in allowing $\mathrm{CO}_{2}$ sequestration to establish a foothold. A proposed approach to define the IOGCC role in sequestration was discussed, and the general consensus was that, for the near term, that the IOGCC focus upon those areas where it has expertise and that are within its traditional sphere of influence, i.e.:

- Oil and gas EOR

- Coal bed methane

The issue of the applicability of how $\mathrm{CO}_{2}$ sequestration might relate to requirements for gas storage was also discussed. While all states have jurisdiction over gas storage, state authorities differ and no specific conclusion was made regarding this.

The general feeling among attendees was that states, through the IOGCC, must gain and retain control of the geologic sequestration issue, especially as it relates to oil and gas production operations, to ensure fair and equitable implementation:

- There is a natural role for states, through the IOGCC, in oil and gas reservoirs, whether active or depleted.

- A policy discussion with the governors needs to be initiated on a future regulatory framework for addressing this issue that balances environmental protection with encouragement of the economic opportunities associated with $\mathrm{CO}_{2}$ sequestration.

Possible areas of IOGCC activity that were discussed included:

- Developing regulatory guidelines for sequestration

- Playing a role in establishing an accounting framework for verification, certification, and monitoring.

- Playing key role in the education of other industries and on non-oil producing states on what can be done 
The session ended with a recap of this discussion, presented by the facilitators.

The evening session consisted of a barbeque dinner followed by a brief presentation by Hugh Guthrie entitled: Perspectives from Day One ( $\&$ War Stories). In the context of a number of personal anecdotes and reminiscences, Mr. Guthrie reiterated the theme he presented earlier of the delicate balance that needs to be managed on this issue, with the interplay of technical, economic, political, and regulatory considerations, and the need for collaboration between industry, government, and academia. He also described the key phases in the process of technology innovation, from the development of a concept, to the proof of the concept, to stage experiments, then staged applications, to, finally, operating improvements. Critical to each stage of the process, Mr. Guthrie reminded the participants, was the exchange of shared perspectives. He complimented the meeting participants at their successful accomplishment of sharing perspectives on this critically important issue.

\section{FRIDAY, JULY 19, 2002}

\section{Development of Action Plan}

The Friday morning session was devoted to the development of an action plan defining the "way forward" for the IOGCC on the issue of $\mathrm{CO}_{2}$ storage/sequestration. Prior to the meeting, the participants were sent a list of possible topics for consideration:

- Formation of special committee/workgroup

- Charter for committee/workgroup

- Establishment of ultimate IOGCC role/objectives

- Components of Action Plan

- Timeline for Action Plan

- Requirements for additional information, demonstration projects, R\&D, etc.

- Staff support needs

- Resource requirements (budget, etc.)

- Description of immediate next steps.

The first part of this session recapped the discussion of the previous day, with the following key themes emerging:

- A consensus needs to be established quickly on IOGCC's role in $\mathrm{CO}_{2}$ sequestration, and that this role be clearly defined.

- This role should, at least initially, should be focused on those areas where IOGCC states generally already have established authority - i.e., the injection of $\mathrm{CO}_{2}$ into oil and gas reservoirs.

- The issue of the "waste" versus "commodity" definition of $\mathrm{CO}_{2}$ needs to be addressed by the IOGCC relatively soon.

- The governors of the oil and gas producing states need to be engaged on this issue and can drive the discussion to facilitate the option of injection of $\mathrm{CO}_{2}$ into oil and gas reservoirs as a viable climate mitigation option.

- Oil and gas producing states have tremendous "assets" that can contribute to addressing global climate concerns, while still bringing economic benefits to the states.

- The need clearly exists to develop a generic set of regulatory recommendations or guidelines to take to the broader IOGCC membership for review and consideration. 
- Local and state control of geologic $\mathrm{CO}_{2}$ storage is needed because of site-specific nature of the issues that need to be addressed.

- Opportunities for the beneficial use of $\mathrm{CO}_{2}$ to enhance recovery (EOR, ECBM) along with other possible benefits (e.g., water management) need to be identified.

- The IOGCC should, at this stage, focus on the issue of injection of $\mathrm{CO}_{2}$, and not on issues associated with capture, separation, and transport to the ultimate storage site.

A number of possible actions were proposed for the IOGCC to consider undertaking. These included:

- Facilitate the early resolution of the "waste versus commodity" definition issue. On its face resolution of this issue would appear to be rather straightforward as even "waste" $\mathrm{CO} 2$ today ( $\mathrm{CO} 2$ which has been captured) has economic value.

- Conduct advocacy with all stakeholders.

- Proactively pursue an educational role with state and local regulators.

- Publish a pamphlet on the current sequestration regulatory environment and technology.

- Bring a draft resolution on sequestration and storage to the IOGCC annual meeting.

A proposed "four-point plan" was offered as a starting point for discussion, with the objective of establishing an action plan for the IOGCC. This proposal is paraphrased as follows:

1. Encourage the IOGCC to take a policy position on $\mathrm{CO}_{2}$ sequestration, emphasizing its beneficial use and long-term storage.

2. Mobilize IOGCC resources to begin development of regulatory guidelines and/or guidance documents on $\mathrm{CO}_{2}$ sequestration.

3. Recommend that DOE characterize suitable formations and sites for long-term $\mathrm{CO}_{2}$ storage, allowing its use by states to develop regulatory requirements compatible with the characteristics of suitable sites.

4. Recommend that DOE continue and expand research, development, and demonstration of technologies for $\mathrm{CO}_{2}$ sequestration in oil and gas reservoirs, coalbeds, and other suitable formations.

The participants generally agreed that these four points represented the key components of recommended IOGCC actions on this issue. The following summarizes the key points of the discussions concerning each of these four points, and provides better definition of the some of the suggested actions and activities.

Point 1 - IOGCC Establishes Policy Position on $\mathrm{CO}_{2}$ Storage/Sequestration:

- Develop resolution to take to IOGCC membership establishing an IOGCC policy position on the issue of $\mathrm{CO}_{2}$ storage/sequestration in oil and gas fields and coal seams

- Shoot for resolution to present at December meeting, draft in November

- Work with governors to advocate appropriate position on this issue as it pertains to oil/gas producing states, to bring geologic sequestration forward as an issue worthy of consideration.

○ Work through NGA, NARUC, WGA, etc.

- Use Association of American State Geologists (AASG) as forum to engage nonproducing states into the discussion. These states may also contain possible sites for storage, and are also likely to contain many major sources of $\mathrm{CO}_{2}$.

- Advocate for regulatory control of $\mathrm{CO}_{2}$ storage/sequestration at state level 
- Generally, issue of applicability will be very specific to local geology

- Expertise, regulatory framework, etc., already exists at state level

- Establish proactive education role to inform public about this issue and the "win-win" opportunities that $\mathrm{CO}_{2}$ storage/sequestration can provide to oil/gas producing states.

- Managing public perceptions early will be critical

○ Develop " $\mathrm{CO}_{2}$ sequestration primer"

- Advocate for market-based incentives to encourage $\mathrm{CO}_{2}$ injection into oil/gas fields, coal seams to enhance recovery. This represents a logical extension to the IOGCC/s "conservation" mandate.

- Work to ensure that "access to assets" is maintained to encourage and facilitate $\mathrm{CO}_{2}$ injection for enhancing recovery and long-term storage/sequestration opportunities.

Point 2 - IOGCC Begins Process to Develop Regulatory Guidelines:

- Review current guidance documents and regulatory frameworks for applicability to storage/sequestration.

- Identify and characterize gaps and/or needs in those frameworks

○ Work collaboratively with industry

○ Recommend and develop "gap-filling" information.

- Emphasize need for long-term monitoring as part of gap-filling technologies.

○ How long? How? By whom?

- Have legal sub-committee review current laws and regulations for application to sequestration. Identify needed changes to allow implementation of the long-term geologic storage of $\mathrm{CO}_{2}$.

$\circ$ Landowner issues (surface rights, mineral rights, etc.)

○ Definitional issues - "storage" vs. "disposal" vs. "injection"

- Any necessary statutory changes?

- Track storage and sequestration activity worldwide for application within the U.S.

- Publish a "Sequestration and Storage Primer" for use by regulators, business, and public.

Point 3 - Recommend DOE Characterize Suitable Formations and Sites for Long-Term $\mathrm{CO}_{2}$ Storage:

- DOE should address local technical needs and geological issues for specific sites.

- State oil/gas regulators already know well existing oil/gas reservoirs, geologic horizons, etc. within their states

- National coordination and collaborate will still be essential, especially for matching sources to viable sinks

- IOGCC should take on role as advocate for the development of databases (sources and sinks, geologic, locale, suitable characteristics, etc.) to aid in helping to ensure that state needs are met and existing information taken into account.

- State regulators and industry need access to required information on a state-by-state basis. State geological surveys must be involved to help ensure this

- Should consist of a geospatial database, building upon on going efforts in Midcontinent and elsewhere, that includes information such as:

- Well type, condition, and location information

- Suitable formation availability, volume, type, etc.

- Source locations relative to suitable sinks, including characteristics of sources (where, how much is generated, over what periods, flue stream characteristics, etc.). 
- Transportation needs and issues.

- IOGCC/DOE can serve as "portal" to essential state-based information -- provide coordinating role to aid states.

- Such a database can provide critical information for state regulators and companies interested in pursuing geologic $\mathrm{CO}_{2}$ storage/sequestration as a business opportunity.

Point 4-Recommend DOE Continue and Expand Research, Development, and Demonstration of Technologies for Sequestration:

- While many states, for instance, Oklahoma, could make use of CO2 today if it were readily and economically available without any new $\mathrm{RD} \& \mathrm{D}$, it is nonetheless very important that DOE continue to take a role in coordinating information on storage technologies and processes

- Prototype demos are needed on a wide variety of applications in alternative settings

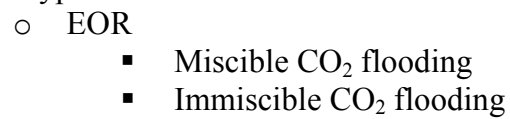

$\circ \quad$ Enhanced coal bed methane (ECBM)

- Enhanced gas recovery

- Conventional reservoirs

- Gas shales

- Focus needs to be placed on issues associated with long-term monitoring and verification critical to state regulators.

- May be useful to identify some old $\mathrm{CO}_{2}$ floods, late in their productive life, as candidate $\mathrm{R} \& \mathrm{D}$ sites for studies on long-term storage.

- DOE lead development of technologies through basic and applied research in the area of $\mathrm{CO}_{2}$ storage.

$\circ \quad$ Also need to address long-term integrated resource management issues, including potential future uses/applications for the stored, probably relatively pure, $\mathrm{CO}_{2}$

- DOE support implementation at the local and regional level.

- DOE ensure communication of results to regulators.

- Also need to establish critical baseline data necessary to demonstrate public safety is maintained

- Managing public perceptions early will be critical to success

- IOGCC needs to assist by advocating for sufficient R\&D resources to carry out required tasks

- IOGCC support the work through its influencing role with governors and legislatures.

\section{CLOSING COMMENTS}

As a closing to the meeting, the participants were asked to provide some summary comments about the meeting and what may be at issue going forward. The following provides a brief sampling of some of the comments:

- Issue is very important because of large $\mathrm{CO}_{2}$ bearing formations in Alaska

- Meeting was valuable.

- Not too important an issue in my state.

- Large role of state geological survey in sequestration.

- Timing is right for a cultural change in states on this issue - can begin to address the "black eye" characteristic of oil/gas industry 
- Traditional battleground between environmental NGO's and business are blurred on this issue

- Opportunity for state role in storage shouldn't be missed.

- More we learn about issues, the more potential applications in state can be seen.

- Keep this group together.

- Encourage communication between IOGCC and public on this issue.

- Different perspectives and perceptions of stakeholders coming to the front.

- Appreciated the opportunity to attend and participate - allowed interaction not otherwise possible.

- The interaction between regulators and geologists was helpful. Hope we look back on this as a starting point.

- Storage is a long-term issue. We must be prepared to follow a rational agenda in the face of the conflicting agendas.

- Production of naturally occurring $\mathrm{CO}_{2}$ is an $\$ 80$ million business in Colorado. Storage may be viewed as a threat to that business.

- Wish my state regulators were here and had interacted with their peers and the technology community.

- Will take back information to help in developing guidelines for state regulation.

- Appreciate the proactive action by IOGCC, rather than waiting until a crisis occurs.

- Potential cost of $\mathrm{CO}_{2}$ storage is incredible. There will be substantial impact on living standards and disposable income.

- There is considerable work to be done by private sector, IOGCC, DOE.

- This will be a major financial burden.

- Plan developed (four recommendations) is a concrete start to address the problem. 


\section{ATTACHMENTS}




\title{
Agenda \\ IOGCC MEETING ON \\ LONG-TERM STORAGE OF CO $\mathrm{O}_{2}$ IN GEOLOGIC FORMATIONS
}

\author{
WEDNESDAY, JULY 17, 2002 \\ 6:00 - 7:00 p.m. - Reception \\ 7:00 - 8:30 p.m. - Working Dinner \\ Dave Thomas, Advanced Resources International: \\ Climate Change: A Challenge and Opportunity
}

THURDAY, JULY 18, 2002

7:30 - 8:30 a.m. Continental Breakfast

8:30 - 8:45 a.m. General Introductions

Self-introduction - workshop participants

Utah host representative

IOGCC (Christine Hansen)

DOE (Scott Klara)

\section{Background and Information}

8:45 - 9:45 a.m. Scott Klara and Dave Beecy, U.S. Department of Energy DOE R\&D/Programs in $\mathrm{CO}_{2}$ Sequestration

9:45 - 10:15 a.m. Break

10:15 - 11:00 a.m. Craig Lewis, Chevron-Texaco /Carbon Capture Project

Technical Issues and Information Development on Storage, Monitoring and Verification of $\mathrm{CO}_{2}$ in Geologic Formations

11:00 - 12:00 a.m. Steven Seni - Texas Railroad Commission

Jack Ford - New Mexico Energy, Minerals, and Natural Resources

Department, Oil Conservation Division

State Experiences with $\mathrm{CO}_{2} /$ Gas Injection and Storage

12:00 - 1:00 p.m. Working Lunch

1:00 - 2:30 p.m. Panel Discussion - Technical and Other Considerations For Long Term Storage of $\mathrm{CO}_{2}$ in Geologic Formations

(See "Questions Posed to Panel Discussion Presenters," attached) 
Panel Participants:

$$
\begin{aligned}
& \text { Vello Kuuskraa - Advanced Resources International (Chair) } \\
& \text { Overview of } \mathrm{CO}_{2} \text { Sequestration Economics } \\
& \text { Craig Lewis, Chevron-Texaco: Major Producer's Perspectives } \\
& \text { Steve Melzer, Ridgeway: Independent Producer's/ } \\
& \qquad \mathrm{CO}_{2} \text { Provider's Perspectives } \\
& \text { Russell Martin, Kinder-Morgan } \mathrm{CO}_{2} \text { Company: } \\
& \mathrm{CO}_{2} \text { Provider Perspectives } \\
& \text { Hugh Guthrie U.S. DOE: } \\
& \text { Federal Government Perspectives } \\
& \text { Charlie Mankin, Oklahoma Geological Survey: } \\
& \text { State Government Perspectives }
\end{aligned}
$$

2:30 - 3:00 p.m. Break

\section{State Workshop}

3:00 - 3:15 p.m. Christine Hansen: Purpose and Expectations for Workshop

3:15 - 5:15 p.m. Issues and Barriers for Developing State Guidelines for Permitting, Monitoring, and Verification of Long-Term Storage of $\mathrm{CO}_{2}$ in Geologic Formations

(See "Topics of Consideration by State Regulators/Geologists" attached)

Facilitated Group Discussion (All workshop participants) -- Two concurrent sessions

Represents opportunity for States to present their issues, concerns, etc.

5:15 - 5:45 p.m. Report Out from Facilitated Group Discussions

6:30 p.m. Barbeque Dinner

Hugh Guthrie: Perspectives from Day One (\& War Stories)

FRIDAY, JULY 19, 2002

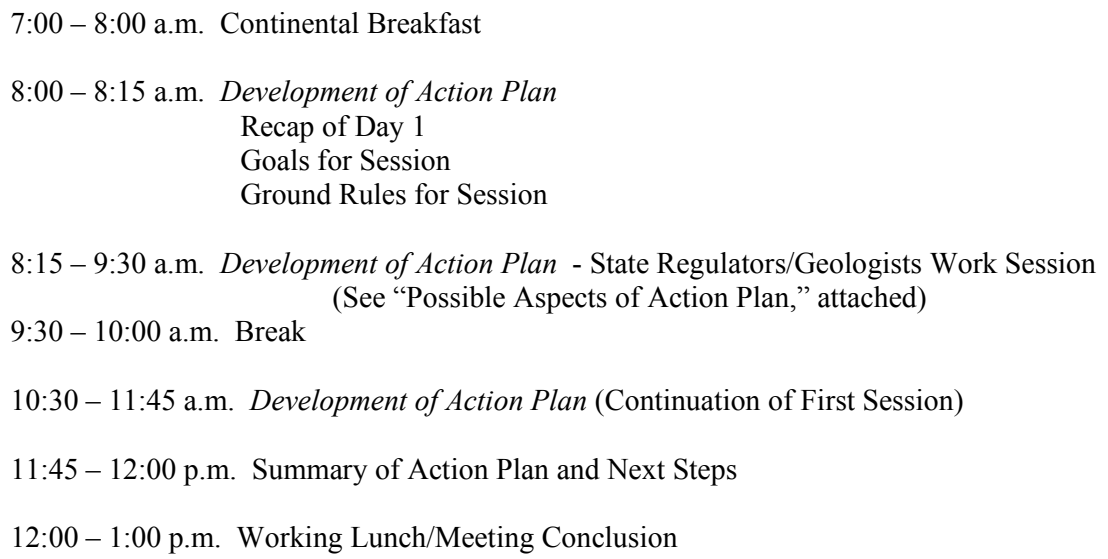




\section{Questions Posed to Panel Discussion Presenters}

- What is your (the stakeholders that you represent) specific interest and potential role in long-term storage of $\mathrm{CO}_{2}$ in geologic formations?

- What barriers currently exist that may impede your role in combining additional oil and gas recovery with long-term storage of $\mathrm{CO}_{2}$ ?

- What set of actions, including additional information, technology development, field demonstrations, and market-based incentives, would best enable you (and the stakeholders you represent) to fully participate in long-term storage of $\mathrm{CO}_{2}$ and associated gases and products in geologic formations?

- How could the IOGCC best assist in supporting increased energy production, the economic use of depleted geologic structures, and maximum, safe long-term storage of $\mathrm{CO}_{2}$ ?

Issues and Barriers for Developing State Guidelines -

\section{$\underline{\text { Topics for Consideration by State Regulators/Geologists (7/18/02 - 3:15-5:15 session) }}$}

- How might regulatory requirements for the long-term sequestration of $\mathrm{CO}_{2}$ differ from current requirements for gas $/ \mathrm{CO}_{2}$ injection and storage?

- Should the IOGCC develop recommended state regulatory guidelines?

- How will state requirements support verification needs of state greenhouse gas emission reduction registries?

- What set of geologic options should be included in any guidelines/regulatory framework?

$\circ$ Currently producing oil and gas fields

- Unmineable coal seams

- Depleted oil and gas fields

- Deep saline aquifers

- Would further field unitization be required?

- How would the interests of various parties be considered and protected?

$\circ$ Oil and gas producers

$\circ \mathrm{CO}_{2}$ providers

- Royalty holders

- Landowners

O Others?

- What, if any, additional studies, information, demonstrations, etc. may be required?

Possible Aspects of Action Plan

\section{$\underline{\text { Topics for Consideration by State Regulators/Geologists (7/19/02 session) }}$}

- Formation of special committee/workgroup

- Charter for committee/workgroup

- Establishment of ultimate IOGCC role/objectives

- Components of Action Plan

- Timeline for Action Plan

- Requirements for additional information, demonstration projects, $R \& D$, etc.

- Staff support needs

- Resource requirements (budget, etc.)

- Description of immediate next steps 


\section{IOGCC-Sponsored Participants in Alta, Utah CO2 Sequestration Meeting}

July 17-19, 2002

\begin{tabular}{|c|c|c|c|c|}
\hline$\frac{\text { State/Affiliati }}{\text { on }}$ & Attendee & Title & Email Address & Telephone Number \\
\hline Alaska & Dan Seamount & Commissioner, O\&GCC & dan seamount@admin.state.ak.us & $907-279-1433$ \\
\hline California & Mike Stettner & UIC Program Manager & stettner@consrv.ca.gov & $916-323-1781$ \\
\hline Colorado & Brian Macke & Deputy Director, O\&GCC & brian.macke@state.co.us & $303-894-2100$ ext.122 \\
\hline Colorado & Vicki Cowart & State Geologist & vicki.cowart@state.co.us & $303-866-2611$ \\
\hline Illinois & Larry Bengal & Div. Supervisor, O\&G & Ibengal@dnrmail.state.il.us & 217-782-1689 \\
\hline Illinois & Robert Finley & Dir., Energy \& Earth Res. Ctr. & finley@isgs.uiuc.edu & $217-244-8389$ \\
\hline Kansas & M.L. Korphage & Dir., O\&G Conserv. Div. & m.korphage@kcc.state.ks.us & $316-337-6200$ \\
\hline Kansas & Tim Carr & Senior Scientist and Section Chief & tcarr@kgs.ukans.edu & $785-864-2135$ \\
\hline Nebraska & Bill Sydow & Director, O\&GCC & bsydow@hamilton.net & $308-254-6919$ \\
\hline New Mexico & Jack Ford & Environmental Engineer OCDiv. & jwford@state.nm.us & $505-476-3489$ \\
\hline New Mexico & Peter Scholle & Dir. \& State Geologist & pscholle@gis.nmt.edu & $505-835-5420$ \\
\hline North Dakota & Tom Heck & Geologist, Geol. Survey & theck@state.nd.us & $701-328-8000$ \\
\hline Ohio & Dennis Hull & Asst. Chief/Asst. State Geologist & dennis.hull@dnr.state.oh.us & $614-265-6596$ \\
\hline Oklahoma & Mike Schmidt & Dep. Dir., O\&G Conserv. Div. & m.schmidt@occmail.occ.state.ok.us & $405-521-2302$ \\
\hline Oklahoma & Charles Mankin & Dir. \& State Geologist & cjmankin@ou.edu & $405-325-3031$ or 3821 \\
\hline Texas & Steven Seni & Asst. Dir., Envir. Svcs., RRC & steven.seni@rrc.state.tx.us & $512-463-3296$ \\
\hline Texas & Paul Knox & Research Assoc., Bur. Econ. Geol. & paul.knox@beg.utexas.edu & $512-471-1534$ \\
\hline Utah & Lowell Braxton & Dir., Division of Oil, Gas \& Mining & lowellbraxton@Utah.Gov & $801-538-5370$ \\
\hline Utah & John Baza & Associate Director, O\&G & JohnBaza@utah.gov & $801-538-5334$ \\
\hline Utah & Richard Allis & Dir. Geol. Survey/State Geol. & rickallis@utah.gov & $801-537-3300$ \\
\hline West Virginia & Dave Bassage & $\begin{array}{c}\text { Director of Innovation, Dept. Envir. } \\
\text { Prot. }\end{array}$ & dbassage@mail.dep.state.wv.us & 304-389-7510 Ext. 223 \\
\hline West Virginia & Lee Avary & Head of Oil and Gas, Geol. Survey & avary@geosrv.wvnet.edu & 304-594- \\
\hline Wyoming & Pat Pitet & Dir., Energy \& Min., WY Bus. Cncl. & ppitet@state.wy.us & $307-777-2800$ \\
\hline IOGCC & Christine Hansen & Executive Director & c.hansen@iogcc.state.ok.us & $405-525-3556$ \\
\hline IOGCC & Kevin Bliss & Washington Representative & kbliss@erols.com & $202-518-3176$ \\
\hline IOGCC & Bill LeMay & Consultant to IOGCC & blemay@cybermesa.com & $505-988-1773$ \\
\hline IOGCC & Mark Carl & Envir. Proj. Manager & mark.carl@iogcc.state.ok.us & $405-525-3556$ \\
\hline USDOE/NETL & Scott Klara & Senior Analyst/Engineer & scot.klara@netl.doe.gov & $412-386-4864$ \\
\hline USDOE/NETL & Hugh Guthrie & Senior Advisor & hguthr@netl.doe.gov & $304-285-4632$ \\
\hline USDOE/HQ & David Beecy & Dir., Off. Of Envir. Systems & david.beecy@hq.doe.gov & $301-903-2787$ \\
\hline $\begin{array}{l}\text { USDOE/NETL } \\
\text { /NPTO }\end{array}$ & Dexter Sutterfield & Assoc. Dir., Tech. Mngmnt. & Dexter.Sutterfield@npto.doe.gov & 918-699-2039 \\
\hline $\begin{array}{l}\text { Private } \\
\text { Consultant }\end{array}$ & L. Stephen Melzer & Consulting Engineer & melzerls@aol.com & $915-682-7664$ \\
\hline $\begin{array}{l}\text { Kinder Morgan } \\
\text { Co. }\end{array}$ & Russell Martin & Vice President & russell martin@kindermorgan.com & $713-369-9159$ \\
\hline $\begin{array}{l}\text { Chevron } \\
\text { Texaco }\end{array}$ & Craig A. Lewis & Advisor, Global Policy \& Strat. & cral@chevrontexaco.com & $713-432-2614$ \\
\hline $\begin{array}{l}\text { Advanced } \\
\text { Res. Int'l. }\end{array}$ & Vello Kuuskraa & President & vkuuskraa@adv-res.com & $703-528-8420$ \\
\hline $\begin{array}{l}\text { Advanced } \\
\text { Res. Int'l. }\end{array}$ & Michael Godec & Senior Technical Advisor & mgodec@adv-res.com & $703-528-8420$ \\
\hline Advanced & David C. Thomas & Senior Technical Advisor & david-thomas@notwires.com & $630-922-3667$ \\
\hline
\end{tabular}




\section{Greenhouse Gas Mitigation References and Websites}

(Below are listed a series of websites and snapshot descriptions of the contents of those sites for your information and use. The list is representative of the literature on climate change and includes sites that I have found to be useful. DCT)

National Energy Technology Laboratory's Carbon Sequestration Product Area

U. S. DOE, Office of Coal and Environmental Systems

\section{http://www.netl.doe.gov/coalpower/sequestration/main.html}

We seek to define carbon sequestration's role in stabilizing atmospheric carbon dioxide levels by developing a scientific understanding and environmentally acceptable technologies. Our research areas include capture \& storage, geologic, ocean, and terrestrial sequestration, advanced $\mathrm{CO}_{2}$ conversion \& reuse, and modeling \& analysis.

\section{$>$ Carbon Sequestration Technology Roadmap}

http:/www.netl.doe.gov/coalpower/sequestration/pubs/CS_roadmap_0115.pdf

Carbon sequestration has emerged as a third option for reducing greenhouse gas (GHG) emissions. Joining improved energy efficiency and the use of low-carbon fuels, carbon sequestration will enable the removal and permanent storage of carbon dioxide from fossil-energy systems. Carbon sequestration holds great potential to reduce GHG's at costs and impacts that are economically and environmentally acceptable. Other energy-related GHG's such as methane and nitrous oxides are important and are addressed as part of the U.S. Department of Energy's Carbon Sequestration Program. However, this roadmap only addresses carbon dioxide.

The effort to develop carbon sequestration technology involves extensive public-private partnerships among government, industry, academia, non-governmental organizations, and the public at large. Many of these partnerships are international in scope, and include the International Energy Agency's Greenhouse Gas Research and Development Programme (IEA/GHG), the European Commission, international science organizations, and individual countries. Domestic partners include industry, DOE Office of Science, National Science Foundation, scientific and academic communities, non-governmental environmental organizations, and regional, state, and local organizations. This collaborative approach supports the NCCTI objectives of providing market-based options that build on science and technology innovations.

CO2 CAPTURE AND STORAGE IN GEOLOGIC FORMATIONS - A white paper prepared for the National Climate Change Technology Initiative

\section{http://www.netl.doe.gov/coalpower/sequestration/pubs/CS-NCCTIwhitepaper.pdf}

On June 11, 2001 President Bush directed the Secretaries of Energy and Commerce, along with the Administrator of the EPA, to develop a National Climate Change Technology Initiative (NCCTI). The NCCTI will develop innovative approaches in accordance with several basic principles, as outlined by the President. The approaches will be:

(1) consistent with the long-term goal of stabilizing greenhouse gas concentrations in the atmosphere;

(2) measured, as we learn more from science, and build on it;

(3) flexible to adjust to new information and take advantage of new technology;

(4) ensure continued economic growth and prosperity; 
and,

(5) pursue market-based incentives and spur technological innovation.

This report, $\mathrm{CO} 2$ Capture and Storage in Geologic Formations, is one of eight energy-related white papers produced in response to the guidance for the NCCTI white paper. This white paper covers the capture of carbon dioxide (CO2) from current and planned fossil energy systems and its direct sequestration in geologic structures. Indirect sequestration, the enhanced uptake and storage of $\mathrm{CO} 2$ in soils, vegetation, and the oceans, along with direct injection of $\mathrm{CO} 2$ into oceans, is covered in other white papers.

The $\mathrm{CO}_{2}$ Capture Project:

\section{http://www.co2captureproject.org/}

The CO2 Capture Project is an international effort funded by eight of the world's leading energy companies, the U.S. DOE, the European Commission, and Norway's Klimatek. This project is addressing the issue of reducing emissions in a way that will contribute to an environmentally acceptable, and competitively priced, continuous energy supply for the world. $\mathrm{CO}_{2}$ capture and geologic storage offer a new set of options for reducing greenhouse gas emissions that can complement the current strategies of improving energy efficiency and increasing the use of nonfossil energy resources.

The project seeks to develop new technologies to reduce the cost of capturing $\mathrm{CO}_{2}$ from combustion sources and to safely store it underground. These technologies will be applicable to a large fraction of $\mathrm{CO}_{2}$ sources around the world - such as power plants and other industrial processes. Implementing these new technologies during this decade will reduce the impact of continued fossil energy use while cleaner energy sources are being developed.

The main contributor to increasing atmospheric $\mathrm{CO}_{2}$ concentration is fossil fuel combustion for power generation, transport, industry, and domestic use. Fossil fuels (coal, oil and natural gas) have underpinned the development of the economies in the industrialized countries around the world. The demand for energy is expected to grow in the developed countries and in particular in the developing countries, as they strive to obtain a higher standard of living.

Energy companies have been investing in alternatives to fossil fuels, including renewable sources such as solar power, but believe that these are unlikely to replace fossil fuels in the short to medium term if the world's ever-increasing energy requirements are to be met at an acceptable cost. Fossil fuels will still be in demand for the foreseeable future and progressive energy companies have recognized that, in supplying fossil fuels, prudent precautionary measures to limit combustion emissions are required now.

Intergovernmental Panel on Climate Change

\section{http://www.ipcc.ch/pub/reports.htm}

(The Summaries for Policy Makers (SPM) of the Third Assessment Report, are particularly useful discussions of the overall findings and issues. I recommend them to anyone interested in learning more about climate change issues at the global level-DCT).

Recognizing the problem of potential global climate change, the World Meteorological Organization (WMO) and the United Nations Environment Programme (UNEP) established the Intergovernmental Panel on Climate Change (IPCC) in 1988. It is open to all members of the UNEP and WMO. The role of the IPCC is to assess the scientific, technical and socio-economic information relevant for the understanding of the risk of human-induced climate change. It does not carry out research nor does it monitor climate related data or other relevant parameters. It bases its assessment mainly on peer reviewed and published scientific/technical literature. 
The IPCC has three Working Groups and a Task Force:

*Working Group I assesses the scientific aspects of the climate system and climate change.

$w$ Working Group II addresses the vulnerability of socio-economic and natural systems to climate change, negative and positive consequences of climate change, and options for adapting to it.

wWorking Group III assesses options for limiting greenhouse gas emissions and otherwise mitigating climate change.

w The Task Force on National Greenhouse Gas Inventories is responsible for the IPCC National Greenhouse Gas Inventories Programme.

The Panel meets in plenary sessions about once a year. It accepts/approves/adopts IPCC reports, decides on the mandates and work plans of the Working Groups and the Task Force, the structure and outlines of its reports, the IPCC Principles and Procedures, and the budget. The Panel also elects the IPCC Chairman and the rest of its Bureau.

The IPCC completed its First Assessment Report in 1990. The Report played an important role in establishing the Intergovernmental Negotiating Committee for a UN Framework Convention on Climate Change (INC) by the UN General Assembly. The UNFCCC was adopted in 1992 and entered into force in 1994. It provides the overall policy framework for addressing the climate change issue.

The IPCC has continued to provide scientific, technical and socio-economic advice to the world community, and in particular to the 170-plus Parties to the UNFCCC through its periodic assessment reports on the state of knowledge of causes of climate change, its potential environmental and socio-economic impacts and options for addressing it. Its Second Assessment Report, Climate Change 1995, provided key input to the negotiations, which led to the adoption of the Kyoto Protocol in 1997. The IPCC also prepares Special Reports and Technical Papers on topics where independent scientific information and advice is deemed necessary and it supports the UNFCCC through its work on methodologies for National Greenhouse Gas Inventories.

\section{International Energy Agency - Greenhouse Gas R\&D Programme (IEA/GHG)}

\section{http://www.ieagreen.org.uk/}

The IEA Greenhouse Gas R\&D Programme (IEA GHG) is an international collaboration which aims to:

$>$ Evaluate technologies for reducing emissions of greenhouse gases;

$>$ Disseminate the results of these studies;

$>$ Identify targets for research, development and demonstration and promote the appropriate work.

The IEA Greenhouse Gas R\&D Programme operates under an Implementing Agreement provided by the International Energy Agency (IEA). The IEA itself was established in 1974 within the framework of the Organisation for Economic Co-operation and Development (OECD) to implement an international energy programme. The IEA fosters co-operation amongst its 26 member countries, and with other countries, in order to increase energy security by improved efficiency of energy use, development of alternative energy sources and research, development and demonstration on matters of energy supply and use. This is achieved through a series of collaborative activities, organised under more than 40 Implementing Agreements. These 
agreements cover more than 200 individual items of research, development and demonstration. IEA GHG operates under one of these Agreements.

The IEA GHG Programme started in November 1991 and the fourth phase began in November 2000. Its main activities concern methods of reducing greenhouse gas emissions, particularly from fossil fuels. The principal anthropogenic greenhouse gas is $\mathrm{CO}_{2}$ and its major source is power generation so this is where IEA GHG has put much of its effort. Other greenhouse gases and other sources of $\mathrm{CO}_{2}$ are also examined - for example, methods of reducing methane emissions from many sources have been investigated; also use of renewable sources of energy has been assessed so as to put the different mitigation options in perspective.

IEA GHG has given much attention to the option of capture and storage or utilisation of $\mathrm{CO}_{2}$. As well as establishing the feasibility of this option, the Programme is working to put it in perspective with other methods of reducing greenhouse gas emissions.

\section{EPA Global Warming Site}

\section{http://www.epa.gov/globalwarming/}

The EPA Global Warming Site is provided as a public service by the U.S. Environmental Protection Agency. EPA's climate change programs and activities are an integral part of the Agency's mission and purpose. With the Global Warming Site, we strive to present accurate information on the very broad issue of climate change and global warming in a way that is accessible and meaningful to all parts of society - communities, individuals, business, public officials and governments.

The United States has based its climate change policies on the conclusions of the Intergovernmental Panel on Climate Change (IPCC), which has provided an authoritative international consensus on the science of climate change. Content presented on the Global Warming Site relies heavily on the IPCC literature, as well - particularly the reports listed below.

The United States, the International Community, and the Global Warming Site also rely on the work of the U.S. Global Change Research Program (USGCRP). In fact, the USGCRP provides a major contribution to the research base on which the IPCC assessments rely. In addition, the Site uses reports related to climate change that have been produced by or for the Agency over the years; many of these reports are available within the Site's Publications section.

\section{Pew Center on Global Climate Change}

\section{http://www.pewclimate.org/}

The objective of the Pew Center on Global Climate Change is to educate the public and key policy makers about the causes and potential consequences of climate change, and to encourage the domestic and international community to reduce emissions of greenhouse gases. To accomplish this objective, the Pew Center will: (1) release highly publicized reports on environmental impacts, economics and policy issues; (2) educate the public through advertising, public-speaking events and conferences; and (3) advance international negotiations on climate change by coordinating cross-country policy, industry and government discussions.

Addressing global climate change is serious business, and a great deal is at stake. Scientists have indicated that we may expect impacts on the global environment, including damage to our coastal areas, accelerated rates of species loss, altered agricultural patterns and increased incidences of infectious diseases. These impacts also could have substantial economic ramifications as they affect health care costs, property insurance, and worker productivity. 
The Pew Center on Global Climate Change is a non-profit, non-partisan and independent organization dedicated to providing credible information, straight answers and innovative solutions in the effort to address global climate change. Established in 1998 by the Pew Charitable Trusts, the Center is led by Eileen Claussen, former U.S. Assistant Secretary of State for Oceans and International Environmental and Scientific Affairs. Thirty-seven major companies, with most included in the Fortune 500, are working together through the Center to educate the public on the risks, challenges and solutions to climate change. These efforts are spearheaded by the Center's Business Environmental Leadership Council, a group of leading companies worldwide that are responding to the challenges posed by climate change. 
Appendix 8 


\section{1 \\ Chairman's \\ Stewardship Awards}

Interstate Oil and Gas Compact Commission

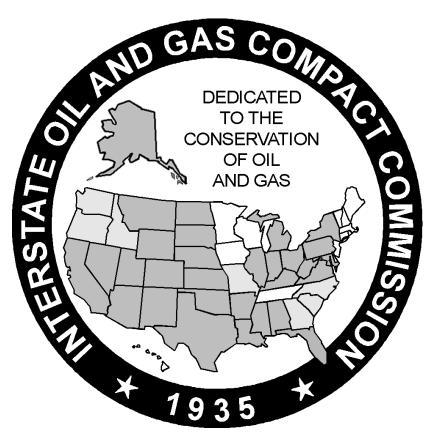

Gov. Jony Thowles

State of Alaska

Chairman 


\section{ĐaGle of Contents}

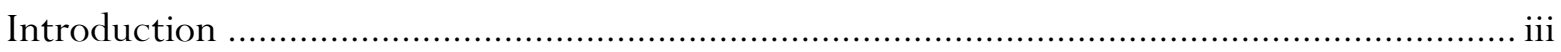

Subcommittee Chairman's Comments ……............................................................. iv

\section{CHAIRMAN'S STEWARDSHIP AWARDS WINNERS}

\section{Major/Large Company}

Phillips Alaska Inc. 1

Independent/Small Company

Evergreen Resources Inc.

Environmental Partnership

Southwest Indiana Brine Coalition ................................................................................. 3

Energy Education

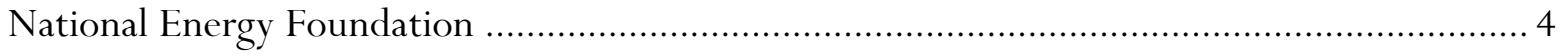

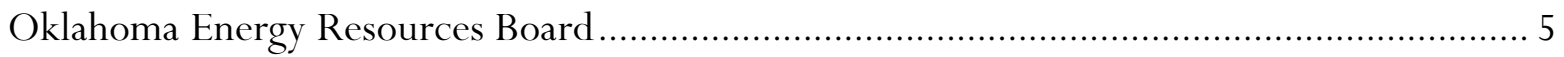

\section{CHAIRMAN'S STEWARDSHIP NOMINEES}

Major/Large Company

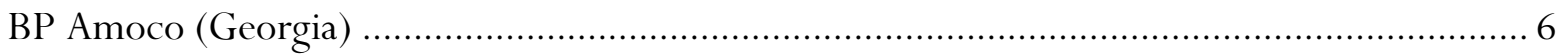

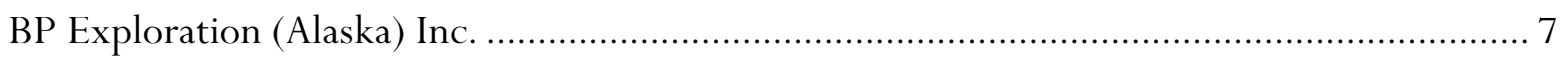

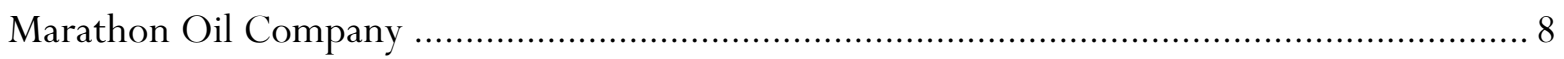

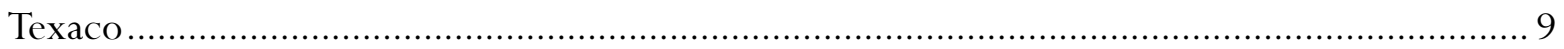

Independent/Small Company

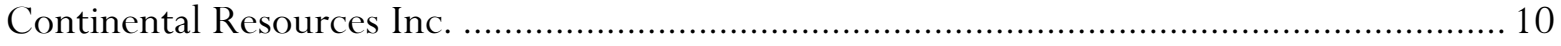

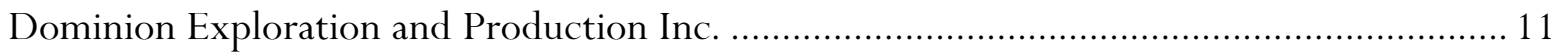

Environmental Partnership

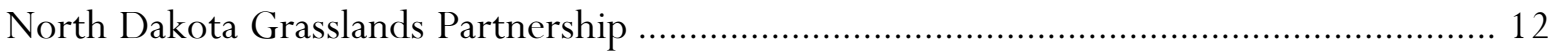

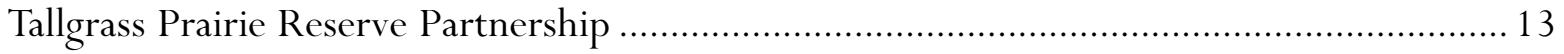

Energy Education

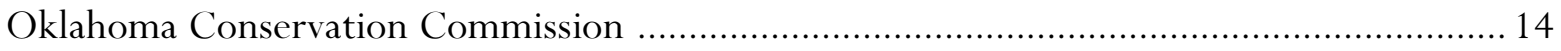


2001 Chairman's Stewardship Awards • Page ii 


\section{Introduction}

Operations in today's oil and natural gas provinces reflect the growing commitment of all segments of the industry to balancing the needs of environmental protection with those of delivering energy to America.

Rarely do producers receive praise for their many conservation efforts and achievements. More frequently, they are criticized for negative effects petroleum production can have on the environment as the public remembers problems of the past.

In an effort to focus on positive accomplishments, the Interstate Oil and Gas Compact Commission (IOGCC), through its annual Chairman's Stewardship Awards, honors producers and organizations for their diligent efforts to protect the environment.

Since its inception in 1935, the IOGCC has voiced the need for sound oil and natural gas environmental policy. Through efforts of state leaders, the organization works to minimize the waste of a nonrenewable resource vital to economic development, national security and the lifestyle of Americans while protecting health, safety and the environment. The industry does not take its responsibilities to future generations and conservation lightly.

The IOGCC honors significant achievements in four categories - major or large company, independent company, environmental partnership and energy education. To qualify in the first three categories, a company or organization must successfully complete a project that demonstrates the compatibility between resource development and ecosystem conservation. In the energy education category, companies, industry associations and state agencies have undertaken outstanding projects to enhance the reputation of domestic petroleum and provide the public with a greater understanding of the industry and its challenges.

Projects contained within this publication are examples of responsible environmental stewardship. We praise the efforts of all of the nominees, and honor the best with the 2001 Chairman's Stewardship Awards.

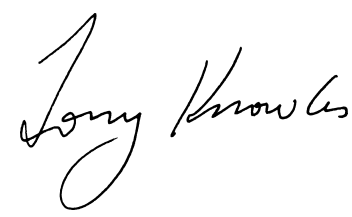

Gov. Tony Knowles, Alaska

IOGCC Chairman 


\section{Comments}

Members of the Chairman's Stewardship Awards Subcommittee selected winners for 2001.

The IOGCC received 14 nominations for the awards in four categories:

1. Major or large oil or natural gas company.

2. Independent or small oil or natural gas company.

3. Environmental partnership.

4. Energy education.

Winners were selected in each category, with judges utilizing written descriptions, photographs, videos and CD ROMs relative to the specific project.

Selection of winners was difficult, because each project had distinct meritorious facets and all were worthy of commendation. However, keeping in mind Webster's definition of stewardship "the individual's or party's responsibility to manage his, her or its life and property with proper regard to the rights of others" - and the concept of "above and beyond," the subcommittee members made the following selections: Philips Alaska Inc. for the large company award; Evergreen Resources Inc. for the small company award; Southwest Indiana Brine Coalition for the environmental partnership award; and National Energy Foundation and Oklahoma Energy Resources Board, CO-winners of the energy education award.

Members of the Chairman's Stewardship Subcommittee - Thomas Aalto, U.S. Environmental Protection Agency, Denver; James E. Erb, Pennsylvania; Del Fortner, U.S. Bureau of Land Management, California; Mark Shreve, Kansas; Thomas E. Stewart, Ohio; Lori Wrotenbery, New Mexico - and I were honored to be a part of selecting the winners. It is indeed a pleasure to serve as chairman.

We believe the award expresses not only the desires of individual states, but also that of the oil and gas industry to supply our nation's energy needs while preserving and enhancing the environment. It is our goal to encourage more participation in the Chairman's Stewardship Awards program in 2002 and beyond.

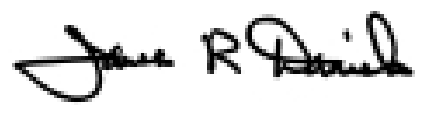

James R. Daniels

Subcommittee Chairman 


\section{Phillips Alaska Inc.}

$\mathrm{P}^{\prime}$ hillips Alaska Inc. has achieved a major company milestone - the start-up of a significant new oil field development in one of Alaska's most biologically productive regions. The field, known as The Alpine Development Project, is in one of the state's largest and most dynamic braided river deltas in an area historically important to subsistence user groups. The Alpine project encompasses land owned by the state and the Kuukpik Village Corporation, and is one of the first significant production facilities located on native-owned surface estates under the Alaska Native Claims Settlement Act.

The Alpine Development Project, targeted to produce approximately 80,000 barrels of oil per day, occupies just 97 acres of footprint on Alaska's North Slope. Incorporating directional drilling technology maximizes reservoir production from this limited pad area and allows a sub-surface area of about 40,000 acres to be reached from minimal surface facilities. The Alpine Development Project operates safely without a permanent road connecting the development to adjacent infrastructure.

Through careful planning, innovative design and dedicated compliance oversight, Phillips Alaska's first fully remote operation avoids or mitigates environmental damage to local physical and biological resources, all in partnership with the local community. 


\section{Evergreen CPesources Inc.}

The Raton Basin of Colorado is a remote, arid area where quality water is scarce. Since the start of its operations in the Raton Basin, Evergreen Resources Inc. has worked to make quality water from its coalbed methane operation available to local landowners for stock watering and enhanced wildlife habitat.

As part of its water supply efforts, Evergreen has proposed to fund the construction and initial operation of a water system for local residents. Many of the household water wells in the basin provide only small quantities of poor quality water that does not meet federal and state secondary drinking water standards. Residents, lacking reliable wells, haul water to fill home cisterns. The Evergreen water supply project will meet this need for a reliable supply of quality drinking water.

Evergreen is funding construction of one of two water systems depending upon the preferences of local residents and government.

The first option is a reverse osmosis system that would process a portion of the water produced from the coalbed methane operation. The option has the appeal of converting fairly good quality water - technically a waste by-product of coalbed methane production - into potable water to benefit local landowners and homeowners. After initial construction and operation, Evergreen plans to transfer the facility to a local water supply district or municipal government.

Certain technical and financial hurdles are associated with the operation of a reverse osmosis facility by a municipality or local water district. For this reason, Evergreen has proposed a second option in which it plans to pay for a large-diameter water tap on an existing municipal water supply pipeline that passes through the area.

Most residents in the area do not have access to this treated-water supply pipeline. Adjacent to the water pipeline, Evergreen plans to construct a facility that incorporates storage tanks and a truck load-out on an easement already obtained by the company for this purpose. Local water supply studies point to this system as a cost-effective, long-term solution to local water needs especially given the very low density of homes in this rural area. Once constructed, this simple-tooperate facility could be turned over to Trinidad (a nearby city) or a local water district organized by nearby residents.

Evergreen is continuing to work with residents and municipal authorities to finalize the choice and design of a facility that will address their drinking water needs. The facility is expected to be operational this year.

2001 Chairman's Stewardship Awards • Page 2 


\title{
Southwest Indiana Brine Coalition
}

\begin{abstract}
The Southwest Indiana Brine Coalition (SWIBC), a citizen group actively working with the Indiana Division of Oil and Gas, compiles information and conducts pilot projects of costeffective solutions for remediating old, historically contaminated oil production sites.
\end{abstract}

The coalition has made significant progress in establishing an inventory system and educating county leaders and landowners about the opportunity to work together to address these old sites.

The SWIBC has worked with and supported the state's oil and natural gas industry. Many group members began working with the Indiana Department of Natural Resources in 1995, when the division implemented a citizen-input process called Direct Dialogue ${ }^{\mathrm{TM}}$. The process was supported and funded by the Interstate Oil and Gas Compact Commission (IOGCC) through a grant from the U.S. Department of Energy.

In October 2000, the SWIBC completed its first pilot project, bringing together farmers, citizens, government and industry. The organization remediated a historically contaminated site stabilizing the soil and support vegetation - for less than half the cost of traditional contracting methods.

The SWIBC, supported by seven southwest Indiana counties, works under the umbrella of the Four Rivers Resource, Conservation and Development. The coalition has consulted with oil and natural gas operators for technical assistance since its inception. The Division of Oil and Gas expanded technical assistance to the organization since the division's establishment in 1997. The SWIBC began formally working with the Indiana Oil and Gas Association in 1999, providing key support to the association in legislative committee meetings directed at the orphan well site issue.

The organization is operating with a small grant. Recently the SWIBC received approval for another grant to continue its inventory work and provide funding for a couple of pilot projects to demonstrate cost-effective techniques to be used by landowners and farmers for remediation of historically contaminated sites. 


\section{National Energy Foundation}

The oil embargo of the early 1970s indicated that Americans did not fully understand fundamental energy-related matters. The National Energy Foundations (NEF), seeing a need for energy education, decided to pinpoint its efforts on teachers and students, with a secondary focus on the public.

For 25 years, NEF has served the oil and gas industry by providing teaching and learning opportunities that promote a better understanding of energy, natural resources and the environment.

During the past two decades, NEF has maintained its commitment to energy education through the following initiatives:

- Distributing more than a half million instructional posters.

- Conducting teacher-training sessions for more than 50,000 teachers.

- Providing more than 4,000 university graduate credit courses through the NEF Academy.

- Establishing a nationwide material distribution (fulfillment) program now reaching more than 8,000 teachers each year in 46 states.

- Conducting classroom educational programs for nearly a half million students annually, including such popular activities as debates, field trips, competitions and expositions.

- Collaborating in major materials development, distribution and implementation project alliances with several hundred sponsors from government, industry, organizations and the education community. 


\section{CO-WINNER - ENERGY EDUCATION}

\section{OkLahoma Energy CResources Board}

The Oklahoma Energy Resources Board (OERB) has designed and established an up-todate hands-on oil and science curriculum for both grade school and middle school children. OERB provides teacher training and all material necessary for the six- to eightweek curriculum. Last year "Fossils to Fuel" was taught in more than 875 grade school classrooms throughout Oklahoma to more than 25,800 students. "Petro-Active," the middle school curriculum, which was first introduced at the beginning of the year, has trained more than 87 teachers and was presented to 2,200 students. This program is expected to grow at a rate similar to "Fossils to Fuel."

In addition to its curriculum, OERB provides training and kits for industry volunteers under its "Petro-Pros" program that has standardized, yet flexible, presentations for students of all ages. "Petro-Pros" is a model for many similar programs throughout the United States. It is the longest running and most successful program of its type, having been presented to more than 18,102 students.

Later this year, students from across the country will be able to "log on" to a state-of-the-art, fun and educational Web site that will contain everything from games to "fun facts" about the oil and gas industry. OERB also seeks funding to develop a CD ROM game similar to the popular "You Don't Know Jack." The game will address different levels of expertise, and, if played in conjunction with the Web site, will allow students to win prizes and receive recognition.

Having already produced an effective safety video, OERB will produce two 22 -minute films. The first will present the drilling of an oil and gas well and the second will show the completion of an oil and gas well. The videos will be available to classrooms where "Fossils to Fuel" and "Petro-Active" are taught, as well as local educational television stations.

OERB, through voluntary contributions of oil and gas producers, is committed to the oil and gas industry education of Oklahoma's students. 


\section{BP Amoco (Georgia)}

Tn July 1999, BP Amoco announced the North American rollout of its low sulfur premium fuels for use in Atlanta, enabling an area unable to comply with U.S. Environmental Protection Agency (EPA) air quality standards to purchase cleaner burning sulfur fuel year-round without additional charges. This voluntary effort was the first by any U.S. oil company in the fight against destruction of the ozone.

In a joint announcement with Georgia Gov. Roy Barnes and EPA Chief Administrator Carol Browner, BP Amoco's Deputy Group Chief Executive Rodney Chase said that BP and Amoco service stations would offer premium gasoline year-round with a 30 parts per million (ppm) average sulfur level, five times lower than the legally required average of $150 \mathrm{ppm}$. These fuels are four years ahead of the state mandate for sulfur reduction. According to BP Amoco's calculations, which used accepted industry methodologies and were reviewed by the Georgia Environmental Protection Division, the company's gasoline sulfur reductions and resulting emissions reductions are the equivalent of removing 12,000 cars from Atlanta roads each day. Barnes and Browner lauded the breakthrough program as an example of business/government partnership. The Atlanta program was followed by similar cleaner fuels programs in Chicago and Milwaukee.

Building on its prior success, BP Amoco is launching the BP Connect service station concept. These stations, now opening in Atlanta and other cities, feature state-of-the art environmental advantages such as solar photovoltaic (PV) canopies, powered by BP Solar, and low-sulfur premium gasoline. The PV canopies fully cover the pump islands. The canopies contain a special semi-transparent laminated glass that is laser-etched to generate solar electricity while also allowing some light through to the surface below. In Atlanta, BP Amoco and Georgia Power are featuring free recharging stations for electric cars. 


\section{BP Exploration (Alaska) Inc.}

$\mathrm{B}$ P Exploration (Alaska) Inc. (BPXA) has developed and implemented a strategic Environmental Management System (EMS) that has resulted in significant benefits within and outside the company. BPXA's focus on strategic environmental management is influencing the contractor community, a critical factor in compliance and environmental performance. Its influence has extended to other oil companies and other industries.

Since initiating EMS in 1997, BPXA progressed with a systematic approach consistent across Alaska and the Lower 48 Upstream Business Units.

The benefits and improvements realized by EMS implementations at BPXA are fundamental and sweeping:

- Integration of environmental management into core business processes.

- Uniformity and consistency of assets across Alaska and around the world.

- Improved interface with partners' and suppliers' management systems.

- Enhanced reputation and increased public confidence in the oil industry.

- Improved compliance assurance.

- Cost savings through pollution prevention.

- Cost savings in streamlined business processes.

- Predictable outcomes in environmental matters.

By setting the standard for expectations within industry, BPXA aspires to be the catalyst for greater environmental performance across society. An example of such external outreach is the BPXA Toolbox and Mentoring Program (Toolbox Program).

The Toolbox Program was established in early 1999 to help contractors demonstrate environmental compliance and improve performance through development and implementation of their own EMS systems. The knowledge-based program provides workshops, site assessments, mentoring and follow-up site visits using an innovative combination of electronic resources, classroom, instruction and technical support.

Partnerships interact with the program personnel and share best practices on a protected Web site and in classroom and field sessions. The sharing of best practices and feedback from program participants has provided continual improvement of the program. 


\section{Marathon Oil Company}

$\mathrm{M}$ arathon Oil Company demonstrated resource conservation and environmental stewardship with two projects in the Indian Basin Field located in Eddy County, New Mexico. Marathon is using a technology to treat produced water for use in drilling operations, which reduces demand on local groundwater. Marathon also reduced emissions by installing "clean-burn" compressor engine technology.

Oil and gas drilling rigs in Indian Basin typically use fresh water obtained locally to circulate mud during drilling operations. However, in this arid climate, the availability of fresh groundwater is limited.

To save groundwater resources and to reduce costs, Marathon evaluated the feasibility of using produced water. The main problem encountered was water produced with oil and gas in the area had a naturally occurring hydrogen sulfide $\left(\mathrm{H}_{2} \mathrm{~S}\right)$ gas entrained in it. $\mathrm{H}_{2} \mathrm{~S}$ gas reacts with water to form a weak acid that is corrosive to drilling equipment. But breaking out the water could pose a safety concern.

Marathon developed a system that removes enough $\mathrm{H}_{2} \mathrm{~S}$ gas to allow the produced water to be used safely for drilling operations. Since the start of the project, Marathon has saved more than 100,000 barrels of groundwater. Based on its current development plans, an additional 200,000 barrels could be saved in the next drilling cycle.

Marathon also voluntarily reduced air emissions from natural gas-fired compressor engines by upgrading 14 less fuel-efficient engines with nine "clean" burn engines. The engines power compressors compact the natural gas for transportation in gathering lines to the field gas processing plant. The new engines reduced the natural gas fuel consumption by 350 thousand cubic feet per day, or $13 \%$ of total fuel requirements. The voluntary installation of the engines reduced both criteria air pollutants and greenhouse gases. 


\section{Nominee - Major/Large Company}

\section{】exaco}

Texaco, with the cooperation of the state of Wyoming, completed in December 1999 two environmental projects at its former refinery in Casper. These multi-million-dollar projects remove sources of hydrocarbon contamination and prevent migration of contaminants into the North Platte River.

Texaco began decommissioning its Casper Refinery in 1996, removing all inactive underground piping, concrete foundations and other subsurface structures to eliminate possible sources of environmental contamination. The company developed and implemented a program to identify, screen and remove petroleum-contaminated soils as a voluntary corrective action to reduce average concentrations of petroleum hydrocarbons in subsurface soils. The company also completed an aggressive surface reclamation program designed to provide optimal management of storm water and to improve the appearance of the site.

Between 1993 and 1997, Texaco installed an extensive network of groundwater interceptor trenches along the south bank of the North Platte River and operated them to successfully contain and remove subsurface contaminants that exhibited potential to adversely influence surface water quality. Texaco launched a barrier project in mid-1997 to provide an added measure of protection. Texaco completed the project with installation of rip-rap on the outboard side of the barrier and construction of performance monitoring systems. Replacement of topsoil, reseeding, painting and other reclamation work was completed at the end of 1999.

Operations and monitoring data gathered during 2000 indicate that the barrier is meeting all of the original monitoring and performance criteria.

One of the more important design and performance considerations was the need to control groundwater elevations along the inboard side of the barrier so that they are at least six inches lower than surface water elevations along the outboard side. Weekly monitoring data gathered from the 12 stations reveal a flawless record during the past 13 months. In addition, Texaco's close monitoring of water quality in the North Platte River has indicated the absence of any measurable adverse influence during the past three years. 


\section{Continental desources Inc.}

The Medicine Pole Hills West Unit (MPHWU) is located in southwest North Dakota in Bowman County. The purpose of Continental Resources' 14,300-acre enhanced recovery project is to double or triple the estimated primary oil production by injecting air into approximately 5,000-foot horizontal well bore laterals at a depth of almost 9,000 feet.

The MPHWU is the first deep horizontal, high-pressure air injection project in the world. The project is designed to recover incremental oil from the existing reservoir without drilling additional wells by injecting a non-polluting gas, which ensures protection of the environment. 


\section{Dominion Exploration and $P_{\text {roduction Inc. }}$}

Wo subsidiaries of Dominion Exploration and Production, Inc. - Dominion Appalachian Development Corporation and Virginia Power - donated a 477-acre natural area known as Bear Rocks to The Nature Conservancy of West Virginia. The donation, valued at $\$ 1.5$ million, is the largest nature preserve gift to the conservancy.

Bear Rocks in the eastern part of the state, is a well-known landmark on the Dolly Sods plateau, a popular recreation destination and a natural area with ecological and historical significance.

The conservancy plans to create interpretive materials to make Bear Rocks accessible for hiking and observing wildlife in a manner compatible with the protection of the area's natural resources.

Safeguarding Bear Rocks, combined with Dolly Sods Wilderness and the Monongahela National Forest, extends protection of the upper Red Creek watershed - the fulfillment of a decades old effort of the conservancy in West Virginia. 


\section{North Dakota Grasslands Partnership}

\section{The North Dakota Oil and Gas Association, North Dakota Industrial Commission, North Dakota Association of Oil and Gas Producing Counties, North Dakota Petroleum Council, United States Forest Service and Bureau of Land Management have partnered to}

produce a video that demonstrates the exemplary environmental stewardship of the oil and natural gas industry in the North Dakota National Grasslands.

The video explains how industry and state and federal regulators have developed permitting, production and reclamation practices that have spawned production of 200 million barrels of oil from the grasslands during the past 46 years, reclamation of 500 well sites and reclamation of 480 miles of roads.

Through this unique partnership, everyone has been able to realize the greatest possible good for North Dakota's natural resources. 


\section{Dallgrass $\mathbb{P}_{\text {rairie }}$ Peserve $\mathbb{P a r t n e r s h i p}$}

T the Tallgrass Prairie Reserve in Osage County, the Oklahoma Chapter of The Nature Conservancy (TNC), University of Tulsa (TU) and the Bureau of Indian Affairs (BIA) is recreating a functioning tallgrass prairie ecosystem using bison grazing and fires. More than 100 producing oil wells - operated by independent producers - share the preserve with the bison.

Mineral rights in Osage County are owned by the Osage Tribe and managed for the tribe by the BIA.

What would seem on the surface to be a volatile mixture of stakeholders is a model of cooperation and mutual respect for the goals of each. This unique cooperation between an environmental organization and an extraction industry should serve as an example of how similar groups can work together protecting the environment while respecting the business needs of industry.

Rectifying occasional spills of produced fluids in the preserve illustrates the cooperation within this group of stakeholders and introduces a new partner in the restoration of damaged sites science and engineering faculty from TU.

When a producer reports a spill to TNC, TU faculty is notified and they advise TNC on first response and remediation of the site. TU faculty employ students in site assessment and remediation. These students gain valuable field experience and conduct research aimed at lowering the cost of remediation. Producers participate in the remediation effort by providing manpower and equipment to TNC or TU.

What results is a win-win situation for all stakeholders. A damaged site is restored, TU students gain valuable field experience, the cost of restoration is greatly reduced and the producers and the BIA gain experience in new, more cost-effective methods of cleaning up spills. 


\section{OkLahoma Conservation Commission}

The Oklahoma Conservation Commission created an energy education project to inform landowners about the process involved in the exploration for petroleum products and the protection of soil and water quality.

The project - with technical assistance from BP America, Latimer and LeFlore County Conservation Districts, Oklahoma Corporation Commission, United States Department of Agriculture, Natural Resources Conservation Service and Veritas DGC Land, Inc. - was developed to educate landowners and the public in Oklahoma about seismic surveying.

The survey is one of the first steps in searching for oil and gas resources that directly affects the land. Landowners can benefit from an understanding of what occurs during the survey and what can be done to reclaim disturbed areas once the survey is complete.

The project includes both an informational video and a brochure that covers seismic surveying, access permission, special conditions, impact mitigation and reclamation techniques. This helps foster good communication, which leads to enhanced cooperation between landowners, oil and gas companies and governmental agencies. This type of energy education helps minimize the impact to land and water resources, while providing technical assistance for erosion control and water quality issues. 


Appendix 9 


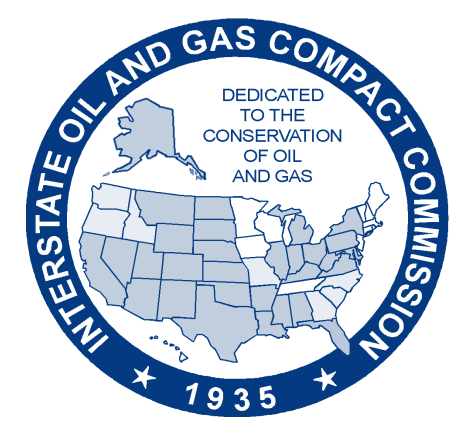

\section{2} IOGCC

Chairman's Stewardship

Awards Application Checklist

\section{2 \\ Chairman's Stewardship Awards}

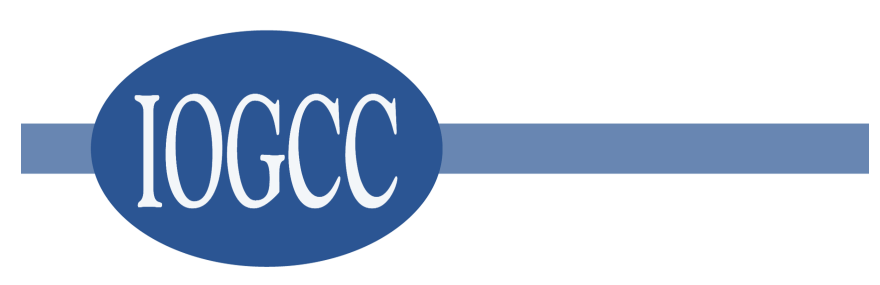

Stewardship Awards Interstate Oil and Gas Compact Commission P.O. Box 53127

Oklahoma City, OK 73152-3127 
Honoring the Industry's Environmental Stewardship

The Interstate Oil and Gas Compact Commission (IOGCC) created the Chairman's Stewardship Awards to shine a spotlight on the many positive projects and programs initiated by the oil and natural gas industry.

The Chairman's Stewardship Awards are presented each year at IOGCC's Midyear Meeting. In addition to recognizing existing environmental achievements, these awards are intended to challenge companies and organizations to produce projects that demonstrate to the American people an attitude of creativity and sensitivity to the environment while meeting the country's energy needs.

\section{Four Categories}

\section{Major Company}

Award recognizes innovative projects by large oil and natural gas companies that demonstrate positive environmental stewardship.

\section{- Small Independent Company}

Award recognizes similar projects by small, independent oil and natural gas companies.

\section{$\checkmark$ Energy Education}

This award is presented to a group or organization that has created a program to educate the public about petroleum and the hundreds of ways it affects the lives of Americans each day.

\section{- Environmental Partnership}

The Environmental Partnership award recognizes projects other than those created exclusively by an oil or natural gas company, but do involve industry participation.

\section{We Need Nominees for 2002}

The Chairman's Stewardship Awards subcommittee is seeking nominations for the 2002 Chairman's Stewardship Awards. The winners will be honored at the IOGCC Midyear Meeting at Traverse City, Michigan, in June 2002. You may nominate your own company or organization, or any other group that you feel has made a contribution in one of the categories listed above.

For more information, contact:

Interstate Oil and Gas Compact Commission (405) 525-3556

iogcc@iogcc.state.ok.us

Visit our Web site at www.iogcc.state.ok.us

\section{2}

IOGCC Chairman's Stewardship Award Application

Nominee Information:

Company

Contact

I

| Address

I City

| City

State

Zip Code

Phone

FAX

E-Mail

Visual Aids (Please include 8 copies):

Video (fewer than 10 minutes)

Y Video

O Other

Category:

Major/Large
Independent/Small
Energy Education
Environmental Partnership
Please attach project description
$\quad$ on a separate sheet
Submitted by:
Name
Business
Address
City/State/Zip_
Phone_-
FAX
E-mail 